\title{
DEFENDING LUCK EGALITARIANISM
}

\author{
Nicholas Barry \\ This thesis is presented for the degree of Doctor of Philosophy of The \\ University of Western Australia. \\ School of Social and Cultural Studies \\ Political Science and International Relations \\ 2006
}




\section{DEFENDING LUCK EGALITARIANISM Nicholas Barry}

ABSTRACT: In this thesis, I seek to determine whether luck egalitarianism is a compelling interpretation of egalitarian justice. In answering this question, I challenge existing interpretations and criticisms of luck egalitarianism, and highlight its radical consequences. I propose a revised theory of luck egalitarianism, and conclude that it does represent a compelling interpretation of egalitarian justice. In the first chapter, I trace the evolution of luck egalitarianism, highlighting the variety of theories that have been grouped under this label. In chapter 2, I defend the approach against an influential critique by Elizabeth Anderson, who argues that luck egalitarianism is inherently disrespectful, trapped in the distributive paradigm, and harsh in its approach towards the victims of bad option luck. I argue against these criticisms, pointing out that the harsh treatment problem will rarely arise because few inequalities result entirely from option luck, and that luck egalitarianism is not disrespectful to those it seeks to assist, nor trapped in the distributive paradigm. In chapter 3, I analyse the distinction between option luck and brute luck, which is crucial to luck egalitarianism. I argue that the option-brute distinction is inconsistent with the underlying impulse of luck egalitarianism because it allows morally arbitrary inequalities to go uncorrected and because it is insufficiently sensitive to the impact of background inequalities on individual choice. I propose a revised theory of luck egalitarianism that focuses on the extent to which a person's level of advantage has been genuinely chosen, rejecting the option-brute distinction. In chapter 4, I give a broader justification of this theory, analysing recent critiques by Susan Hurley and Samuel Scheffler, who have both questioned the moral foundations of luck egalitarianism. In chapter 5, I outline a conception of egalitarian advantage to work alongside the revised theory of luck egalitarianism. I support Cohen's claim that egalitarians should adopt a heterogeneous account of advantage, which includes resources, welfare, and midfare. However, I extend this account so that it is sensitive to the objective advantage associated with egalitarian social relations, and the objective disadvantage associated with social oppression. In order to make this account more precise, I develop Cohen's proposal that egalitarians adopt a lexical ordering of the different components of advantage. In chapter 6, I compare luck egalitarianism to alternative theories of social justice and equality. I argue that it is superior to the priority view, the sufficiency view, and to theories of social equality. In chapter 7, I highlight the counter-intuitive social policy applications of luck egalitarianism, arguing that the universal approach to social provision associated with the social democratic welfare state comes closer to achieving luck-egalitarian objectives than the residual and conditional provision of benefits and services that is associated with the liberal welfare state. I conclude that luck egalitarianism, in the revised form I outline in chapter 3 , is a compelling interpretation of egalitarian justice. 


\section{TABLE OF CONTENTS}

Introduction $\quad 1$

Chapter 1: Luck Egalitarianism 11

Chapter 2: Defending Luck Egalitarianism 57

Chapter 3: Reassessing the Option-Brute Distinction 93

Chapter 4: Justifying Luck Egalitarianism 131

Chapter 5: Egalitarian Advantage 163

Chapter 6: Rival Theories 229

Chapter 7: Luck Egalitarians and the Welfare State 271

$\begin{array}{ll}\text { Conclusion } & 301\end{array}$

$\begin{array}{ll}\text { Bibliography } & 307\end{array}$ 


\section{ACKNOWLEDGEMENTS}

I would like to thank my family, friends, and colleagues for their support during my candidature. Special thanks to Alex Coram, Rhys Davies, Natalie Mast, Narelle Miragliotta, Sandra Penrose, Shlomi Segall, and Bruce Stone who have provided me with useful comments on the project at various stages. Thanks also to G.A. Cohen, for providing me with access to unpublished material, and for allowing me to cite this material. UWA's discipline of political science provided me with their resources and professional support, and I owe a great debt to David van Mill, who supervised me throughout the project.

Material in this thesis draws on the following single-authored conference papers and publications:

Chapter 2 was published as "Defending Luck Egalitarianism," Journal of Applied Philosophy, V. 23, no. 1, 2006, pp. 89-107.

Chapter 3 was presented at the ALSP Annual Conference, University of Wales, Newport, July 2004.

Chapter 7 was presented at the Australasian Political Studies Association Conference, University of Otago, Dunedin NZ, September 2005, and was published in conference proceedings. 


\section{INTRODUCTION}

Over the last 15 years, the notion of individual responsibility has played an increasingly important role in left-liberal politics. Politicians such as former US President Bill Clinton, and British Prime Minister Tony Blair, have enjoyed electoral success after "modernising" the liberal/social democratic political program, placing greater emphasis on individual responsibility. This development is not surprising because appeals to responsibility resonate strongly with the electorate, as the success of the New Right demonstrates. ${ }^{1}$ According to critics, traditional left-liberal policies undermine individual responsibility, so it is no surprise that politicians have sought to "modernise" by tightening the eligibility criteria for welfare payments, emphasising the importance of lower tax rates, and generally distancing themselves from “old-style” redistributive politics.

Recent work in normative theory has reflected these developments and left-liberal theorists have developed an approach to egalitarian justice that shifts the notion of individual responsibility to centre-stage. ${ }^{2}$ Elizabeth Anderson labelled this approach "luck egalitarianism” because it aims to neutralise the impact of luck on the lives of individuals. ${ }^{3}$ However, luck egalitarians are only concerned with correcting the effects of brute luck, which is unchosen, whilst the effects of option luck, which arises from deliberate gambles, are allowed to stand. ${ }^{4}$ The purpose of this distinction is to hold individuals responsible for the consequences of their actions.

In this thesis, I seek to determine whether luck egalitarianism is a compelling interpretation of egalitarian justice. In answering this question, I challenge existing versions of and objections to luck egalitarianism, and highlight its radical consequences. I propose a revised theory of luck 
egalitarianism, and conclude that it does represent a compelling interpretation of egalitarian justice.

I should emphasise from the start that I am writing from the perspective of value-pluralism. ${ }^{5}$ I assume that a range of moral values exist, but that these values may be in conflict with each other. This means that we should not expect a compelling theory of egalitarian justice to provide a complete guide to morality. For instance, the recommendations of egalitarian justice may conflict with the recommendations of other values, such as benevolence, and loyalty to family and friends. If conflict occurs between luck egalitarianism and such values, this is not, in itself, grounds for rejecting luck egalitarianism as a theory of egalitarian justice. ${ }^{6}$ I am also interested in egalitarian justice at the level of fact-insensitive principle, which means that I can abstract from problems involved in implementing the theory. ${ }^{7}$ The fact that a theoretically appealing interpretation of egalitarian justice is difficult to apply in practice is no reason to reject it.

As a working definition, I define justice as "giving to each his due.” Egalitarian justice means that each is due something equally, and the debate amongst proponents of egalitarian justice is over what this "something" is. Those engaged in this debate seek to answer the question posed by Amartya Sen: “Equality of What?" Although technically, this suggests that egalitarians could seek to equalise anything they like, the common usage of “egalitarianism" tends to suggest that the "something” in question will be connected to the material condition or well-being of individuals. Thus, in contemporary times, it would be unusual to refer to someone who supports formal equality before the law as an "egalitarian.” However, this does not mean that egalitarians must support some form of equality of outcome. A 
supporter of equality of opportunity could still be considered an egalitarian, on this usage of the term.

In order to determine whether luck egalitarianism is a compelling interpretation of egalitarian justice, I will focus on four key issues. Firstly, I will assess whether luck egalitarianism is consistent with our intuitive understanding of egalitarian justice. In order to test this, I will draw on hypothetical examples that demonstrate the logical implications of the theory and assess whether these implications seem consistent with our intuitive understanding of what egalitarian justice entails. ${ }^{8}$ Of course, our intuitions are not perfect and we may conclude that there are strong reasons to revise them to accord with luck egalitarianism. But if this is so, we must make a clear case for such revision. Secondly, I will analyse the internal consistency of luck egalitarianism. If inconsistencies do exist, the next task is to determine whether the theory can be revised to overcome them. If it cannot, then there seem to be strong grounds for abandoning the theory. Thirdly, I will seek to determine whether it is possible to provide a more sophisticated justification of luck egalitarianism, giving the theory firmer moral foundations. Fourthly, I assess how luck egalitarianism compares to alternative theories of justice and/or equality. If an alternative theory is more compelling than luck egalitarianism, then we must consider abandoning luck egalitarianism in favour of this more appealing alternative. ${ }^{9}$ I pursue the first task in chapter 2 , the second task in chapter 3 , the third task in chapter 4 , and the fourth task in chapter 6 . The other chapters seek to clarify our understanding of the theory of luck egalitarianism and its consequences.

In chapter 1, I trace the evolution of luck egalitarianism, beginning with Rawls, and analysing the ways in which luck egalitarians have 
responded to his work, trying to develop a theory of egalitarian justice that is more sensitive to notions of individual choice and responsibility, and to differences in our natural abilities. I focus particularly on the work of Dworkin, Arneson, Cohen, Roemer, and Rakowski and I emphasise that there are significant differences between these theorists. Thus, the notion of luck egalitarianism is ambiguous.

In chapter 2, I set aside the task of refining the theory in detail, in order to defend a general form of luck egalitarianism against a series of powerful criticisms levelled against it by Elizabeth Anderson. These criticisms are 1) that it is motivated by feelings of pity rather than equality, 2) that it is trapped in the distributive paradigm, 3) that it leads to an intrusive state that makes disrespectful and moralizing judgements about individuals, and 4) that it treats the victims of bad option luck too harshly. I challenge the first criticism, arguing against Anderson's claim that luck egalitarianism is motivated by feelings of pity. Rather, its motivation lies in the idea that all persons should have equal access to equally fulfilling lives. Against the second criticism, I argue that luck egalitarianism will condemn non-material inequalities and injustices if an appropriate conception of advantage is adopted. I demonstrate this by showing how the approach is sensitive to the five faces of oppression developed by Iris Young. In response to the third criticism, I concede Anderson's claim that implementing luck egalitarianism requires an intrusive state, but I deny that this a fundamental flaw in the theory as an abstract interpretation of the ideal of egalitarian justice. In the final section of the chapter, I respond to Anderson's fourth criticism of luck egalitarianism by showing that few of the inequalities that arise in the real world result from option luck. Further, 
when cases do occur, it is difficult to argue that the victims of bad option luck are victims of injustice. This chapter comes early in the thesis because it is important to establish the intuitive appeal of luck egalitarianism before we proceed with further analysis.

In chapter 3, I analyse the consistency of luck egalitarianism in more detail. I emphasise that the term luck egalitarianism is a misnomer because luck egalitarians only seek to equalise the effects of brute luck, not option luck. I highlight two major flaws with the distinction between compensable brute luck and non-compensable option luck. My first criticism is that the distinction is difficult to justify because some instances of option luck inequality are unjust, according to the underlying impulse of luck egalitarianism. My second criticism is that the distinction is insensitive to the way background inequalities shape individual choice. I illustrate the second point by focusing on the different interpretations of brute luck egalitarianism developed by Ronald Dworkin and G.A. Cohen. I propose a new form of luck egalitarianism that draws on Cohen's approach to choice, but explicitly rejects the option-brute distinction, focusing instead on the extent to which individuals have genuinely chosen particular outcomes. I conclude by highlighting the radical redistributive implications of this proposal. The rest of the thesis is devoted to refining and defending this revised form of luck egalitarianism.

Having established the intuitive appeal of luck egalitarianism, and having outlined a clearer, more consistent form of the theory that clearly captures this appeal, chapter 4 provides a broader justification of the theory. Responding to recent criticisms that luck egalitarianism lacks secure moral foundations, I attempt to situate the theory within a broader account of 
equality as a moral ideal. I argue that the equal moral worth of all persons means that they should have equal access to the good life. Responding to Scheffler's challenge, I also argue that luck egalitarianism is consistent with, and in fact is implied by the ideal of a society of equals. Although I do not provide a knock-down justification of luck egalitarianism in this chapter, I clearly explain how it emerges from the idea that all persons have equal moral worth and equally valuable lives. This establishes a firmer moral grounding for the theory.

In chapter 5, I outline a conception of egalitarian advantage to work alongside the revised theory of luck egalitarianism developed in chapter 3. I support Cohen's claim that egalitarians should adopt a heterogeneous account of advantage, which includes resources, welfare, and midfare. However, I extend this account so that it is sensitive to the objective advantage associated with egalitarian social relations, and the objective disadvantage associated with social oppression. In order to make this account more precise, I develop Cohen's proposal that egalitarians adopt a lexical ordering of the different components of advantage.

In chapter 6, I compare luck egalitarianism to alternative theories of egalitarianism and social justice. Firstly, I argue that it is superior to the sufficiency view ${ }^{10}$ because inequalities above the threshold of "sufficiency" will be unfair, as long as conditions of scarcity obtain. Secondly, I pay particular attention to the Levelling Down Objection, drawing on work by Parfit and Temkin. ${ }^{11}$ I conclude that this is not a decisive objection to a value-pluralist form of luck egalitarianism. Moreover, the notion of relative fairness has independent moral significance, which means that luck egalitarianism cannot be replaced by the Priority View. ${ }^{12}$ Thirdly, I argue 
that a theory of social equality cannot replace luck egalitarianism because its distributive implications are ambiguous, ungenerous, or collapse into luck egalitarianism.

In chapter 7, having completed my theoretical defence of the theory, I explore its social policy applications. Although my argument in this chapter does not contribute directly to the theoretical defence of luck egalitarianism, it is important because I highlight how critics of the theory have misunderstood its implications for contemporary debate over the welfare state. Any state that tried to implement luck egalitarianism would need detailed information about each citizen in order to determine the extent to which they are responsible for their income, wealth, health, etc. In other words, the state would need to assess each citizen to determine the level of tax they should pay, and the level of benefits (if any) they should receive from the state. In the current policy climate, the theory seems to lend support to the "liberal" model of the welfare state, with its emphasis on the conditional provision of welfare payments. In this chapter, I will argue against this view, providing two central reasons for luck egalitarians to support the universal, social democratic model in contemporary disputes over the welfare state. Firstly, I argue that luck egalitarianism has radical redistributive implications when applied to modern societies, and that the pattern of distribution secured by the social democratic welfare state is more in keeping with this radicalism. Secondly, luck egalitarians should focus on the extent to which individuals are able to live a life they find fulfilling. This is best achieved through the social democratic welfare state, which partially decommodifies labour. I highlight the significance of this argument for the role of normative political theory in public policy debate. Whilst I argue that 
we must be careful to focus clearly on the specific policy options available when using political theory to inform policy debates, I also defend the relevance of focusing on seemingly bizarre hypothetical examples to understand better particular theoretical approaches.

I conclude that the form of luck egalitarianism I outline in chapter 3 is a compelling interpretation of egalitarian justice. However, this conclusion is a mixed result for liberal and social democratic politicians who are motivated by the goal of short-term political success. Whilst this revised form of luck egalitarianism provides a way of linking left-liberal political theory to the popular notion of individual responsibility, it also has radical redistributive implications that run counter to the recent direction of liberal and social democratic policy "modernisation." This provides no reason to reject luck egalitarianism as a theory of egalitarian justice, ${ }^{13}$ but it does highlight the enormous tension between consistently egalitarian leftliberal political theory, and the apparent demands of short-term political expediency. 


\section{NOTES}

${ }^{1}$ See S. Scheffler, "Responsibility, Reactive Attitudes, and Liberalism in Philosophy and Politics," in Boundaries and Allegiances: Problems of Justice and Responsibility in Liberal Thought, New York, Oxford University Press, 2001, pp. 12-31, especially pp. 3, 22-6.

${ }^{2}$ For a good overview see W. Kymlicka, Contemporary Political Philosophy: An Introduction, second edition, New York, Oxford University Press, 2002, pp. 53-101; and W. Kymlicka, "Left-Liberalism Revisited," in C. Sypnowich (ed.), The Egalitarian Conscience: Essays in Honour of G.A. Cohen, Oxford, Oxford University Press, 2006, pp. 9-35.

${ }^{3}$ E.S. Anderson, “What is the Point of Equality?” Ethics, V. 109, no. 2, 1999, pp. 287-337. Luck egalitarianism has been discussed in many subsequent publications, including R.J. Arneson, "Luck Egalitarianism and Prioritarianism,” Ethics V. 110, no. 2, 2000, pp. 339349; A. Callinicos, Equality, Cambridge, Polity, 2000; R. Dworkin, "Sovereign Virtue Revisited," Ethics, V. 113, no. 1, 2000, pp. 106-143; R. Dworkin, "Equality, Luck and Hierarchy,” Philosophy and Public Affairs V. 31, no. 2, 2003, pp. 190-198; M. Ramsay, “Equality and Responsibility,” Imprints V. 7, no. 3, 2004, pp. 269-96; S. Scheffler, "What is Egalitarianism?” Philosophy and Public Affairs V. 31, no. 1, 2003, pp. 5-39; S. Scheffler, "Equality as the Virtue of Sovereigns: A Reply to Ronald Dworkin," Philosophy and Public Affairs V. 31, no. 2, 2003, pp. 199-206; S. Segall, “Unconditional Welfare Benefits and the Principle of Reciprocity," Politics, Philosophy \& Economics, V. 4, no. 3, 2005, pp. 331-54; and P. Vallentyne, "Brute Luck, Option Luck and Equality of Initial Opportunities," Ethics V. 112, no. 3, pp. 529-57. See also a 1999 BEARS online symposium on anderson's article at $<$ http://www.brown.edu/Departments/Philosophy/bears>.

${ }^{4}$ Note Vallentyne, “Brute Luck, Option Luck and Equality of Initial Opportunities,” p. 540 n. 17.

${ }^{5}$ For an account of this approach see, for example, I. Berlin, “The Pursuit of the Ideal,” in H. Hardy (ed.), The Crooked Timber of Humanity: Chapters in the History of Ideas, New York, Alfred A. Knopf, 1991, pp. 1-19. 
${ }^{6}$ In Cohen's terminology, I am making a qualified or weak equalisandum claim: “A qualified or weak equalisandum claim says that... [people] should be as equal as possible in some dimension but subject to whatever limitations need to be imposed in deference to other values: those limitations are not specified by the claim in question.” See G.A. Cohen, “On the Currency of Egalitarian Justice,” Ethics, V. 99, no. 4, 1989, pp. 906-44, at p. 908.

${ }^{7}$ G.A. Cohen, “Facts and Principles,” Philosophy and Public Affairs, V. 31, no. 3, 2003, pp. 207-245.

${ }^{8}$ This is what Wolff refers to as the "egalitarian methodology." See J. Wolff, "Fairness, Respect, and the Egalitarian Ethos,” Philosophy and Public Affairs, V. 27, no. 2, 1998, pp. 97-122, at pp. 98-103.

${ }^{9}$ Admittedly, the approaches that I examine in chapter 6 are alternative interpretations of social justice and/or equality, rather than egalitarian justice, per se. Consequently, if one of these alternatives is superior to luck egalitarianism, this may show that egalitarian justice should be rejected in favour of a broader notion of egalitarianism (that is, a form of egalitarianism with broader concerns than justice), or a non-egalitarian theory of justice. In other words, it would be possible to conclude that luck egalitarianism is the best interpretation of egalitarian justice available, but that egalitarian justice is not a compelling ideal.

${ }^{10}$ According to the sufficiency view, distributive justice only matters up to the point at which everyone is able to live a sufficiently good life. Thus, inequalities are acceptable provided that everyone has “enough.”

11 The Levelling Down Objection arises because certain forms of egalitarianism will support achieving equality by "levelling down" the well-off so they have the same (low) level of well-being as the badly-off, even if this has no beneficial effect on the well-being of the badly-off.

12 The Priority View focuses on improving the condition of the worse off, rather than achieving equality, per se.

${ }^{13}$ Note also Cohen, "Facts and Principles;” \& cf. Ramsay, "Equality and Responsibility;” \& B. Barry, Why Social Justice Matters, Cambridge, Polity, 2005. 


\section{CHAPTER 1}

\section{LUCK EGALITARIANISM}

The term "luck egalitarianism" was first used by Elizabeth Anderson to describe a theoretical approach to the concept of egalitarian justice that emphasises the importance of individual choice and responsibility. ${ }^{1}$ Luck egalitarianism, which she also terms "equality of fortune," "takes the fundamental injustice to be the natural inequality in the distribution of luck."2 As Richard Arneson, puts it:

The concern of distributive justice is to compensate individuals for misfortune. Some people are blessed with good luck, some are cursed with bad luck, and it is the responsibility of society -- all of us regarded collectively -- to alter the distribution of goods and evils that arises from the jumble of lotteries that constitutes human life as we know it... Distributive justice stipulates that the lucky should transfer some or all of their gains due to luck to the unlucky. ${ }^{3}$

This involves two key ideas -- "that people should be compensated for undeserved misfortunes and that the compensation should come only from that part of others’ good fortune that is undeserved." ${ }^{4}$ In part, this approach aims to address conservative and libertarian criticisms of egalitarianism for ignoring the idea of individual responsibility and drawing on resources which others deserve. $^{5}$ Thus, the approach is essentially concerned with correcting inequalities that reflect undeserved bad luck.

Luck egalitarians distinguish between two different kinds of luck -option luck and brute luck. Option luck is when an outcome results from an adult's voluntary choices, whereas brute luck refers to "good or bad outcomes that occur independent of her choice or of what she could have reasonably foreseen."6 Inequalities that reflect the first are regarded as just whilst those regarding the second are unjust. This is because individuals are responsible for 
the inequalities that result from option luck, whereas they are not responsible for inequalities that result from bad brute luck.

The luck-egalitarian approach has strong appeal as an interpretation of egalitarian justice because it attacks the fundamental inequalities associated with brute luck, whilst respecting individual choice. The differential impact of brute luck has enormous significance for the quality of a person's life. Differences in family background, schooling and natural capacity are major sources of inequality that fit within the brute luck category. Luck egalitarianism is intuitively appealing to egalitarians because it condemns these inequalities and seeks to eliminate them. However, luck egalitarianism also has broader intuitive appeal because it is sensitive to individual choice. When people choose to take a gamble, the good or bad fortune that arises is regarded as option luck that should not be corrected. This is of enormous significance because it means that luck egalitarianism incorporates "the most powerful idea in the arsenal of the anti-egalitarian right: the idea of choice and responsibility."7 In this way, luck egalitarianism eliminates the impact of morally arbitrary features on well-being (by ensuring that unchosen characteristics do not have an influence), whilst allowing individuals to disturb a pattern of distribution through their decisions and actions. Thus, luck egalitarianism targets the key source of inequality in the world today whilst respecting the idea of individual choice.

Anderson believes that "[e]quality of fortune is now one of the dominant theoretical positions among egalitarians” and suggests that Richard Arneson, G.A. Cohen, Ronald Dworkin, Thomas Nagel, John Roemer, Eric Rakowski and, in part, Philippe Van Parijs, all fall within this approach. ${ }^{8}$ However, as Anderson admits, there are important differences between these 
theorists. ${ }^{9}$ In this chapter I want to briefly outline the development of luck egalitarianism, focusing on the work of prominent luck egalitarians Dworkin, Arneson, Cohen, Roemer, and Rakowski. ${ }^{10}$ I will emphasise the significant differences between these theorists, particularly on the issue of whether individuals are responsible for their preferences, and on the kind of devices, such as insurance mechanisms and equal decision trees that are needed to render luck egalitarianism more complete. I will argue that because of the diversity of these approaches, and because few of these devices succeed, it is unclear exactly what luck egalitarianism is. This explains why further work is needed to develop a more concrete theory that captures the underlying impulse of luck egalitarianism. Before I get to these issues, I begin with a brief overview of John Rawls's work, which has played a crucial role in the development of the approach, although Rawls is not generally considered a luck egalitarian. $^{11}$

\section{RAWLS}

Rawls is linked to luck egalitarianism because he develops a theory of justice that aims to prevent morally arbitrary features from affecting the quality of life individuals enjoy. For Rawls, principles of justice establish fair terms of social cooperation. In order to determine what constitutes "fair terms," he develops the notion of the original position, in which representatives of different classes in society meet to agree on principles of justice. These representatives deliberate behind the "veil of ignorance," which means that they do not know important information about personal characteristics that are morally arbitrary from the point of view of justice. This list of morally arbitrary features goes beyond the traditional liberal concern with family background and educational 
opportunities to include "natural talents.” This concern with preventing morally arbitrary factors, such as natural talents, from influencing justice, has become the driving force behind luck egalitarianism. ${ }^{12}$

The veil of ignorance leads to "objective" principles of justice. ${ }^{13}$ Everybody is on an equal footing because nobody knows what advantages they will possess when the veil is lifted. Consequently, representatives will support social arrangements that are fair to all citizens, regardless of their ethnicity, family background, or natural abilities. If we factor in certain assumptions, Rawls argues, representatives under the veil of ignorance will select two principles of justice with the first being lexically prior to the second:

\section{First Principle}

Each person is to have an equal right to the most extensive total system of equal basic liberties compatible with a similar system of liberty for all.

Second Principle

Social and economic inequalities are to be arranged so that they are both:

(a) to the greatest benefit of the least advantaged, consistent with the just savings principle, and

(b) attached to offices and positions open to all under conditions of fair equality of opportunity. ${ }^{14}$

Part (a) of the second principle is known as the difference principle. It is principally designed to justify inequalities that improve the conditions of the least advantaged by, for instance, creating incentives for faster innovation and a more efficient economic process. ${ }^{15}$

Rawls emphasises the egalitarian nature of these principles, ${ }^{16}$ highlighting the way "the difference principle gives some weight to the considerations singled out by the principle of redress." ${ }^{17}$ This principle holds 
"that undeserved inequalities call for redress; and since inequalities of birth and natural endowment are undeserved, these inequalities are to be somehow compensated for.”18 The difference principle is different from the principle of redress, but there are similarities between the two:

[A]lthough the difference principle is not the same as that of redress, it does achieve some of the intent of the latter principle. It transforms the aims of the basic structure so that the total scheme of institutions no longer emphasizes social efficiency and technocratic values. We see then that the difference principle represents, in effect, an agreement to regard the distribution of natural talents as a common asset and to share in the benefits of this distribution whatever it turns out to be. Those who have been favored by nature, whoever they are, may gain from their good fortune only on terms that improve the situation of those who have lost out... No one deserves his greater natural capacity nor merits a more favorable starting place in society. But it does not follow that one should eliminate these distinctions. There is another way to deal with them. The basic structure can be arranged so that these contingencies work for the good of the least fortunate. Thus we are led to the difference principle if we wish to set up the social system so that no one gains or loses from his arbitrary place in the distribution of natural assets or his initial position in society without giving or receiving compensating advantages in return. ${ }^{19}$

The emphasis on regarding "the distribution of natural talents as a common asset" and the concern with "[t]hose who have been favored by nature” has strong similarities to luck egalitarianism. However, for Rawls the natural distribution of talents and social positions is not, in itself, a matter of justice. ${ }^{20}$ Rather, what is a matter of justice is how social institutions deal with these morally arbitrary natural inequalities. This distinguishes Rawls's position from luck egalitarianism, at least as Anderson presents it. ${ }^{21}$ Nonetheless, the notion that we should design social institutions so as to redress the impact of morally arbitrary natural talents is central to justice as fairness. It is only legitimate for 
those with lucrative talents to benefit from their good fortune if this improves the position of the least advantaged. This creates a strong presumption in favour of equality.

However, critics have attacked the consistency of Rawls's position. Firstly, they question whether we should automatically support improving the position of the least advantaged. After all, the least advantaged might be responsible for being the least advantaged. Their condition may be a result of their own choices and behaviour, not their lack of lucrative natural talents. ${ }^{22}$ If the central concern of justice is to prevent morally arbitrary inequalities, then there is no reason of justice to assume we should automatically aim to improve the position of the least advantaged, or adopt equality as a default position. Secondly, Rawls argues against distribution on the grounds of desert because our natural talents influence our preparedness to make an effort, which means that individuals are only partly responsible for the effort they put in. ${ }^{23}$ Because it is too difficult to distinguish between the effects of good fortune and individual choice in this context, we should simply assume that the return to talents is morally arbitrary. However, this seems inconsistent with Rawls's views on individual preferences. Because some people's preferences are easier or cheaper to satisfy than other people's are, providing each person with an equal share of primary goods will lead to inequalities in the level of welfare they enjoy. Rawls does not believe that this a problem and he argues against providing extra resources to those with expensive tastes. Nonetheless, he maintains that a person's preferences are partly involuntary, and partly within her control. Consequently, individuals with a partly involuntary expensive taste end up with a lower level of welfare than others because of a disadvantage they are only partly responsible for. In contrast, the fact we are only partly 
responsible for our preparedness to make an effort means that we should reject desert-based principles of distributive justice. ${ }^{24}$ The third and related problem arises because individuals vary in their ability to convert resources into

welfare. $^{25}$ Some people are born with, or come to develop, illnesses or disabilities which require costly medical care and extra support. If the individual concerned is not responsible for the fact she develops this illness or disability, then it is clearly morally arbitrary, and she should be entitled to an extra share of resources to help redress this disadvantage. But Rawls focuses on the resources individuals have, not the level of welfare they enjoy, and thus he is insensitive to these morally arbitrary inequalities. It is the inadequacy of Rawls's approach to the issues of individual responsibility, handicaps, talents, and preferences that has led to the emergence of luck egalitarianism.

\section{DWORKIN}

In 1981, Ronald Dworkin published two essays in Philosophy and Public Affairs, the first of which criticised the welfarist approach to equality, and the second of which outlined Dworkin's theory of "equality of resources."26 Although Dworkin follows Rawls in focusing on resources, not welfare, and in striving to prevent differences in our natural talents from affecting distributive shares, there are important differences between equality of resources and justice as fairness. In particular, equality of resources is based on a broader conception of "resources" than primary goods, and it is also more sensitive to the impact of individual choices on distributive shares.

The notion of responsibility plays an important part in Dworkin's critique of equality of welfare. $^{27}$ One of Dworkin's major objections to approaches which seek to equalise the level of welfare people enjoy is that they 
give extra resources to individuals whose tastes are expensive. To illustrate this, he presents the hypothetical example of Louis, who lives in a society where equality of welfare obtains until he "deliberately" cultivates a taste for fine wine. Louis is left with a lower level of welfare because this taste is expensive to satisfy, and thus it constitutes an expensive taste. ${ }^{28}$ According to equality of welfare, Louis should receive the extra resources he needs to ensure that he has an equal level of welfare to everybody else. This seems a counter-intuitive conclusion for an egalitarian theory.

Dworkin goes on to suggest that in reality, people never fully choose their preferences because these preferences are formed against a background of unchosen beliefs about the good life. ${ }^{29}$ However, even if Louis’s cultivation of an expensive taste was influenced by unchosen beliefs, there is still a "powerful and appealing” argument against compensating him for it. ${ }^{30}$ After all, Louis does control how he acts in response to these background beliefs, and he should be aware that cultivating an expensive taste will impinge on the resources of other citizens (because the extra resources he needs must be taken from them). ${ }^{31}$ In a sense, Dworkin's expensive tastes objection can be reduced to the claim that people should be held responsible for the costs their choices impose on others:

Louis has a choice. He may choose to keep the presently equal resources I said he had, and settle for a life with the enjoyment he now has but without the tastes or ambitions he proposes to cultivate. Or he may keep his present resources and settle for a life that he deems more successful overall than his present life, but one that contains less enjoyment. It is quite unfair that he should have a third choice, that he should be able, at the expense of others, to lead a life that is more expensive than theirs at no sacrifice of enjoyment to himself just because he would, quite naturally, consider that life a more successful life overall than either of the other two. ${ }^{32}$ 
Thus, choice plays an important role in Dworkin's argument against equality of welfare. $^{33}$

Dworkin's theory of equality of resources is an alternative and (in his view) superior interpretation of the idea of equal treatment, which Dworkin believes is at the heart of political morality. It is based on the idea that equal treatment means giving each individual an equal bundle of resources throughout her life. ${ }^{34}$ To determine what this entails, Dworkin outlines a hypothetical island scenario, where a group of individuals have been shipwrecked on an island (Dworkin refers to these individuals as "immigrants" to the island). The immigrants share the belief that nobody is antecedently entitled to the island's abundant resources, and, with rescue unlikely for years, an immigrant is elected to divide up these resources on the basis of the "envy test," which holds that “[n]o division of resources is an equal division if, once the division is complete, any immigrant would prefer someone else's bundle of resources to his own bundle.”35

However, a simple interpretation of the envy test may result in unfairness because of the difficulties we face in taking individual tastes into account. Even if resources are divided into weighted, different-sized bundles so that nobody prefers anybody else's bundle to their own, one immigrant may have preferred dividing resources up another way, so that a different set of bundles were available. ${ }^{36}$ Thus, the initial distribution would not pass the envy test. The problem is that determining whether or not "the resources devoted to each person's life... [are] equal” depends on the importance of these social resources to others. ${ }^{37}$ Unless we take this into account, we cannot hope to satisfy the envy test. 
To overcome this problem, Dworkin proposes a hypothetical auction mechanism. All immigrants are given an equal number of clamshells that are used to bid for every item on the island (aside from immigrants themselves) at an auction. ${ }^{38}$ Each item is a lot with prices set by the auctioneer who adjusts the prices in order to clear all markets, so that "there is only one purchaser at that price and all lots are sold.”39 The immigrants may then change their bids or suggest different lots, but Dworkin supposes that eventually everyone will be happy with the result of the auction and it can be used to distribute the resources. ${ }^{40}$ The envy test will be satisfied:

No one will envy another's set of purchases because, by hypothesis, he could have purchased that bundle with his clamshells instead of his own bundle. Nor is the choice of sets of bundles arbitrary. Many people will be able to imagine a different set of bundles meeting the no-envy test that might have been established, but the actual set of bundles has the merit that each person played, through his purchases against an initially equal stock of counters, an equal role in determining the set of bundles actually chosen. ${ }^{41}$

Admittedly, luck does influence the satisfaction a person receives from their stock of resources because they may dislike the resources available on the island, and because the popularity/unpopularity of their tastes affects the cost of the resources available. ${ }^{42}$ But for Dworkin, this is an inextricable part of equality of resources -- unlike equality of welfare, it is factored in from the start and "people decide what sort of lives to pursue against a background of information about the actual cost their choices impose on other people and hence on the total stock of resources that may fairly be used by them."43 This suggests that individuals choose the kind of lives they live, and that they should bear the costs associated with these lives. Thus, "the contingent facts of raw material and the distribution of tastes are not grounds on which someone might 
challenge a distribution as unequal." ${ }^{, 4}$ The outcome of the hypothetical auction is a distribution of resources that satisfies the requirements of egalitarian justice.

However, before long, this initially equal distribution of resources will be upset as individuals engage in trade and production and are affected by various natural contingencies. ${ }^{45}$ In order to assess the impact of this on equality, Dworkin proposes two concepts that have come to play a major role in subsequent egalitarian theory -- option luck and brute luck.

He defines option luck as being "a matter of how deliberate and calculated gambles turn out -- whether someone gains or loses through accepting an isolated risk he or she should have anticipated and might have declined." ${ }^{46}$ In contrast, "[b]rute luck is a matter of how risks fall out that are not in that sense deliberate gambles." ${ }^{47}$ Dworkin's example of the former is when a stock option rises and of the latter, when a person is struck by a falling meteorite with an unpredictable course. ${ }^{48}$ However, Dworkin highlights the fact that "the difference between these two forms of luck can be represented as a matter of degree, and we may be uncertain how to describe a particular piece of bad luck., 49

Dworkin claims that insurance links option luck and brute luck because the decision whether or not to insure against a particular misfortune is a case of option luck. ${ }^{50}$ It is a "calculated gamble," and because individuals should bear the costs of the life they have chosen to lead, other things being equal, we owe no compensation to individuals who choose not to insure against future risks, when insurance was available. ${ }^{51}$ For example, if two people know they have an equal chance of suffering an accident that will blind them, and insurance against this eventuality is available, then other things being equal, any 
difference in their subsequent level of well-being will be "a difference in option luck against a background of equal opportunity to insure or not.” ${ }^{52}$ Thus, there is no argument for redistribution from one to the other whether they are both blinded in the same accident; or only the uninsured person goes blind; or neither goes blind. The availability of insurance means that the inequality that emerges between them is a matter of option luck. Although Dworkin does leave open the possibility of redistribution on the grounds of paternalism, ${ }^{53}$ this seems a very harsh version of egalitarianism. Effectively, Dworkin is saying that a person could fall to a very low level of well-being through being blinded in an accident, for example, without egalitarian justice demanding they be given assistance (although as we shall see, practical considerations lead Dworkin to retreat from this claim).

But Dworkin's treatment of the uninsured blind person also seems unjust for reasons internal to his own account of equality of resources. Earlier, he acknowledges the limited capacity of insurance to rectify the effects of bad brute luck, admitting that it “does not erase the distinction” between brute and option luck. ${ }^{54}$ Yet he proceeds to hold an uninsured individual completely responsible for her low level of well-being. Although Dworkin believes this is simply holding people responsible for the gamble they chose to take, the reason for the inequality between a blinded uninsured person and a non-blinded insured or uninsured one is surely a reflection of brute luck. In addition, whilst Dworkin acknowledges that "the difference between these two forms of luck can be represented as a matter of degree, ${ }^{55}$ he is prepared to argue for the extreme claim that egalitarian justice provides no reason to assist an uninsured person who goes blind. This highlights a broader risk that luck egalitarianism 
will hold individuals responsible for outcomes they have not genuinely chosen. I return to this point in chapter 3.

However, Dworkin faces a problem once he lifts the simplifying assumptions in the island scenario. In reality, individuals do not decide whether or not to purchase insurance from a position of equality. Instead, the odds of suffering an accident or illness are unequally distributed through the population, and people often lack knowledge of the odds involved, or develop the handicap before they have the opportunity to take out insurance. ${ }^{56}$ To deal with this problem, Dworkin proposes a hypothetical insurance market, which is used to determine the level of compensation that should be provided to individuals who suffer from bad brute luck:

If (contrary to fact) everyone had at the appropriate age the same risk of developing physical or mental handicaps in the future (which assumes that no one has developed these yet) but the total number of handicaps remained what it is, how much insurance coverage against these handicaps would the average member of the community purchase? We might then say that but for (uninsurable) brute luck that has altered these equal odds, the average person would have purchased insurance at that level, and compensate those who do develop handicaps accordingly, out of some fund collected by taxation or other compulsory process but designed to match the fund that would have been provided through premiums if the odds had been equal. Those who develop handicaps will then have more resources at their command than others, but the extent of their extra resources will be fixed by the market decisions that people would supposedly have made if circumstances had been more equal than they are. ${ }^{57}$

Although there are some problems with this proposal, Dworkin concludes that it is likely to be the best approach available. ${ }^{58}$

One of the main advantages of the hypothetical insurance market is the way it holds individuals responsible for their tastes, but not for their talents. It "produces a certain view of the distinction between a person and his 
circumstances, and assigns his tastes and ambitions to his person, and his physical and mental powers to his circumstances." ${ }^{59}$ Dworkin reiterates the point he made in his discussion of the Louis example: we should not treat expensive tastes as compensable handicaps because people form "ambitions with a sense of their cost to others against some presumed initial equality of economic power, and though this is different from the picture assumed by equality of welfare, it is a picture at the center of equality of resources.”60 However, Dworkin qualifies this conclusion, arguing that tastes can be regarded as handicaps if they are unwanted cravings/obsessions/lusts/drives, which hinder a person's life and cause frustration and pain if they remain unsatisfied. $^{61}$ More simply, preferences count as handicaps if they are impediments to a person living her conception of a successful life, rather than forming part of this conception. ${ }^{62}$ Like other handicaps, the level of compensation for having these "cravings" is determined through the hypothetical insurance market. ${ }^{63}$ However, few tastes will be regarded as handicaps deserving compensation under this scheme because aside from mental illness, few people will insure against the risk of having a particular preference. Thus, the hypothetical insurance market appears to be a very successful instrument for achieving equality of resources.

An initially equal distribution of resources will also be disrupted as the immigrants engage in production and trade. Once again, option luck and brute luck are the key to determining whether departures from this initially equal distribution are legitimate. Provided that the immigrants are equally talented, it is just for Adrian to increase his holding of resources by working hard to produce a good that the other immigrants want (such as farming the land to produce tomatoes). The reason for this is that we are interested in the resources 
each person enjoys over her whole life, including her occupation as a resource. If nobody else wanted to spend his life engaged in the kind of production Adrian did, then nobody will envy Adrian. ${ }^{64}$ However, when equality of resources is applied to a more realistic world where people have different talents, the situation becomes more complicated. Because equality of resources is not a theory of equality of opportunity, ${ }^{65}$ it must be sensitive to inequalities that result from unequal talents, whilst ensuring that people pay the cost of the lives they live. If Claude wanted to spend his life engaged in the same kind of productive activity as Adrian, but was prevented from doing so (or doing so lucratively) by his lack of farming talent, he is entitled to compensation. Equality of resources must be “ambition-sensitive," but not "endowmentsensitive” and natural talents are an important part of our endowment. ${ }^{66}$

However, it is difficult to work out exactly how to compensate individuals in Claude's position. The first strategy Dworkin considers is to extend his hypothetical auction to labour. ${ }^{67}$ Thus, the labour time of each immigrant on the island is included in the resources put to auction, so that each immigrant can bid to control the labour of other immigrants. However, Dworkin rejects this approach because he believes it will result in the slavery of the talented. The labour of those with highly lucrative talents will be in high demand, forcing up the price that must be paid to control it. Presumably, a key motivation for most immigrants will be obtaining control over their own labour, so they can determine what kind of productive activity (if any) they perform throughout their lives. But the consequence of this is that "each would have to spend his life in close to the commercially most profitable manner he could or, at least if he is talented, suffer some very serious deprivation if he did not.”68 The talented will have to spend most of their clamshells buying their own 
labour power, leaving them with little left over to bid for other resources. Consequently, they will end up in a position of deprivation unless they devote themselves to performing very profitable work. This leads to the "slavery of the talented" because the talented may want to devote their lives to other, less remunerative pursuits, but they will not be able to do so without suffering a severe financial penalty. In the end, they may come to envy the occupational freedom of the less talented, and the envy test will fail. For this reason, Dworkin concludes that we should reject the labour auction. ${ }^{69}$

The challenge we face in achieving an ambition-sensitive but endowment-insensitive distribution is determining the extent to which inequalities in the distribution of income reflect the different occupational choices individuals have made, as opposed to differences in their talents. Dworkin turns "to a more familiar idea: the periodic redistribution of resources through some form of income tax." 70 However, it will be impossible to determine the appropriate level at which to set the taxes and transfers. Because our talents and our ambitions are so closely linked, it is impossible to determine what an ambition-sensitive, endowment-insensitive income would look like. ${ }^{71}$ Moreover, it would be impossible to replicate the distribution of income that would obtain in a world where each person has equal productive talents. ${ }^{72}$ How can we know the exact income a particular person will enjoy in such a world?

To deal with this problem, Dworkin endorses a modified form of the hypothetical insurance market that is used to determine the level of compensation that should be provided for handicaps. However, because our natural talents are so closely linked to our ambitions, we assume that individuals participating in the insurance market are aware of the talents that they possess, but are unable to predict the economic rent that these talents will 
bring. ${ }^{73}$ We program a computer with "information about the tastes, ambitions, talents, and attitudes toward risk of each of the immigrants, as well as information about the raw materials and technology available," and use it to predict "the projected income structure -- the number of people earning each level of income -- that will follow the auction once production and trade begin, on the assumption that there will be no income tax."74 The next step is to predict the level of insurance that immigrants would take out against being unable to earn at a particular income level:

Assume each immigrant knows the projected income structure but is ignorant of the computer's data base, except for its information about himself, and is therefore radically uncertain what income level his own talents would permit him to occupy. He supposes, in fact, that he has the same chance as anyone else of occupying any particular level of income in the economy, though he takes the number projected for that level into account. Assume that there is no monopoly in insurance, and insurance firms offer policies of the following sort. Insurance is provided against failing to have an opportunity to earn whatever level of income, within the projected structure, the policyholder names, in which case the insurance company will pay the policyholder the difference between that coverage level and the income he does in fact have an opportunity to earn. Premiums will vary with the level of coverage chosen, must be the same for everyone at any particular coverage level, and will be paid, not out of the policyholder's initial stock of resources (or clamshells), but rather from future earnings after the auction at fixed periods. How much of such insurance would the immigrants, on average, buy, at what specified level of income coverage, and at what cost? ${ }^{75}$

Dworkin believes that people are likely to insure against the risk that they are unable to earn an income that is "well above... [that] presently used to trigger transfer payments for unemployment or minimum wage levels in Britain or the United States.”76 
The average premium and coverage level are used to form the basis of a tax-transfer system. An individual is entitled to a transfer payment (minus a coinsurance payment introduced to reduce moral hazard) which removes the difference between the income he has the capacity to earn, and the average level of coverage purchased. ${ }^{77}$ The insurance premiums are implemented through a system of progressive income tax, which is used to fund the transfer payments. We end up with a progressive income tax system because it will be advantageous for both parties in the hypothetical insurance market if "the insurance firms had offered, in place of the flat-rate premium for a given coverage... a premium fixed as an increasing percentage of the income the policy owner turns out to earn."78 In other words, those who earn higher incomes pay a higher income premium, and thus a higher rate of income tax than others do. Dworkin concludes that this approach is the best way of compensating individuals for inequalities in their talents, although he also says that further refinements may be needed, including adjustments motivated by non-egalitarian considerations such as efficiency. ${ }^{79}$ Thus, Dworkin ultimately ends up endorsing a relatively moderate proposal to address the problems associated with the unequal distribution of talents.

The central features of Dworkin's theory of equality of resources are the way it uses market mechanisms to unite equality and responsibility, which have often been viewed as opposing values, and the distinction it draws between a person and his circumstances. We are responsible for aspects of our person, such as our preferences and choices, but not for our circumstances, such as our talents. Yet there are strong reasons to question the egalitarian credentials of the theory. Even leaving aside considerations of efficiency, Dworkin's theory allows unchosen, morally arbitrary brute luck factors to have a major impact on 
the lives of individuals. In particular, his insurance scheme only offers limited compensation for inequalities which result from innate differences in natural talents. Moreover, the distribution of tastes throughout the population, which is morally arbitrary, will have a big impact on the resources to which a person has access (through the initial auction of the island's resources), and the extent to which she can satisfy her preferences. In these respects, Dworkin's insurance mechanism and his theory more generally seem inconsistent with the notion that we should correct the impact of brute luck on people's lives. ${ }^{80}$ This becomes clearer once we examine the contribution Arneson, Cohen, and Roemer have made to the debate over egalitarian justice.

\section{ARNESON, COHEN, AND ROEMER}

Dworkin's cut between preferences and resources has been strongly criticised, and theorists such as Arneson, Cohen, and Roemer have proposed alternative theories of egalitarian justice that they believe are more consistent with the underlying emphasis on choice and responsibility in Dworkin's work.

Dworkin assigns natural abilities and handicaps (our talents or powers) to our circumstances, whilst our tastes and ambitions are assigned to our person. He argues that we should take responsibility for aspects of our person, but not our circumstances. However, Cohen has challenged this distinction. He points out that our mental powers (which Dworkin assigns to our circumstances), shape the kind of people we are just as much as our tastes and ambitions do, so Dworkin must be using the terms "person" and “circumstances" in a technical sense. ${ }^{81}$ The technical interpretation of the person/circumstances distinction seems to rely on the notion of individual choice. Dworkin seems to assign preferences to our person and powers to our 
circumstances because "people form their preferences but not, presumably, their powers." ${ }^{82}$ In fact, Cohen argues, the central reason Dworkin's theory is appealing is that it shifts the notions of individual choice and luck to centre stage. $^{83}$ As Cohen puts it, "the grounding idea of Dworkin's egalitarianism is that no one should suffer because of bad brute luck" and the powers/ambitions cut only seems appealing because Dworkin obscures the difference between it and this grounding ideal. ${ }^{84}$ The insurance mechanism is also appealing "because it seems to sort out a big difference that really matters for egalitarian justice: between disadvantages that are and disadvantages that are not due to bad brute luck., ${ }^{85}$

Once choice is shifted to the heart of the distinction, it is no longer clear that tastes and ambitions should automatically be assigned to the person. Tastes and ambitions are often shaped by a background of unchosen beliefs, and social and biological factors, so the underlying impulse of Dworkin's theory is inconsistent with his focus purely on the level of resources people enjoy. ${ }^{86}$ Both Arneson and Cohen argue that individuals can end up with a lower level of welfare than others because of "their unchosen liabilities to pain and suffering and... their unchosen expensive preferences." ${ }^{\text {87 }}$ If we follow the underlying impulse of Dworkin's theory to its logical conclusion, we should regard this unchosen disadvantage as compensable. Thus, both Arneson and Cohen conclude that equality of resources is unsatisfactory.

To better understand this position, it may be helpful to consider two of the examples Arneson presents to illustrate his position on the expensive tastes issue. Firstly, he argues that "a person raised in a closed fundamentalist community such as the Amish who then loses his faith and moves to the city may feel at a loss as to how to satisfy ordinary secular preferences, so that equal 
treatment of this rube and city sophisticates may require extra compensation for the rube beyond resource equality." ${ }^{\text {, }}$ Because he is not responsible for his upbringing, he is not responsible for the welfare deficit he suffers, and he thus has a claim to compensation. Arneson gives a second example, involving two tribes who have a low level of welfare and receive subsidies from the government. "The two tribes happen to be identical except that one is strongly committed to traditional religious ceremonies involving a psychedelic made from the peyote cactus while the other tribe is similarly committed to its traditional rituals involving an alcoholic drink made from a different cactus.”89 If the first tribe's psychedelic suddenly becomes more expensive, whilst the second tribe's drink remains cheap, the first tribe may be entitled to an increase in their subsidy. Thus, we should reject equality of resources because it is insensitive to the unchosen disadvantages in welfare that are a feature of these examples.

However, there are also problems with equality of welfare, which is insufficiently sensitive to the notion of individual responsibility. If individuals end up worse off than others as a result of their choices then they are not entitled to compensation for the disadvantage they suffer. ${ }^{90}$ If, for example, two individuals with identical tastes, abilities and resources end up with unequal levels of welfare because they become involved in high-stakes gambling; or because one tries to satisfy an aspirational preference whilst the other pursues self-interested preferences; or because one cultivates an expensive preference, then this inequality is not unjust. $^{91}$ To illustrate this, Cohen returns to Dworkin's example of Louis, the man who deliberately cultivates a taste for expensive wines and plovers' eggs. ${ }^{92}$ Cohen agrees with Dworkin that Louis should not receive compensation, but this is because Louis deliberately 
cultivates his expensive tastes, not because expensive tastes are noncompensable. Thus, equality of welfare is unattractive because it provides extra resources to individuals who deliberately cultivate expensive tastes.

Instead, Arneson and Cohen propose theories which make notions of individual choice and responsibility the key factor in determining whether or not a disadvantage is compensable. Arneson proposes a theory called equal opportunity for welfare. It is motivated by the norm that, "[o]ther things equal, it is bad if some people are worse off than others through no voluntary choice or fault of their own.”93 Equal opportunity for welfare holds when "any actual inequality of welfare in the positions... [individuals] reach is due to factors that lie within each individual's control." ${ }^{94}$ This means that "each must face an array of options that is equivalent to every other person's in terms of the prospects for preference satisfaction it offers." ${ }^{95}$

In order to do this, he proposes a mechanism which is based around the idea that individuals should face equivalent “decision trees.”96 Each decision tree maps the complete range of choices facing an individual once they enter their majority, along with the likely outcomes of each option and the probabilities involved. ${ }^{97}$ The expected level of preference satisfaction associated with each path is calculated, based on an individual's ideally considered preferences. ${ }^{98}$ The satisfaction each person receives from each path should be equal to that received by all others in the equivalent path:

Equal opportunity for welfare obtains among persons when all of them face equivalent decision trees -- the expected value of each person's best (=most prudent) choice of options, second-best, ...nth-best is the same. The opportunities persons encounter are ranked by the prospects for welfare they afford. ${ }^{99}$ 
Moreover, individuals must face "effectively equivalent options," which means that "(1) the options are equivalent and the persons are on a par in their ability to 'negotiate' these options, or (2) the options are nonequivalent in such a way as to counterbalance exactly any inequalities in people's negotiating abilities, or (3) the options are equivalent and any inequalities in people's negotiating abilities are due to causes for which it is proper to hold the individuals themselves personally responsible.”100

However, whilst Arneson's decision tree mechanism is more sensitive to choice than Dworkin's theory of equality of resources, it does not adequately capture the underlying impulse of luck egalitarianism, either. The problem is that two individuals can have an equal opportunity for welfare, but still end up worse off than others through no fault of their own. This could occur if they face effectively equivalent decision trees, choose the option with the highest-expected value, and end up unequally well-off because the choice goes well for one and badly for the other. ${ }^{101}$ To illustrate this, Kasper Lippert-Rasmussen gives the example of Adrian and Bruce, who are stranded on separate volcanic islands. ${ }^{102}$ They face effectively equivalent decisions trees because both volcanoes have an equal chance of erupting, and Adrian and Bruce are each aware of the probabilities involved. Equality of opportunity for welfare seems to hold. However, from the luck-egalitarian point of view, there would be something wrong if Adrian were killed by a volcanic eruption at the age of thirty, whilst Bruce lived until the age of eighty. The problem is that Adrian ends up worse off than Bruce through no fault of his own. Thus, the existence of effectively equivalent decision trees does not ensure that the effects of brute luck are equally shared. ${ }^{103}$ We must search elsewhere for a compelling theory of luck egalitarianism. 
Although Cohen does not propose a decision tree mechanism, he shares Arneson's belief that choice is central to egalitarian justice. He argues that:

a large part of the fundamental egalitarian aim is to extinguish the influence of brute luck on distribution... Brute luck is an enemy of just equality, and, since effects of genuine choice contrast with brute luck, genuine choice excuses otherwise unacceptable inequalities. ${ }^{104}$

However, his theory of equality of access to advantage differs from Arneson's notion of equal opportunity for welfare.

The key difference is that Cohen's notion of “advantage" includes resources, as well as welfare. This is because individuals may have a reasonable welfare level, despite suffering from a major disadvantage in their endowment of resources. ${ }^{105}$ For example, Tiny Tim might have a fortunate disposition which leaves him with a high level of welfare. But Tim is paralysed and can only achieve a basic level of mobility if he has access to a wheelchair. The egalitarian response to this example is to provide Tim with a wheelchair, despite the fact his disposition leaves him with ample opportunity for happiness. This demonstrates that egalitarians should be interested in access to resources, as well as welfare. ${ }^{106}$

Cohen presents other hypothetical examples to explicate and refine his theory of equality of access to advantage. He considers the case of Paul, who is unable to pursue his love of photography because it is such an expensive hobby, ${ }^{107}$ and Fred who, in contrast, loves fishing, which is a much cheaper activity. Because Paul hates fishing and is unable to pursue the hobby he enjoys, he has a much lower level of welfare than Paul. Other things being equal, egalitarian justice requires that we distribute from Fred to Paul, in order to compensate Paul for his involuntary expensive taste. This shows that 
Cohen's approach represents a greater challenge to market pricing than Dworkin's theory of equality of resources does.

Another example is the man who suffers from painful feelings of guilt because of his religious beliefs. ${ }^{108}$ These feelings of guilt are so closely connected to his religious beliefs that he would not choose to be without them, and as a consequence, it would be inappropriate to provide him with compensation. This leads Cohen to modify equality of access to advantage. He concludes that "some of the costs of unchosen commitments (and they are commitments because one would not choose not to have them) are also not bad luck: they are not bad luck when they are so intrinsically connected with his commitments that their bearer would not choose to be without them.”109 However, this does not mean that all expensive commitments are always noncompensable. In many cases, there is no intrinsic connection between our commitments and their costs. For example, "the committed lover of expensive esoteric music” (Cohen refers specifically to Berg lovers) are unlikely to love Berg's music because it is an expensive taste to satisfy, or to feel that the cost is closely linked to their preference in some other way. Rather, "[most] would not choose to lack their esoteric taste, but they would certainly choose not to sustain the frustration that happens to accompany it, and that produces a relevant disanalogy with the case of the guilty religious believer."110 Thus, an expensive commitment to Berg's music is compensable.

The problem of “cheap expensive tastes” also highlights an important feature of equality of access to advantage. To demonstrate this, Cohen presents the case of Jude whose tastes are cheap to satisfy. ${ }^{111}$ However, Jude reads Hemingway and cultivates a desire to watch bullfights, which makes his tastes more expensive than they were before, although they are still cheaper to satisfy 
than others' are. Because Cohen’s conception of advantage extends to resources as well as welfare, Jude is entitled to the extra funds he needs to travel to Spain to watch bullfights. Thus, equality of access to advantage will support providing compensation to those who cultivate cheap expensive tastes.

Although Cohen's approach is an attractive one, it is by his own admission incomplete as a theory of egalitarian justice. In particular, as Roemer argues, Cohen does not "propose a precise definition of his proposal, in the sense of Arneson's decision-tree construction or of Dworkin's insurance mechanism." ${ }^{112}$ Roemer is also critical of Arneson's decision-tree mechanism, ${ }^{113}$ although he is sympathetic to Arneson and Cohen's general approach to distributive justice. Consequently, he draws on their work to develop a precise definition of a theory he calls equality of opportunity for advantage. This theory aims "to find a distribution of social resources which renders persons equal in advantage insofar as they face similar circumstances, but allows inequality of advantage insofar as the freely chosen aspects of their behaviors differ" a principle which he labels the "Equality of Opportunity principle (EOp)."114 This involves dividing the population in question into different types, and ensuring that each faces an equal opportunity to achieve expected overall success.

When dealing with a particular issue of distributive justice, we must first identify the unchosen “circumstances” which influence decision-making and behaviour in this area. In essence, these are the "brute luck" factors which shape our decisions. We then use these factors to group the relevant population into different types, and individuals whose circumstances are similar are classified as belonging to one type. Because all the individuals in one particular type share the same choice-affecting brute luck characteristics, they can be 
considered equally responsible for whatever decisions they make. The great advantage of this approach is that it allows us to make comparisons of responsibility across types. Individuals are responsible for the choices they make within a particular type, so we can rank the relative position of an individual within the group. We can determine how the decisions she makes compare to the median decisions that someone in her circumstances would make. The aim is to ensure that individuals in different groups who have exercised a "comparable degree of responsibility” enjoy an equal level of social indemnity for the harm they suffer as a result of the decisions they have made. $^{115}$

To illustrate this, Roemer gives the example of providing financial assistance to individuals who develop lung cancer as a result of smoking. ${ }^{116}$ Although each society must make its own decisions about the relevant circumstances which shape smoking behaviour, possible factors include occupation, ethnicity, gender, income, and parental smoking history. Individuals who have similar characteristics in each of these categories are grouped in one type. For example, one type could be "a sixty-year-old, white, female college professor whose parents stopped smoking when she was seven” and another could be a sixty-year-old "black, male steelworker whose parents were both chain-smokers." 117 If members of the second type tend to smoke for a greater length of time than members of the first type, then we must take this into account when making judgements of comparable responsibility. For example, assume that the median number of years smoked is eight years for the first type, and twenty-five years for the second type. If one member of the first type smokes for eight years, and a member of the second type smokes for twenty-five years, then "each has exercised a comparable degree of 
responsibility," and "both should receive the same degree of social indemnity: if all the medical expenses of the professor are covered by society, then the same should be the case for the steelworker." ${ }^{118}$ Ideally, we should equalise the position of all those who exercised a comparable degree of responsibility: "equality of opportunity for $X$ holds when the values of $X$ for all those who exercised a comparable degree of responsibility are equal, regardless of their circumstances.”119

Although it does seem an appealing way of making judgements about individual responsibility, it is doubtful how "pragmatic” Roemer's theory will actually be. In the end, as I will argue in chapter 3, there are non-material inequalities, particularly parental attitudes, which have a large role in influencing the different decisions that individuals make. Roemer takes this into account in his scheme, but because everybody's upbringing is different, and because these differences influence the decisions we make, each person is likely to have a unique set of unchosen choice-affecting "circumstances." The end result is that each person will be in a type of her own (perhaps along with her siblings who had a similar upbringing). This is not a decisive objection to Roemer's proposal, but it does seem to reduce its "pragmatic” nature.

Instead of listing general characteristics that seem to shape the decisions we make, I think it is better to focus directly on the information and understanding a person has when he makes a particular decision. For instance, if a person who has reached his majority takes up smoking, ${ }^{120}$ fully aware of the consequences of doing so, he seems largely responsible for the outcome that results, regardless of his social background. To prove otherwise, we would have to show that the consequences of not smoking have such disutility for him that he has no real choice but to smoke. Whether this is the case will depend on the 
social circles in which the person mixes, and the occupation which he has, but we cannot automatically assume that, every black male steelworker will have been in this position. Moreover, it is possible that a white female college professor studied and taught at colleges where, unusually for the time, smoking was de rigueur. If so, she cannot be considered fully responsible for the outcome that results. The point is, being able to judge questions of responsibility accurately requires detailed information about each individual and the situations she faces during her life. Once again, Roemer's proposal can take this into account by extending “circumstances” to include fine-grained information about each individual's social and occupational environment, but the information required is so extensive that the pragmatic advantages of his proposal are lost. Thus, Roemer is unsuccessful in his attempt to develop a pragmatic, precise device to specify luck egalitarianism.

\section{RAKOWSKI}

Before we conclude, it is worth examining Eric Rakowski's theory of equality of fortune, which is a hard-line version of luck egalitarianism that attracted particularly strong criticism from Anderson. Rakowski explains equality of fortune as follows:

[S]ubject to... [certain] constraints... no one should have less valuable resources and opportunities available to him than anyone else, simply in virtue of some chance occurrence the risk of which he did not choose to incur. Differences resulting from voluntary wagers cannot ground redistributive claims, whereas inequalities stemming from ineluctable chance events call for a reshuffling of resources at the behest of the unlucky, in order to eliminate discrepancies that cannot be traced to individuals' choices. ${ }^{121}$ 
Thus, Rakowski endorses the central luck-egalitarian impulse that Arneson, Cohen, and Roemer support. However, he differs from these two theorists in his approach to the issue of responsibility for preferences. Despite supporting the underlying emphasis on choice and luck, he believes that this leads to a theory that focuses on resources, not welfare. Only in exceptional circumstances do individuals deserve compensation for disadvantages resulting from their preferences. This brings Rakowski back towards Dworkin's theory of equality of resources. In this section I will highlight some key features of Rakowski's theory by focusing on his criticisms of Arneson and Cohen.

Firstly, Rakowski argues against Arneson's position on the issue of compensation for religious beliefs. ${ }^{122}$ Compensation may be justified in Arneson's first example (see section 3 above), where a rube who was raised in a closed religious community shifts to the city after losing his faith, and finds it difficult to satisfy secular preferences. ${ }^{123}$ For instance, if he has feelings of constant guilt because of his upbringing, he may be entitled to extra resources which he could spend on counselling to help him overcome this guilt. But the compensation results from the fact his upbringing left him with a psychological handicap. As Rakowski puts it:

In this case... compensation would not be attributable to the rube's religious convictions or to other commitments with which he identifies. Its justification would lie in his seeking to escape from feelings and attitudes he did not instill in himself and of which he disapproves. This is as much a handicap as physical and mental infirmities somebody did not bring on himself, and it places equal demands on others to restore an equal distribution of resources, broadly construed to include the opportunity to live untroubled by exceptionally strong, debilitating feelings of guilt induced by the actions of others from whom, for whatever reason, specific damages cannot be sought. ${ }^{124}$ 
In contrast, the rube's father would not be entitled to compensation if he decided to leave the religious community in middle age and found himself worse off than his new neighbours because of his low level of savings or education (assuming, of course, that "he was aware of other religions and ways of life" when living in the religious community). ${ }^{125}$ Moreover, if compensation is justified in Arneson's tribes example (see section 3 above), this is because the government has, for some reason, undertaken to support both tribes, and because both tribes are badly off, not because "all religious beliefs that carry material costs provide adequate grounds for redistribution.” ${ }^{\prime 26}$ Once we reach a certain age, we have had the chance to evaluate our commitments, and we are obliged to take responsibility for them. ${ }^{127}$ Thus, religious preferences are generally non-compensable.

Rakowski emphasises that he and Cohen share the same "abstract standard” of egalitarian justice.”128 They both believe that, other things being equal, justice is about the elimination of involuntary disadvantage, and that egalitarians should avoid adopting a purely welfarist conception of advantage. Furthermore, they both believe "that compensation would be warranted for a physical or mental abnormality that markedly reduced somebody's pleasure or well-being through no fault of his own, even if that abnormality did not reduce his earning power or his ability to acquire goods and opportunities that he desires" (which means that non-lucrative talents are compensable from the point of view of egalitarian justice). ${ }^{129}$

However, Rakowski has three criticisms of the way Cohen applies "the abstract standard... [they] share.”130 Firstly, he opposes Cohen's view that cheap expensive tastes are compensable. ${ }^{131}$ Contra Cohen, there is no reason why Jude (see section 3 above) should receive extra resources to enable him to travel 
to Spain after cultivating a taste for bullfighting. Individuals must bear the costs of deliberately cultivated expensive tastes. To illustrate this, Rakowski gives an example involving two equally sized groups who have an equal level of welfare W. ${ }^{132}$ Because the first group is blind, its members require $7 x$ resources to reach welfare level $\mathrm{W}$, whilst the second group is sighted, and only requires $3 x$ resources (we assume that an equal level of welfare obtains if social resources are divided 70/30). If members of the second group all cultivate a cheap expensive taste for bullfighting, assume that they will now require an extra $1.9 x$ resources to pay for their trip to Spain, and to maintain welfare level W. But the extra $1.9 x$ resources needed will be redistributed away from the members of the first group, who are visually impaired, leaving them with $5.1 x$ resources, which is less than what they need to achieve welfare level W. Of course, Cohen could respond by arguing that we should redistribute resources so as to equalise access to welfare after members of the second group cultivate their cheap expensive taste, rather than leaving the blind members of the first group with less welfare than others. But Rakowski argues that a better response is to deny any compensation to Jude and members of the second group. The taste for bullfighting was deliberately cultivated so it provides no grounds for compensation.

Rakowski supports Cohen's view that Dworkin's Louis (see sections 2 and 3 above) should receive compensation if his expensive taste for wine results from his upbringing. However, he opposes Cohen's response to the case of Paul (see section 3 above), who has an expensive taste for photography. He says that it is unlikely that Paul's expensive taste for photography is "genuinely involuntary” and that consequently, he should not receive compensation for it: 
Unless Paul's case is highly unusual, he chose to investigate and involve himself more deeply in photography after an initially attractive exposure to it. The strength of his predilection owes more to his own decisions than to any putatively "natural inclination” he has. But if Paul engendered this interest and permitted it to become pronounced, aware of the costs that further sophistication entailed, then it seems only right that he should answer for his choice. ${ }^{133}$

If Paul ends up miserable because he cannot find pleasure in any other pursuit, then there may be grounds for compensation (provided that Paul has not schooled himself into this bizarre set of preferences through his single-minded pursuit of photography). But this is not the normal state of affairs. Rather:

Virtually everyone has a vast range of desires -- some cheap to satisfy, others dear -the satisfaction of which gives them greater or lesser pleasure or welfare. People may choose to strengthen some desires or weaken others out of moral or religious conviction, affection, self-interest, or other concern, but in each case they do so in the knowledge of the possible costs, both material and experiential, of cultivating or preserving various preferences or hankerings. Those costs are a fact of life, determined by the natural availability of the objects of desire, the time and money needed to obtain, process, transport, or protect those natural resources, and the competing desires of other people. To the extent that people elect to expose themselves to, preserve, or suppress certain desires, the more or less expensive preferences they develop are beyond the bounds of justice: no correction need or should be made for them. ${ }^{134}$

Paul's expensive taste for photography is only compensable if, "for whatever reason having to do with his genes or nurturing or later involuntary conditioning, [he is] constitutionally unable to live a life as meaningful and happy as most others in any less expensive way than by engaging in photography to an extent and in a manner that is far more costly than activities in which others find pleasure and significance...But then... [if this is the situation,] Paul’s is truly a singular case.”135 
The final difference relates to Cohen's view that we are entitled to compensation for expensive tastes that arise from unchosen commitments, even if these tastes themselves were deliberately cultivated. Rakowski argues that such commitments are sometimes chosen. ${ }^{136}$ Our choices play a role in shaping our cultural, political, and religious commitments, just as they shape the taste for more mundane expensive tastes for wine and antiques:

In both cases, a person decides, generally following a pleasant initial acquaintance, to repeat and extend that type of experience, growing over time in desire and knowledge. The commitment that comes with deepened experience is a commitment that hinges on a series of choices, in just the same way that refined tastes do. ${ }^{137}$

Moreover, people must assume responsibility for their convictions, and the values, beliefs, and objectives that arise from them, otherwise, citizens end up subsidising projects they do not value and may directly oppose. The community should not provide subsidies to environmentalists, religious groups, Nazi organisations and anti-abortion activists because this forces people to contribute financially to projects they reject. ${ }^{138}$ Rather, “[i]n affirming commitments, just as in choosing to retain, cultivate, distend, or extinguish certain preferences, people decide how best to live their lives in a world where those decisions invariably come with projected costs and benefits attached.” ${ }^{139}$ Expensive tastes are only compensable if they are involuntarily acquired, and if they are held by a person who would rather be without them. ${ }^{140}$

Thus, with Rakowski's theory of equality of fortune, we have come full circle. Equality of fortune explicitly focuses on the underlying principle of luck egalitarianism, which is latent in Dworkin's theory of equality of resources, and central to Arneson and Cohen's work. However, Rakowski disputes Arneson and Cohen's attempt to link this underlying principle to welfarism, ultimately 
endorsing an approach that closely resembles Dworkin's theory of equality of resources. This highlights that there are important differences between the various theories of luck egalitarianism, despite the common focus on notions of choice, luck, and responsibility.

\section{CONCLUSION}

In this chapter, I have discussed the emergence of luck egalitarianism and analysed the work of its leading exponents. I want to conclude the chapter by emphasising two key points that emerge from this discussion. Firstly, it is clear that the term "luck egalitarianism" refers to a diverse range of theorists who disagree about many issues, most importantly, whether the disadvantages associated with welfare are relevant to distributive justice. Secondly, although luck egalitarians have proposed different devices to render the theory more concrete, Dworkin's insurance mechanism, Arneson's decision tree proposal, and Roemer’s pragmatic theory of responsibility all have their drawbacks.

This suggests two desirable features for current research on luck egalitarianism. Firstly, there is a need to fix the appropriate notion of "advantage" to use in the theory. Secondly, there is a need to convert the underlying impulse of luck egalitarianism into a more precise theory. In the rest of the thesis I aim to tackle these issues. Chapter 5 focuses on the appropriate conception of egalitarian advantage we should adopt, whilst chapter 3 outlines a revised form of the theory based on careful analysis of the option-brute distinction. Although I am not optimistic about the chances of developing a mechanism to render the theory more concrete, this may be unnecessary. In chapter 7, I demonstrate how it is possible to apply luck egalitarianism to policy debate without using a precise mechanism. 
Before I tackle these issues, I will defend a general form of luck egalitarianism against Anderson's claim that it misses the point of equality. This is an important issue to explore because Anderson's critique is a powerful attack on the whole luck-egalitarian project, rather than a criticism of one particular luck-egalitarian theory. It is important to explore these criticisms early in the thesis because there is little point in developing more detailed versions of luck egalitarianism if the entire project is fundamentally flawed. 


\section{NOTES}

${ }^{1}$ E. S. Anderson, “What Is the Point of Equality?” Ethics V. 109, no. 2, 1999, pp. 287-337.

2 Anderson, “What Is the Point of Equality?” p. 289. Anderson uses the term “equality of fortune” interchangeably with “luck egalitarianism.” Eric Rakowski also uses the term “equality of fortune" to describe the theory of egalitarian justice he develops in Equal Justice, New York, Oxford University Press, 1991, especially Part I. Although Anderson does pay particular attention to Rakowski's work, the term luck egalitarianism/equality of fortune refers to a broader approach that includes a number of different authors.

${ }^{3}$ Arneson cited in Anderson, “What Is the Point of Equality?” pp. 289-90.

${ }^{4}$ Anderson, “What Is the Point of Equality?” p. 290.

${ }^{5}$ Anderson, “What Is the Point of Equality?” pp. 290-1.

${ }^{6}$ Anderson, “What Is the Point of Equality?” p. 291. The distinction was originally drawn in R. Dworkin, "What is Equality? Part 2: Equality of Resources," Philosophy and Public Affairs, V. 10, no. 4, 1981, p. 293. Reprinted in R. Dworkin, Sovereign Virtue: The Theory and Practice of Equality, Cambridge, Mass., Harvard University Press, 2000, pp. 73-4. Subsequent references to "Equality of Resources" throughout the thesis will be to the reprinted version in Sovereign Virtue.

${ }^{7}$ G.A. Cohen, “On the Currency of Egalitarian Justice,” Ethics, V. 99, no. 4, 1989, pp. 906-944, at p. 933. It should be noted that Cohen is referring specifically to Dworkin here, not luck egalitarianism generally.

${ }^{8}$ Anderson, "What Is the Point of Equality?” p. 290.

${ }^{9}$ Anderson, “What Is the Point of Equality?” p. 295.

${ }^{10}$ I should note here that my general approach in this chapter has been influenced by other discussions of luck egalitarianism’s development, particularly W. Kymlicka, Contemporary Political Philosophy: An Introduction, Oxford, Oxford University Press, 2002, pp. 53-101; Cohen, "On the Currency,"; J. Wolff, "Fairness, Respect, and the Egalitarian Ethos," Philosophy and Public Affairs, V. 27, no. 2, 1998, pp. 97-122, at pp. 99-101; A. Callinicos, Equality, Cambridge, Polity, 2000, pp. 41-64; and S. Hurley, Justice, Luck and Knowledge, Cambridge, Mass., Harvard University Press, 2003, pp. 133-45.

${ }^{11}$ E.g. Anderson, “What Is the Point of Equality?” p. 290. 
${ }^{12}$ For an overview of Rawls's theory, including the ideas developed in this paragraph, see $A$ Theory of Justice, Oxford, Oxford University Press, 1972, pp. 11-17.

${ }^{13}$ Rawls, A Theory of Justice, pp. 516-17.

${ }^{14}$ Rawls, A Theory of Justice, p. 302.

${ }^{15}$ Rawls, A Theory of Justice, p. 78.

${ }^{16}$ See Rawls, A Theory of Justice, especially “The Tendency to Equality,” pp. 100-108.

${ }^{17}$ Rawls, A Theory of Justice, p. 100.

18 Rawls, A Theory of Justice, p. 100. Rawls attributes this principle to H. Spiegelberg, “A Defense of Human Equality,” Philosophical Review, V. 53, no. 2, 1944, pp. 101-24, at pp. 101, 113-123; and D.D. Raphael, “Justice and Liberty,” Proceedings of the Aristotelian Society, V. 51, 1950-51, pp. 167-96, at pp. 187f.

${ }^{19}$ Rawls, A Theory of Justice, pp. 101-2.

${ }^{20}$ Rawls, A Theory of Justice, p. 102.

${ }^{21}$ In chapter 4, I will analyse the relationship between Rawls and luck egalitarianism in more detail.

${ }^{22}$ Kymlicka, Contemporary Political Philosophy, pp. 72-75.

${ }^{23}$ Rawls, A Theory of Justice, pp. 311-12.

${ }^{24}$ Cohen, “On the Currency,” pp. 914-16. For relevant discussion of his views on the issue of responsibility for preferences see Rawls “Social Unity and Primary Goods,” in S, Freeman (ed.) Collected Papers, Cambridge, Mass., Harvard University Press, 1999, p. 371.

${ }^{25}$ E.g. Sen, “Equality of What?” in S. Darwall (ed.), Equal Freedom, Ann Arbor, University of Michigan Press, 1995, pp. 307-330, at pp. 323-36; Kymlicka, Contemporary Political Philosophy, pp. 70-72.

26 “What is Equality? Part I: Equality of Welfare,” Philosophy \& Public Affairs, V. 10, no. 3, 1981, pp. 185-246; and “What is Equality? Part II: Equality of Resources,” Philosophy and Public Affairs, V. 10, no. 4, 1981, pp. 283-245. Reprinted in R. Dworkin, Sovereign Virtue: The Theory and Practice of Equality, Cambridge, Mass., Harvard University Press, 2000, pp. 11-64 and pp. 65-119. Subsequent references to both essays throughout the thesis will be to the reprinted versions in Sovereign Virtue. 
${ }^{27}$ Dworkin, Sovereign Virtue, pp. 48-59. The expensive tastes criticisms of equality of welfare will be examined in more detail in chapter 5 .

${ }^{28}$ Dworkin, Sovereign Virtue, p. 49.

${ }^{29}$ Dworkin, Sovereign Virtue, p. 52.

${ }^{30}$ Dworkin, Sovereign Virtue, p. 57.

${ }^{31}$ Dworkin, Sovereign Virtue, pp. 56-7.

${ }^{32}$ Dworkin, Sovereign Virtue, p. 56.

${ }^{33}$ However, the expensive tastes objection is not Dworkin's sole argument against equality of welfare. I will examine some of his other arguments in chapter 5.

${ }^{34}$ In his initial outline of the theory, which we will focus on in this section, Dworkin restricts his discussion to the distribution of privately owned resources. See Sovereign Virtue, pp. 65-66. However, the full version of the theory extends beyond private resources, as subsequent chapters of Sovereign Virtue illustrate.

${ }^{35}$ Dworkin, Sovereign Virtue, pp.66-67, quotation at p. 67.

${ }^{36}$ Dworkin, Sovereign Virtue, pp. 67-68.

${ }^{37}$ Dworkin, Sovereign Virtue, p. 70.

${ }^{38}$ Dworkin, Sovereign Virtue, p. 68.

${ }^{39}$ Dworkin, Sovereign Virtue, p. 68.

${ }^{40}$ Dworkin, Sovereign Virtue, p. 68.

${ }^{41}$ Dworkin, Sovereign Virtue, p. 68.

${ }^{42}$ Dworkin, Sovereign Virtue, pp. 68-9.

${ }^{43}$ Dworkin, Sovereign Virtue, p. 69.

${ }^{44}$ Dworkin, Sovereign Virtue, p. 69.

${ }^{45}$ Dworkin, Sovereign Virtue, p. 73.

${ }^{46}$ Dworkin, Sovereign Virtue, p. 73.

${ }^{47}$ Dworkin, Sovereign Virtue, p. 73.

${ }^{48}$ Dworkin, Sovereign Virtue, p. 73.

${ }^{49}$ Dworkin, Sovereign Virtue, p. 73. I will analyse the option luck-brute luck distinction in more detail in chapter 3 .

${ }^{50}$ Dworkin, Sovereign Virtue, p. 74. 
${ }^{51}$ Dworkin, Sovereign Virtue, pp. 74-75.

52 Dworkin, Sovereign Virtue, pp. 76-77, quotation at p. 77.

${ }^{53}$ Dworkin, Sovereign Virtue, p. 77.

${ }^{54}$ Dworkin, Sovereign Virtue, p. 74.

${ }^{55}$ Dworkin, Sovereign Virtue, p. 73.

${ }^{56}$ Dworkin, Sovereign Virtue, p. 77.

${ }^{57}$ Dworkin, Sovereign Virtue, pp. 77-8. Dworkin recognises the problem that he is relying on averages to determine the appropriate level of compensation, not what each individual would have done. He leaves open the possibility of refining his approach to avoid this problem, but without full information about what an individual would have done, the approach outlined is the best available. See p. 78 and p. 478 n. 5.

${ }^{58}$ Dworkin, Sovereign Virtue, pp. 78-80.

${ }^{59}$ Dworkin, Sovereign Virtue, p. 81.

${ }^{60}$ Dworkin, Sovereign Virtue, pp. 81-82.

${ }^{61}$ Dworkin, Sovereign Virtue, p. 82.

${ }^{62}$ Dworkin, Sovereign Virtue, p. 82.

${ }^{63}$ Dworkin, Sovereign Virtue, pp. 82-83.

${ }^{64}$ Dworkin, Sovereign Virtue, p. 83.

${ }^{65}$ Dworkin, Sovereign Virtue, p. 86.

${ }^{66}$ Dworkin, Sovereign Virtue, p. 89.

${ }^{67}$ See Dworkin, Sovereign Virtue, pp. 89-90.

${ }^{68}$ Dworkin, Sovereign Virtue, p. 90.

${ }^{69}$ Dworkin's argument here is not a decisive objection to the talent auction, as Miriam Cohen Christofidis argues. See “Talent, Slavery, and Envy,” in J. Burley (ed.), Dworkin and His Critics, Malden, Mass., Blackwell Publishing, 2004, pp. 30-44. Although this is not the place for a full discussion of the flaws in Dworkin's criticism, one of the most obvious objections is that the less talented have less occupational freedom than the talented precisely because of their lesser talents.

${ }^{70}$ Dworkin, Sovereign Virtue, pp. 90-1.

${ }^{71}$ Dworkin, Sovereign Virtue, p. 91. 
${ }^{72}$ Dworkin, Sovereign Virtue, pp. 91-2.

${ }^{73}$ Dworkin, Sovereign Virtue, pp. 93-94.

${ }^{74}$ Dworkin, Sovereign Virtue, p. 94.

${ }^{75}$ Dworkin, Sovereign Virtue, p. 94.

${ }^{76}$ Dworkin, Sovereign Virtue, p. 97.

${ }^{77}$ Dworkin, Sovereign Virtue, p. 102. See the discussion of moral hazard and co-insurance on p. 101.

${ }^{78}$ Dworkin, Sovereign Virtue, p. 100.

${ }^{79}$ Dworkin, Sovereign Virtue, p. 102. In particular, Dworkin notes that "[w]e might decide that... a scheme that tied redistribution to actual earnings rather than to ability to earn... was a better second-best approximation to the ideal of mimicking the insurance market than any other scheme we could develop."

${ }^{80}$ It is important to note that Dworkin denies he is a luck egalitarian. He does "believe that luck should play less of a role in fixing the distribution of wealth than it now does in, for example, the United States.” However, he claims that the envy test is the central idea of equality of resources, and that this is different from the idea of luck neutralisation: "I... argued... that the appropriate version of that test requires not... that people be fully compensated for any bad luck after it has occurred, but rather that people be made equal, so far as this is possible, in their opportunity to insure or provide against bad luck before it has occurred, or, if that is not possible, that people be awarded the compensation it is likely they would have insured to have if they had had that opportunity. That latter goal is not a compromise or second-best solution that accepts some injustice out of necessity. It is what equality, properly understood, itself requires.” See Dworkin, “Equality, Luck and Hierarchy,” Philosophy and Public Affairs, V. 31, no. 2, 2003, pp. 190-98, quotations at pp. 190-91. However, this seems inconsistent with the way he originally presents his scheme. The notions of option luck and brute luck have a key role in Dworkin's theory (as we saw above), and the very appeal of the insurance mechanism is that it provides a way of incorporating notions of individual choice and responsibility into a theory of equality resources. Thus, I agree with Scheffler that it is better to regard Dworkin's theory as "an interpretation or a refinement of the core idea" of luck egalitarianism. See 
Scheffler, "Equality as the Virtue of Sovereigns: A Reply to Ronald Dworkin,” Philosophy and Public Affairs, V. 31, no. 2, 2003, pp. 199-206, at pp. 199-200.

${ }^{81}$ Cohen, “On the Currency of Egalitarian Justice,” p. 928.

${ }^{82}$ Cohen, “On the Currency of Egalitarian Justice,” p. 928, his emphasis.

${ }^{83}$ Cohen, “On the Currency of Egalitarian Justice,” pp. 927-29.

${ }^{84}$ Cohen, “On the Currency of Egalitarian Justice,” p. 922.

${ }^{85}$ Cohen, “On the Currency of Egalitarian Justice,” p. 931. Cohen also argues that Dworkin’s work suggests another interpretation of the person/circumstances distinction. Beliefs and attitudes that define an individual's conception of a successful life constitute aspects of their person, whilst means/impediments to it are part of the individual's circumstances. But this is not an appealing way of understanding the distinction. It is difficult to characterise attitudes such as cheerfulness or gloominess on the basis of this distinction because they neither define a successful life nor (necessarily) impede/aid its achievement. See Cohen "On the Currency of Egalitarian Justice,” pp. 929-31.

${ }^{86}$ Cohen, “On the Currency of Egalitarian Justice,” pp. 928-9; \& see also Arneson, "Equality and Equal Opportunity for Welfare,” Philosophical Studies 56, 1989, pp. 77-93, at p. 79. I should note that Arneson directs his criticism at equality of resources generally, rather than focusing specifically on the inconsistency in Dworkin’s approach.

${ }^{87}$ Cohen, “On the Currency of Egalitarian Justice,” pp. 932-33, quotation at p. 932. See also

Arneson, “Equality and Equal Opportunity for Welfare,” pp. 79-80, 80-82.

${ }^{88}$ Arneson, "Equality and Equal Opportunity for Welfare,” p. 81. However, in the real world, non-egalitarian considerations mean that it is unfeasible to adopt a policy of compensation in such cases.

${ }^{89}$ Arneson, “Equality and Equal Opportunity for Welfare,” p. 81.

${ }^{90}$ At least, this disadvantage is not compensable on the grounds of egalitarian justice. This rider applies to all subsequent discussions of compensation in this chapter.

${ }^{91}$ Arneson, “Equality and Equal Opportunity for Welfare,” pp. 79, 83-84.

${ }^{92}$ Cohen, “On the Currency,” pp. 922-23.

${ }^{93}$ Arneson, “Equality and Equal Opportunity for Welfare,” p. 85.

${ }^{94}$ Arneson, “Equality and Equal Opportunity for Welfare,” p. 86. 
${ }^{95}$ Arneson, “Equality and Equal Opportunity for Welfare,” p. 85.

${ }^{96}$ Arneson, “Equality and Equal Opportunity for Welfare,” p. 85.

${ }^{97}$ Arneson, “Equality and Equal Opportunity for Welfare,” p. 85.

98 Arneson distinguishes between first-best and ideally considered second-best preferences. Essentially, first-best rational preferences are an individual's ideal preferences, chosen with full information and operating under the assumption that one can costlessly change one's actual preferences to accord with the ideal preferences chosen through this process. In contrast, second-best preferences are those that an individual would choose if they had to factor in “information regarding (a) one's actual resistance to advice regarding the rationality of one's preferences, (b) the costs of an educational program that would break down this resistance, and (c) the likelihood that anything approaching this educational program will actually be implemented in one's lifetime. What it is reasonable to prefer is then refigured in the light of these costs.” See Arneson, “Equality and Equal Opportunity for Welfare,” p. 83. If there is a conflict between the two, then ideally-considered second-best preferences should be used as the basis for determining an individual's expected welfare for the purposes of equal opportunity for welfare. See Arneson, “Equality and Equal Opportunity for Welfare,” p. 85.

${ }^{99}$ Arneson, “Equality and Equal Opportunity for Welfare,” pp. 85-6.

${ }^{100}$ See Arneson, “Equality and Equal Opportunity for Welfare,” p. 86.

${ }^{101}$ K. Lippert-Rasmussen, “Arneson on Equality of Opportunity for Welfare,” The Journal of Political Philosophy, V. 7, no. 4, 1999, pp. 478-87, at p. 482.

${ }^{102}$ Lippert-Rasmussen, “Arneson on Equality of Opportunity for Welfare,” pp. 482-82.

${ }^{103}$ Arneson concedes that revisions to equal opportunity for welfare will be needed to overcome this problem. However, it is also worth noting here that (for other reasons) he now favours “responsibility-catering prioritarianism” (RCP) over equal opportunity for welfare, as the best theoretical understanding of distributive justice. See R.J. Arneson, "Equality of Opportunity for Welfare Defended and Recanted,” The Journal of Political Philosophy, V. 7, no. 4, 1999, pp. 488-97. For his comments on the Adrian and Bruce example, see pp. 489-90. I explain RCP and the challenge posed by prioritarianism more generally, in chapter 6 .

${ }^{104}$ Cohen, “On the Currency of Egalitarian Justice,” p. 931.

${ }^{105}$ Cohen, “On the Currency of Egalitarian Justice,” pp. 917-18. 
106 Cohen uses the broader term “access” rather than “opportunity” because "access” takes into account the limitations imposed by an individual's capacities in a way that "opportunity," in its normal usage, does not. See “On the Currency of Egalitarian Justice,” pp. 916-17.

${ }^{107}$ Cohen, “On the Currency of Egalitarian Justice,” p. 923.

${ }^{108}$ Cohen, “On the Currency of Egalitarian Justice,” pp. 937-38.

${ }^{109}$ Cohen, “On the Currency of Egalitarian Justice,” p. 937, his emphasis.

${ }^{110}$ Cohen, “On the Currency of Egalitarian Justice,” pp. 937-38.

${ }^{111}$ Cohen, “On the Currency of Egalitarian Justice,” p. 925.

112 J.E. Roemer, Theories of Distributive Justice, Cambridge, Mass., Harvard University Press, 1996, p. 274.

${ }^{113}$ Roemer, Theories of Distributive Justice, pp. 267-72.

114 Theories of Distributive Justice, p. 276. Rather than adopting Cohen's conception of advantage, Roemer remains uncommitted on precisely what “advantage” entails.

${ }^{115}$ My presentation of Roemer's proposal in this paragraph draws on his discussion in "A Pragmatic Theory of Responsibility for the Egalitarian Planner,” Philosophy and Public Affairs, pp. 146-166, especially pp. 149-51. See also Roemer's Theories of Distributive Justice, especially pp. 276-315; and Equality of Opportunity, Cambridge, Mass., Harvard University Press, 1998.

${ }^{116}$ Roemer, “A Pragmatic Theory of Responsibility for the Egalitarian Planner,” pp. 150-52.

${ }^{117}$ Roemer, “A Pragmatic Theory of Responsibility for the Egalitarian Planner,” p. 151.

${ }^{118}$ Roemer, “A Pragmatic Theory of Responsibility for the Egalitarian Planner,” p. 151.

119 Roemer, “A Pragmatic Theory of Responsibility for the Egalitarian Planner,” p. 149, his emphasis. Roemer demonstrates mathematically that it is impossible to develop a tax policy that achieves equality of opportunity as presented here, so he proposes a second-best proposal (see pp. 156-63). But examining this alternative, and Roemer's proof, takes us too far from our central concern here. The short summary of Roemer's approach provided above will suffice for our purposes.

${ }^{120}$ In reality, of course, this will be less of a problem because most people take up smoking in their childhood, before they are deemed to be fully rational agents. But in this case, it is unclear 
why male black steelworkers or female professors who began smoking in childhood should be treated any differently.

${ }^{121}$ Rakowski, Equal Justice, pp. 1-2.

${ }^{122}$ He also criticises Arneson's theory on other grounds. See Equal Justice, pp. 44-49.

${ }^{123}$ Rakowski, Equal Justice, pp. 50-51.

${ }^{124}$ Rakowski, Equal Justice, pp. 50-51.

${ }^{125}$ Rakowski, Equal Justice, p. 51. Rakowski does not pursue the possibility of providing compensation on other grounds, relating to the dramatic nature of the change in preferences involved. See p. 51 n. 42.

${ }^{126}$ Rakowski, Equal Justice, pp. 51-52, quotation at p. 52.

${ }^{127}$ Rakowski, Equal Justice, p. 52.

${ }^{128}$ Rakowski, Equal Justice, pp. 53-4, quotation at p. 54.

${ }^{129}$ Rakowski, Equal Justice, pp. 53-4.

${ }^{130}$ Rakowski, Equal Justice, p. 54.

${ }^{131}$ Rakowski, Equal Justice, pp. 54-56.

${ }^{132}$ Rakowski, Equal Justice, pp. 55-56.

${ }^{133}$ Rakowski, Equal Justice, p. 57.

${ }^{134}$ Rakowski, Equal Justice, pp. 57-8.

${ }^{135}$ Rakowski, Equal Justice, p. 58.

${ }^{136}$ Rakowski, Equal Justice, pp. 61-62.

${ }^{137}$ Rakowski, Equal Justice, p. 62.

${ }^{138}$ Rakowski, Equal Justice, p. 63.

${ }^{139}$ Rakowski, Equal Justice, pp. 63-64.

${ }^{140}$ Rakowski, Equal Justice, p. 64. 


\section{CHAPTER 2}

\section{DEFENDING LUCK EGALITARIANISM}

Elizabeth Anderson has attacked the emphasis contemporary egalitarian philosophers place on luck and responsibility. ${ }^{1}$ She argues that luck egalitarianism fails to capture the key motivation of egalitarian justice -- it is a poor interpretation of the egalitarian ideal because it treats some citizens with disrespect, treats others too harshly, and is embedded in the distributive paradigm that dominates contemporary theories of justice. In contrast, the underlying point of equality is best captured by the theory of democratic equality, which emphasises the importance of equal citizenship. Many writers have subsequently drawn on Anderson's article, particularly her criticisms of luck egalitarianism and contemporary theories of egalitarian justice. ${ }^{2}$

In this chapter, I will defend luck egalitarianism against Anderson’s critique. In section 1, I summarise her key criticisms of luck egalitarianism, and briefly outline her alternative approach to equality. In section 2, I will evaluate three objections, all of which relate to Anderson's belief that equality is about establishing relationships of equal respect, and opposing social hierarchy and oppression. I will pay particular attention to her claim that luck egalitarianism focuses too much on patterns of distribution rather than social relations. I will argue that, on the contrary, non-distributive inequalities like oppression, marginalisation and domination are central to a broader interpretation of luck egalitarianism. The third section of the chapter will focus on Anderson's “harsh treatment" criticism, which represents a stronger challenge to the theory. I will argue, firstly, that harsh treatment rarely occurs if we apply luck egalitarianism to the real world today, where inequality is rife. Secondly, when cases of harsh 
treatment do arise, there is nothing wrong from the point of view of egalitarian justice. I conclude by defending luck egalitarianism, arguing that the emphasis on choice is important, even if inequalities in the real world rarely reflect option luck. Thus, luck egalitarianism remains an appealing interpretation of egalitarian justice, despite Anderson's powerful critique.

\section{MISCONCEIVED EQUALITY: ANDERSON'S CRITIQUE}

Anderson believes that luck egalitarianism misunderstands the true point of equality. Rather than focusing on the extent to which individuals are living in a community of equals, it focuses on responsibility and natural luck. Although it aims to combine the positive aspects of capitalism and socialism, it actually unites the worst features of both ${ }^{3}$-- it relies too much on the market, fails to assist some people who are deserving of assistance, leads to excessive state intervention and actually discourages personal responsibility. It is also disrespectful and demeaning towards those it does help. In sum, luck egalitarianism misunderstands the ideal of equality.

At times, Anderson argues, luck egalitarianism treats the victims of bad option luck too harshly. Like capitalism at its worst, it relies too much on market outcomes. People can end up with a very low level of well-being, without being entitled to state support:

Luck egalitarians tell the victims of very bad option luck that, having chosen to run their risks, they deserve their misfortune, so society need not secure them against destitution and exploitation. ${ }^{4}$

In a "hard-line version of equality of fortune, once people risk and lose their fair share of natural wealth, they have no claims against others to stop their free fall into misery and destitution." ${ }^{5}$ The approach is also too reliant on markets 
and choices, failing to analyse the real choices individuals face. ${ }^{6}$ Thus, luck egalitarianism treats some people too harshly to be considered a truly egalitarian theory.

Anderson groups the various types of harsh treatment into a number of categories. One of the key problems is the abandonment of negligent victims. ${ }^{7}$ A faulty driver, for instance, might be denied medical treatment after an accident. ${ }^{8}$ In other cases, the victims of bad option luck might be forced into exploitative debt peonage and sweatshop labour in order to meet their material needs. ${ }^{9}$ Luck egalitarianism will also lead to discrimination amongst citizens. Those suffering from similar disadvantages/afflictions will not receive the same level of compensation or financial assistance if they bear different degrees of responsibility for their predicaments. This could lead to discrimination amongst the disabled (penalising those deemed responsible for their disability), geographical discrimination against victims of natural disasters who choose to live in dangerous areas, and discrimination against those employed in dangerous occupations. ${ }^{10}$ The unpaid caretakers of children, the ill, and the infirm may also be held responsible for the fact they earn no wage, leading to poverty or dependency on others. ${ }^{11}$ These problems all relate to Anderson's concern that luck egalitarianism does not guarantee the existence of a welfare safety net that protects the needy. ${ }^{12}$ Consequently, it would allow the victims of very bad option luck to fall to an extreme level of deprivation. This seems inconsistent with a reasonable approach to egalitarian justice.

Anderson believes that most luck egalitarians recognise this problem but propose unsatisfactory measures to deal with it. This generally involves appealing to a non-egalitarian value such as paternalism to justify mandatory 
social insurance programs, which will protect individuals from destitution in the event of very bad option luck. ${ }^{13}$ However, Anderson believes this treats individuals disrespectfully, "effectively telling citizens that they are too stupid to run their lives."14 Moreover, it is not a strong enough justification for the significant restriction on personal liberty compulsory contribution to these programs involves. ${ }^{15}$

An alternative may be to argue that participation in such a scheme is required by luck egalitarianism. After all, the aim of luck egalitarianism is to prevent undeserved misfortune and "some outcomes are so awful that no one deserves to suffer them, not even the imprudent."16 However, Anderson claims that this argument "goes against the spirit of equality of fortune" because it makes a distinction between goods that citizens are guaranteed by society, and those that are not. ${ }^{17}$ As a result, the harsh treatment problem remains.

Anderson's second major criticism is that luck egalitarianism treats the victims of bad brute luck with disrespect. ${ }^{18}$ Although egalitarian justice requires that they receive compensation, Anderson argues that this assistance is motivated by feelings of pity, not equality. The well-off pity the unlucky, who receive compensation on the basis of their inferiority to others, ${ }^{19}$ and this is inconsistent with the idea of equal respect. ${ }^{20}$ Instead, egalitarianism is driven by humanitarian compassion, which "is based on an awareness of suffering, an intrinsic condition of a person" 21 and "seeks to relieve suffering wherever it exists, without passing moral judgment on those who suffer.”22 Luck egalitarianism, on the other hand, "focuses...on the gap between the least and most fortunate,” motivated by the condescending emotion of pity. ${ }^{23}$ It replicates the Poor Laws in the stigma and acceptance of inferiority associated with 
receiving state aid. ${ }^{24}$ Thus, luck egalitarianism is demeaning and disrespectful to the very people it is supposed to help.

Luck egalitarianism also rewards people for expensive tastes and offers inappropriate compensation for the wrong disadvantage. For example, a person's anxiety at the possibility he/she could develop a hooked nose, may lead to the public funding of plastic surgery. ${ }^{25}$ In another case, luck egalitarians may compensate the Deaf for their deafness when, in fact, "most people who identify as members of the Deaf community do not believe that being deaf is such a grievous defect that there is any hearing person whose abilities are preferable to theirs." 26 The real injustice is the fact that communication is structured in a way that marginalises deaf people. Thus, luck egalitarianism attempts to compensate/justify social oppression with private, material compensation instead of directly tackling the real, social injustice. ${ }^{27}$

Luck egalitarianism is also disrespectful towards people because it requires a high level of intrusion and interference in their lives. In this way, it shares one of socialism's major flaws, ${ }^{28}$ requiring the state to make "grossly intrusive, moralizing judgments of individual's choices.”29 This is necessary in order to determine whether an individual's level of well-being reflects brute luck or option luck. Judgements about individual responsibility are essential for this. However, individuals should be able to follow their own judgements about how they live their lives and act in particular situations. For the state to be assessing their choices in this way “interferes with citizens’ privacy and liberty” and involves making disrespectful judgements about the extent to which a person is capable of being responsible. ${ }^{30}$ It also encourages people "to deny personal responsibility for their problems.”31 
These criticisms reflect an overall problem with luck egalitarianism -- it misses the true point of equality, which is to oppose social hierarchy. ${ }^{32}$ More specifically, Anderson argues in favour of a democratic conception of equality (“democratic equality”) which differs from luck egalitarianism in three main ways. ${ }^{33}$ Firstly, its central aim is to end social oppression, rather than to rectify natural injustice. Secondly, it is "a relational theory of equality: it views equality as a social relationship.” In contrast, luck egalitarianism “is a distributive theory of equality: it conceives of equality as a pattern of distribution. Thus... [it] regards two people as equal so long as they enjoy equal amounts of some distributable good - income, resources, opportunities for welfare, and so forth.” Thirdly, “democratic equality is sensitive to the need to integrate the demands of equal recognition with those of equal distribution. Goods must be distributed according to principles and processes that express respect for all.”34 These three differences reflect a broader view that equality is about relationships of equal respect and opposition to social hierarchy and oppression, not the impact of luck on the distribution of goods. ${ }^{35}$

This last criticism is particularly troubling because it suggests that luck egalitarianism fundamentally misinterprets the ideal of equality. The next section will examine the extent to which this is true, concluding that luck egalitarianism is not trapped in the distributive paradigm as Anderson implies. I will also consider Anderson's distinct but related criticisms that luck egalitarianism is motivated by feelings of pity, rather than equal respect, and her claim that it supports intrusive and disrespectful interference in the lives of citizens. 


\section{SOCIAL OPPRESSION, PITY, AND INTRUSION}

Luck egalitarianism recognises the injustice of social oppression, to the extent that oppression is a form of bad brute luck that lowers the well-being of individuals. The theory is fundamentally concerned with ensuring that characteristics such as gender, ethnicity, religion and sexual preference do not lower the level of advantage an individual enjoys. ${ }^{36}$ If luck-egalitarian theorists fail to recognise this, it is because of the way they understand advantage, not because of their belief in luck egalitarianism per se. ${ }^{37}$

Any reasonable measure of human advantage must be sensitive to the effects of oppression, including its non-material forms, such as cultural imperialism. This excludes a purely resource-based conception of advantage, which has difficulty dealing with non-material factors (except to the extent that they have distributive implications). However, a purely subjective welfarebased conception may also be unsatisfactory. What we need is some objective view of well-being that includes non-material factors. ${ }^{38}$

Combating social oppression becomes a very important goal for luck egalitarians if they adopt this conception of advantage. Anderson mentions Iris Young's five faces of social oppression when discussing the aims of real egalitarian political movements, and Young, like Anderson, emphasises the importance of social structures and institutions in matters of egalitarian justice, so I will use these categories as the basis for my analysis. If luck egalitarianism can explain why the five faces violate egalitarian concerns, it can successfully handle a broad range of non-distributive and distributive issues, thus refuting one of Anderson's most significant criticisms and strengthening its appeal as an interpretation of the egalitarian ideal. 
According to Young, "[o]ppression refers to structural phenomena that immobilize or diminish a group,"39 where group is defined as "a collective of persons differentiated from at least one other group by cultural forms, practices, or way of life. ${ }^{40}$ In essence, this means that people end up with a lower level of well-being because of their ethnic, gender, religious or class identity. This seems to imply that a key question for luck egalitarians is whether or not individuals are responsible for this group identity.

In fact, people can rarely be held responsible for choosing their group identity. Usually it is a reflection of an individual's upbringing, social environment or physical appearance. Young suggests that group affinity is often linked to the way we are perceived by others and that this has a profound influence on our sense of identity. ${ }^{41}$ This does not mean that individuals passively accept, for the rest of their lives, an identity prescribed by others, ${ }^{42}$ but it does suggest that it is not simply a matter of individual choice. If this is the case, it is difficult to see how individuals can really be considered responsible for their own group identity, and consequently, any oppression they suffer as a result of this identity is a matter of bad brute luck.

At any rate, in most cases of social oppression, it does not matter to luck egalitarianism whether individuals are responsible for their affinity with an oppressed group. This is because an egalitarian conception of advantage is partly based on an objective account of the good life, and this will include the idea of being able to follow one's legitimate beliefs and preferences for certain things, without being persecuted by others. This does not extend to all beliefs and preferences, but it does include those that are essential to one's identity, relating to matters such as religion, lifestyle and work. The key question for 
luck egalitarianism is whether individuals are responsible for the fact their legitimate preferences in such areas are restricted. If the restriction is the result of social oppression, clearly no such responsibility exists. In other words, this approach assumes that people have certain preferences that are important to them, such as their religious preferences/beliefs, and that oppression of these preferences/beliefs would be unjust, regardless of whether they were deliberately cultivated. For example, it does not matter if somebody has deliberately cultivated an affinity for an oppressed religion. What matters is the fact that he/she is not responsible for the oppression of this religion. Thus, luck egalitarianism should be able to handle most instances of social oppression.

This can be seen if we examine Young's five faces of oppression. The first of these is exploitation, which encompasses a broader range of issues than distributive injustice: ${ }^{43}$

The injustice of exploitation consists in social processes that bring about a transfer of energies from one group to another to produce unequal distributions, and in the way in which social institutions enable a few to accumulate while they constrain many more. The injustices of exploitation cannot be eliminated by redistribution of goods, for as long as institutionalized practices and structural relations remain unaltered, the process of transfer will re-create an unequal distribution of benefits. $^{44}$

Generally, exploitation violates the luck-egalitarian interpretation of egalitarian justice because exploitation is a matter of structural relations between social groups and therefore reflects brute luck. Exploited individuals face a lower level of well-being because of their group identity within this system of structural relations and are thus victims of bad brute luck. Luck egalitarianism would condemn this situation and argue for its rectification. For example, as a social group, "women undergo specific forms of gender exploitation in which 
their energies and power are expended, often unnoticed and unacknowledged, usually to benefit men by releasing them for more important and creative work, enhancing their status or the environment around them, or providing them with sexual or emotional service."45 An obvious case of this is the disproportionate responsibility women have for child rearing. ${ }^{46}$ This gives men the opportunity to achieve "[t]he freedom, power, status and self-realization" ${ }^{47}$ associated with performing privileged activities that many women are excluded from. This dominant view of gender roles often restricts women's options, lowering their level of well-being. Because they are not responsible for the way gender roles are constructed, the lower well-being that results from this restricted range of options is a matter of bad brute luck. Thus, luck egalitarianism would condemn exploitation on the basis of gender. ${ }^{48}$

However, in some circumstances luck egalitarianism may react differently to exploitation. As Anderson highlights, individuals who suffer from an extreme level of material deprivation may be forced to enter demeaning social relations where they are exploited, in order to have enough money to survive. ${ }^{49}$ If this deprivation is the result of bad option luck rather than bad brute luck, this situation does not violate egalitarian justice. Consequently, an inequality considered acceptable by luck egalitarians leads to another inequality (in relation to hierarchy and exploitation) that many luck egalitarians would find intrinsically wrong. This does count against luck egalitarianism and relates to the harsh treatment criticism explored in more detail below (section 3). For now it is enough to conclude that luck egalitarianism can generally handle the injustice of exploitation. 
Luck egalitarianism would also condemn injustices associated with oppression through marginalisation. This second face of oppression is about the exclusion of individuals "from useful participation in social life," rendering them "marginal." 50 This can lead to material deprivation; to the deprivation of the rights and freedoms of those dependent on welfare; and to "the deprivation of cultural, practical, and institutionalized conditions for exercising capacities in a context of recognition and interaction." ${ }^{51}$

At first, it might seem that luck egalitarianism has difficulty handling this kind of injustice because the idea of "responsibility" is often used to attack welfare dependency. On a philosophical level, luck egalitarianism might also be guilty of ignoring the material deprivation associated with marginalisation, when people can be held responsible for their exclusion from social participation. ${ }^{52}$ But if luck egalitarianism were applied to the world today, few individuals could seriously be considered responsible for their unemployed status, particularly if we accept that a job must be suitable for individuals if they are to accept it. ${ }^{53}$ In fact, the very idea of marginality is that some groups are excluded from employment (or, more generally, fulfilling participation in social life), which implies that they are not responsible for their position. A similar approach explains how the Deaf are victims of injustice. The bad brute luck here is the way society is "strongly coordinated on communication by sound," which marginalises those who cannot hear. ${ }^{54}$ Luck egalitarianism would aim to end this marginalisation. If this were not practically possible then financial compensation would be offered to the Deaf but this would be because of the socially imposed disadvantage they suffer, not because their lives are 
inherently inferior. ${ }^{55}$ Thus, marginalisation is a clear case of bad brute luck that luck egalitarianism should condemn.

A similar response can be given in cases where those dependent because of age, poverty or disability are denied the rights associated with equal citizenship, particularly relating to privacy, respect and individual choice. $^{56}$ Again, whilst this could be a problem for those deemed responsible for the poverty or disability which leaves them dependent, ${ }^{57}$ the reality is that people usually are not responsible for their dependency, so this form of marginalisation is also unjust.

Luck egalitarianism does not have any difficulties dealing with powerlessness, the third face of oppression, either. Powerlessness is about the division of labour between planners and executors in advanced capitalist societies, although it also has distributive consequences. ${ }^{58} \mathrm{~A}$ number of injustices relate to powerlessness such as "inhibition in the development of one's capacities, lack of decisionmaking power in one's working life, and exposure to disrespectful treatment because of the status one occupies."59 Because this relates to an individual's social group and because power and autonomy are crucial aspects of human well-being, these kinds of inequalities will be of concern to luck egalitarians. Young argues, for example, that professional workers have a number of advantages over non-professionals in relation to power, including greater opportunities to develop their capacities and achieve recognition through education, professional advancement, and higher status; more autonomy at work and authority over others; and a way of life that is linked to the dominant notion of "respectability" in society. ${ }^{60}$ If this claim is accurate then the inequality is unjust because non-professionals cannot be 
considered responsible for their powerless position. As I argued above, the important thing is that people perform work that they believe is suitable for them. If they do so and still experience powerlessness then the lower well-being they experience relative to professionals is a result of bad brute luck and is compensable.

The injustice of cultural imperialism, the fourth face of oppression, should also be evident to luck egalitarians. As Young defines it:

To experience cultural imperialism means to experience how the dominant meanings of a society render the particular perspective of one's own group invisible at the same time as they stereotype one's group and mark it out as the Other . ${ }^{61}$

In other words, the identity of the oppressed group is defined as deviant whilst its “own experience and interpretation of social life finds little expression that touches the dominant culture.”62 Presumably, the reason Young is concerned with cultural imperialism is because she believes group identity and cultural expression of this identity are vitally important to an individual's level of wellbeing. This is another case of individual well-being being affected by group identity, which individuals are generally not responsible for. For example, Young mentions the stereotype "that Indians are alcoholics."63 This means that an individual Indian in America is subject to harmful assumptions and judgements that are not based on any knowledge of his/her real character. In contrast, white males tend to escape group marking and are viewed as individuals, escaping such stereotypes. ${ }^{64}$ In this way bad luck leads to unequal well-being -- some groups are denied individuality and subjected to disparaging judgements whilst others avoid it. This clearly violates luck egalitarianism. ${ }^{65}$ 
The same can be said of the final face of oppression -- systematic violence that includes harassment, intimidation and ridicule. Young considers acts of violence a matter of social justice if they result from "the social context surrounding them, which makes them possible and even acceptable."66 Young is primarily concerned with random, systemic violence with a primarily irrational motivation related to fear and hatred. ${ }^{67}$ Its effects are pervasive because any member of a targeted group knows they could be subjected to it. ${ }^{68}$ Such violence obviously has a dramatic impact on individuals, and they end up with a lower level of well-being because of their group identity. Examples include violence against women, gay men and lesbians, and racially motivated attacks. $^{69}$ The social context of this violence -- including the daily threat of knowing one is liable to it and the fact it is often tolerated ${ }^{70}$-- has a major impact on the well-being of the individuals under threat. This violence is not something the individuals affected are responsible for, so it violates luck egalitarianism. Thus, the theory is sensitive to all five faces of social oppression.

In response to a similar argument by Arneson, Anderson emphasises that equality is about treating persons as moral equals, independent of questions of well-being. ${ }^{71}$ For example, racial segregation (and the kind of social oppression discussed above) would be wrong, even if it had no effect on the well-being of the persons involved. ${ }^{72}$ However, I argued above that luck egalitarians should assess well-being against an objective account of the good life that is sensitive to the disadvantage associated with social oppression. ${ }^{73}$ On this account, individuals who are oppressed are regarded as objectively disadvantaged. Luck egalitarianism will condemn this oppression if it occurs 
because of an individual's valued beliefs and preferences, or because of her unchosen personal characteristics. Consequently, it condemns racial segregation independent of its impact on the subjective welfare level of the persecuted.

Anderson is also incorrect to suggest that the theory is motivated by pity. Anderson criticises luck egalitarianism for missing the point of equality, but in many ways, Anderson has missed the point of luck egalitarianism. ${ }^{74}$ It is not motivated by feelings of pity or superiority, but by the belief that all persons should have equal access to equally fulfilling lives in a true society of equals. This means ensuring that nobody suffers from bad brute luck. If the effects of this bad luck cannot be corrected, financial compensation should be offered instead. Rather than disparaging or pitying the unlucky, the whole point of luck egalitarianism is that inequalities reflecting bad brute luck are unjust, illegitimate and unacceptable. $^{75}$

Whilst this demonstrates that luck egalitarianism is sensitive to social oppression and motivated by egalitarian considerations, not pity, I have yet to address Anderson's claim that the theory supports intrusive and disrespectful state intervention in the lives of citizens. It is true that implementing luck egalitarianism entails intrusive intervention and potentially disrespectful judgements, but this is not a decisive objection to the theory. It is important to remember that I am principally interested in whether luck egalitarianism is a compelling interpretation of the abstract ideal of egalitarian justice, and questions of practical implementation are separate from this issue. ${ }^{76}$ Moreover, when making public policy decisions, policy-makers need to take into account a range of considerations, only one of which is egalitarian justice. ${ }^{77}$ Thus, a policy-maker who wants to achieve luck-egalitarian outcomes may still believe 
(independently) in the principle of individual privacy, and this will also influence his policy decisions. I will return to these issues in chapter 7, when I discuss the practical applications of luck egalitarianism in more detail.

In this section, I have argued that, pace Anderson, luck egalitarianism is not insensitive to the injustice associated with social oppression, or motivated by a sense of pity. I have also defended the theory - at least as an abstract interpretation of the ideal of egalitarian justice - against Anderson’s “intrusion” objection. In the next section, I will assess a further criticism -- that luck egalitarianism treats the victims of bad option luck too harshly.

\section{HARSH TREATMENT}

Luck egalitarianism allows individuals to fall to an extreme level of material deprivation if this results from option luck. For instance, if a person makes an autonomous decision to invest her fortune in a high-risk project, fully aware of the high possibility she could lose her money, and the project collapses, leaving her without enough to meet her basic needs for food and shelter, she has no claim against luck egalitarianism for assistance. There may be non-egalitarian reasons to assist her, such as benevolence, but she has no claim against egalitarian justice per se. For many egalitarians, this will seem counterintuitive.

However, because real-world inequalities rarely reflect option luck, few cases of harsh treatment will arise. Option luck stems from "deliberate and calculated gambles" when a person accepts "an isolated risk he or she should 
have anticipated and might have declined." ${ }^{\text {78 }}$ But people rarely make decisions in this way. For a start, it is unusual to have full knowledge of the risks involved in taking a particular option. In fact, the outcome an individual expects from an action or decision may differ markedly from the actual outcome. In this situation, individuals should not be held responsible for their choices. Moreover, option luck often arises from "intentional actions done in ignorance of brute luck effects." ${ }^{, 79}$ This is the situation that occurs when, for, example, two people decide to pursue the same profession but end up with unequal earnings because, contrary to their expectations, one has more talent than the other. ${ }^{80}$ In this situation, the outcome was not expected -- both individuals viewed choosing the profession as a sound decision, not a gamble. This means that although the inequality results from a chosen act, it reflects bad brute luck, not bad option luck, and should be corrected. Thus, in reality, harsh treatment may not be a widespread problem.

This conclusion is strengthened if we factor in the compulsory nature of some decisions and the limited range of options that a person may have to choose from. Often, the need to make a decision is foisted upon individuals who are forced to take risks. In other words, "life in market societies involves a large number of compulsory gambles" ${ }^{81}$ where people are forced to make decisions they may rather not make. For example, most adults must perform some kind of work to maintain a reasonable standard of living. ${ }^{82}$ In advanced capitalist societies this generally involves making a compulsory gamble -choosing an occupation. This decision is a gamble because future technological development and changes in demand will render some jobs obsolete. It does not seem fair to hold individuals responsible for their choices in such situations if 
they would rather not have made any decision at all. A similar conclusion holds if the range of options available is limited. If, for example, a man must (for reasons beyond his control) choose between two equally dangerous occupations and he ends up suffering an injury at work, this would be more appropriately ascribed to brute luck than option luck. ${ }^{83}$ The particular injury results from a risk he knowingly took, but this does not mean he is responsible for it. The range of options was so limited, little choice was actually involved -- he was exposed to danger either way. This further reduces the scope of the harsh treatment problem.

Finally, there is a strong egalitarian argument that persons must choose from equal starting points if they are to be held equally responsible for their decisions. ${ }^{84}$ However, even in advanced capitalist nations, large inequalities in income, wealth, education and family background mean that individuals choose from very different positions. Family background and degree of education, for instance, could have a great effect on how people spend and invest their money, which could generate significant inequalities in the long-term. ${ }^{85}$ This inequality would seem to be more a matter of brute luck than option luck, further weakening the incidence and strength of the harsh treatment criticism. ${ }^{86}$

However, Anderson's argument has not been defeated. The issue we are dealing with is whether luck egalitarianism is a good interpretation of the ideal of equality. Even if the harsh treatment problem only arises in a utopian luckegalitarian society where all persons start from positions of complete equality, this may still be regarded as a flaw with luck egalitarianism as an interpretation of egalitarian justice. For instance, suppose that in this utopian society, a welleducated person without any addiction to gambling decides to give up his 
health insurance. He uses the money he saves to bet at the races, regularly picking horses that he knows are only an outside chance to win, motivated by the desire to make more money. He is also a regular participant in a dangerous extreme sport and is fully aware the chance of injury is relatively high. Suppose he is injured pursuing such an activity, and in order to recover fully, needs expensive, on-going medical treatment over a six-month period. The cost of this treatment exceeds his income (which is at the appropriate luck-egalitarian level for a person who has made his choices in his circumstances). As a result, he cannot afford the medical treatment he needs. His condition reflects option luck so he has no claim against luck egalitarianism for compensation. Thus, the harsh treatment problem arises.

One possible response is that luck egalitarianism can avoid this problem because protecting individual autonomy is an important implication of the theory. ${ }^{87}$ In other words, luck egalitarianism is based on the idea that individuals should be held responsible for their choices. One of the prerequisites of this is having a basic level of autonomy that requires, in part, the satisfaction of basic needs such as food, shelter and medical care. Consequently, luck egalitarianism requires that the basic needs of all persons are satisfied throughout their lives. If it were otherwise, society would need to constantly redistribute resources to the victims of bad option luck who end up indigent and thus not responsible for many of the actions they take in their nonautonomous state.

Whilst this argument seems a strong one, it is flawed. There is no direct link between the luck-egalitarian interpretation of equality and the requirement that we protect individual autonomy unconditionally. ${ }^{88}$ Considerations of 
efficiency mean it is logical for a luck egalitarian to support redistribution to protect individual autonomy, but this does not solve the harsh treatment problem. Anderson is arguing that luck egalitarianism treats some victims of bad option luck so harshly that it is inconsistent with the ideal of egalitarianism. In other words, a theory of equality cannot allow any citizen to fall below a certain level of well-being regardless of the choices they have made. The efficiency argument is a good one, but does not get to the heart of the matter -any successful response to the harsh treatment criticism must come from the concept of egalitarianism itself, not something external to it.

In the end, it is unlikely that any solution to Anderson's criticism can be found from within luck egalitarianism, as she and others understand it. At the heart of her attack is the claim that in some situations, egalitarianism requires us to provide assistance to the victims of bad option luck. Yet luck egalitarianism is based on the idea that victims of bad brute luck deserve compensation whilst victims of bad option luck do not. As long as this remains the case, there does not seem to be any way it can escape the harsh treatment problem.

However, luck egalitarians can respond by denying that harsh treatment is a problem of egalitarian justice. There may be reasons such as paternalism or pity to help an individual who has fallen to a low level of material deprivation because of bad option luck, but this has nothing to do with egalitarianism. This person has been treated equally and that is all egalitarian justice requires. ${ }^{89} \mathrm{I}$ think this is a satisfactory response to the harsh treatment criticism. Most egalitarians believe that poverty is an injustice because the poor, in the real world, are not badly off as a result of voluntary risk-taking in a roughly 
egalitarian society. Rather, deeper structural inequalities and other forms of bad luck explain why they are badly off. They are the victims of bad brute luck, not option luck, and thus, according to luck egalitarianism, they will be entitled to assistance. It is still theoretically possible to imagine situations where no compensation is provided, but in these cases I think the judgement of luck egalitarianism is correct -- the victims of bad option luck have no claim against egalitarian justice. If we are living in a more egalitarian world where people start from equal positions and instances of deprivation arise from genuine risktaking, it seems strange to call this deprivation an injustice. It is possible that we would feel moved to provide assistance to the destitute on some other grounds, such as benevolence or charity, but this is different from a claim against egalitarian justice.

Nonetheless, critics of luck egalitarianism could propose an alternative theory that explains why egalitarian justice demands that we provide assistant to those who are destitute because of bad option luck. Anderson proposes a theory of democratic equality, which attempts to do this. Democratic equality entails the existence of a basic welfare safety net below which no citizen can be allowed to fall. ${ }^{90}$ The theory arises from a belief in the universal moral equality of all persons, ${ }^{91}$ which gives rise to two central aims. The negative aim is to abolish social oppression, and the positive aim is to "seek a social order in which persons stand in relations of equality."92 This positive aim means that “people are entitled to the capabilities necessary for functioning as an equal citizen in a democratic state." ${ }^{93}$ The theory is partly justified with reference to the idea of a social contract. Anderson argues that citizens have a collective obligation "to secure the social conditions of everyone's freedom"94 and 
democratic equality "claims that the social condition of living a free life is that one stand in relations of equality with others." 95 In order to achieve this, democratic egalitarians aim to achieve "equality for all in the space of capabilities." ${ }^{96}$ However, only a restricted range of capabilities are equalised, in particular, those that are necessary to help citizens avoid oppressive social relationships and to achieve equal citizenship. ${ }^{97}$ Consequently, democratic equality is a threshold account of justice ${ }^{98}$ because it is only concerned with distributive justice up to the point at which citizens have "enough resources to avoid being oppressed by others and to function as... equal[s] in civil society." ${ }^{99}$ Inequalities do not matter once citizens reach this threshold.

However, Anderson's argument for this theory is unconvincing. Firstly, it is unclear why the social contract process will result in democratic equality, not luck egalitarianism or equality of outcome. After all, these alternative theories might be better expressions of "universal moral equality" than democratic equality. Secondly, it is also unclear precisely why equal citizenship, in the sense of equal standing in civil society, is a requirement of freedom. If Anderson supports a theory of positive freedom, then she must provide a more detailed justification of this theory, and explain why it is likely to be chosen by participants in the social contract process. Thirdly, threshold approaches to justice seem ungenerous because they allow brute luck to have a significant impact on the quality of life individuals enjoy, and this seems unfair. ${ }^{100}$ Although I will return to a number of these issues in chapter 6 , these objections demonstrate why Anderson has not done enough to establish democratic equality as a compelling alternative to luck egalitarianism. 
Thus, luck egalitarianism should not be rejected because of the harsh treatment problem. However, I have partly defended luck egalitarianism by claiming that inequalities reflecting option luck rarely arise. This claim may cast doubt on whether the distinction between option luck and brute luck has any significance. If I am correct in claiming that instances of social oppression and harsh treatment usually reflect brute luck, and if few of the inequalities that exist today reflect option luck, why bother with the luck-egalitarian project? ${ }^{101}$

Although on the surface this appears to be a damaging criticism, the fact that inequalities in the real world rarely reflect option luck is no reason to reject luck egalitarianism. Throughout this chapter, I have assumed that strict conditions regulate when egalitarians can and cannot hold persons accountable for their choices. In particular, I have assumed that choices which bring option luck into play cannot reflect pre-existing, background inequalities; otherwise, luck egalitarianism simply becomes a means of perpetuating these inequalities. For instance, two persons may make different decisions as a result of their very different backgrounds. If these decisions generate further inequality between them, this inequality is deemed to reflect brute luck rather than option luck, and is not considered legitimate. In addition, egalitarians should consider the range of alternatives a person faced when they are trying to categorise the luck that arises from his/her choice. If none of the options available were attractive, then the luck that results from this choice falls into the brute luck category. These assumptions are important because they ensure that luck egalitarians use choice in a way that is fair, but they do not defeat the purpose of developing a choicesensitive form of luck egalitarianism. ${ }^{102}$ 
The reason option luck occurs so infrequently in the world today is because individuals rarely make decisions under the appropriate conditions. We live in an unequal world where people face hugely unequal starts in life. Brute luck is rife, affecting factors crucial to our well-being such as our health, educational performance and ultimately, the income we earn and lifestyles that we lead. Against an existing backdrop of stark inequality, it is unsurprising that few of the inequalities that arise today reflect option luck.

This does not indicate that the luck-egalitarian project is flawed. The fact that individuals rarely make decisions under conditions sufficient to generate option luck simply means that persons are rarely responsible, in any meaningful sense of the word, for the inequalities which exist today. The luckegalitarian project has worth precisely because it allows egalitarians to explain why the inequalities that exist in the real world are unjust. Even if all inequalities are unjust, luck egalitarianism retains its theoretical importance. ${ }^{103}$

Thus, luck egalitarianism, as I have interpreted it, is both a radically egalitarian and a desert-based theory. It is desert-based because it holds individuals accountable for their choices, arguing that people should enjoy the level of advantage that, through their actions, they deserve. However, I have argued that, in reality, applying this theory leads to the conclusion that few of the inequalities that exist today are acceptable. The value of luck egalitarianism is that it highlights the radical implications of shifting the notion of individual choice to centre-stage in political debate. ${ }^{104}$

\section{CONCLUSION}

Luck egalitarianism, properly understood, is able to escape Elizabeth 
Anderson's criticisms. The approach is not motivated by feelings of pity, and provided that a suitable conception of advantage is adopted, it is sensitive to non-material injustices. Moreover, whilst practically implementing luck egalitarianism seems to require detailed information about the lives of individuals, this does not constitute a decisive objection to the approach as an abstract interpretation of the ideal of egalitarian justice. Anderson's harsh treatment objection also fails. If we closely examine the market opportunities individuals face in the real world, we reach the conclusion that the destitute will almost always receive assistance. In cases where a person ends up in poverty as a result of voluntary risk-taking, it is difficult to argue that we have an obligation of egalitarian justice to provide assistance. Anderson's theory of democratic equality is predicated on the assumption that we should provide such compensation, but I argued that her theory is flawed. Finally, although my defence has partly relied on the claim that individual choice rarely generates inequalities in the real world, this does not render the luck-egalitarian project obsolete, but simply highlights its radical implications. Thus, despite the significant challenge presented to it by Anderson’s critique, luck egalitarianism remains an appealing interpretation of the egalitarian ideal.

Nonetheless, the defence of luck egalitarianism I have outlined here gives rise to three further challenges. Firstly, my argument in section 3 draws on the assumption that individual choices only generate option luck if conditions are fair. However, this assumption remains unjustified, especially given the way the concept of option luck is defined and used in the literature. I will explore this issue in the next chapter, subjecting the option luck-brute luck distinction to close analysis, and questioning whether it is consistent with the 
underlying motivations of the theory. Secondly, I argued in section 2 that luck egalitarians should adopt a conception of well-being that is sensitive to the disadvantage associated with social oppression. However, I have not offered a full account of this conception, beyond indicating that it must include an objective component. I take up this task in chapter 5. Thirdly, although I have highlighted flaws in Anderson's theory of democratic equality, a more extensive response is needed to the challenge posed by threshold accounts and theories of social equality. I deal with this issue in chapter 6. 


\section{NOTES}

${ }^{1}$ E.S. Anderson, “What is the Point of Equality?” Ethics, V. 109, no. 2, 1999, pp. 287-337.

${ }^{2}$ The most notable example is S. Scheffler, What is Egalitarianism? Philosophy and Public Affairs, V. 31, no. 1, 2003, pp. 5-39. Anderson's argument is directly examined by one of the authors she criticises, in R.J. Arneson, "Luck Egalitarianism and Prioritarianism,” Ethics, V. 110, no. 2, 2000, pp. 339-49. See also A. Callinicos, Equality, Cambridge, Polity, pp. 64-6; A. Stark, "Beyond Choice: Rethinking the Post-Rawlsian Debate over Egalitarian Justice," Political Theory, V. 30, no. 1, 2002 pp. 36-67; R. Dworkin, "Sovereign Virtue Revisited," Ethics, V. 113, no. 1, 2002, pp. 106-143; A. Phillips, “Defending Equality of Outcome,” V. 12, no. 1, 2004, pp. 1-19; and a 1999 BEARS online symposium on Anderson's article at $<$ http://www.brown.edu/Departments/Philosophy/bears $>$.

${ }^{3}$ Anderson, "What is the Point of Equality?” p. 308.

${ }^{4}$ Anderson, “What is the Point of Equality?” p. 308.

${ }^{5}$ Anderson, "What is the Point of Equality?” p. 298. This comment is referring, in particular, to Rakowski, Equal Justice.

${ }^{6}$ Anderson, "What is the Point of Equality?” pp. 308-10. Anderson argues that Cohen and Roemer do question this to a greater extent than other luck egalitarians, but they do not focus enough on non-wage-earning dependent caretakers. See p. 300.

${ }^{7}$ Anderson, “What is the Point of Equality?” pp. 295-96.

${ }^{8}$ Anderson, “What is the Point of Equality?” pp. 295-96.

${ }^{9}$ Anderson, "What is the Point of Equality?” p. 298.

${ }^{10}$ Anderson, “What is the Point of Equality?” pp. 296-7.

${ }^{11}$ Anderson, "What is the Point of Equality?" pp. 297-8. This is because they might be considered responsible for choosing unpaid occupations and thus are ineligible for government assistance.

${ }^{12}$ Anderson, "What is the Point of Equality?" p. 298. Anderson highlights this as a separate problem.

${ }^{13}$ Anderson, “What is the Point of Equality?” pp. 300-1.

${ }^{14}$ Anderson, “What is the Point of Equality?” p. 301. 
${ }^{15}$ Anderson, "What is the Point of Equality?" p. 302. Anderson makes this argument in response to comments attributed to Amy Gutmann. See p. 301 n. 50.

${ }^{16}$ Anderson, "What is the Point of Equality?” p. 301. Anderson also attributes this point to Amy Gutmann.

${ }^{17}$ Anderson, “What is the Point of Equality?” pp. 301-2.

${ }^{18}$ Anderson, “What is the Point of Equality?” pp. 304-7.

${ }^{19}$ Anderson, “What is the Point of Equality?” pp. 306-7.

${ }^{20}$ Anderson, “What is the Point of Equality?” p. 306. According to Anderson, resource-based luck egalitarianism is also motivated by envy of the more fortunate. This is also "profoundly disrespectful.” See p. 307.

${ }^{21}$ Anderson, "What is the Point of Equality?” pp. 306.

${ }^{22}$ Anderson, "What is the Point of Equality?” p. 307.

${ }^{23}$ Anderson, "What is the Point of Equality?” p. 307.

${ }^{24}$ Anderson, "What is the Point of Equality?" p. 311.

${ }^{25}$ Anderson, "What is the Point of Equality?" p. 303.

${ }^{26}$ Anderson, "What is the Point of Equality?" p. 304.

${ }^{27}$ Anderson, "What is the Point of Equality?" p. 304.

${ }^{28}$ Anderson, "What is the Point of Equality?” pp. 310-12.

${ }^{29}$ Anderson, "What is the Point of Equality?" p. 310.

${ }^{30}$ Anderson, “What is the Point of Equality?” p. 310, italics removed.

${ }^{31}$ Anderson, "What is the Point of Equality?” p. 311, italics removed.

${ }^{32}$ Anderson, "What is the Point of Equality?” p. 312.

${ }^{33}$ There is not scope for a detailed discussion of Anderson's theory of democratic equality in this chapter, but I will briefly highlight some of its flaws in section 3. I analyse theories of social/democratic equality in more detail in chapters 4 and 6 .

${ }^{34}$ Anderson, "What is the Point of Equality,” pp. 313-14.

${ }^{35}$ Anderson links her argument to Iris Young’s claim that theoretical work on justice is trapped in a "distributive paradigm." The "distributive paradigm” refers to the dominant way theorists understood the concept of "justice" (at the time Young was writing). For theorists within this paradigm, justice refers "to the morally proper distribution of benefits and burdens among 
society's members." However, this leads to two main problems. Firstly, it focuses debate on the pattern of distribution of material goods, rather than on the structures and institutions that influence this; and secondly, it means that nonmaterial goods are viewed as static things, obscuring the role played by social relations and processes. See Justice and the Politics of Difference, Princeton, Princeton University Press, 1990, especially pp. 15-16. For Anderson’s discussion of Young see "What is the Point of Equality?” p. 312. For a related criticism of luck egalitarianism on these grounds, see also Scheffler, "What is Egalitarianism?”

${ }^{36}$ Here and throughout the thesis, I use the term "advantage" to refer to the aspect or aspects of a person's condition which matter to egalitarians. Thus, advantage could be resources, subjective welfare, objective well-being, etc. Proponents of equality of outcome believe that we should equalise the level of advantage individuals enjoy, whilst those who support a form of equality of opportunity believe that we should equalise opportunities to achieve advantage. As we saw in chapter 1 , Cohen uses the term to describe the heterogeneous approach he supports. I am using it in a more general sense here, rather than referring specifically to Cohen's conception of advantage. I outline my own account of advantage in chapter 5.

${ }^{37}$ Arneson makes a similar point in his reply to Anderson. He argues that a concern for the well-being of individuals should be the key concern when assessing distributive fairness. This means that human relationships may be important, but only to the extent that they are “instrumental to well-being.” See Arneson, “Luck Egalitarianism and Prioritarianism,” pp. 3412. Kymlicka's work on cultural membership and aboriginal rights also has interesting links to my argument in this section. See, for example, W. Kymlicka, Liberalism, Community, and Culture, Oxford, Clarendon Press, 1989, especially Chapter 9, pp. 182-205.

${ }^{38}$ For further discussion of this point, see below, and, for a more in-depth analysis, see chapter 5. For a discussion of recent debate over the use of an objective conception of well-being in egalitarian justice, see Callinicos, Equality, pp. 60-4. He highlights the link between Anderson's critique and the need for an objective conception, on p. 64. See also Arneson, "Welfare Should Be The Currency of Justice,” Canadian Journal of Philosophy, V. 30, no. 4, 2000, pp. 497-524. For discussion of the role a perfectionist account of human flourishing could play in a theory of egalitarian justice see C. Sypnowich, "Equality: From Marxism to Liberalism (and Back Again),” Political Studies Review, V. 1, no. 3, 2003, pp. 333-343. 
${ }^{39}$ Young, Justice and the Politics of Difference, p. 42.

${ }^{40}$ Young, Justice and the Politics of Difference, p. 43.

${ }^{41}$ Young, Justice and the Politics of Difference, pp. 45-6.

${ }^{42}$ Young, Justice and the Politics of Difference, pp. 45, 46.

${ }^{43}$ Young, Justice and the Politics of Difference, pp. 52-3.

${ }^{44}$ Young, Justice and the Politics of Difference, p. 53.

${ }^{45}$ Young, Justice and the Politics of Difference, p. 51.

${ }^{46}$ Young, Justice and the Politics of Difference, p. 51.

${ }^{47}$ Young, Justice and the Politics of Difference, p. 50.

${ }^{48}$ For a similar argument centred on the economic dependency of women see Callinicos, Equality, p. 65. For a good discussion of how luck egalitarianism (or as he calls it, the "equal access view") handles the fact gender socialisation shapes our choices, see also A. Mason, “Equality, Personal Responsibility, and Gender Socialisation,” Proceedings of the Aristotelian Society, V. 100, no. 3, 2000, pp. 227-246.

${ }^{49}$ Anderson, “What is the Point of Equality?” p. 298.

${ }^{50}$ Young, Justice and the Politics of Difference, p. 53.

${ }^{51}$ Young, Justice and the Politics of Difference, pp. 53-5.

${ }^{52}$ This is another example of the harsh treatment criticism, which is examined below (see section 3).

${ }^{53}$ This point may seem controversial, but people cannot be held responsible for the fact a lack of suitable work is available. There may be non-egalitarian reasons to force somebody to contribute to society somehow, but these have nothing to do with equality (unless all citizens have to perform unsuitable work.)

${ }^{54}$ T. Christiano, “Christiano Reviews Anderson,” Brown Electronic Article Review Service, <http://www.brown.edu/Departments/Philosophy/bears/9904chri.html>, $\quad$ (accessed 14 November 2003). Articles from the BEARS symposium do not have numbered pages.

${ }^{55}$ Christiano, "Christiano Reviews Anderson.”

${ }^{56}$ Young, Justice and the Politics of Difference, p. 54.

${ }^{57}$ This is another example of the harsh treatment problem, which will be examined below.

${ }^{58}$ Young, Justice and the Politics of Difference, p. 58. 
${ }^{59}$ Young, Justice and the Politics of Difference, p. 58.

${ }^{60}$ Young, Justice and the Politics of Difference, pp. 56-8.

${ }^{61}$ Young, Justice and the Politics of Difference, pp. 58-9.

${ }^{62}$ Young, Justice and the Politics of Difference, pp. 59-60, quotation at p. 60.

${ }^{63}$ Young, Justice and the Politics of Difference, p. 59.

${ }^{64}$ Young, Justice and the Politics of Difference, p. 59. Whilst this is often the case, I do not think it is so in all circumstances -- people sometimes do make stereotypical assumptions about white males.

${ }^{65}$ The question of how to tackle the problem of cultural imperialism is a difficult issue not examined in this chapter.

${ }^{66}$ Young, Justice and the Politics of Difference, pp. 61-2, quotation at p. 61.

${ }^{67}$ Young, Justice and the Politics of Difference, p. 62.

${ }^{68}$ Young, Justice and the Politics of Difference, p. 62.

${ }^{69}$ Young, Justice and the Politics of Difference, p. 61.

${ }^{70}$ Young, Justice and the Politics of Difference, p. 62.

${ }^{71}$ Anderson, “Anderson Replies to Arneson, Christiano, and Sobel,” Brown Electronic Article Review Service, <http://www.brown.edu/Departments/Philosophy/bears/9912ande.html>, (accessed 14 November 2003).

${ }^{72}$ Anderson, “Anderson Replies to Arneson, Christiano, and Sobel.”

${ }^{73}$ Although, as will become clear in chapter 5, this is only one component of a broader egalitarian conception of advantage that also has a place for subjective welfare and resources.

${ }^{74}$ Moreover, Anderson's criticism that luck egalitarianism is motivated by pity seems to sit uneasily with her own argument that luck egalitarianism treats the badly-off too harshly. The idea behind the harsh treatment criticism is that living in deprived conditions is too horrible to allow. In many ways, this judgement seems to be based on an attitude of pity towards the badlyoff who need the state's assistance to escape their pitiful condition. I thank an anonymous reviewer at the Journal of Applied Philosophy for highlighting this inconsistency. A related point is made by Sobel, who suggests that Anderson's own theory of democratic equality may also draw on pity (at least as Anderson interprets that emotion). See D. Sobel, "Sobel Reviews Anderson,” Brown Electronic Article Review Service, 
November 2003).

${ }^{75}$ Related points defending luck egalitarianism against the charge it is motivated by pity or that it treats the victims of bad brute luck as inferior are made by Arneson, "Luck Egalitarianism and Prioritarianism,” pp. 343-4; Sobel, “Sobel Reviews Anderson;” Christiano, “Christiano Reviews Anderson;” Dworkin, “Sovereign Virtue Revisited,” pp. 116-17; and C. Knight, “In Defence of Luck Egalitarianism,” Res Publica, V. 11, no. 1, 2005, pp. 55-73, at pp. 64-5.

76 See G.A.Cohen, "Facts and Principles," Philosophy and Public Affairs, V. 31, no. 3, 2003, pp. 207-245, especially pp. 244-45. Of course, Anderson might object here that certain policies (especially Thatcherite welfare policies) are intrinsically inconsistent with our intuitive understanding of egalitarianism. If luck egalitarianism endorses these policies, then it must, in some way, fail to capture our intuitive understanding of the egalitarian ideal. The fact that egalitarians find these policy applications so counter-intuitive is symptomatic of a broader problem with luck egalitarianism at the fact-insensitive, theoretical level. I will address this issue in chapter 7.

${ }^{77}$ As I pointed out in the introduction, my aim in this thesis is to defend a value-pluralist form of egalitarianism. See also G.A. Cohen, “On the Currency of Egalitarian Justice,” Ethics, V. 99, no. 4, 1989, pp. 906-44, at p. 908.

${ }^{78}$ Dworkin, Sovereign Virtue, p. 73.

${ }^{79}$ Christiano, “Christiano Reviews Anderson.”

${ }^{80}$ Christiano, “Christiano Reviews Anderson.”

81 B.T. Coram, "Why Social Scientists Should Be Interested in Luck: A Note on Some Fallacies,” Social Science Quarterly, V. 79, no. 1, 1998, p. 130. See also A.T. Coram, “Social Class and Luck: Some Lessons from Gambler’s Ruin and Branching Processes,” Political Studies, V. 45, no. 1, 1997, pp. 66-77, at p.66.

${ }^{82}$ A similar example is given in Coram, “Social Class and Luck: Some Lessons from Gambler’s Ruin and Branching Processes,” p. 66.

${ }^{83}$ A related example is mentioned in Callinicos, Equality, p. 78.

${ }^{84}$ Dworkin partly recognises this, claiming that individuals must face a similar array of options for the inequality that emerges between them to reflect option luck. He also develops his 
hypothetical insurance market to combat the influence of background differences on insurance choices. See Dworkin, Sovereign Virtue, pp. 76 ff. A related point is also made by Christiano in “Christiano Reviews Anderson;” and by A. Kaufman in "Choice, Responsibility and Equality,” Political Studies, V. 52, no. 4, 2004, pp. 819-836, at pp. 822, 825-26. In the next chapter, I will raise doubts about whether Dworkin and other luck egalitarians can incorporate these assumptions about background equality into a coherent notion of option luck. But I put this issue aside for now.

${ }^{85}$ This relates to Callinicos's point "that circumstances are likely often to shape choices." See Callinicos, Equality, pp. 65, 71-3.

${ }^{86}$ An obvious response to my argument in this section is to claim that luck egalitarianism is pointless if option luck inequalities rarely arise. This objection will be addressed in below.

${ }^{87}$ This argument was suggested to me by Dr David van Mill. For a discussion of the links between personal autonomy and the justification of the welfare state see R. Goodin, Reasons for Welfare: The Political Theory of the Welfare State, Princeton, Princeton University Press, 1988, pp. 46-50.

${ }^{88}$ This relates to Goodin's belief "that personal autonomy is morally important" but unable to justify the welfare state. See Reasons for Welfare, p. 50.

${ }^{89}$ Shlomi Segall has recently argued along these lines, suggesting that Anderson asks too much of egalitarian justice. There are reasons to help people who end up badly off as a result of bad option luck, but they are non-egalitarian reasons of justice. See S. Segall, "Health Care Allocation Between Luck-Egalitarianism and Democratic Equality,” presented at the ALSP Annual Conference, University of Wales, Newport, July 5, 2004. See also M. Clayton, \& A. Williams, "Egalitarian Justice and Interpersonal Comparison,” European Journal of Political Research, V. 35, no. 4, 1999, pp. 446-7.

${ }^{90}$ Nonetheless, there is some ambiguity in Anderson's views on whether social support should be provided unconditionally. Anderson states that individuals have a duty to contribute productively to society if they have the ability to do so, and she also criticises luck egalitarians, particularly Van Parijs, for supporting the provision of financial assistance to work-avoiding surfers. Presumably, this means that at least some forms of social provision will be conditional. But this would seem to sit uncomfortably with her attacks on luck egalitarianism for replicating 
Poor Law thinking, treating citizens disrespectfully and abandoning the imprudent. For her comments on surfers and the obligation to contribute productively, see "What is the Point of Equality?” pp. 287, 299, 321.

${ }^{91}$ Anderson, "What is the Point of Equality?” p. 313.

${ }^{92}$ Anderson, "What is the Point of Equality?” p. 313.

${ }^{93}$ Anderson, "What is the Point of Equality?" p. 316.

${ }^{94}$ Anderson, "What is the Point of Equality?” p. 314.

${ }^{95}$ Anderson, "What is the Point of Equality?” p. 315.

${ }^{96}$ Anderson, "What is the Point of Equality?" p. 316.

${ }^{97}$ Anderson, "What is the Point of Equality?" p. 316.

${ }^{98}$ Note Arneson, “Luck Egalitarianism and Prioritarianism,” p. 347.

${ }^{99}$ Anderson, "What is the Point of Equality?” p. 320.

${ }^{100}$ See Arneson, “Luck Egalitarianism and Prioritarianism,” p. 347. For related criticisms of democratic equality see Stark, "Beyond Choice: Rethinking the Post-Rawlsian Debate over Egalitarian Justice,” p. 38; Knight, “In Defence of Luck Egalitarianism,” pp. 68-9.

101 I am grateful to an anonymous reviewer at the Journal of Applied Philosophy for highlighting this issue.

${ }^{102}$ I shall explore this issue in more detail in the next chapter.

${ }^{103}$ My line of argument here is consistent with the thinking of many luck egalitarians, particularly Arneson and Cohen, who both argue that luck egalitarianism simply implies equality of outcome, if hard determinism is true. See Arneson, "Equality and Equal Opportunity for Welfare,” Philosophical Studies V. 56, no.2, 1989, pp. 77-93, at p. 86; \& Cohen, “Equality of What? On Welfare, Goods, and Capabilities,” in M. Nussbaum, \& A. Sen (eds.), The Quality of Life, Clarendon Press, Oxford, 1993, pp. 9-29, at p. 28.

${ }^{104}$ Some of the radical implications of liberal egalitarianism generally, are examined in C.M. Macleod, Liberalism, Justice, and Markets: A Critique of Liberal Equality, Oxford, Clarendon Press, 1998; \& W. Kymlicka, Contemporary Political Philosophy: An Introduction, Oxford, Oxford University Press, 2002, pp. 88-96. Cohen has also commented on the radical implications of liberal egalitarianism in "Self-Ownership, History and Socialism: An Interview with G.A. Cohen,” Imprints, V. 1, no. 1, 1996. For a critical discussion of the links between 
liberal egalitarianism and the market, see Callinicos, Equality. 


\section{CHAPTER 3}

\section{REASSESSING THE OPTION-BRUTE DISTINCTION}

In this chapter, I will reassess the option luck-brute luck distinction which lies at the heart of luck egalitarianism. Whilst continuing to support the idea that egalitarianism should be sensitive to notions of choice, luck, and responsibility, I challenge the option-brute distinction, arguing that it ultimately undermines the central impulse of luck egalitarianism. In section 1 , I question whether we have a basis for distinguishing between compensable brute luck and noncompensable option luck, suggesting that some instances of option luck inequality may be unjust. In section 2, I develop a second criticism, suggesting that the option-brute distinction has inegalitarian implications because it is insensitive to the way background inequalities shape the different choices that individuals make. Although Ronald Dworkin, who first developed the concepts of option luck and brute luck, put egalitarian conditions on the circumstances in which individual choice can lead to legitimate inequalities, his conditions are insufficient. In section 3, I analyse whether G.A. Cohen's alternative interpretation of brute luck egalitarianism can escape this problem. ${ }^{1}$ Whilst supporting Cohen's overall approach, which focuses on how choices were formed and how genuine they really were, I argue that he should explicitly revise his definition of option luck, if not reject the option-brute distinction altogether, because it cannot handle such nuanced judgements. In section 4, I propose a revised form of luck egalitarianism that focuses on the extent to which individuals have genuinely chosen outcomes, rather than option luck and brute luck. I highlight the radical redistributive implications of this approach and explain how it overcomes the two objections discussed in the chapter. 


\section{COMPENSABLE OPTION LUCK}

To recap, Dworkin developed the distinction between option luck and brute luck to help egalitarians handle the problem that emerges as an initially equal distribution of social resources is disrupted over time by various events and actions. When deviations from the original distribution reflect brute luck, they are unjust and should be corrected, whilst those arising from option luck are just and non-compensable because they reflect individual choice. Dworkin explains the two concepts as follows:

Option luck is a matter of how deliberate and calculated gambles turn out -whether someone gains or loses through accepting an isolated risk he or she should have anticipated and might have declined. Brute luck is a matter of how risks fall out that are not in that sense deliberate gambles. If I buy a stock on the exchange that rises, then my option luck is good. If I am hit by a falling meteorite whose course could not have been predicted, then my bad luck is brute (even though I could have moved just before it struck if I had had any reason to know where it would strike). Obviously the difference between these two forms of luck can be represented as a matter of degree, and we may be uncertain how to describe a particular piece of bad luck. $^{2}$

This distinction means that we can believe in equality and hold individuals responsible for their choices.

However, in many cases, being worse off because of option luck is different from having directly chosen to be worse off. After all, option luck is a form of luck, even when it arises from deliberate and calculated gambles. Inequalities that reflect option luck may arise from the decisions people have made, but (usually) luck plays a role in determining the outcome of these

decisions. ${ }^{3}$ Take, for instance, two equally experienced race-goers who each decide to risk a week's earnings at the racetrack by placing bets on different 
horses with similar odds. One ends up winning, the other losing. They may be equally responsible for the decision to gamble, but they cannot be considered equally lucky. Both took the same risk and fortune led to a significant gain for one, and a significant loss for the other. ${ }^{4}$ Although the inequality that emerges between them arises because of choices they have made, it is still partly a result of luck. Thus, brute luck egalitarianism allows inequalities to emerge even if they have not been directly chosen.

In response, it could be argued that it is good judgement that explains why some people's option luck is good whilst others' is bad. ${ }^{5}$ For instance, in the example above, one person picks the winner because her judgement is better -- she is better able to determine accurately the winning horse. But if this is the case, morally arbitrary luck is still in play because no matter how good one's judgement is, one can never be sure about the outcome of a race (unless one is aware that it has been rigged). Moreover, good judgement is, at least in part, a natural talent and, to that extent, is a matter of brute luck. ${ }^{6}$ Of course, as with any natural talent there are further issues relating to whether one cultivates the talent by, for instance, spending time with people who are knowledgeable about the racing industry. A successful gamble may also reflect background research that is unconnected to one's horse betting ability, and not a matter of luck, such as reading the form guide. To the extent that a person's success reflects this, it is less to do with luck and more to do with choice. However, I do not think there will be any cases where a person's success is entirely due to individual choice and hard work. So our conclusion holds: in refusing to offer compensation for option luck, brute luck egalitarianism allows inequalities which have not been directly chosen. 
On closer analysis, this aspect of the theory -- the idea that option luck inequalities are always non-compensable -- seems difficult to justify. ${ }^{7}$ One possible justification lies in the idea that option luck is deserved, but this does not make sense in situations where two individuals both take risks and end up unequally well-off because of option luck. For instance, in the example above, does the gambler who wins really deserve greater wealth than the gambler who loses? Both individuals knowingly took a risk, but why does this mean we should ignore the role luck plays in generating the inequality between them? Just because a person has chosen to bring luck into play is no reason for her to be entitled to all its fruits. Why should a person enjoy the full benefits of luck when all she has done is place a bet? It seems a strange position for egalitarians to take if they aim to prevent morally arbitrary differences in well-being. ${ }^{8}$

A second possible justification lies in Dworkin's claim that gamblers have chosen to take a risk and "that the possibility of loss was part of the life they chose - that it was the fair price of the possibility of gain.”9 ${ }^{\text {But there are }}$ problems with this justification when it is applied to cases of inequality between individuals who all take risks, exposing themselves to option luck. Firstly, if individuals end up with different outcomes from the same gamble, they pay different costs for the same choice (as Dworkin recognises), and this seems unfair from a luck egalitarian point of view. Secondly, the risk-takers may pay a cost that is disproportionate to the risk they have taken. ${ }^{10}$ For instance, a motorcycle rider who is paralyzed in an accident suffers an excessively high cost for choosing to ride a bike. ${ }^{11}$ In these cases, it seems reasonable for the beneficiaries of good option luck to provide assistance to those who suffer excessively bad option luck. ${ }^{12}$ 
A more convincing argument for the non-compensable character of option luck is that redistributing the costs and benefits of risk-taking will prevent individuals from being able to live the kinds of lives that they value. As Dworkin puts it, "[i]f winners were made to share their winnings with losers, then no one would gamble, as individuals, and the kind of life preferred by both those who in the end win and those who lose would be unavailable."13 Whilst luck egalitarianism provides no reason, in itself, to worry about the diversity of activities available in a society, this criticism becomes more concerning to luck egalitarians if it indicates a failure to respect individual choice. ${ }^{14}$ If, for example, we correct the inequality that emerges between two individuals who decide to bet 100 dollars on a coin toss, we effectively undermine the choice they have made. ${ }^{15}$ Similarly, those who decide to participate in a lottery choose to expose themselves to an activity where the odds of losing are high, in order to have a small chance of a big win. These examples are "gambles proper" because in each case the "gambler prefers facing the gamble to having its expected value.”16 Thus, to equalise the impact of option luck would undermine the purpose of the gamble by reducing the thrill of the risk involved, and removing the chance of a substantial win. To provide compensation in such cases would represent a failure to respect the choice each participant has made.

However, as Lippert-Rasmussen points out, luck egalitarians tend to classify gambles as option luck, even if they are really “quasi-gambles,” not gambles proper. ${ }^{17}$ In these cases, the preceding argument against compensable option luck is less convincing because the individuals involved would rather be guaranteed the expected value of the option than face a small chance of a great win. They are motivated by the (likely) prospect of a solid improvement in their 
financial position, rather than the (unlikely) possibility of a massive pay-off, and provided that sharing out the benefits and burdens of luck secures such an improvement for each person, those who participate in the gamble will support the idea of compensable option luck. ${ }^{18}$ In these cases, compensation should be provided because, firstly, the outcome each individual ends up with is partly the result of luck and, secondly, because each participant would prefer to receive a guaranteed share of the overall winnings, than to let luck run its course. The second condition is important because it ensures that providing compensation is consistent with the motivation of the participants' initial decision to gamble. When these two conditions are met, luck egalitarians should support compensation for option luck inequalities.

I will outline the framework for a revised version of luck egalitarianism in section 4. The next two sections will develop a second major criticism of brute luck egalitarianism, relating to the inegalitarian implications of the option-brute distinction. I argue that brute luck egalitarians risk perpetuating existing inequalities if they ignore the way economic and social circumstances shape individual choice. In order to avoid this problem, brute luck egalitarians must adopt an "equal footing proviso" which holds that option luck can only arise in situations where individuals choose on an equal footing. However, I demonstrate in section 2 that this leads to a more radically egalitarian notion of individual responsibility than Dworkin is prepared to support. Dworkin's account of the option-brute distinction is sensitive to the impact of material inequalities on individual choice, but the equal footing proviso also demands that brute luck egalitarians take into account the impact of non-material inequalities, including inequalities which influence the process of preference 
formation. This clashes with Dworkin's long-held view that individuals should be considered responsible for their preferences. In section 3, I will examine Cohen's version of brute luck egalitarianism, which is based on the kind of radical notion of responsibility that is required.

\section{BACKGROUND INEQUALITY AND CHOICE: \\ DWORKIN'S APPROACH}

When assessing the egalitarian credentials of the option-brute distinction, it is important to note that Dworkin applies the distinction to a world where a number of egalitarian conditions are already in place. One of the most important is that all individuals have an equal share of social resources -Dworkin is using the option-brute distinction to analyse the inequalities that emerge in a world where everybody starts from an initial position of material equality. This is different from the real world, where individuals start from very unequal positions. Moreover, Dworkin goes on to make a stronger egalitarian assumption, noting "that the argument in favor of allowing differences in option luck to affect income and wealth assumes that everyone has in principle the same gambles available to him.”19 In effect, there are significant egalitarian constraints on the background conditions required for inequalities to be considered the result of option luck. ${ }^{20}$

These conditions are crucial for brute luck egalitarianism to be considered an egalitarian theory, because the kind of lives people live and the decisions they make are likely to be strongly shaped and limited by their

upbringing and social environment. ${ }^{21}$ If people start from very unequal positions, then there is a risk that the decisions they make and lifestyle they 
lead will perpetuate this inequality. Choices about education, occupation and investment are likely to be strongly influenced by a person's wealth and income. For instance, a high school graduate from a poor family is likely to find the choice between immediate work and further study more difficult than a similarly talented graduate from a more affluent family. For the poorer family, there is much greater need for the extra income work would bring in, so it will be far more difficult for the individual concerned to take the option of further study. This is particularly important because the choice involved has significant implications for one's future occupation and income. Another example relates to investment. When there is material inequality, the wealthy will have greater opportunity to increase their wealth than other citizens will, as they have more money to invest. But the outcome of an investment seems to be a clear case of option luck, so allowing option luck inequalities to emerge in a world of preexisting material inequality will simply perpetuate this inequality. Dworkin's egalitarian conditions are vital in shoring up the egalitarian credentials of his theory.

In effect, Dworkin builds an “equal footing” proviso into the brute luckegalitarian conception of individual responsibility. ${ }^{22}$ Behind the egalitarian conditions he sets in place is the idea that individuals are only responsible for being worse off or better off than others if they start on an equal footing. The high school graduates in my example are not on an equal footing, so they cannot be held responsible for the level of advantage they enjoy relative to each other. The equal footing proviso ensures that brute luck egalitarians use the concepts of choice and individual responsibility in a way that is consistent with egalitarian notions of fairness. ${ }^{23}$ 
However, the equal footing proviso leads to a more radically egalitarian notion of responsibility than Dworkin is prepared to accept. The underlying force of the proviso comes from the notion that it is unfair to hold individuals equally responsible for decisions taken in unequal circumstances, if these unequal circumstances directly influence the decision-making process. But if this unfairness is our key concern, the equal footing proviso must apply to nonmaterial inequalities which influence our choices, such as parental attitudes, not simply to inequalities in the distribution of income and wealth.

The problem is that social background can have an enormous impact on an individual's beliefs, preferences and decisions, even against a baseline of material equality. ${ }^{24}$ Take, for example, two equally talented students who have recently completed school. With similar marks, both are eligible for the same further educational experiences. However, one comes from a family where a college education is highly valued and the other from a background where it is regarded negatively. Both students have recently attained their majority and meet the requirements of rational agency. Both students choose, with the first deciding to attend college, and the other deciding against it. Ultimately, the college-attendee secures a higher-paid position than the non-attendee because of her higher level of education. This shows that Dworkin must extend the equal footing proviso to non-material inequalities, otherwise, his reliance on individual choice risks perpetuating existing social inequalities relating to class, gender and ethnicity. ${ }^{25}$

However, Dworkin cannot extend the proviso without abandoning a key plank of his theory. Dworkin holds us responsible for our preferences, regardless of whether we have exercised control over their development. ${ }^{26}$ 
Even if our preferences have been strongly shaped by our social environment, we are obliged to take responsibility for them. But if he extends the equal footing proviso to non-material inequalities, individuals will no longer be considered fully responsible for their preferences. Parental attitudes not only shape our understanding of the options we face (as in the second college example), but they also shape our preferences and behaviour. For example, a person may develop a propensity for participating in a risky activity such as boxing as a result of his family background. According to the equal footing proviso, he should not be held fully responsible for the outcomes that result from his participation in this activity. Dworkin, in contrast, will hold him fully responsible for this preference, and the choices that result from it. This is a troubling conclusion because it means that by respecting individual choice, a purportedly egalitarian theory simply perpetuates existing non-material inequalities. ${ }^{27}$ If he is serious about ensuring that individuals choose from an equal footing, Dworkin must revise his views on responsibility for preferences.

However, this would mark a major change in Dworkin's theory. His long-held view is that egalitarians should hold individuals responsible for their tastes, particularly their expensive tastes, regardless of how these tastes were cultivated. ${ }^{28}$ For Dworkin, this is crucial if we are to incorporate individual choice and responsibility into egalitarian thinking. For instance, a person with an expensive taste for leisure may have been raised in a household where working hard was regarded with contempt. ${ }^{29}$ Dworkin would want to hold this person responsible for this taste, making him pay the costs of his life of leisure (except in the unlikely event that the person considers his aversion to work a handicap). But if he extends the equal footing proviso to background 
inequalities such as parental attitudes, he can no longer classify this man's taste for leisure as option luck, because it largely reflects his upbringing. This is precisely the kind of egalitarianism that Dworkin wishes to avoid, and, in all likelihood, is the reason he does not refer to non-material inequalities when initially outlining the option-brute distinction. ${ }^{30}$

Nonetheless, it must be acknowledged that Dworkin shows greater sensitivity to the issue of preference formation in his later work, ${ }^{31}$ suggesting that certain conditions must be in place for a person's preferences to be considered authentic. Although he does not provide much detail on exactly what these conditions involve, he says that a principle of authenticity has a passive and an active aspect. Individuals should have "both an opportunity to form and reflect on their own convictions, attachments, and projects, and an opportunity to influence the corresponding opinions of others” and presumably, option luck can only arise from actions that reflect preferences which meet this test of authenticity. ${ }^{32}$ However, strengthening the background conditions on option luck in this way is not enough to rescue Dworkin's theory. This account of authenticity demands little more than rational agency in a community with freedom of speech, so the option-brute distinction remains insensitive to the impact of background inequalities. For example, the school graduate in the second example above may well have the opportunity for critical reflection in a society characterised by freedom of speech. But this does not mean that she is exposed to alternative opinions or that she subjects her parents' views to critical scrutiny. ${ }^{33}$ Thus, the principle of authenticity does not rescue Dworkin from the dilemma outlined in the preceding paragraph. 
In this section, I have demonstrated that the option-brute distinction has inegalitarian implications if it is applied to a world where individuals start from unequal positions. To overcome this, brute luck egalitarians must adopt an equal footing proviso, where significant egalitarian conditions regulate the operation of the option-brute distinction and our judgements of responsibility. But this proviso demands that we take into account the impact of non-material background inequalities on preference formation, a conclusion which brute luck egalitarians such as Dworkin are likely to resist. In the next section, I examine whether G.A. Cohen's more nuanced form of brute luck egalitarianism can better handle this problem.

\section{GENUINE CHOICE AND EQUALITY: COHEN'S APPROACH}

Although Elizabeth Anderson describes G.A. Cohen as a "luck egalitarian,” he has criticised Dworkin's theory of equality of resources, as we discussed in chapter 1 . The key point of contention between the two theorists relates to the requirements that are needed for individuals to be held responsible for their tastes and preferences. Unlike Dworkin, Cohen believes that egalitarians should focus closely on how individuals come to hold particular tastes and preferences when making judgements about whether they should be held responsible for them. The "control” view of responsibility that underlies Cohen's theory seems more consistent with an interpretation of the option-brute distinction that takes into account the impact of non-material background inequalities on individual choice. This section examines whether Cohen's approach rescues brute luck egalitarianism from the charge of inegalitarianism. 
Like Dworkin, Cohen supports the basic impulse of the option luckbrute luck distinction. He argues that:

A person is exploited when unfair advantage is taken of him, and he suffers from (bad) brute luck when his bad luck is not the result of a gamble or risk which he could have avoided. I believe that the primary egalitarian impulse is to extinguish the influence on distribution of both exploitation and brute luck. ${ }^{34}$

He explicitly links this to the option-brute distinction ${ }^{35}$ and argues that whether an inequality in "advantage” (however this is understood) is legitimate, depends on whether or not an agent can be considered responsible for it. ${ }^{36}$

However, Cohen’s understanding of responsibility is very different from Dworkin's. His view of responsibility is more akin to a control view: ${ }^{37}$

I shall... argue that the grounding idea of Dworkin's egalitarianism is that no one should suffer because of bad brute luck and that, since the relevant opposite of an unlucky fate is a fate traceable to its victim's control, my cut is more faithful to Dworkin's grounding idea than the one he ostensibly favors is. ${ }^{38}$

This difference between them is most obvious in the way they handle the issue of responsibility for tastes, which I discussed in chapter 1. Whereas Dworkin holds persons responsible for their tastes and believes that the inequalities that arise from them are legitimate, Cohen believes that compensation for these tastes is sometimes justified. In particular, determining the extent to which a person is responsible for his/her tastes depends on the role the person played in forming them, whether he/she could now unform them, and whether a person endorses them as valuable:

I distinguish among expensive tastes according to whether or not their bearers can reasonably be held responsible for the fact that their tastes are expensive. There are those that they could not have helped forming and/or could not now unform without violating their own judgment, and then there are those for whose cost, by 
contrast, they can be held responsible, because they could have forestalled their development, and/or because they could now quite readily unlearn them, without violating their own judgment. ${ }^{39}$

Thus, unlike Dworkin, Cohen will not automatically hold persons responsible for the costs associated with having certain preferences, even if they identify with these preferences.

For Cohen, questions of responsibility hinge on the distinction between genuine choice and brute luck, whilst for Dworkin they hinge on the distinction between preferences and resources. ${ }^{40}$ So under Cohen's approach, a person is responsible for something if it reflects the choices she has made, rather than brute luck. In contrast, Dworkin automatically holds individuals responsible for their preferences, and not their resources. However, Cohen's approach to the question of responsibility is more complex than this suggests. He emphasises that the whole idea of genuine choice is less clear-cut than some might think:

We are not looking for an absolute distinction between presence and absence of genuine choice. The amount of genuineness that there is in a choice is a matter of degree, and egalitarian redress is indicated to the extent that a disadvantage does not reflect genuine choice. That extent is a function of several things, and there is no aspect of a person's situation which is wholly due to genuine choice. ${ }^{41}$

Although he does not provide a detailed outline of the conditions needed for choice to be considered genuine, Cohen has re-emphasised and expanded on his approach in his more recent work:

It is false that the only relevant questions about choice and responsibility are whether or not something (an action, a preference) is, simply, chosen (that is, tout court), and that the only relevant upshot is whether the agent is responsible, tout court. Here, as elsewhere, we make judgments of degree of responsibility, and they are based on graded and shaded judgments about choice. It always bears on 
the matter of responsibility that a person chose a certain course, but it is also always pertinent how genuine that choice was and how constraining the circumstances were in which it was made. The genuineness of a choice is a function of the chooser's knowledge, self-possession, and so forth. ${ }^{42}$

Thus, the extent to which inequalities will be reduced/eliminated depends on the extent to which they reflect a person's decisions/actions, and is relative to the amount of genuine choice involved in this decision or action. This leaves much scope for making the relative judgements that are needed for an egalitarian theory.

Cohen explicitly links his approach to Dworkin’s claim that option luck and brute luck sit on a continuum ${ }^{43}$ and explicitly endorses the option-brute distinction. However, I believe that his support for the distinction clashes with his claim that the genuineness of a choice, and thus responsibility, is a matter of degree. ${ }^{44}$ If, as Cohen says, choices are never completely genuine then it is difficult to see how the luck they generate can be categorised as option luck or brute luck, as luck that is avoidable or luck that is not. ${ }^{45}$ We cannot apply the distinction sensibly to situations where an inequality emerges because an individual makes a choice that is partly, though not fully genuine (because it partly reflects background inequality of some sort). Presumably, an individual in such a situation could have avoided exposing herself to the effects of luck by making a different decision or taking a different course of action, so according to Cohen's definition, the inequality reflects option luck and is noncompensable. Yet I think that Cohen would rightly object to this because existing inequality has shaped the decision or action (which means that it is not genuine). Although it was avoidable (and thus generates option luck), there was a high possibility that this person would act as she did given her circumstances 
and background. Consequently, an egalitarian would wish at least partly to correct the effects of the luck that results, although it is technically classified as option luck.

We cannot solve this problem by redrawing the option-brute distinction to reflect the idea of partial responsibility, either. ${ }^{46}$ When a person takes a risk that she is only partially responsible for, we cannot say that its outcome is partly a matter of option luck, partly brute luck. Under Cohen's definition of the distinction, this would mean that the risk was partly unavoidable. But individuals may take risks that are fully avoidable, but not genuinely chosen. For instance, assume that the high school graduate in my first example wanted to attend college, appreciated the likely financial benefits of doing so, but was swayed by the short-term material consequences for her family. ${ }^{47}$ The constraints she faced, which entitle her to compensation, affected the genuineness not the avoidability of her decision. The option luck-brute luck distinction, which is based on the idea of avoidable risks and gambles, cannot capture the nuanced judgements that egalitarians need to make in such a complex example, where inequality results from a fully avoidable decision/action that is influenced by background inequalities. ${ }^{48}$

The point here is not to reject Cohen's interpretation of egalitarianism. By focusing on whether a disadvantage is genuinely chosen, he has developed an approach that is sensitive to the kind of background inequalities that influence decision-making, providing an egalitarian way to regulate the use of choice in distributive justice, and ensuring that it is not used in a way that simply perpetuates existing inequalities. My point is that the option luck-brute luck distinction, at least as Cohen initially defines it, is ill suited to the nuanced 
approach he supports. The concept of option luck is concerned with whether individuals could have avoided exposing themselves to the effects of luck, and cannot sensibly be used to describe the "genuineness" of a choice. Egalitarians should support Cohen's focus on luck and the genuineness of choice, but to do so they must revise their definition of the option-brute distinction, if not reject it altogether. ${ }^{49}$

This conclusion has more than semantic significance. A major criticism of brute luck egalitarianism is that it too readily excuses inequalities because of choices which may reflect deeper structural inequalities. ${ }^{50}$ If my argument is correct, brute luck egalitarianism may be vulnerable to this criticism. Dworkin cannot avoid the objection without significantly revising a key feature of his theory, whilst Cohen is exposed because of the way he defines option luck. Unless we can recast the option-brute distinction to cohere with Cohen's nuanced approach to responsibility, brute luck egalitarianism remains vulnerable to the charge of inegalitarianism.

The most promising response available to brute luck egalitarians is to redefine option luck as luck that arises from genuinely chosen risks and to redefine brute luck as luck from all other sources, including non-genuine choices. This brings the notion of genuineness to the fore, so that we can make relative judgements, attributing outcomes to a mix of option luck and brute luck. ${ }^{51}$ This move would resolve the tension in Cohen's approach, and provide a way to incorporate the equal footing proviso within the notion of option luck. $^{52}$

Nonetheless, some readers may feel this over-extends the concept of option luck. The key idea of brute luck egalitarianism is that we should hold 
individuals responsible for the outcomes of their choices, and this responsibility is not affected by the fact that some chose in more difficult circumstances than others did. Once we start adjusting for the impact of background inequalities on our behaviour, we are no longer left with any meaningful concept of individual responsibility or option luck.

However, we have not adopted an empty conception of responsibility. Choice and responsibility are still linked, it is simply that our judgements of responsibility should be sensitive to the way background social circumstances affect these choices. ${ }^{53}$ Nonetheless, I do fear that we over-extend the term “option luck” by re-defining it in this way. In the literature, the term "option luck" is associated with gambling, risk-taking, and choice, but under the revised approach, a person will not be held fully responsible for taking risks if she has a predilection for risk-taking as a result of her upbringing. Individuals are not held fully responsible for choices which result from preferences that have been affected by background inequalities. Brute luck egalitarians are obviously free to define the key concepts of their theory however they wish, but I do not think the term "option luck" felicitously describes a notion of responsibility that is this sensitive to the circumstances of preference formation. To avoid confusion, it would be better to refer directly to "genuine choice,” not option luck.

Even if we were to accept that redefining option luck in terms of genuine choice helps brute luck egalitarianism overcome the problem of background inequality that I highlight in sections 2 and 3, it cannot solve the problem of non-compensable option luck that I highlight in section 1. Brute luck egalitarianism, even with this revised definition of option luck, will still hold individuals fully responsible for the outcomes of genuinely chosen risks, 
and as I argued above, this is unfair. As I will explain in section 4, we should stop examining whether we have exposed ourselves to the forces of luck as a result of risks, gambles, and choices, and instead explicitly focus on the extent to which we have genuinely chosen a particular outcome. Once we have made this move, there is no longer any reason to distinguish between different kinds of luck, and thus there is no need to preserve the option-brute distinction. In the next section, I will outline a revised version of luck egalitarianism that is based on this idea and that avoids the criticisms I have advanced in this chapter.

\section{TOWARDS A REVISED THEORY OF LUCK EGALITARIANISM}

Cohen is correct to suggest that the idea of genuine choice should be at the heart of egalitarian justice. The focus should be on the extent to which people have chosen their current condition/level of well-being/advantage, and the extent to which this choice is genuine, as opposed to a reflection of pre-existing inequalities, or a lack of reasonable alternatives. To the extent that a person's level of well-being has not been chosen, and to the extent that a relevant choice is not genuine, it can be considered a matter of luck. According to luck egalitarianism, we should equalise the extent to which luck affects the lives of individuals. ${ }^{54}$ This means that those who enjoy good luck are obliged to share its benefits with their fellow citizens, and that individuals will only be unequally well-off if it is justified by differential individual choice, with the egalitarian constraints I have outlined above.

This version of luck egalitarianism avoids the problem of noncompensable option luck because it does not regard differential option luck as inherently just -- the victims of bad option luck may be entitled to a share of the 
advantages enjoyed by the beneficiaries of good option luck. ${ }^{55}$ The revised version also avoids the problem discussed in sections 2 and 3 because it is sensitive to the impact of background inequalities on choice. By focusing on the genuineness of choice, it is better equipped to make nuanced judgements than approaches which rely on the option luck-brute luck distinction, with its emphasis on the deliberateness and avoidability of gambles.

The level of compensation owed to an individual under this revised theory of luck egalitarianism will reflect the extent to which luck has influenced her well-being. In situations where no choice is exercised, the outcome is purely the result of luck - which brute luck egalitarians would classify as brute luck -- and thus the outcome should be completely corrected. ${ }^{56}$ On the other hand, in situations where choice does play a role, determining the amount of luck involved - which brute luck egalitarians would classify as option luck -- is conceptually difficult, but not impossible. Luck contrasts with genuine individual choice, and in making egalitarian judgements, we are interested in the extent to which a person has chosen her level of well-being, whilst adjusting for the role background inequalities played in shaping her behaviour. In assessing the extent to which we should correct the impact of a specific decision, we have to consider the impact it had on her well-being, the expected value of the option she chose (and thus the odds involved and the size of the outcomes at stake), the extent to which this decision was made instead of other viable alternatives open to her, the extent to which she accurately understood the implications of each option, the extent to which she could reasonably have been expected to assess these options accurately, the extent to which all these 
factors were influenced by her background, and how the options she faced related to the experiences and options open to other people.

To illustrate how we apply this set of considerations, it will be helpful to focus on three main types of situation where a person is entitled to compensation for an outcome that appears to arise from a choice she has made. The first type of situation arises when unchosen background inequalities mean that one person finds it more difficult than others do to pursue certain options. If this explains why she chooses differently from everybody else, and if she ends up worse off as a result, the disadvantage she suffers is luck-derived and fully compensable. This explains why the inequality that emerges between the two students in the first college example is unjust.

In the second type of situation, background factors cause people to perceive their options differently. For instance, in the second college example, one individual has a more accurate perception of the advantages of college education than the other because of differences in their upbringing. These kinds of cases are important because many of the decisions we make in the real world are shaped by expectations or assumptions rather than careful analysis. To the extent that an individual makes a bad decision because her family background or social environment caused her to misread the implications of her options, the inequality that results is unjust. The person in the second school graduate example, for instance, could easily accept her parents' judgement in the matter of college attendance, without appreciating the significance of her decision. Information may have been available if she had cared to investigate, but it would not have been unusual for a person in her circumstances to be strongly guided by her parents' views, even to the extent that she may not have seriously 
entertained college education as an option. In this case, the inequality that results would be unjust. ${ }^{57}$ If, on the other hand, she knew she was making a decision without sufficient information that was readily available, the outcome begins to have less to do with luck and more to do with choice, which means that some degree of inequality is legitimate. ${ }^{58}$

Unjust inequalities may also emerge in the third type of situation, where individuals make decisions in conditions of background equality. To understand how luck egalitarians should approach the issue of redistribution in such cases, we must return to the two conditions outlined in section 1 . The first condition is that redistribution is only appropriate (in cases of risk-taking) if the outcome each individual enjoys is partly the result of luck. Thus, if individuals choose options that involve some element of risk, luck shapes the outcomes they end up with, and the differential impact of luck on the lives of these risk-takers provides grounds for redistribution. However, the implication of this condition is that redistribution should only occur between those who have genuinely chosen to take a risk. Individuals who decide to play it safe, selecting a riskfree option, effectively choose the outcome they end up with, so the first condition remains unsatisfied. They should not share in the benefits or burdens associated with risk-taking because any inequality that emerges between risktakers and non-risk-takers is rooted in the different initial choice they made about whether to expose themselves to the vagaries of fortune. ${ }^{59}$ The second condition is that risk-takers must prefer redistribution to letting luck run its course. In the following two paragraphs, I will assume that this second condition is satisfied, unless otherwise stated. 
The amount of redistribution that should occur amongst those who decide to take risks depends on the relative impact that luck has on each of them. All risk-takers have elected to take a chance, and consequently, the outcome that they each end up with will, at least in part, reflect luck rather than choice. I say "in part” because individuals may select options that involve a greater/lesser degree of risk, and in such cases, it would be inappropriate to ascribe the outcome completely to the effects of luck. ${ }^{60}$ In these cases of risktaking in conditions of background equality, luck egalitarians should measure the impact of luck on a person's life with reference to the divergence between the expected value of the option she selects, and the actual outcome. If the divergence is in a positive direction (the value of the actual outcome exceeds the expected value), then she has benefited from good luck. If the divergence is in a negative direction (the value of the actual outcome is less than the expected value), she has suffered from bad luck. To apply luck egalitarianism, we must calculate the impact of luck on each person, and act to ensure that the benefits and burdens associated with this luck are shared equally amongst all risktakers.

For instance, person A ends up with 10000 dollars after choosing option 1, which has an expected value of 5000 dollars. Person B, on the other hand, chooses option 2, which has an expected value of 4000 dollars, but he ends up with nothing. ${ }^{61}$ A enjoys 5000 dollars worth of good luck, whilst B suffers 4000 dollars worth of bad luck. Half of A's 5000 dollars worth of good luck goes to B who now has 2500 dollars, leaving A with 7500 dollars. The next step is to share out the cost of B's 4000 dollars of bad luck by taking 2000 dollars from A and giving it to B. This leaves A with 5500 dollars and B with 
4500 dollars. There is still a gap between A and B because B chose a riskier option than A, but we have now equalised the impact of luck on their lives. This approach solves the difficult issue of redistribution amongst those who take gambles in conditions of equality.

Nonetheless, we must remember that this redistributive scheme only applies to cases which satisfy both the conditions outlined in section 1 . Condition 2, in particular, is likely to reduce the number of cases in which luck egalitarianism supports the equalisation of the benefits and burdens associated with risk-taking. Whilst fully assessing the impact of condition 2 is beyond the scope of this chapter, we can at least note that it is unlikely to rule out redistribution in cases where individuals take small risks, motivated by the desire to moderately improve their position. For example, individuals who invest in "safe" shares are aiming to achieve a steady improvement in their financial position, and equalising the impact of luck on their investments is unlikely to prevent them from achieving this goal. If this is the case, then we do not violate their choice by applying the redistributive scheme, so condition 2 will be satisfied. Once again, this highlights the radical nature of luck egalitarianism - it supports redistribution in even the most extreme cases, where individuals on an equal footing freely choose to engage in risk-taking behaviour.

But although the theoretical underpinnings of the approach are now clear, in order to apply the theory in real life we would need to have detailed information about the decisions people have made, the expected value of the options they confronted, their natural capacities, family background, etc., and in practice, we are unlikely to have this information. ${ }^{62}$ Even if it were possible for 
the state to gather this data, it could only do so through mechanisms which would violate important values such as individual privacy. In the face of these difficulties, we may be tempted to reject luck egalitarianism as a fatally flawed interpretation of egalitarian justice. However, this would be too hasty. My aim in this chapter is to establish a more precise understanding of egalitarian justice on an abstract level, leaving aside questions of implementation, and competing values such as individual privacy. In assessing the merits of the different theories on offer, I am concerned with fact-insensitive normative principles, not regulative principles that are designed to take practical limitations into account. $^{63}$ The aim of luck egalitarianism is to provide a compelling theory of egalitarian justice, not to provide an exhaustive guide to political morality or public policy.

Nonetheless, it is still possible to draw conclusions about the likely practical applications of luck egalitarianism. ${ }^{64}$ Unable to gather the detailed information we need to implement a pure form of the theory, we are forced to rely on general judgements about the extent to which real-world inequalities reflect the differential impact of luck, rather than the different choices individuals have made. If we look at the key determinants of one's income and wealth, luck seems to play a crucial role in the lives of most individuals. For instance, one's occupation is greatly influenced, as brute luck egalitarians recognise, by differences in natural talent. In addition to this, the revised form of luck egalitarianism is sensitive to differences in upbringing, such as parental attitude towards education, which also have a big impact on a child's educational performance. This suggests that differences in occupation and income will largely reflect luck rather than choice, and this occurs to such an 
extent that almost no inequalities resulting from them are just. ${ }^{65}$ We reach a similar conclusion in relation to wealth. For a start, people inherit very different amounts of wealth, which is an obvious example of luck. Moreover, the very fact some people have extra money to invest reflects differences in income inequality, which in turn reflect luck. ${ }^{66}$ When combined with the fact that return on investment will also have a lot to do with luck, few inequalities in wealth will reflect genuine choice for which a person is fully responsible.

Once we recognise the extent to which inequalities in income and wealth reflect the impact of luck, rather than choice, we get a sense of the radical implications of luck egalitarianism. The effects of luck are so pervasive that, if we are unable to make judgements about individuals on a case-by-case basis, we should adopt a general presumption in favour of equality of outcome. Absent more detailed information, we should assume that any inequalities in income and wealth are the result of luck rather than genuine individual choice. ${ }^{67}$ This may produce some injustices, redistributing resources towards those who are responsible for being worse off than others, ${ }^{68}$ but the pervasive nature of luck means that this is the most reliable second-best strategy for implementing luck egalitarianism.

In practice, policy-makers may need to further compromise luck egalitarianism in order to avoid adverse outcomes. For instance, a familiar objection to radical egalitarianism is that it distorts the market and leads to economic disaster. If this criticism is correct, policy-makers would need to water-down the radical redistributive implications of luck egalitarianism when attempting to implement the theory. Nonetheless, it is important to recognise that such changes are compromises. As I argued above, we are interested in the 
best interpretation of the value of egalitarian justice. We are not looking for a complete theory of political morality, or a set of policy recommendations, so the fact that compromises are necessary in the name of other values, or because of practical limitations does not, in itself, indicate that the theory is flawed. My aim in this chapter has been to trace the radical consequences of shifting notions of choice and responsibility to the centre of egalitarian justice, and these radical consequences remain, even if other considerations force us to depart from them.

Before I conclude, I must briefly address one final criticism that may be advanced against my argument in this chapter. Even if a person's success at the races or on the stock market partly reflects luck, why should his/her winnings be redistributed to somebody else? Why does a person have a claim to winnings that resulted from a risk that he/she has not taken ${ }^{69}$ The answer is that as a community of equals, we need to treat all citizens equally in some way. The most relevant way of doing this is to stop arbitrary factors from adversely affecting the well-being of all persons. If we truly are equals in society then we should not be worse off than others because of things we do not genuinely control. The corollary of this is that people should share out the benefits of their own good fortune. A society where people have lives of vastly unequal quality because of the effects of luck is inconsistent with the idea of living in a community of equals. I will return to this issue in the next chapter.

\section{CONCLUSION}

In this chapter, I have argued that luck egalitarians should reject the distinction between option luck and brute luck, and instead support a revised version of 
luck egalitarianism that focuses on the extent to which persons have chosen the level of advantage they enjoy, and the extent to which this choice is genuine, as opposed to a reflection of background inequalities which shape choice. This approach avoids the inegalitarianism highlighted in sections 2 and 3 and meets the objection highlighted in section 1 by providing compensation for some instances of option luck inequality. Thus, having rejected the distinction between compensable brute luck and non-compensable option luck, we are left with a theory that incorporates choice in a truly egalitarian way. Having outlined a more precise theory of luck egalitarianism, I will focus on providing a broader justification for it in the next chapter. In chapter 5 I will outline an egalitarian conception of advantage that can be incorporated into this new theory. 


\section{NOTES}

${ }^{1}$ I use the term "brute luck egalitarianism" in this chapter to refer to the orthodox form of luck egalitarianism that is supported by Dworkin and Cohen, which focuses on equalising the impact of brute luck. This distinguishes Dworkin and Cohen's approach from the revised version of luck egalitarianism that I outline in section 4, which abandons the option luck-brute luck distinction. The term "brute luck egalitarianism" is from P. Vallentyne, "Brute Luck, Option Luck and Equality of Initial Opportunities,” Ethics, V. 112, no, 3, 2002, pp. 529-57, at p. 540 n. 17.

${ }^{2}$ R. Dworkin, Sovereign Virtue: The Theory and Practice of Equality, Cambridge, Mass., Harvard University Press, 2000, p. 73.

${ }^{3}$ I say "usually" because the term "option luck" is also used to describe instances where a person has directly chosen an outcome, and where there is consequently no luck involved. See Vallentyne, “Brute Luck, Option Luck and Equality of Initial Opportunities,” p. 534 n. 12.

${ }^{4}$ See also T. Christiano, "Christiano Reviews Anderson,” Brown Electronic Article Review Service, $1999 \quad<$ http://www.brown.edu/Departments/Philosophy/bears/9904chri.html>, (accessed 14 November 2003); M. Fleurbaey, “Equality Among Responsible Individuals,” in J.F. Laslier, M. Fleurbaey, N. Gravel, A. Trannoy (eds.) Freedom in Economics, London, Routledge, 1998, p. 213; K. Lippert-Rasmussen, “Arneson on Equality of Opportunity for Welfare,” The Journal of Political Philosophy, V. 7, no. 4, 1999, pp. 478-87, at pp. 482-83.

${ }^{5}$ I thank David van Mill for this suggestion.

${ }^{6}$ See S. Hurley, Justice, Luck and Knowledge, Cambridge, Mass., Harvard University Press, 2003, pp. 169-70; D. Parfit, “Equality or Priority?” in M. Clayton \& A. Williams (eds.), The Ideal of Equality, Houndmills, Palgrave Macmillan, 2002, p. 93.

${ }^{7}$ See also Lippert-Rasmussen 2001, 551-7 for an excellent critique of the idea that option luck is noncompensable.

${ }^{8}$ Christiano, “Christiano Reviews Anderson.”

${ }^{9}$ Dworkin, Sovereign Virtue, pp. 74-75.

${ }^{10}$ Christiano, “Christiano Reviews Anderson;” M. Fleurbaey, “Egalitarian Opportunities,” Law and Philosophy, V. 20, no. 5, 2001, pp. 499-530, at p. 511. 
${ }^{11}$ Christiano, “Christiano Reviews Anderson;” \& see also M. Fleurbaey, “Equal Opportunity or Equal Social Outcome,” Economics and Philosophy, V. 11, 1995, pp. 25-55, at pp. 40-41.

${ }^{12}$ Also note Vallentyne, “Brute Luck, Option Luck and Equality of Initial Opportunities,” pp. $549-56$.

${ }^{13}$ Dworkin, Sovereign Virtue, p. 75.

${ }^{14}$ I say "in itself" because most luck egalitarians are likely to value such diversity, but this would be for reasons that are independent of egalitarian justice (and hence luck egalitarianism). See \& cf. Dworkin, Sovereign Virtue, p. 75.

${ }^{15}$ I thank Colin Macleod for this example.

${ }^{16}$ K. Lippert-Rasmussen, “Egalitarianism, Option Luck, and Responsibility,” Ethics V. 111, no. 3, 2001, pp. 548-579, at pp. 554-56.

${ }^{17}$ Lippert-Rasmussen, “Egalitarianism, Option Luck, and Responsibility,” pp. 554-56.

${ }^{18}$ Lippert-Rasmussen, “Egalitarianism, Option Luck, and Responsibility,” pp. 555-56. For a related discussion, see also Vallentyne, "Brute Luck, Option Luck, and Equality of Initial Opportunities,” pp. 549-52. The italicized clause is necessary because redistributing the benefits and burdens of option luck could leave all participants worse off, or with such minimal gains that they would prefer to forgo redistribution in order to preserve the (smaller) chance of a bigger win. In these cases, the importance luck egalitarians place on respect for individual choice means that option luck is noncompensable.

${ }^{19}$ Dworkin, Sovereign Virtue, p. 76.

${ }^{20}$ As I discussed in chapter 1, Dworkin believes that the availability of insurance against (some) instances of bad brute luck converts this bad luck into option luck. People have the option of protecting themselves against the risk of bad brute luck with insurance, so choosing not to insure counts as risk-taking behaviour that gives rise to option luck. However, this conclusion is also limited by egalitarian conditions. It only holds "if everyone had an equal risk of suffering some catastrophe that would leave him or her handicapped, and everyone knew roughly what the odds were and had ample opportunity to insure.” See Dworkin, Sovereign Virtue, pp. 73-79. The quote is from Dworkin's discussion of insurance for handicaps, on p. 77. 
${ }^{21}$ A. Phillips, “Defending Equality of Outcome,” The Journal of Political Philosophy, V. 12, no. 1, pp. 1-19, at pp. 15-16. For discussion of related issues, see also C.M. Macleod, "Liberal Equality and the Affective Family,” in D. Archard \& C.M. Macleod, (eds.), The Moral and Political Status of Children, New York, Oxford University Press, 2002, pp. 212-230.

${ }^{22}$ I thank an anonymous reviewer at the Journal of Politics for helping to clarify my thinking on this point, and for suggesting the "equal footing” terminology.

${ }^{23}$ Cf. C. Lake, Equality and Responsibility, Oxford, Oxford University Press. 2001, pp. 83105; \& Hurley, Justice, Luck and Knowledge, pp. 146-80 who highlight the potential tension between the notion of individual responsibility, and egalitarianism. See also LippertRasmussen, "Arneson on Equality of Opportunity for Welfare," The Journal of Political Philosophy, V. 7, no. 4, pp. 478-87, at 486-87. I take the "background" inequality terminology from Lake (e.g. p. 83).

${ }^{24}$ E.g. J. Rawls, A Theory of Justice, Oxford, Oxford University Press, 1972, p. 74; A. Mason. “Equality, Personal Responsibility, and Gender Socialisation,” Proceedings of the Aristotelian Society, V. 100, no. 3, 2000, pp. 227-246; A. Mason, “Equality of Opportunity and Differences in Social Circumstances,” The Philosophical Quarterly, V. 54, pp. 368-388.

${ }^{25}$ See also Phillips, “Defending Equality of Outcome,” pp. 1-19, especially at p. 17. Phillips makes a related point that the focus on luck and choice in the literature may lead egalitarians to neglect the links between social structures and inequality.

${ }^{26}$ E.g. Dworkin, Sovereign Virtue, pp. 289-91, 298; “Ronald Dworkin Replies,” In J. Burley (ed.) Dworkin and His Critics: with Replies by Dworkin, Malden, Blackwell Publishing, 2004, pp. 346-47. This is what Fleurbaey calls a "delegation" view of responsibility because individuals are automatically delegated responsibility (held to be responsible) for their preferences, regardless of the aetiology of these preferences. See Fleurbaey, "Equality Among Responsible Individuals,” pp. 208, 225; \& see also Fleurbaey, "Equality and Responsibility,” European Economic Review, V. 39, no. 3, 1995, pp. 683-89, at p. 684; and Vandenbroucke, Social Justice and Individual Ethics in an Open Society: Equality, Responsibility, and Incentives, Berlin, Springer, 2001, pp. 11-14. Also recall that Dworkin makes an exception for some preferences, which are more appropriately treated as handicaps. A preference counts as a 
handicap or "drive" if the person who holds it would rather be without it. See Dworkin, Sovereign Virtue, pp. 82-83.

${ }^{27}$ Also note the discussion of preference formation in C.M. Macleod, Liberalism, Justice, and Markets: A Critique of Liberal Equality, Oxford, Clarendon Press, 1998, pp. 19-45.

${ }^{28}$ Dworkin, Sovereign Virtue, pp. 48-59, 287-99; “Ronald Dworkin Replies,” pp. 339-50.

${ }^{29}$ Scanlon gives a related example, featuring a man who is undisciplined, unreliable, and hence unemployable as a because of his poor upbringing. See What We Owe to Each Other, Cambridge, Mass., Harvard University Press, 1998, p. 292.

${ }^{30}$ In an unpublished commentary on my thesis, Colin Macleod has challenged my characterisation of Dworkin's use of the option luck concept. According to Macleod, "Dworkin thinks that choices unconnected with luck can result in distributions of resources in which individuals have different holdings... The point is that responsibility (or what Dworkin sometimes calls 'ambition-sensitivity') arises in contexts that are removed from matters of option luck.” In other words, Dworkin does wish to hold us responsible for our choices, but not all the relevant distribution-affecting choices count as "option luck.” I have already recognised (see n. 3 above) that Dworkin holds us responsible for choices that have nothing to do with luck, but in contrast to Macleod's interpretation, I presented such choices as if they fall within the "option luck" category. If Macleod is correct, and such choices are something other than option luck, then my critique of Dworkin might seem misplaced. But this is not the case. Whether or not Dworkin classifies all such choices as "option luck," his theory will perpetuate background inequality unless he adopts the equal footing proviso that takes into account the impact of this background inequality on these choices. For example, Dworkin might not include individuals' different decisions regarding college attendance, choice of occupation, and work-leisure balance as matters of "option luck," but he does wish to hold people responsible for the impact of these choices on their holdings. As the examples given in this section demonstrate, these choices will be affected by family background and other forms of background inequality, and Dworkin must modify his theory to take this into account. However, if he attempts to do this by introducing an equal footing proviso, Dworkin will also 
have to change his position on the issue of responsibility for preferences, which leads him back into the dilemma outlined in this paragraph.

${ }^{31}$ Macleod, Liberalism, Justice, and Markets: A Critique of Liberal Equality, p. 42.

${ }^{32}$ Dworkin, Sovereign Virtue, p. 160.

${ }^{33}$ See \& cf. Mason, “Equality, Personal Responsibility, and Gender Socialisation,” pp. 240-46.

${ }^{34}$ Cohen, “On the Currency of Egalitarian Justice,” Ethics V. 99, no. 4, 906-944, at p. 908.

${ }^{35}$ Cohen, "On the Currency of Egalitarian Justice," 908 n. 3. In n. 3, which follows the first sentence of the quotation above, Cohen says: "The latter kind of luck is option luck." (His emphasis). He then attributes the distinction to Dworkin. However, Cohen's explanation of option luck as luck that arises from avoidable gambles or risks is subtly different from Dworkin's definition which refers to a deliberate gamble that could have been declined. I will use Cohen's definition as the basis for the analysis below.

${ }^{36}$ Cohen, “On the Currency of Egalitarian Justice,” p. 921.

${ }^{37}$ M. Fleurbaey, “Equality Among Responsible Individuals,” p. 277; Vandenbroucke, Social Justice and Individual Ethics in an Open Society, p. 12.

${ }^{38}$ Cohen, “On the Currency of Egalitarian Justice,” p. 922.

${ }^{39}$ Cohen, "Expensive Taste Rides Again,” p. 8. Cohen has revised his position and this “flagship statement” since his earlier work. See \& cf. Cohen 1989, 923. For his explanation of this modification see Cohen 2004, 7-8.

${ }^{40}$ Cohen, “On the Currency of Egalitarian Justice,” pp. 916-34.

${ }^{41}$ Cohen, “On the Currency of Egalitarian Justice,” p. 934, his emphasis.

${ }^{42}$ Cohen, “Expensive Taste Rides Again,” pp. 21-22, his emphasis.

${ }^{43}$ Cohen, “On the Currency of Egalitarian Justice,” p. 934 n. 62. In Sovereign Virtue, Dworkin does indeed claim that "the difference between these two forms of luck can be represented as a matter of degree” (p. 73), but his subsequent use of the distinction does not seem consistent with this claim. Insurance, for example, creates “a link between brute and option luck” (p. 74), but those who suffer an accident after failing to take out insurance are not entitled to any compensation on the grounds of egalitarian justice (pp. 76-77). Admittedly, Dworkin later retreats from this conclusion, but this is because certain conditions, outlined in $\mathrm{n} .17$ above, are 
not satisfied in the real world (e.g. p. 77), not because option luck is a matter of degree. See chapter 1 for further discussion.

${ }^{44}$ See also Vallentyne, “Brute Luck, Option Luck and Equality of Initial Opportunities,” pp. 537-38.

${ }^{45}$ Recall that I am using Cohen's explanation of option luck, which refers to avoidability rather than Dworkin's notion of a deliberate and calculated gamble. See n. 28 above.

${ }^{46}$ I thank David van Mill for his suggestion that the option-brute distinction could be redrawn to reflect notions of partial responsibility.

${ }^{47}$ It should be noted that this decision is not really a gamble/risk, as such. Although Cohen defines option luck in terms of a gamble/risk that is avoidable, presumably he would also hold persons accountable for the outcome of sub-optimal decisions they take with full knowledge of the consequences.

${ }^{48}$ This conclusion would hold even if we were to adopt Dworkin's original "deliberate and calculated gamble" definition of option luck. Deliberateness is a relative rather than absolute notion. It does not make sense to say that a decision was partly a deliberate gamble, and partly not.

${ }^{49}$ For a related discussion of the tension between equality of opportunity and responsibility in Cohen's work see Lake 2001, 93-94.

${ }^{50}$ E.g. Phillips, “Defending Equality of Outcome;” \& see also A. Mason, "Equality, Personal Responsibility, and Gender Socialisation.”

${ }^{51}$ An anonymous reviewer at the Journal of Politics has suggested to me that this is how Cohen intends the distinction to be understood in the first place. This might be the case, but when Cohen initially introduces the concept of option luck, he defines it in terms of avoidability (see the quotations from Cohen on p. 87, and p. 105 n. 28 above, where he talks about the avoidability of risks or gambles) and, as I have pointed out, this definition clashes with the nuanced approach to responsibility he supports. If Cohen does intend the option-brute distinction to be understood in terms of genuinely chosen risks, he must recast his definition of the distinction accordingly. 
${ }^{52}$ Another possibility is to define option luck in terms of risk-taking that was reasonably avoidable, so option luck can only arise when an individual faced and rejected reasonable alternatives to the option she took. However, this does not solve the problem, because the idea of reasonable avoidability may also be insensitive to the impact of background inequalities. In the first example above, it is not unreasonable to expect the school-leaver to sacrifice her family's short-term financial position for the sake of her future career, as this will probably allow her to better support her family in the long-term. An individual may take a risk that is reasonably avoidable without being fully genuine. For work on the role a notion of reasonableness might play in distinguishing option luck and brute luck see Vallentyne, "Brute Luck, Option Luck and Equality of Initial Opportunities;” M. Otsuka, "Luck, Insurance, and Equality,” Ethics, V. 113, no. 1, 2002, pp. 40-54; Z. Stemplowska, The Concept of Luck in Contemporary Theories of Egalitarian Justice, M.Phil thesis, Oxford University, 2002; A. Ripstein, Equality, Responsibility and the Law, Cambridge, Cambridge University Press, 1999, 264-295; M. Sandbu, “On Dworkin’s Brute-Luck-Option-Luck Distinction and the Consistency of Brute-Luck Egalitarianism,” Politics, Philosophy \& Economics, V. 3, no. 3, pp. 283-312; and Lippert-Rasmussen, "Egalitarianism, Option Luck, and Responsibility.” See also Macleod, Liberalism, Justice, and Markets: A Critique of Liberal Equality, especially pp. 73-5.

${ }^{53}$ I expand on this point in chapter 6.

${ }^{54}$ I say equalise, rather than neutralise, because we are interested in the luck individuals enjoy, relative to each other. For instance, if I make a bad decision because of my background then that is a case of bad luck. If everybody else chose better (because of their background), then the bad luck involved becomes worse. On the other hand, if everybody else made the same mistake as me because of some similarity in our upbringing, and we all ended up equally badly off, then I would still suffer from bad luck, but it is less severe than it would be in the first example. Moreover, in the second case, mutatis mutandis, there is no real injustice involved. Of course, it would have been better per se if people had chosen more prudently, but individuals are all in the same position so there is no injustice in how we have been treated. See also Cohen, “Expensive Taste Rides Again,” pp. 14-15. 
${ }^{55}$ The revised version of luck egalitarianism outlined here is similar to an approach Vallentyne 2002, 539-40, describes as follows: "Equality of luck holds that all factors except direct choice call for equalization. It calls for compensating for all kinds of luck (both brute and option luck) but allows uncompensated differences in outcomes when they are due solely to differences in choices...” However, unlike this approach, I allow some inequality that does not result from direct choice (a gambler will not usually be entitled to receive the full sum they lose from their unsuccessful gamble, mutatis mutandis). Vallentyne links equality of luck to Arneson's idea of “strict equality of opportunity”. See Vallentyne, 540 n. 17 \& Arneson 1999, 490-1.

${ }^{56}$ For the sake of simplicity, I assume here that society has the resources to equalise the impact of luck on the well-being of all persons by entirely removing it/compensating for it.

${ }^{57}$ I have not yet discussed the issue of adaptive preferences. One of the ways in which background inequalities affect the genuineness of individual choice, it might be argued, is by lowering the expectations of individuals, so those who suffer from severe disadvantage over a long period of time become accustomed to this disadvantage (such as the "tamed housewife"). If opportunities became available which would allow these individuals to improve their position, they choose not to take them because they have adjusted their preferences and expectations over time to accord with their disadvantaged position. I acknowledge that adaptive preferences are concerning to egalitarians, and it is open to luck egalitarians to revise their conception of genuine choice to overcome the problems these preferences present. However, I think there is reason to be wary of expanding the notion of genuineness too far. If the "tamed housewife" is rational and she decides against pursuing certain options because she is satisfied with her current life, it is difficult to deny that she makes a genuine choice. Thus, from the point of view of luck egalitarianism, there is nothing unjust about the situation that results. Of course, justice is not the only value that matters, and it is possible that egalitarians will wish to intervene in this situation for reasons other than justice, but luck egalitarianism does not, in itself, provide grounds for such intervention.

There is no contradiction between my view on this issue, and my comments on preference formation earlier in the chapter. In section 2, I gave the example of someone who has a strong aversion to work as a result of his upbringing, and I argued that luck egalitarians 
should take this into account when making judgements about the decisions he has made. In effect, this aversion to work is a form of background inequality that makes it more difficult for him to pursue certain options (such as hard work), and luck egalitarians must take this into account when assessing the decisions he has made throughout his life. However, this is different from the case of the "tamed housewife." The problem with the "tamed housewife" is that her luck-shaped preferences mean she is satisfied with less than others have, and that she would refuse to take up opportunities others regard as beneficial because she sees no need to improve her current position. In contrast, the problem with the work-avoider is that his luckshaped preferences lead him to make decisions which leave him worse off than others. Unlike the "tamed housewife," he is unhappy that he ends up with less than others, and cannot be considered to have genuinely chosen this outcome. I thank an anonymous reviewer at the Journal of Politics for highlighting the need to address this issue.

${ }^{58}$ See also Cohen, “On the Currency of Egalitarian Justice,” p. 934.

${ }^{59}$ See also Dworkin, Sovereign Virtue, p. 74.

${ }^{60}$ See also Vallentyne, “Brute Luck, Option Luck and Equality of Initial Opportunities,” pp. 535-36. I assume here that the individuals involved have accurate information about the expected value of each option, and that the choice they make is a free one.

${ }^{61}$ Although option 2 has a lower expected value than option 1, assume that B chooses the former because it gives him a chance of a bigger win than is possible under the latter.

${ }^{62}$ See also Fleurbaey, “Egalitarian Opportunities,” pp. 515-16.

${ }^{63}$ Cohen, “Facts and Principles,” Philosophy and Public Affairs, V. 31, no. 3, 2003, pp. 207245, at pp. 244-45.

${ }^{64}$ I will expand on this argument in chapter 7, where I explore the implications of luck egalitarianism for debates over the welfare state.

${ }^{65}$ For further discussion, and supporting statistics on intergenerational economic mobility, see Chapter 7, section 2.

${ }^{66}$ See also P. Van Parijs, Real Freedom for All: What (if anything) can justify capitalism? Oxford, Clarendon Press, 1995, p. 119. 
${ }^{67}$ I expand on this point in chapter 7. Ramsay and Barry make similar arguments about the radical implications of luck egalitarianism and related approaches, and contrast this with the kind of policies that politicians try to justify in the name of individual responsibility. But whereas they are both critical of the luck-egalitarian project, I continue to defend it. There is no need for luck egalitarians to be embarrassed about the radical implications of the theory they support. See M. Ramsay, “Equality and Responsibility,” Imprints V. 7, no. 3, 2004, pp. 269-96; B. Barry, Why Social Justice Matters, Cambridge, Polity, 2005. A related argument is offered in Phillips, "Defending Equality of Outcome."

68 It is worth noting that we can depart from equality of outcome if information becomes available which allows us to make more precise judgements in certain situations. That is, we might determine that particular inequalities are more appropriately ascribed to genuine individual choice rather than luck. For example, we might conclude that a man who genuinely chooses to work part-time is responsible for the fact he has a lower income than a man who works full-time. But in making this judgement we would also have to be sure that the man working part-time genuinely chose to work part-time, and that this decision it was not forced upon him by his employer, or by the fact he had extra obligations to provide unpaid care to those dependent on him. Absent such information, our default position should be equality of outcome.

${ }^{69}$ This objection was raised by David van Mill. 


\section{CHAPTER 4}

\section{JUSTIFYING LUCK EGALITARIANISM}

In this chapter I will attempt to situate luck egalitarianism within a broader account of equality as a moral ideal. In particular, I will address recent criticisms that luck egalitarians have not offered a full-blooded defence of the theory they support. Rather, they assume that equality is an important, defensible value and that the key issue of contention is how best to interpret this value. ${ }^{1}$ Little attempt has been made to justify the ideal of equality to a broader non-egalitarian audience. This relates to Hurley's argument that luckneutralisation does not necessarily justify an egalitarian pattern of distribution, and to Lake's claim that equality and responsibility pull in different directions. ${ }^{2}$

In this chapter, I will explain the deeper roots of luck egalitarianism. I will argue that its central appeal lies in the sense that it is unfair or unjust if luck has an unequal impact on our lives. Section 1 reviews recent work which suggests that responsibility and equality may sit in tension with each other, focusing particular attention on Hurley's argument that luck-neutralisation cannot provide a basis for egalitarianism. In section 2, I turn to possible justifications of luck egalitarianism, focusing on work by Rawls, Dworkin, and Scheffler. I argue that the concern to live in a society of equals naturally lends support to the idea that we should adhere to principles of justice. In section 3, I conclude by explaining why we consider inequality in the distribution of luck to be unfair. This explanation relies on the idea that persons with equal moral worth have an equal entitlement to a good life. 


\section{RESPONSIBILITY AND LUCK NEUTRALISATION}

The aim in this chapter is to provide a broader justification of luck egalitarianism, rather than testing simply whether the theory is consistent with our intuitive understanding of equality. This task is urgent because of recent work by Christopher Lake and Susan Hurley, who point out that notions of luck and responsibility do not necessarily lead us in an egalitarian direction. I have tried to develop a theory that incorporates these notions in a way that seems consistent with our intuitive understanding of egalitarianism, but this project may have been misguided. Perhaps the desire to make choice and responsibility crucial aspects of justice is guided by a belief in the importance of responsibility and choice that has nothing to do with egalitarianism? Perhaps there is nothing authentically egalitarian about luck egalitarianism?

I have already gone part of the way to addressing this line of criticism in chapters 2 and 3. However, in these chapters I established how responsibility and choice can be used in a way that is consistent with our egalitarian intuitions, rather than offering a positive argument for the relevance of these notions. It is one thing to argue that a theory based on responsibility and choice is consistent with our intuitive understanding of the egalitarian ideal, and another to explain why these notions are a required part of this ideal, and this is the issue I address in this chapter. I will begin by exploring whether responsibility and luck can provide a grounding for egalitarianism, focusing on recent work in this area. I will support Hurley’s conclusion that they cannot do so, and emphasise that the focus on responsibility and luck actually arises from a concern with egalitarian justice, not the other way around.

Christopher Lake has argued that equality and responsibility do not fit together naturally. At heart, responsibility is an absolute, not relative measure, 
so whether a person is responsible for a decision depends on whether she satisfies the conditions needed to be considered an autonomous, responsible agent, not on how her background compares to others. ${ }^{3}$ I am responsible for choosing to take one path instead of another, regardless of the decisions other people make. This highlights that responsibility is not well-suited to making the comparative judgements we associate with egalitarianism.

Susan Hurley makes a related claim "that the aim to neutralize luck cannot provide a basis for egalitarianism." She uses the term "luck" in what she calls the "thin" sense, which holds that "luck is simply the inverse correlate of responsibility, so that what is a matter of luck for someone is what he is not responsible for." ${ }^{5}$ She understands the term "basis" in two ways. Providing a basis for egalitarianism can mean providing a justification for egalitarianism, or, in another sense, providing a specification of it, but Hurley denies that luck neutralisation can play either role. ${ }^{6}$

The only place where considerations of responsibility seem to have a role in distributive justice is "in defining the currency of egalitarian justice"7 (that is, in determining what things we are interested in distributing). Questions of distributive justice only pertain to goods whose distribution is a matter of luck, so if individuals are responsible for their holdings of certain goods then these goods are excluded from consideration. ${ }^{8}$ But whilst responsibility helps determine the currency of distributive justice, it cannot fully specify what this currency should be. It cannot, for instance, determine whether we are interested in welfare or resources. As Hurley puts it:

Responsibility in its currency role contributes to telling us what to redistribute, by in effect acting as a filter on some independently specified good or goods, but it does not determine that independent specification. For example, we could aim to equalize 
resources for which people are not responsible, or welfare for which people are not responsible, or both... The obvious point is that some such independent specification of the good is needed; it is not provided by responsibility. We don't aim to equalize just anything and everything of any kind for which someone is not responsible; that would be absurd. ${ }^{9}$

Thus, responsibility cannot by itself provide a complete account of the currency of egalitarian justice.

Moreover, once we have fixed the currency of distributive justice, the notion of responsibility cannot be used to determine the pattern according to which this currency should be distributed. Contrary to first appearances, there is no direct, non-trivial link between responsibility and egalitarian patterns of distribution. For instance, goods that fall as if manna from heaven are a matter of luck because no person is responsible for them, so we may think that the only fair way to neutralise luck is to distribute them equally. If we were to distribute on some other basis, such as maximin (which aims to maximise benefits to the worse off), this is likely to result in an unequal distribution. Because these goods are purely the result of luck, this would be inconsistent with the luck-neutralising aim. ${ }^{10}$ But, as Hurley points out, equalising the distribution of these resources would not actually neutralise the impact of luck, either:

If we equalize instead of maximin goods that are a matter of luck, then there will be equalities between people with respect to goods that are a matter of luck. But people are no more responsible for an equal distribution of goods that are a matter of luck than they are for an unequal distribution. Equalities can be just as much a matter of luck as inequalities. The fact that people are not responsible for difference does not entail that they are responsible for nondifference. There is no more a priori reason to assume that equalities are not a matter of luck than there is to assume that differences are not a matter of luck: people may not be responsible for either. If so, then equalizing 
no more neutralizes luck than maximining does. ${ }^{11}$

Hurley warns against the danger of the "egalitarian fallacy":

It is a fallacy to infer from:

(9) It is a matter of luck that $a$ and $b$ are unequal

to:

(10) It would not be a matter of luck if $a$ and $b$ were equal. ${ }^{12}$

This is an important conclusion because it suggests that luck and responsibility cannot provide the basis for an egalitarian distribution.

A similar line of argument applies to the "equality-default view” which takes equality as the default position, and uses "responsibility... to justify departures from equality."13 In effect, our aim is to "neutralize differences that are a matter of luck,"14 but to allow differences (inequalities) when individuals are responsible for them. In this way, luck-neutralisation appears to play an egalitarian patterning role. However, in the equality-default view, responsibility still provides no basis for equality. ${ }^{15}$ Rather, we just assume that an egalitarian pattern is valuable and that it should be taken as the default position, independent of the luck-neutralising aim. It is this assumption, not luckneutralisation that is doing all the egalitarian work. For instance, we could use responsibility in the same way, but as part of an "inequality-default view," which only allows departures from inequality if individuals are responsible for them. This shows that luck-neutralisation provides no basis for egalitarianism in the equality-default view.

Hurley also offers a more general argument for her claim that neutralising luck does not provide a basis for favouring egalitarianism. This argument is developed through "the luck neutralizer's dilemma." ${ }^{16}$ It relies on the distinction between the interpersonal and counterfactual reading of "bad 
luck,” which Hurley describes as follows:

In the interpersonal reading, I compare my situation with other people's situations. I have bad luck when what I and others have is a matter of luck, and I am worse off than others. In the counterfactual reading, I compare my actual situation with other possible situations I might have been in. I have bad luck when what I have is a matter of luck and I am worse off than I might have been. The badness of my luck can be assessed by comparison either to how well off others are, or by comparison to how well off I might have been. ${ }^{17}$

In other words, interpersonal bad luck means being worse off than others when neither you nor they are responsible for this (particular) inequality, whilst counterfactual bad luck means being worse off than you (as an individual) could have been in some alternative situation. The luck neutraliser's dilemma has two horns, relating to these two interpretations of the phrase "bad luck."

The first horn of the dilemma arises if we try to neutralise bad luck in the interpersonal sense of the word. ${ }^{18}$ If we do this, then we will end up supporting an egalitarian pattern of distribution because bad luck is defined as being worse off than others (when everybody's position is a matter of luck). But this only establishes a trivial relationship between equality and luckneutralisation. Interpersonal bad luck is defined in terms of inequality (it arises when we are worse off than others), so obviously neutralising bad luck will result in an egalitarian pattern of distribution. If bad luck means inequality then neutralising bad luck will lead to equality, and still no justification for egalitarianism has been provided. Thus, luck-neutralisation can provide only a trivial basis for equality, on the interpersonal reading of luck.

The second horn of the dilemma arises if we adopt the counterfactual reading of bad luck. The problem here is that neutralising the badness of luck (whether by "eliminating all better worlds possible for me, or putting me in the 
best world possible for me”) will not necessarily lead to an egalitarian pattern of distribution. ${ }^{19}$ After all, if we abolish all better worlds, we leave the individuals concerned in their current state, which may be unequal, whilst putting them in their best worlds may also lead to inequality because different individuals may have unequal best worlds (that is, some will have better prospects than others, so bringing everybody to their best-prospect world will result in inequality). If we just focus on neutralising counterfactual luck, rather than the badness of counterfactual luck, then we also find little basis for equality. ${ }^{20}$ If we eliminate the factors we are not responsible for, then we might both end up in a better position (the position we would have been in had it not been for our bad luck), but there is no reason why our positions will now be equal (assuming that we can even make the judgement about what we are responsible for when luck is stripped away from our lives). In fact, we could actually move from a position where we are initially equal, to one where we are unequal. $^{21}$ Thus, the luck neutraliser's dilemma arises because on the interpersonal reading of "luck," luck neutralisation can at best provide a trivial specification (not justification) of egalitarianism, whilst on the counterfactual reading, luck neutralisation will not support an egalitarian pattern of distribution. $^{22}$

In fact, Hurley takes this argument further, suggesting that there are a number of reasons why responsibility cannot play any pattern-specifying role at all in distributive justice (aside from the equality-default view discussed above). ${ }^{23}$ Firstly, this is because of the "boring problem" that "responsibility judgments are not primarily about interpersonal relations, relations between the goods positions of different people.” ${ }^{24}$ On an interpersonal understanding of luck, individuals are not wholly responsible for the relations between them. For 
instance, Ernest and Bertie may hold different amounts of goods. But even if each is responsible for his own holding of goods, neither is fully responsible for the inequality that now exists between them. Ernest bears no responsibility for Bertie's goods position, and as a result, he is not fully responsible for the precise difference between them. ${ }^{25}$ And the same conclusion holds for Eleanor and Kate, who have the same holdings as when they started. ${ }^{26}$ We cannot escape this problem by using a counterfactual notion of luck, either. Once again, the actual relations between the goods positions of Ernest and Bertie, and between Eleanor and Kate will at least partly be a matter of luck because nobody is responsible for the goods position of anybody else. And we cannot imagine a counterfactual distribution of goods that would change this situation. We cannot redistribute the goods in such a way that Ernest and Bertie are responsible for the relations between them, and Eleanor and Kate for the relations between them. ${ }^{27}$

More generally, the pattern of distribution that emerges from counterfactual luck neutralisation may be indeterminate. That is, "responsibility judgments may not extend in any determinate way to counterfactual situations.”28 If I am not responsible for my current share of goods then what counterfactual share would I be responsible for? How can we know what this would be? Inheritance is one of the few areas where we are able to make a precise determination. If we inherit money, then that seems clearly to be something we are not responsible for. ${ }^{29}$ But in most situations, we will be unable to make such judgements because the actual choices we make are closely bound up with the luck we are trying to neutralise. For instance, Sam's low income may be a matter of luck for him because it reflects his deprived upbringing. But if we wish to neutralise this luck, how can we determine a level 
of income that he can be considered responsible for? If his income were fivetimes greater than it currently is, would this remove the luck from the situation? How can we go about answering this question? If Sam's low income reflects his deprived childhood, determining his luck-neutral income means determining the kind of life he would have led, and the income he would have earned, if he had not had this deprived childhood. But we cannot be sure what kind of life he would have led in this counterfactual world. Just because Sam chose to surf instead of work in the real, luck-affected world is no reason to assume that he would have done so in the luck-neutral counterfactual world. Perhaps he would have become a high-income workaholic? Conversely, if he worked hard in the real world, but this produced little material success because of his deprived background, then we cannot simply assume he would have been a hard worker without this deprived background. He might have spent his time surfing instead. The problem is that our choices are affected by luck. As Hurley puts it, “[d]ifferent luck levels may feed into the formation of Sam's character and dispositions and hence affect the content of his responsible choices. Sam isn't responsible for his good or bad luck, but he can still be responsible for choices he makes, given that luck. This leads to the difficulty of understanding how we should redistribute in order to neutralize luck."30

However, the fact that choice and luck are inseparable is no reason to assume that responsible choice is impossible. Hurley rejects the idea of regressive responsibility, which holds "that responsibility for something requires responsibility for its causes." ${ }^{31}$ This requirement is so strict that it seems to make it impossible for individuals to be responsible for anything. ${ }^{32}$ Luck may always exercise some influence on the choices of rational agents, somewhere down the line, but this does not automatically lead to the abrogation 
of responsibility. Other things being equal, we can hold Sam responsible for his choices, even if they have been affected by luck at some point in the past. ${ }^{33}$ Nonetheless, this view of responsibility is open to challenge. A critic might argue that responsibility is regressive, and therefore impossible, and that this provides grounds for supporting an egalitarian distribution. I will examine Hurley's response to this possibility below.

A proponent of the luck-neutralisation view might respond to the indeterminacy problem by arguing for the equalisation of luck-derived goods. If individuals are not responsible for the goods they hold, then we should distribute them so that each person is equally well-off. But there is no reason why this distribution of goods will neutralise luck. The fact we are not responsible for our current holdings is no reason to think that we would become responsible for them if they were equally distributed amongst us. There may be other reasons to endorse an egalitarian pattern, but luck neutralisation is not one of them. ${ }^{34}$

Underlying the indeterminacy problem is the sense that we are trying to push the notion of responsibility too far. It is not suited to making counterfactual judgements:

We have a use for confirming someone's responsibility for what he does and for what he has. We also have a use for excusing people from responsibility. But when we excuse, we do not generally reinstate responsibility for some counterfactual state of affairs. Our judgments of responsibility often simply do not extend determinately this far. Efforts to wring more determinacy out of our concept of responsibility than it is designed for invite arbitrariness. ${ }^{35}$

Luck neutralisation is unsuited to playing a patterning role in distributive justice.

This conclusion holds even if we believe that luck is everywhere, or that 
responsibility is impossible. ${ }^{36}$ That is, if nobody is responsible for anything, then luck-neutralisation still provides no reason to adopt equality as a default position. To suggest otherwise is likely to expose you to the egalitarian fallacy. ${ }^{37}$ There is also a danger of indeterminacy. If individual choice always reflects the effects of luck, then how are we to know what we are responsible for? If we take this further and maintain that responsibility is impossible, then it is also impossible to come up with a distribution that is free of luck. As Hurley states, "[i]t is incoherent to hold both that responsibility is impossible and that equality would neutralize luck." ${ }^{38}$ Once again, luck neutralisation provides no basis for egalitarianism.

Hurley's analysis demonstrates that there is no straightforward link between responsibility and egalitarianism, and highlights why it is important to provide a broader account of the moral foundations of luck egalitarianism. However, the form of luck egalitarianism I outlined in the previous chapter is different from the luck-neutralisation view that forms the basis of Hurley's critique. It views luck as the currency of egalitarian justice, not as a filter that helps determine what this should be. Rather than neutralising luck, as such, the aim is to equalise its impact on the lives of all individuals. Luck egalitarians are not egalitarians because they care about choice and responsibility. Instead, choice and responsibility matter to them because they are egalitarians. Nonetheless, whilst this clarifies the link between responsibility and equality, a broader justification of the approach remains to be given. ${ }^{39}$ 


\section{IN SEARCH OF A JUSTIFICATION: RAWLS AND DWORKIN}

Samuel Scheffler explores related themes to Hurley and Lake in a recent critique of luck egalitarianism. He points out that luck egalitarians rarely attempt to provide a broader justification of their approach, and instead work on the assumption that equality is a valuable ideal, participating in an internal egalitarian debate over how this ideal is best understood. Rather than providing an independent defence of their position, they tend to write as if they are extending Rawls, developing a theory that is more faithful to the insights of his work than Rawls's own theory of justice as fairness. ${ }^{40}$

I explained the Rawlsian origins of luck egalitarianism in chapter 1, but it may help to briefly recap the main ways in which Rawls's work is considered to be an example of "(imperfectly developed) luck egalitarianism." ${ }^{41}$ Firstly, Rawls condemns the "system of natural liberty" (an alternative to justice as fairness that is more limited, securing equal liberty and formal equality of opportunity for citizens in an otherwise free market economy) on the grounds that it allows morally arbitrary factors such as natural talents and social position at birth to influence strongly the distribution of resources. ${ }^{42}$ Secondly, Rawls draws on the notion of responsibility to defend his use of primary goods. Against the criticism that those with expensive tastes will suffer a lower level of welfare than others, "Rawls argues that we have 'a capacity to assume responsibility for our ends,' and that 'citizens can regulate and revise their ends and preferences in the light of their expectations of primary goods." ${ }^{43}$ As Scheffler points out, "[t]his response has been cited as an early expression of the luck-egalitarian position that people must bear the cost of their own choices and that economic inequalities are therefore legitimate provided they arise from differences in the choices that people make."44 However, Rawls's theory of 
justice is inconsistent with these luck-egalitarian elements. Firstly, this is because it only guarantees individuals an equal share of primary social goods, which means that those with expensive medical needs, for which they may not be responsible, are likely to have a lower level of well-being than others. ${ }^{45}$ Secondly, the difference principle maximises the primary goods share of the worst-off social class when members of this class may actually be responsible for the fact they are worse off than others if, for instance, they have chosen to work shorter hours. ${ }^{46}$

Scheffler does not support this interpretation of Rawls's work and denies that justice as fairness depends on the circumstances-choices distinction or the endowment insensitive-ambition sensitive distinction, which is central to luck egalitarianism. Rather, Rawls's holds “a view that is substantively quite different from luck egalitarianism.” ${ }^{47}$ Despite remarks with a luck-egalitarian flavour, "it is quite clear from his discussion as a whole that the underlying motivation for Rawls's theory of justice is not the general elimination of the influence of brute luck on distribution." 48 Rather, he is focused on equality as a broader social and political ideal associated with free and equal citizenship. Rawls "gives some weight to the considerations singled out by the principle of redress," which holds that we should correct undeserved inequalities, but he explicitly differentiates his theory from this principle. ${ }^{49}$ The reason he is concerned with the impact of natural and social contingencies is, firstly, because they have no moral basis. Secondly, Rawls believes that our standing as equal citizens is morally fundamental and this is compromised by a distribution of resources that too closely matches the distribution of natural and social contingencies. In a system of natural liberty, these contingencies will significantly hamper citizens' ability to pursue rational plans of life. Thus, as 
Scheffler puts it, "Rawls's emphasis on the moral arbitrariness of people's natural attributes and social starting points is meant to undercut our tendency to treat those factors as morally authoritative, especially when doing so would compromise something morally fundamental." ${ }^{50}$ But he does not mean to shift luck-neutralisation to the centre of social justice.

Rawls's defence of primary goods does not lend support to luck egalitarianism, either. ${ }^{51}$ He holds individuals responsible for their ends "because it is reasonable to expect people to make do with their fair shares" and because most people have the capacity to moderate their plans to meet this requirement. ${ }^{52}$ Rawls is not using a notion of responsibility here that is based on a metaphysical distinction between choices and circumstances. Moreover, primary goods provide a practicable and public basis for interpersonal comparisons when adjudicating between individuals' claims in matters of social justice. This contrasts with the "intrusive and conceptually problematic judgments about the inner sources of people's disadvantages" that luck egalitarianism requires. $^{53}$

More generally, Rawls is interested in a broader notion of equality than luck egalitarians, who tend to focus on how best to interpret the ideal of distributive equality. ${ }^{54}$ Rawls is interested in equality as a social and political ideal. With strong echoes of Young, Wolff, and Anderson, Scheffler emphasises that equality is about the nature of social relationships, not patterns of distribution:

[A] plausible form of distributive egalitarianism can be anchored in a more general conception of equality as a social and political ideal. Rawls's theory shows how this can be done. For Rawls, people are conceived of as free and equal citizens, and the aim is to determine which principles of distributive justice are most appropriate for a modern 
democratic society whose members are so understood. In other words, the question is which principles of justice are most consistent, in modern conditions, with the freedom and equality of persons. Equality is understood as a social and political ideal that governs the relations in which people stand to one another. The core of the value of equality does not, according to this understanding, consist in the idea that there is something that must be distributed or allocated equally, and so the interpretation of the value does not consist primarily in seeking to ascertain what that something is. Instead, the core of the value is a normative conception of human relations, and the relevant question, when interpreting the value, is what social, political, and economic arrangements are compatible with that conception. $^{55}$

The problem is that luck egalitarians have not, for the most part, attempted to anchor their approach in such an ideal of equality, nor, more generally, explained the philosophical underpinnings of the theory. ${ }^{56}$

A major exception to this is Dworkin whose theory of equality of resources is rooted in a more general ideal of equality as equal treatment. ${ }^{57}$ The members of a political community have a collective obligation to treat people as equals which, for Dworkin, means treating people with equal concern. This obligation arises from the authority the political community collectively claims to exercise over its members. Thus, a government is only just and legitimate if it treats each citizen with equal concern. Otherwise, it is tyrannical.

However, there are a number of problems with this "statocentric view"58 or "administrative conception"59 of equality. For a start, the idea of equal treatment and respect does not necessarily lead to the theory of equality of resources. As Cohen says, "it seems quite unclear that a state which forthrightly refuses to pursue a norm of strict distributive equality ipso facto shows failure to treat its subjects with equal respect and concern." ${ }^{60}$ It is not clear, for instance, that a state treats its citizens with disrespect if it ensures all citizens 
have a guaranteed high minimum income, but otherwise adopts a laissez-faire approach to distribution. ${ }^{61}$ Secondly, distributive equality seems to have an appeal that is independent of political equality. Egalitarians do not simply care about distributive equality because the alternative is political tyranny. ${ }^{62}$ Finally, Dworkin believes that citizens are collectively responsible for distributive justice, and that this responsibility is exercised through the state. If the state is not behaving in a way that is consistent with egalitarianism then individual citizens have a duty to engage in political action to change the state's behaviour. ${ }^{63}$ But it is unclear why this responsibility holds given that individual citizens may not claim authority over others. ${ }^{64}$ Scheffler takes this further. He argues that the whole idea of equal treatment by the state is an "administrative conception" of equality where the focus is on government officials administering equality. This would be quite consistent with social hierarchy. The underlying problem is that Dworkin pays little attention to the nature of social relationships in an egalitarian community. His administrative conception of equality largely ignores social equality which, in fact, should be at the heart of any compelling theory of egalitarianism. ${ }^{65}$

However, as Dworkin himself points out in response to Scheffler's critique, there is no reason to think that the dimensions of equality are competitive. ${ }^{66}$ Rather, Dworkin believes that all political values are interrelated and interdependent and although no one value is dominant, they do "come together in an overall account of a society of equals." ${ }^{67}$ Amongst these values are political and social equality which, he emphasises, he does support. ${ }^{68} \mathrm{He}$ also concludes with a strong defence of the independent value of economic equality:

It is hardly enough to say (although many political philosophers apparently think it is 
enough) that society owes everyone care for their most basic needs, but not economic equality. It is not a question of discrete prior obligation, but of equal status. If everyone's basic needs were met, but some citizens still had an opportunity to make their lives much more exciting, productive, varied or interesting than others could, the question would remain whether laws that distribute resources with that consequence are justified. ${ }^{69}$

Thus, Dworkin believes that his theory of liberal equality is rooted in a broader idea of a society of equals, and that it gives an important place to social, political, and distributive equality.

However, this does not resolve the problems in Dworkin's approach. As Scheffler points out, the political values Sovereign Virtue examines are presented as arising from a general ideal of equality. This general ideal is that the state should treat people with equal concern. ${ }^{70}$ The point Scheffler makes is that this general ideal cannot adequately provide the basis for social or political equality, even though Dworkin himself may support these dimensions of egalitarianism. ${ }^{71}$

This problem is significant because Dworkin's approach remains one of the few attempts to develop a broader justification of luck egalitarianism. In attempting to justify distributive equality an excessive focus on the state does seem to imply a hierarchical form of egalitarianism that conflates distributive and political equality. But this does not mean that the notion of equal respect and concern, separated out from the "statotcentric" focus, is flawed. Instead of making the state the locus of agency we could make equal respect the duty of every person in a society of equals, so we are obliged to treat each other with equal respect and concern, in recognition of our equal moral worth. ${ }^{72} \mathrm{~A}$ vital component of this is adhering to the principles of egalitarian justice that are most consistent with this idea of equal worth. If we do not abide by these 
principles, we are not expressing equal respect and concern for all because we are demanding more than we are justly entitled to. Thus, principles of egalitarian justice should guide the behaviour of individuals as well as social institutions in a "society of equals."73

However, the state's organisational and coercive powers mean that it will have a crucial role to play in implementing these principles. To be true to the idea of equal respect for moral equals, we must ensure that the principles of justice obtain (at least to the extent permitted by non-egalitarian considerations), and the state is likely to have a crucial role in achieving the pattern of distribution that is consistent with these principles. Thus, although principles of egalitarian justice extend to the behaviour of individuals, we must not forget that they are also binding on the state.

In this section, I have partly addressed Scheffler's concerns, arguing that individuals should abide by principles of egalitarian justice in a "society of equals,” so proponents of a particular theory of egalitarian justice (such as luck egalitarianism) need not reject the notion of a "society of equals.” However, I have not firmly established that luck egalitarianism provides the relevant principles of justice. In order to do this, I must provide the broader justification of luck egalitarianism that Scheffler believes is necessary. I will take up this task in the next section.

\section{MORAL EQUALS}

Like many theories, luck egalitarianism begins from the assumption that all persons have an equal moral worth, which means that their lives have equal value. ${ }^{74}$ I argue this means that all persons have a claim to equally valuable lives. Thus, it is unfair or unjust if some have much better lives than others, 
purely as a result of luck, and luck egalitarianism arises from the desire to correct this unfairness or injustice, ensuring that the effects of luck are borne equally by moral equals. ${ }^{75}$ In this sense, it is what Derek Parfit would call a “Telic” notion of equality because equality has intrinsic value. ${ }^{76}$

However, Scheffler has criticised the attempt to root luck egalitarianism in notions of fairness and equal moral worth. ${ }^{77}$ For a start, the fact that rival theories of justice also claim to be anchored in the equal moral worth of all persons suggests the luck-egalitarian interpretation of this principle is contestable. He also doubts that luck egalitarianism is consistent with our intuitive understanding of fairness. Rather, he thinks that " $[\mathrm{t}]$ he more common or intuitive view... is that the fairness or unfairness of differences in advantage resulting from, on the one hand, factors beyond people's control and, on the other hand, people's voluntary choices, is highly dependent on the prevailing social context and institutional setting."78 For example, Scheffler doubts many people would think it unfair if one philosopher had a more successful career than another because of his "superior philosophical gifts.",79 Similarly, few would dispute the fairness of offering a more talented athlete a more lucrative contract. In contrast, people generally believe that doctors should treat patients who were injured as a result of foolish decisions. People should also enjoy guaranteed access to legal representation, even if they are unable to afford it because of poor decision-making. These examples are intended to shake our confidence in the intuitive plausibility of luck egalitarianism as an interpretation of the ideal of equal moral worth.

However, pace Scheffler, I think there are strong reasons to favour luck egalitarianism if we start from the idea of equal moral worth. If we truly believe that we are moral equals then we must also accept that our lives are equally 
valuable, and that we should all have the same access to advantage. If there is significant inequality in the quality of life that individuals enjoy, purely as a result of luck, then it is very difficult to say to the worse-off that we truly regard them as moral equals. But although this shows that luck egalitarianism is a justifiable interpretation of the idea of equal moral worth, it does not in itself prove that luck egalitarianism is superior to every rival interpretation of this idea. To demonstrate this would require a large-scale comparative study that is beyond the scope of this project. Nonetheless, I will look at three prominent alternatives to luck egalitarianism in chapter 6. For now, it is enough to conclude that the theory does have a plausible grounding in the notion of equal moral worth.

Scheffler's examples are not decisive against luck egalitarianism, either. I think there is something unfair in the case of the two philosophers, if we make the reasonable assumption that both individuals wish (to the same extent) to enjoy successful careers, and regard this preference as one of their most important. It might be inevitable that the more naturally talented philosopher enjoys more success, but other things being equal, this does not mean that it is fair. In fact, it is unfair because only one person can accomplish the goal they place a high value on achieving. Similarly, it might be inevitable that the more naturally talented athlete is paid more than a less talented athlete in a capitalist society, but is this really fair? For luck egalitarians, our lives are equally important, so it is unfair if luck leaves us unequally well-off. This response may be counter-intuitive, but it does have strong moral foundations and, in this instance, I think we should revise our intuitions to accord with luck egalitarianism.

Scheffler's second set of examples are not decisive against luck 
egalitarianism, either. They are essentially forms of the harsh treatment criticism that I contested in chapter 2 and the same responses apply once again. Firstly, few individuals will actually be deemed fully responsible for the injuries they suffer, or the poverty they endure, even if they result from voluntary participation in risky activities. Secondly, in the rare instances where luck egalitarianism does not provide adequate support, I agree that most people would support providing assistance, but not on the grounds of egalitarian justice. In the medical example, our intuitive response is likely to be motivated by feelings of benevolence rather than egalitarianism. In the legal example, on the other hand, we are motivated by a concern with procedural fairness. These examples do not succeed in undermining the intuitive appeal of luck egalitarianism. ${ }^{80}$

Scheffler also emphasises "that equality is most compelling when it is understood as a social and political ideal that includes but goes beyond the proposition that all people have equal moral worth. It is this ideal that we invoke when we say that our society should be organized as a society of equals." ${ }^{81}$ He says that "our notion of a society of equals expresses a normative ideal of human relations. Luck egalitarians must either reject this ideal or argue that it too supports their distributive principles." 82 I endorsed the notion of a society of equals in section 2, and claimed that principles of justice should guide individual behaviour in such a society. In a society of equals, we must treat each other with equal respect and concern, and this means acting in a way that is consistent with principles of justice. If, as I have argued in this section, luck egalitarianism arises from the claim that all persons have equal moral worth, then individuals in a society of equals are obliged to do what they can to ensure that all persons enjoy equal access to a good life, and that the effects of 
luck are equally distributed throughout the population. If individuals are the victims or beneficiaries of avoidable injustice, then we cannot seriously claim that all members of society are in “a relationship of equals.”83

However, whilst individuals in a society of equals should adhere to luck-egalitarian principles, the moral grounding of luck egalitarianism is independent of this social ideal. Luck egalitarianism arises directly from the idea that all persons have equal moral worth, and thus it retains its moral force, regardless of whether we are living in a society of equals. This is important because implementing the requirements of egalitarian justice in non-ideal circumstances may damage our chances of fostering egalitarian social relationships. As I emphasised above, egalitarians cannot afford to ignore the state. Whilst recent work on egalitarianism has made an important contribution by cautioning against a preoccupation with social institutions rather than individual relationships and behaviour, egalitarians must be careful to avoid paying insufficient attention to the state. In reality, meeting the demands of egalitarian justice will require extensive redistribution by the state because it is usually the only body with the coercive and organisational capacity to achieve widespread egalitarian reform. The state's coercive power is important because in reality, there is unlikely to be unanimous support for egalitarian justice throughout the community. Implementing egalitarian justice will require extensive taxation to fund social provision and redistribute wealth, which means that the state will end up taking resources away from individuals who may not support egalitarianism (and who in some cases will be fiercely antiegalitarian). Egalitarians must be able to provide a justification of this coercive activity.

The justification emerges naturally from the claim that is unjust or 
unfair for the effects of luck to be borne unequally. From the point of view of egalitarian justice, equally distributing luck is so important that coercive taxation is justified. Individuals who oppose this taxation are behaving unjustly, so it is legitimate to force them to pay tax. Considerations of justice provide no reason for egalitarians to respect the demands of anti-egalitarians (although notions of political equality may).

However, this coercion sits uncomfortably with the notion of a "society of equals” that Scheffler and other proponents of social equality endorse. People are forced to adhere to the luck-egalitarian interpretation of equality whether or not they support it. ${ }^{84}$ Opponents of luck egalitarianism (even those who are explicitly anti-egalitarian) must pay tax on their income and wealth as part of a luck-egalitarian redistributive scheme to help alleviate the unfairness of the differential impact of luck, but this does not establish a relationship of equality between the persons involved, in the sense in which Scheffler and other proponents of social equality understand that ideal. Opponents of luck egalitarianism are likely to resent the redistribution that has occurred and the fact that their wishes have been ignored. Although the government acts in the name of egalitarian justice, the individuals concerned are likely to deny that they have been treated with equal respect, and will feel that their public standing has been lowered. This is a particular problem for Scheffler because he seeks to ground distributive principles in a broader notion of social and political equality as a "normative ideal of human relations." In a society where an egalitarian ethos is universally accepted, citizens will tend to support whatever distribution is required to bring about the appropriate egalitarian pattern of distribution. But when egalitarian justice is not universally supported, attempts by an egalitarian government to achieve distributive equality through a coercive 
system of taxation that extends to anti-egalitarians, may conflict with the very "normative ideal of social relations" that gives rise to distributive equality in the first place. In this case, the dimensions of equality may be in competition with each other. ${ }^{85}$

In order to achieve egalitarian justice, on any reasonable interpretation, we will have to force some people to pay tax. But if we only care about egalitarian justice and the distribution of wealth because of a broader concern with egalitarian social relations, we may be unable to justify the coercion involved. If we believe that egalitarians should support coercion in these circumstances, this does not mean that we should abandon the ideal of living in a "society of equals" characterised by the widespread acceptance of an egalitarian ethos. Rather, it simply means that principles of egalitarian justice have intrinsic value, independent of their connection to egalitarian social relationships. Whilst my account of egalitarianism is consistent with this idea, Scheffler's is not. On my account, luck egalitarianism is justified because all persons have equal moral worth, which means they should have equal access to a good life. This has implications for individual behaviour and social relationships, not just the state, but this concern with egalitarian social relationships is informed by luck egalitarianism. The justification of luck egalitarianism does not depend on its contribution to achieving egalitarian social relations and thus, coercive taxation to achieve a just distribution of resources is justified, even in the face of anti-egalitarian opposition. ${ }^{86}$

The preceding discussion may have left the reader with a sense of unease. I have justified state coercion in the name of equality, but I have not set limits to the kind of coercion required, which opens the door to state tyranny in the name of equality. Doesn't the ideal of equality itself demand that we 
introduce such limits? In response to this point, it is necessary to emphasise once again that I am concerned here with egalitarian justice, not other values such as individual liberty and individual rights, which will place limits on the state.

\section{CONCLUSION}

In this chapter I have attempted to situate luck egalitarianism within a broader account of egalitarianism, and to explain why we should care about the theory in the first place. I began by drawing on Hurley's work in order to explain why the desire to neutralise luck cannot provide the basis for egalitarianism, and to help clarify the role responsibility plays in my own theory. In the second section, I showed why the work of Rawls and Dworkin cannot provide us with the justification we require. However, I emphasised that Dworkin's notion of equal treatment and respect could apply to individuals as well as to the state, and that principles of justice have a key role to play in any "society of equals." In section 3, I argued that luck egalitarianism arises from the idea that all persons have equal moral worth, and refuted Scheffler's criticisms of this argument. If all persons have equal worth, then we should all have equal access to an equally good life, and this leads to the idea of luck egalitarianism. I concluded by emphasising that whilst egalitarians should be sensitive to the egalitarian obligations of individuals, they must also be able to justify coercive activity by the state to achieve a more egalitarian pattern of distribution. This requires principles of egalitarian justice that are independent of the ideal of a society of equals. Having explained the deeper moral foundations of luck egalitarianism, the next chapter seeks to determine the appropriate conception of advantage for luck egalitarians to use. 


\section{NOTES}

${ }^{1}$ S. Scheffler, “What is Egalitarianism?” Philosophy \& Public Affairs, V. 31, no. 1, 2003, pp. 539, especially pp. 7, 13-17, 30-31.

2 S.L. Hurley, Justice, Luck, and Knowledge, Cambridge, Mass., Harvard University Press, 2003, Chapter 6, pp. 146-80; Lake, Equality and Responsibility, Oxford, Oxford University Press, 2001.

${ }^{3}$ Lake, Equality and Responsibility, pp. 87-89, 97-98, 105.

${ }^{4}$ Hurley, Justice, Luck, and Knowledge, chapter 6, pp. 146-80, quotation at p. 147.

${ }^{5}$ Hurley, Justice, Luck, and Knowledge, p. 106. According to this usage, option luck, at least as brute luck egalitarians understand it, is not really luck because the individuals involved are responsible for it. See p. 146 n. 1.

${ }^{6}$ Hurley Justice, Luck, and Knowledge, p. 147. Hurley also places "a minimal independent constraint on what could count as egalitarianism." She says that "[t]o count as egalitarian, a doctrine must, for some $X$, favor relatively more equal patterns of distribution of $X$ over relatively less equal patterns of $X$, other things equal. It must, that is, count relative equality in the pattern of distribution in some dimension as pro tanto a good thing, even if it can be outweighed by other values. This assumption provides a patterning constraint: a constraint on how egalitarianism distributes whatever it distributes, rather than on what it distributes."

${ }^{7}$ Hurley, paraphrasing G.A. Cohen, in Justice, Luck, and Knowledge, p. 149, original emphasis.

${ }^{8}$ Hurley, Justice, Luck, and Knowledge, pp. 149-50.

${ }^{9}$ Hurley, Justice, Luck, and Knowledge, p. 150, original emphasis.

${ }^{10}$ Hurley, Justice, Luck, and Knowledge, p. 151.

${ }^{11}$ Hurley, Justice, Luck, and Knowledge, pp. 151-2.

${ }^{12}$ Hurley, Justice, Luck, and Knowledge, p. 152. For our purposes, we can ignore the numbers preceding these quotations.

${ }^{13}$ Hurley, Justice, Luck, and Knowledge, p. 153.

${ }^{14}$ Hurley, Justice, Luck, and Knowledge, p. 154.

${ }^{15}$ Hurley, Justice, Luck, and Knowledge, pp. 154-5.

${ }^{16}$ Hurley, Justice, Luck, and Knowledge, pp. 155-59. 
${ }^{17}$ Hurley, Justice, Luck, and Knowledge, p. 156.

${ }^{18}$ Hurley, Justice, Luck, and Knowledge, pp. 156-7.

${ }^{19}$ Hurley, Justice, Luck, and Knowledge, pp. 157.

${ }^{20}$ Hurley, Justice, Luck, and Knowledge, pp. 157-58.

${ }^{21}$ Hurley Justice, Luck, and Knowledge, pp. 157-58.

${ }^{22}$ See Justice, Luck, and Knowledge, pp. 158-9. To put the second half of this last sentence more precisely, there is no necessary connection between neutralising counterfactual luck and egalitarianism because an equal distribution could arise simply by chance. That is, there might still be situations when neutralising luck does lead to equality. The point is just that counterfactual luck-neutralisation, as a rule, provides no general support for egalitarianism. Moreover, as we shall soon see, Hurley actually argues that the patterning implications of counterfactual luck-neutralisation may simply be indeterminate.

${ }^{23}$ Hurley, Justice, Luck, and Knowledge, p. 159.

${ }^{24}$ Hurley, Justice, Luck, and Knowledge, p. 159, italics removed from quotations. See also Lake, Equality and Responsibility, chapter 5, pp. 83-105.

${ }^{25}$ Hurley, Justice, Luck, and Knowledge, pp. 160-1.

${ }^{26}$ Hurley, Justice, Luck, and Knowledge, p. 161.

${ }^{27}$ Hurley, Justice, Luck, and Knowledge, pp. 161-2.

${ }^{28}$ Hurley, Justice, Luck, and Knowledge, p. 159, italics removed from quotation. Hurley expands on this point, pp. 162-68. The following paragraph draws on this discussion.

${ }^{29}$ Cf. Rakowski, Equal Justice, New York, Oxford University Press, 1991, pp. 158-162. Rakowski suggests that gifts and bequests tend to reflect a mix of option luck and brute luck. Option luck plays a role because we receive gifts and bequests from friends and partners, and "[s]taunch friendships and marriage are voluntary associations that ordinarily require patience, affection, and self-renunciation if they are to endure. When they flourish, the credit rarely belongs to Providence, and therefore the right that others might have to part of the assistance that friends lend one another, financial or otherwise, is often attenuated.” Quotation at pp. 16061.

${ }^{30}$ Hurley, Justice, Luck, and Knowledge, p. 165. The discussion of Sam is drawn from pp. 16466. 
${ }^{31}$ Hurley, Justice, Luck, and Knowledge, p. 171.

${ }^{32}$ Hurley, Justice, Luck, and Knowledge, p. 171. For a full discussion, see Part I of Hurley’s book, especially pp. 89-90.

${ }^{33}$ Hurley, Justice, Luck, and Knowledge, pp. 165-66.

${ }^{34}$ Hurley, Justice, Luck, and Knowledge, pp. 166-67.

${ }^{35}$ Hurley, Justice, Luck, and Knowledge, p. 167.

${ }^{36}$ See Hurley, Justice, Luck, and Knowledge, pp. 174-75.

${ }^{37}$ Hurley, Justice, Luck, and Knowledge, p. 175. See the definition of the egalitarian fallacy on p. 113 above.

${ }^{38}$ Hurley, Justice, Luck, and Knowledge, p. 175.

${ }^{39}$ Hurley does emphasise in her discussion that she has not provided any reason to reject egalitarianism: "I have not argued against egalitarianism, or against the view that equality should be taken as a default position when people are not responsible for what they have. Rather, I have argued that considerations of responsibility and luck do not provide a basis for these views. But there may well be some other basis for them." See Justice, Luck, and Knowledge, p. 180. In a response to Hurley's article, Arneson denies that prominent egalitarians such as Rawls, Dworkin, Cohen, and Roemer rely on the egalitarian fallacy. See "Luck and Equality,” Proceedings of the Aristotelian Society, supp. Vol. 75, pp. 73-90, at pp. 77-78.

${ }^{40}$ Scheffler, “What is Egalitarianism?” especially pp. 7, 13-17, 30-31.

${ }^{41}$ Scheffler, “What is Egalitarianism?” pp. 9-10, quotation at p. 9.

${ }^{42}$ Scheffler, "What is Egalitarianism?” p. 9

${ }^{43}$ Rawls, cited in Scheffler, "What is Egalitarianism?” p. 10.

${ }^{44}$ Scheffler, “What is Egalitarianism?” p. 10.

${ }^{45}$ Scheffler, "What is Egalitarianism?” pp. 10-11. A related criticism is that Rawls fails to give extra resources to those who have involuntary expensive tastes. See chapter 1 , section 1 for more discussion. I return to this issue in chapter 5.

${ }^{46}$ Scheffler, “What is Egalitarianism?” p. 11.

${ }^{47}$ See Scheffler, “What is Egalitarianism?” pp. 11-12, quotation at p. 11.

${ }^{48}$ Scheffler, "What is Egalitarianism?” pp. 24-5, quotation at p. 25.

${ }^{49}$ Rawls, quoted in Scheffler, “What is Egalitarianism?” p. 25. 
${ }^{50}$ Scheffler, “What is Egalitarianism?” pp. 25-26, quotation at p. 26.

${ }^{51}$ See Scheffler, "What is Egalitarianism?” pp. 26-28.

${ }^{52}$ Scheffler, “What is Egalitarianism?” pp. 27-28.

${ }^{53}$ Scheffler, “What is Egalitarianism?” p. 28.

${ }^{54}$ Scheffler, “What is Egalitarianism?” especially pp. 21-24, 31.

${ }^{55}$ Scheffler, “What is Egalitarianism?” p. 31.

${ }^{56}$ Scheffler, “What is Egalitarianism,” p. 31.

${ }^{57}$ Scheffler, "What is Egalitarianism?” p. 34; Dworkin, Sovereign Virtue, Cambridge, Mass., Harvard University Press, 2000, pp. 1-3. My interpretation of Dworkin's argument has also been influenced by G.A. Cohen, If You're an Egalitarian, How Come You're So Rich? Cambridge, Mass., Harvard University Press, 2000, pp. 164-66.

${ }^{58}$ Cohen, If You're an Egalitarian, How Come You're So Rich? p. 165.

${ }^{59}$ Scheffler, “What is Egalitarianism?” p. 37.

${ }^{60}$ Cohen, If You're an Egalitarian, How Come You're So Rich? p. 165. Scheffler also uses this quotation in "What is Egalitarianism," p. 34.

${ }^{61}$ Cohen, If You're an Egalitarian, How Come You're So Rich? p. 165.

${ }^{62}$ Cohen, If You're an Egalitarian, How Come You're So Rich? pp. 165-6.

${ }^{63}$ Cohen, If You're an Egalitarian, How Come You're So Rich? p. 164.

${ }^{64}$ Cohen, If You're an Egalitarian, How Come You're So Rich? p. 166.

${ }^{65}$ Scheffler, “What is Egalitarianism?” especially pp. 35-38.

${ }^{66}$ Dworkin, “Equality, Luck and Hierarchy,” Philosophy \& Public Affairs, V. 31, no. 2, pp. 190-98, at pp. 190, 195.

${ }^{67}$ Dworkin, “Equality, Luck and Hierarchy,” p. 197.

${ }^{68}$ Dworkin, “Equality, Luck and Hierarchy,” pp. 195-97.

${ }^{69}$ Dworkin, “Equality, Luck and Hierarchy,” p. 198.

${ }^{70}$ S. Scheffler, "Equality as the Virtue of Sovereigns: A Reply to Ronald Dworkin,” Philosophy \& Public Affairs, V. 31, no. 2, 2003, pp. 199-206, at p. 204.

${ }^{71}$ Scheffler, “Equality as the Virtue of Sovereigns: A Reply to Ronald Dworkin,” p. 206.

${ }^{72}$ Thus, as Cohen argues, principles of justice apply to individual behaviour within the basic structure of society, not just to social institutions. See, for example, If You're an Egalitarian, 
How Come You're So Rich? especially chapters 8-10, pp. 117-79.

${ }^{73}$ For a similar line of argument, see W. Kymlicka, "Left-Liberalism Revisited," in C. Sypnowich (ed.), The Egalitarian Conscience: Essays in Honour of G.A. Cohen, Oxford: Oxford University Press, 2006, pp. 9-35, especially at pp. 21-22.

${ }^{74}$ Scheffler “What is Egalitarianism?” p. 32. See also A. Sen, Inequality Reexamined, Oxford, Clarendon Press, 1992, pp. 12-16; W. Kymlicka, Contemporary Political Philosophy: An Introduction, Oxford, Oxford University Press, 2002, pp. 3-5.

${ }^{75}$ Temkin gives a similar formulation of the egalitarian ideal. He argues "that it is bad-- unjust and unfair-- for some to be worse off than others through no fault of their own.” See L.S. Temkin, Inequality, New York, Oxford University Press, 1993, e.g. p. 13.

${ }^{76}$ D. Parfit, “Equality or Priority?” in M. Clayton \& A. Williams (eds.), The Ideal of Equality, Houndmills, Palgrave Macmillan, 2002.

${ }^{77}$ Scheffler, “What is Egalitarianism?” pp. 31-4.

${ }^{78}$ Scheffler, “What is Egalitarianism?” pp. 32-3.

${ }^{79}$ Scheffler, “What is Egalitarianism?” p. 33.

${ }^{80}$ Scheffler also criticises the metaphysical foundations of luck egalitarianism, particularly the way it understands the notions of responsibility and choice. I will not examine his arguments here because I examined the luck-egalitarian approach to responsibility and choice in chapter 3 . I do not believe anything that Scheffler says here directly challenges my arguments in these chapters. See Scheffler, “What is Egalitarianism?” pp. 17-21.

${ }^{81}$ Scheffler, "What is Egalitarianism?” p. 33.

${ }^{82}$ Scheffler, "What is Egalitarianism?” p. 34.

${ }^{83}$ The quotation is from Scheffler, “What is Egalitarianism?” p. 33. I should note here that we may wish to revise this conclusion if some other feature of a "society of equals" requires that we ignore instances of injustice. An example might be providing welfare payments unconditionally because it is demeaning and disrespectful to assume that welfare recipients, who are our moral equals, are trying to cheat the system. See J. Wolff, "Fairness, Respect, and the Egalitarian Ethos.” I will discuss Wolff's argument further in chapter 7.

${ }^{84}$ They are "forced" at least to the extent that their income or wealth is at a sufficient level to be taxed, and to the extent that the state can legally enforce this obligation. Of course, in practice, 
many very wealthy individuals seem able to avoid the coercive powers of the state, at least in terms of taxation.

${ }^{85}$ A critic might object here that the distributive implications of equality still hold, even if we are unable to achieve the kind of broader egalitarian social relations that we require. I support this line of thinking, as is evident in the next paragraph, but it is unavailable to us if, like Scheffler, we believe that the distributive dimension of equality is only desirable insofar as it helps promote these social relations of equality. If such relations do not hold, then forcing antiegalitarians to pay tax in the name of equality is likely to work against this goal by fostering anti-egalitarian feelings.

${ }^{86}$ Nonetheless, egalitarians may decide to hold back on this taxation for pragmatic reasons. They may decide that a widespread egalitarian ethos is more likely to emerge in the long-term if they avoid coercive taxation, and that the egalitarian benefits of such a widespread ethos outweigh the benefits of implementing a system of coercive taxation now. 


\section{CHAPTER 5}

\section{EGALITARIAN ADVANTAGE}

In chapter 3, I outlined a theory of luck egalitarianism that focuses on the extent to which an individual has genuinely chosen the level of advantage she enjoys. In this chapter I will outline the appropriate conception of "advantage" to use in this theory of luck egalitarianism.

The literature is dominated by two competing conceptions of egalitarian advantage. Egalitarians such as Arneson focus on the level of welfare that individuals enjoy, whilst others, such as Rawls and Dworkin are interested in their share of resources. In recent years, Amartya Sen has developed an alternative approach which focuses on capabilities, whilst Cohen has developed a heterogeneous notion of advantage which includes welfare, resources, capabilities and something he calls "midfare."

This chapter will examine each of these approaches and conclude that Cohen's heterogeneous conception best captures the aspects of human wellbeing that are of most concern to egalitarians. However, Cohen's account of advantage is, by his own admission, undeveloped. I attempt to outline a more precise account of advantage than Cohen's, building on his proposal that egalitarians adopt a lexical ordering of the different components of advantage. I conclude by extending this account so that it is sensitive to the objective advantage associated with egalitarian social relations, and the objective disadvantage associated with the kind of social oppression we examined in chapter 2 . 


\section{RESOURCES}

When dealing with questions of justice, Rawls argues that the relevant conception of advantage is "expectations of primary social goods.” ${ }^{1}$ Primary social goods are defined as "things which it is supposed a rational man wants whatever else he wants." ${ }^{2}$ Expectations of these goods are understood in terms of "the index of these goods which a representative individual can look forward to.” ${ }^{3}$ The main categories of “primary social goods... are rights and liberties, opportunities and powers, income and wealth" and "the bases of self-respect."4 When determining principles of justice, we do not take into account natural goods such as health because "although their possession is influenced by the basic structure, they are not so directly under its control." ${ }^{5}$ However, Rawls's position on this issue has been strongly attacked, as we shall see below.

In his later work, Rawls revised his theory of justice as fairness, emphasising that it is a political conception of justice, built around a particular conception of the person. ${ }^{6}$ Justice as fairness begins from the assumption "that citizens are free and equal moral persons who can contribute to, and honor the constraints of, social cooperation for the mutual benefit of all."7 More specifically:

Justice as fairness regards each person as someone who can and who desires to take part in social cooperation for mutual advantage. Thus in formulating a conception of justice for the basic structure of society, we start by viewing each person as a moral person moved by two highest-order interests, namely, the interests to realize and to exercize the two powers of moral personality. These two powers are the capacity for a sense of right and justice (the capacity to honor fair terms of cooperation), and the capacity to decide upon, to revise, and rationally to pursue a conception of the good. Moral persons also have a higher-order (as opposed to a highest-order) interest in advancing their determinate conceptions of the good (defined by certain specific final 
ends and aspirations) that they have at any given time. In sum, then, this conception of the person gives regulative primacy to the two highest-order interests, so that moral persons are said to have both the capacity and the desire to cooperate on fair terms with others for reciprocal advantage; and this implies a regulative desire to conform the pursuit of one's good, as well as the demands one makes on others, to public principles of justice which all can reasonably be expected to accept. ${ }^{8}$

This conception of the person is fundamental to the revised Rawlsian approach to justice, and explains important aspects of his account of primary goods.

For a start, this conception helps explain why parties in the original position would choose primary goods as the basis for evaluating principles of justice. $^{9}$ Firstly, we need the basic liberties in order to choose, revise, and pursue the good, and to "allow for the development and exercise of the sense of right and justice under political and social conditions that are free.” ${ }^{10}$ Secondly, “[f]reedom of movement and free choice of occupation against a background of diverse opportunities are required for the pursuit of final ends as well as to give effect to a decision to revise and change them, if one so desires." Thirdly, “[p]owers and prerogatives of offices of responsibility are needed to give scope to various self-governing and social capacities of the self.” Fourthly, income and wealth can be used to achieve many ends. Fifthly, "[t]he social bases of self-respect are those aspects of basic institutions that are normally essential if citizens are to have a lively sense of their own worth as moral persons and to be able to realize their highest-order interests and advance their ends with selfconfidence." The highest-order interests are also used to help rank these primary social goods in order of importance. ${ }^{11}$ This demonstrates the close connection between the Rawlsian conception of the person, and his support for the use of primary goods.

Another major advantage of primary goods is their "practical nature," 
which, as Rawls explains, "mean[s] that we can actually provide a scheme of basic equal liberties which, when made part of the political constitution and instituted in the basic structure of society (as the first subject of justice), ensures for all citizens the development and exercise of their highest-order interests, provided that certain all-purpose means are fairly assured for everyone.” ${ }^{12}$ This is because the conception of the person combined with "a knowledge of the general circumstances and requirements of social life,"13 particularly "the normal structure of rational plans of life" ${ }^{14}$ leads to the conclusion that justice as fairness can accommodate "a sufficiently wide range of ends... to secure ways of life fully worthy of human endeavor". 15 Thus, despite the fact people have "conflicting and incommensurable conceptions of the good"16 primary goods are a suitable basis for conducting interpersonal comparisons within the Rawlsian framework of justice.

An index of primary goods "seems the most feasible way to establish a publicly recognized objective measure, that is, a common measure that reasonable persons can accept” for the purposes of interpersonal comparison. ${ }^{17}$ They are objective because they are, in effect, the needs of citizens, where citizens are understood in accordance with the Rawlsian conception of the person. ${ }^{18}$ Thus, working from the liberal assumption that individuals have different and competing conceptions of the good life, Rawls manages to come up with an objective basis for interpersonal comparisons.

However, despite its initial appeal, there is a major problem with using primary goods as the basis for interpersonal comparisons of advantage. It ignores differences in the ability of individuals to convert primary goods into welfare. Many criticisms of primary goods have drawn on this objection, which is most famously associated with the work of Kenneth Arrow and Amartya 
Sen. ${ }^{19}$ For example, people with special health and medical requirements are likely to need a higher-than-average income to achieve an average quality of life. More generally, people’s needs vary greatly depending on factors such as "health, longevity, climatic conditions, location, work conditions, temperament, and even body size (affecting food and clothing requirements)." ${ }^{20}$ Rawls's approach is open to the charge of "fetishism" because it understands advantage in terms of primary goods, rather than focusing on the "relationship between persons and goods.” 21 “In fact, “[j]udging advantage purely in terms of primary goods leads to a partially blind morality.”22

Rawls's response to this line of criticism does not rescue the primary goods approach. He assumes "that while citizens do not have equal capacities, they do have, at least to the essential minimum degree, the moral, intellectual, and physical capacities that enable them to be fully cooperating members of society over a complete life.”23 This does not just apply to ill health, but to other variations in the capacities of individuals. If people are unable to be "fully cooperating members of society” we should aim to provide them with the assistance they need to reach this level. ${ }^{24}$ Rawls leaves the details to be worked out "at the legislative stage when the prevalence and kinds of these misfortunes are known and the costs of treating them can be ascertained and balanced along with total government expenditure.”25

However, primary goods cannot adequately capture all the disadvantages faced by individuals who lack the basic capacities needed for social cooperation. Rawls recognises this, explicitly stating that the use of primary goods operates alongside the capabilities approach: "it should be stressed that the account of primary goods does take into account, and does not abstract from, basic capabilities: namely, the capabilities of citizens as free and 
equal persons in virtue of their two moral powers. It is these powers that enable them to be normal and fully cooperating members of society over a complete life and to maintain their status as free and equal citizens.”26 Rawls adds that "the framework of justice as fairness as a whole... does recognize the fundamental relation between primary goods and persons’ basic capabilities. In fact, the index of those goods is drawn up by asking what things, given the basic capabilities included in the (normative) conception of citizens as free and equal, are required by citizens to maintain their status as free and equal and to be normal, fully cooperating members of society.” ${ }^{27}$ Thus, Rawls recognises that primary goods must be supplemented by the capabilities approach if they are to handle satisfactorily complex situations where interpersonal comparisons are required. $^{28}$

This approach is also flawed because it is insensitive to disadvantages which reduce individuals’ quality of life, without preventing them from being fully cooperating members of society. For example, someone with a painful medical condition suffers a major disadvantage in her level of welfare, but it does not necessarily prevent her from engaging in social cooperation. ${ }^{29}$ If egalitarians wish to take this into account, it will be necessary for them to adopt a more complex understanding of advantage than the primary goods approach. This might involve shifting to a welfarist approach or to a broader capabilities approach that extends beyond the capabilities required for achieving a basic level of social cooperation. I will examine both these approaches in the next three sections, but before we move on, it is worth briefly noting why Rawls is opposed to a welfarist conception of advantage.

Rawls has two key arguments against welfarism. The first is the “offensive tastes criticism” which arises because some people have perverse 
preferences that we regard as offensive. ${ }^{30}$ These people enjoy a higher level of welfare if such preferences are satisfied, which means that welfarism may produce counter-intuitive results. For example, "if men take a certain pleasure in discriminating against one another, in subjecting others to a lesser liberty as a means of enhancing their self-respect, then the satisfaction of these desires must be weighed in our deliberations according to their intensity, or whatever, along with other desires." ${ }^{31}$ Welfarists are usually interested in increasing, or equalising (or distributing in some other way) the level of welfare people enjoy, which means that they will support doing what is required to satisfy these offensive tastes or, if the tastes are not fulfilled, provide compensation to individuals who have these tastes.

Rawls's second major argument is the expensive tastes objection. This objection arises because some individuals have preferences which are more expensive to satisfy than others' are. For instance, other things being equal, two people with an equal income are likely to have an unequal level of welfare if "one [is] satisfied with a diet of milk, bread, and beans, while the other is distraught without expensive wines and exotic dishes." ${ }^{32}$ An account of justice which understands advantage in terms of primary goods will not offer extra resources to those with more expensive tastes (unless of course the preferences in question prevent us from being able "to cooperate normally in society" and require psychiatric treatment). ${ }^{33} \mathrm{~A}$ welfarist approach, in contrast, views this as a disadvantage. ${ }^{34}$ For Rawls, this is a reason to reject the welfarist conception of advantage, and to focus on primary goods. He says that "[t]he use of primary goods... relies on a capacity to assume responsibility for our ends." 35 This relates to the social division of responsibility, which is based, in part, on the idea that "society... accepts the responsibility for maintaining the equal basic 
liberties and fair equality of opportunity, and for providing a fair share of the other primary goods for everyone within this framework, while citizens (as individuals) and associations accept the responsibility for revising and adjusting their ends and aspirations in view of the all-purpose means they can expect, given their present and foreseeable situation.”36 The conception of the person underlying justice as fairness assumes that citizens are responsible for their ends, which means that having unfulfilled expensive tastes does not count as a disadvantage.

I will return to both the offensive and expensive tastes objections below in my discussion of Dworkin's more detailed critique of welfarism. Nonetheless, it is worth noting a possible inconsistency in Rawls's position. Despite his anti-welfarist comments, he is open to the possibility of including “certain mental states such as freedom from physical pain” in our account of primary goods. ${ }^{37}$ But it is unclear what basis he could have for distinguishing between mental states that should be included, and those that should not. Presumably, the key test for Rawls is whether a particular mental state prevents us from being "fully cooperating members of society," but as I argued above, disadvantages such as pain may not fall into this category. If the "equal cooperation” test is unsatisfactory, then Rawls must provide some other basis for distinguishing between mental states, or, alternatively, adopt a more expansive welfarist conception of advantage.

In sum, the primary goods approach cannot account for the various aspects of advantage which concern egalitarians. It is only satisfactory when we are making judgements in the original position, operating in artificial conditions, which abstract from some of the most important disadvantages that a theory of justice can confront. Once we lift the "equal cooperation" 
assumption, we must expand our concept of primary goods, or perhaps introduce a notion of capabilities/welfare to run alongside it, as Rawls himself recognises. But once we introduce capabilities and subjective welfarist considerations into an account of primary goods, there seems little to recommend the primary goods approach at all. Why not simply focus on advantage in terms of welfare or capabilities instead? I will focus on these conceptions of advantage in sections 2-4. But before we conclude, it is worth considering whether Dworkin's alternative approach can rescue the resourcist conception of advantage.

Dworkin agrees with Rawls that resources should be the currency of egalitarian justice, but rather than focusing on the primary goods individuals hold, he believes that egalitarians should be interested in people's shares of the total resources of the community, as determined through the auction and insurance devices outlined in chapter $1 .^{38}$ Dworkin adopts a very broad notion of "resources" that extends beyond material possessions to include, for instance, our natural endowment of talents and handicaps (our natural capacities). This means that his approach is more sensitive to the physiological diversity of different human beings than Rawls’s primary goods account. ${ }^{39}$

But Dworkin's resourcist approach is flawed because egalitarians are interested in aspects of human well-being that extend beyond what can sensibly be described as a "resource.” Once again, pain is perhaps the best illustration of this point. Most people would agree that pain is a significant disadvantage, to which an egalitarian theory should be sensitive. For instance, Cohen gives the example of a man who can move his arms very well, but who suffers from severe pain after doing so. ${ }^{40}$ Assuming that he is not responsible for this affliction, egalitarians would support providing him with the medicine he needs 
to prevent this pain. Yet we cannot explain why this should occur if we adopt a conception of advantage that focuses solely on resources. After all, the man concerned does not suffer from a resource incapacity. ${ }^{41}$ Similar points can be made in relation to other examples of disutility, which might attract the concern of egalitarians, such as discomfort from the cold. ${ }^{42}$ This demonstrates that egalitarians are interested in the welfare of individuals not just their resources, even under Dworkin's broad construal of that term.

Dworkin is open to the same criticism that Sen makes of Rawls -- rather than focusing on what resources do for the well-being of individuals, he is guilty of resource fetishism. A purely resourcist conception of advantage is insensitive to important aspects of human existence, such as pleasure and pain, which are relevant to egalitarian justice. This does not prove that resources have no place in a conception of egalitarian advantage, but it does mean that focusing solely on resources is inadequate. This leads us to consider the appeal of the welfarist approach.

\section{WELFARE}

Welfarism holds "that the goodness of a state of affairs can be judged entirely by the goodness of the utilities in that state." 43 Its appeal, as even its critics recognise, is that welfare seems to capture "what is fundamental in life rather than what is merely instrumental." 44 There are many different kinds of welfare we could discuss. In this section, I will focus on the three approaches highlighted by Dworkin in his well-known critique of welfare egalitarianism --

success theories, conscious-state theories, and objective theories of welfare, ${ }^{45}$ and I will base my analysis around Dworkin's critique. It is worth emphasising that I am interested in the most theoretically sound understanding of 
“advantage” for egalitarians to use, abstracting from practical considerations. This means that we can largely ignore the difficulties policy-makers face in reliably measuring and comparing the levels of welfare that different individuals enjoy. ${ }^{46}$ Nonetheless, I will briefly touch on the policy significance of adopting a welfarist conception of advantage at the end of section 3, and I will return to the issue when I discuss the practical applications of luck egalitarianism in chapter 7.

Success theories of welfare “suppose that a person’s welfare is a matter of his success in fulfilling his preferences, goals, and ambitions, and so equality of success, as a conception of equality of welfare, recommends distribution and transfer of resources until no further transfer can decrease the extent to which people differ in such success." 47 This category can be divided further, depending on the kinds of preferences that we are interested in. Three varieties of preferences can be distinguished -- political, impersonal or personal. However, Dworkin concludes that all three versions of success theory are flawed as conceptions of advantage for an egalitarian theory.

The underlying problem with the unrestricted success view of advantage (which is unrestricted because it includes all three types of preferences) is that egalitarians should only take the satisfaction of political preferences into account if these preferences are consistent with egalitarian justice and other norms. ${ }^{48}$ For instance, the racist preferences of bigots should not have any bearing on egalitarian justice because they are inconsistent with the idea that all persons have equal moral worth. Consequently, we do not owe compensation to citizens who end up with a low level of welfare because they are dissatisfied with the non-discriminatory nature of our society. ${ }^{49}$ Other problems may arise if we are living in a society where all individuals share a caste-based political 
preference which says that members of a higher caste should have more than members of a lower caste. ${ }^{50}$ Implementing equality of unrestricted success will lead to a distribution that seems inconsistent with our intuitive understanding of egalitarian justice. The theory is only attractive when people have sound, inoffensive, and egalitarian political beliefs. ${ }^{51}$ Nonetheless, provided political preferences satisfy these conditions, they can be taken into account in a conception of egalitarian advantage. ${ }^{52}$

Dworkin is right that offensive and anti-egalitarian views have no place in a theory of egalitarian advantage, and this seems to be a fatal flaw in unrestricted equality of success. However, Dworkin's own theory, equality of resources, is also susceptible to this objection. In a caste society, an unequal distribution that gives more to higher caste members and less to lower caste members will satisfy the envy test. If everybody supports the idea that the higher caste should have more than the lower caste then, presumably, the members of the lower caste will not envy the members of the higher caste who are better off than them. This problem will affect any egalitarian theory that allows anti-egalitarian preferences to influence distributive justice. If preferences are to play a role in egalitarian justice then we must pay careful attention to the kind of preferences that are acceptable, and to how they are formed. ${ }^{53}$ Moreover, as Anderson, Young and others would point out (see chapter 2), no egalitarian theory which focuses solely on the distribution of material resources is sensitive to the unequal nature of social relations in racist and caste-based societies. Dworkin's examples highlight the need for egalitarians to adopt a conception of advantage that recognises the importance of egalitarian social relations, and on this criterion, too, equality of resources may be found lacking. 
If we were to exclude political preferences from consideration, we would be left with a more restricted form of equality of success which only includes impersonal and personal preferences. However, the claim that we should equalise impersonal preferences, which Dworkin defines as people's "preferences about things other than their own or other people's lives or situations" ${ }^{54}$ is subject to a form of the expensive tastes criticism:

Suppose Charles very much and very deeply hoped that life would be discovered on Mars, or that the Great American Novel would be written within his lifetime, or that the coast of Martha's Vineyard would not be eroded by the ocean as it inevitably continues to be. Equality does not require that funds be taken from others, who have more easily fulfilled hopes about how the world will go, and transferred to Charles so that he can, by satisfying other preferences he has, decrease the overall inequality in the degree to which his and their nonpolitical preferences are fulfilled. $^{55}$

An apparent solution is to restrict compensation to disutility resulting from the frustration of reasonable impersonal preferences, but determining precisely which preferences are "reasonable" forces us to draw on an independent theory of justice that gives us some idea of the resources to which each citizen is entitled. In effect, this independent theory of justice, with its account of "fair shares,” replaces welfare as the appropriate conception of advantage. ${ }^{56}$ That aside, the expensive tastes objection is Dworkin's key argument against equalising people’s success in satisfying their impersonal preferences, and we shall analyse this criticism in more depth in the next section.

Equality of personal success is the most restricted version of success theory, focusing solely on personal preferences, which are people's "preferences about their own experiences or situation.”57 Equality of personal success "requires that distribution be arranged so that people are as nearly equal 
as distribution can make them in the degree to which each person's preferences about his own life and circumstances are fulfilled." ${ }^{58}$ It focuses on the extent to which individuals can live lives that they value, that is, lives that are consistent with the conception of the good life that they have developed. Yet there are problems even with this heavily restricted form of equality of success. For a start, there is a risk of a fatal circle because individuals need some idea of the resources that will be available to them when they are choosing the kind of life to live. But they cannot know this until a more precise notion of distributive justice has been identified, and their tastes and ambitions are supposed to play a crucial role in determining this. ${ }^{59}$ However, this is a technical problem, so Dworkin leaves it aside. Instead, he focuses on a greater theoretical challenge. He distinguishes between two different kinds of success -- relative success and overall success. Relative success is a person's "success at meeting the discrete goals he has set for himself.”60 In contrast, overall success refers to something which underlies and shapes these preferences: "a different and more comprehensive ambition, the ambition to make something valuable of the only life they have to lead."61 Evaluating these two notions of success can lead to different conclusions:

Once someone has settled on even a tentative or partial scheme for his own life, once his discrete preferences have been fixed in that way, then he can measure his own relative success in a fairly mechanical way, by matching his situation to that scheme. But he cannot tell whether his life has succeeded or failed in finding value simply by matching his achievements to any set target in that way. He must evaluate his life as a whole to discover the value that it has, and this is a judgment that must bring to bear convictions that, however inarticulate these are, and however reluctant he might be to call them this, are best described as philosophical convictions about what can give meaning or value to any particular human life. I 
shall call the value that someone in this way attributes to his life his judgment of that life's overall success. ${ }^{62}$

However, Dworkin argues that neither approach generates an appealing version of equality of welfare.

Equality of relative success is flawed because “[p]eople put different values on [relative] personal success and failure, not only as contrasted with their political and moral convictions and their impersonal goals, but just as part of their personal circumstances or situation." ${ }^{63}$ People do not care equally about the extent to which they have satisfied their personal preferences, which is a problem given that the initial appeal of the welfarist approach is that it focuses on what is truly important to human beings. ${ }^{64}$ For example, some would rather be successful at achieving limited, easy-to-accomplish goals, whilst others would rather aim higher, even if this carries with it the risk of less relative success. This may have counter-intuitive consequences because those who choose more difficult, ambitious goals are likely to receive extra resources to help them achieve a similar degree of relative success to those with less ambitious goals that are easier to accomplish:

$[\mathrm{M}]$ oney is given to one rather than another, or taken from one for another, in order to achieve equality in a respect some value more than others and some value very little indeed, at the cost of inequality in what some value more. A person of very limited talents might choose a very limited life in which his prospects of success are high because it is so important to be successful at something. Another person will choose almost impossible goals because for him the meaning is the challenge. Equality of relative success proposes to distribute resources -- presumably much fewer to the first of these two and much more to the second -- so that each has an equal chance of success in meeting these very different kinds of goals. ${ }^{65}$

Moreover, Dworkin argues that "it is absurd to suppose that people should find 
value only in relative success without regard to the intrinsic value or importance of the life at which they are relatively successful."66 Thus, pure equality of relative success is an unappealing interpretation of the egalitarian ideal, and we are drawn to the notion of overall success, which takes into account a person's deeper judgements about the nature of the good life.

Nonetheless, there are problems with Dworkin's criticisms. The fact people prefer a particular conception of advantage provides no reason in itself to reject other, less favoured conceptions. ${ }^{67}$ If it were, then we would also have grounds for rejecting Dworkin's approach because many people will care more about the level of subjective welfare they enjoy than about the resources they hold. ${ }^{68}$ Moreover, if we take into account the extent to which a person values a particular preference, we can take into account the kind of deeper judgements concerning the "intrinsic value" of a life without having to adopt welfare as overall success. ${ }^{69}$ Part of the force of Dworkin's objection comes from the claim that relative success theory fetishises success, where success is understood in terms of the accomplishment of goals. Achievement in this sense is regarded as more important than the challenge of attempting a difficult task. Thus, in the example above, we are led to make the mistaken judgement that the talented man suffers from a major disadvantage because he achieves less success than the untalented man. But this conclusion does not automatically follow from the relative success approach because we also need to take into account the importance individuals place on their different preferences. Advantage is not just about who has successfully satisfied the most preferences. We value some preferences more than others, and it is the extent to which we are able to satisfy these deep preferences that is of most importance to us, and 
this has significance for how equality of relative success handles Dworkin's example.

In Dworkin's description of the example, he fails to recognise that equality of relative success must weight the importance of the different preferences that we have. The untalented man may have a series of easy-tosatisfy preferences, but from Dworkin's description, these preferences reflect a deeper, overriding taste for success. He enjoys the feeling of successfully accomplishing simple tasks, and he wants to experience this feeling as often as he can. Successfully satisfying this deeper preference (his taste for success) is likely to have far more importance for him than satisfying his preference for any single easy-to-accomplish task. So when evaluating the level of relative success he enjoys, we are primarily interested in the extent to which he is able to satisfy successfully this deeper preference for the feeling of success (or, to put it more precisely, this deeper preference is heavily weighted to reflect the fact it is amongst his most important preferences). In contrast, the talented man has a deep preference for pursuing difficult goals. He has a taste for challenge, not for the successful accomplishment of a task, per se. Once we prioritise the achievement of these more fundamental preferences, Dworkin's example loses some of its sting. If, for example, the talented man has a taste for attempting difficult mountain climbs, he enjoys a high degree of relative success if he is able to engage in this activity, whether or not he successfully reaches the top of the mountain. Relative success does not adopt a fetishistic approach to the successful completion of tasks.

But expanding relative success theory in this way may still leave it open to the kind of criticisms that Dworkin makes of equality of overall success. Leaving aside a number of technical problems, his major objection to equality 
of overall success is that different individuals might have very different conceptions of what it is to live a successful life. Consequently, they might live similar lives, but each make different judgements about the overall success of his/her life. For instance, Dworkin gives the example of Jack and Jill, "who are both healthy, neither handicapped, both reasonably successful in their chosen occupations, neither outstandingly accomplished or creative. They take roughly the same enjoyment from their day-to-day life.”70 They also have equal resources. However, Jill has a "much more demanding" view of what it is to live a valuable life than Jack does, and, as such, she believes that the overall value of her life is low, whilst Jack believes his is high. Thus, equality of overall success would support redistribution from Jack to Jill, which is a counter-intuitive conclusion. $^{71}$ If, as I have suggested, the relative success approach takes into account the extent to which we value particular preferences, it also appears vulnerable to this criticism.

However, Dworkin's example does not cause problems for equality of relative success because Jack and Jill appear to be equal in their relative level of preference satisfaction. Jill is not unhappy because she enjoys less preference satisfaction than Jack does. Rather, she is unhappy because she wants a life with more preference satisfaction than Jack does. If we exclude judgements of overall success from consideration, then equality of relative success already obtains, so we are not obliged to give extra resources to Jill. ${ }^{72}$ Nonetheless, even on this interpretation, we still owe compensation to those with expensive tastes. For instance, if Jill were actually to have a lower level of relative success than Jack because her tastes were more expensive to satisfy, then equality of relative success would support distribution from Jack to Jill. As I stated above, I will analyse this objection in more detail in the next section. 
The second approach Dworkin examines is conscious-state welfare, which "holds that distribution should attempt to leave people as equal as possible in some aspect or quality of their conscious life."73 Supporters of this approach conceptualise the relevant conscious state in different ways, but Dworkin uses the terms “'enjoyment' and 'dissatisfaction' indiscriminately to name the full range of desirable and undesirable conscious states or emotions that any version of a conscious-state conception of equality of welfare might suppose to matter." ${ }^{74}$ As preference satisfaction contributes to enjoyment, we can distinguish amongst theories of equality of enjoyment using the types of preferences -- political, impersonal and personal -- discussed above. $^{75}$ However, because he opposes factoring in political and impersonal preferences (see above), Dworkin restricts his discussion to enjoyment that individuals "take directly and from their beliefs that their personal preferences are achieved. $^{\text {,76 }}$

Dworkin has two key arguments against equality of enjoyment. Firstly, as with equality of relative success, it seeks to make people equal in an area of life that they do not equally value. The problem is that individuals place a different value on achieving enjoyment:

For almost everyone, pain or dissatisfaction is an evil and makes life less desirable and valuable. For almost everyone, pleasure or enjoyment of some other form is of value, and contributes to the desirability of life. Conscious states of some such form, positive and negative, figure as components of everyone's conception of the good life, but only as components, because almost no one pursues only enjoyment or will make any large sacrifice of something else he values to avoid a small amount of pain. And different people give even these conscious states very different weight. Two scholars, for example, may both value creative work, but one may be willing to give up more, by way of social pleasure or the enjoyments of 
reputation or the satisfaction that comes from completing a piece of research well done, to do work that is in fact more original. ${ }^{77}$

Dworkin argues that most individuals have goals that they consider valuable, independently of the enjoyment they receive from them. ${ }^{78} \mathrm{He}$ also endorses this state of affairs, suggesting that a valuable life consists of more than maximizing one's enjoyment. $^{79}$ Moreover, even if he were wrong about this, equality of enjoyment is unappealing because it is inconsistent with the way many individuals view their own lives. ${ }^{80}$ However, this last point is not a decisive objection to a particular conception of advantage, as I argued above. Moreover, although Dworkin is correct that a valuable life is about more than maximising enjoyment, enjoyment is certainly not irrelevant to how well our life goes. If, for instance, a person has a severely low level of conscious-state welfare, this would seem to be a serious form of disadvantage that should attract the concern of egalitarians.

Dworkin's second major objection is a form of the argument he uses against equality of overall success. Individuals with grand aims may experience dissatisfaction if they cannot achieve their goals and end up living lives that they consider to be fairly unsuccessful overall. Under equality of enjoyment, they may be entitled to extra resources as compensation for the dissatisfaction they experience as a result. ${ }^{81}$ This means that resources may be transferred from the less ambitious to help alleviate the dissatisfaction of the more ambitious. To avoid this problem, a proponent of equality of enjoyment would be forced to adopt some notion of reasonable regret, so compensation would only be forthcoming if the dissatisfaction were reasonable. But as discussed above, this requires an independent theory of distributive justice. ${ }^{82}$ I rejected the theory of equality of overall success that this criticism is based upon, so I 
agree with Dworkin that we should not provide extra resources to individuals who demand more preference satisfaction than others enjoy. However, I did (provisionally) support equality of relative success, ${ }^{83}$ and a modified form of Dworkin's criticism seems to apply to this view because equality of relative success will provide extra resources to those who have a higher level of dissatisfaction (and thus a lower level of conscious-state welfare) than others because they cannot satisfy their expensive preferences. Whether this criticism is decisive against taking into account the enjoyment/dissatisfaction associated with personal preferences depends on whether we can offer a satisfactory response to the expensive tastes objection, which I will discuss in the next section. Dworkin is right to suggest that enjoyment is not the only thing that matters, but he has not shown that it has no role to play in egalitarian advantage.

The third category Dworkin examines is the objective theory of welfare. He focuses on two particular versions of this approach. The first is a more objective version of equality of overall success, which holds "that people be made equal in the amount of regret they should have about their present lives.” ${ }^{84}$ This contrasts with subjective approaches, which focus on the amount of regret which people do, or would have given full information. However, determining whether regret is reasonable again depends on establishing an independent notion of distributive justice, which raises the problems discussed above. ${ }^{85}$ The second possibility is to hold "that a person's welfare consists in the resources available to him.” ${ }^{86}$ But this is actually a theory of equality of resources, not equality of welfare. ${ }^{87}$

Dworkin's criticisms of the objective version of equality of overall 
success are flawed. Even if we accept the need to talk about reasonable regret (which depends on the expensive tastes objection) there is no reason why an independent theory of distributive justice is necessary. Whether or not regret is reasonable need not depend on whether a person has a fair share of resources, but on whether the particular life they want to live is reasonable. The resources available across society in general will be relevant to this judgement, but it does not depend on establishing the precise share of resources to which each person is entitled. For instance, we might believe that the good life for humans involves physical mobility, a satisfactory level of health, the chance to develop our talents, and the chance to perform "decent” work (which is objectively defined). To the extent that we are unable to live this kind of life, the regret we have at the frustration of our aims is reasonable. In this way, an objective version of equality of overall success avoids having to draw on an independent notion of fair shares. ${ }^{88}$

In sum, Dworkin has not presented a knock-down critique of welfare as the appropriate egalitarian conception of advantage. While he gives strong reasons to avoid conscious-state welfare as the only component of advantage, he has not shown that it should be completely excluded from consideration. Rather, suffering from a very low level of conscious-state welfare is a serious form of disadvantage, no matter the cause. His argument against unrestricted equality of success does show that anti-egalitarian and offensive political preferences should be excluded from consideration, but his other arguments are less successful. In particular, he does not show that proponents of success theory must adopt the unattractive idea of equality of overall success. His only powerful criticism against success theory and conscious-state welfare is the expensive tastes objection, which he does not fully develop in his original 
critique of welfarism. Finally, Dworkin has not demonstrated that an objective conception of welfare collapses into a resourcist approach. Whether or not objective welfare has a major role to play in a full account of advantage will depend on whether egalitarians think that there are certain ways of living that are inherently advantageous, or disadvantageous. I shall return to this issue in section 6. In the next section, I will conclude the discussion of the place of welfare in advantage by analysing the strength of the expensive tastes objection, which carries a heavy load in Dworkin's critique.

\section{EXPENSIVE TASTES}

By his own admission, Dworkin does not fully justify the expensive tastes objection in "Equality of Welfare." 89 Instead, he assumes that egalitarians are opposed to compensating individuals for their expensive tastes, and explains how welfare egalitarianism inevitably leads to this counter-intuitive result, drawing on the examples of Louis and Jude (see chapter 1). ${ }^{90}$ However, as we saw in chapters 1 and 3, G.A. Cohen strongly challenges Dworkin's position on this issue.

Cohen emphasises that he and Dworkin are using the term "expensive tastes" in a technical sense. As he puts it, "[t]o say that someone has expensive tastes, in the present meaning of the phrase, which is its meaning in Dworkin's article on 'Equality of Welfare,' is to say that that person 'need[s] more income' than others do 'simply to achieve the same level of [some form of] welfare as those with less expensive tastes'... But the ordinary understanding of the expression 'expensive tastes' does not match the technical Dworkinmeaning that I just stated, and, to the extent that resonances from the ordinary meaning of the phrase continue to occupy the mind, the issue of whether 
uncompensated expensive tastes represent an injustice risks being clouded.”91 In its ordinary usage, “expensive tastes” tends to refer to people who live an extravagant lifestyle, regardless of whether they are more inefficient at converting resources to welfare than others are:

A person's tastes are expensive in the required [technical] sense if and only if, as I have explained, they are such that it costs more to provide that person than to provide others with given levels of satisfaction or fulfillment. People who insist on expensive cigars and fine wines are not eo ipso possessed of expensive tastes, in the required sense. For they may thereby be insisting on a higher level of fulfillment than the norm. In the present acceptation, people have expensive tastes if, for example, ordinary cigars and cheap wine that give pleasure to most people leave them cold, and they can get something like that pleasure (and, ex hypothesi, not a greater one) only with Havana cigars and Margaux. People's expensive tastes, here, are a matter neither of their behavior nor of their will but of their constitution. They are a matter of what they are satisfied by, not of what they are satisfied with. ${ }^{92}$

To fully understand the debate over expensive tastes, it is important to recognise that the term is being used in this technical sense.

Cohen also draws a distinction between two different kinds of tastes. There are “judgmental tastes,” which “are informed by valuational judgment,” and "brute tastes,” which “do not embody judgments of valuation... such as... [Cohen's] own liking for Diet Coke, which implies no particular approval of it." 93 An expensive brute taste is only compensable on the grounds of egalitarian justice if it is an unchosen taste that a person has not deliberately cultivated. $^{94}$ On the other hand, an expensive judgemental taste is potentially compensable, even if it was chosen ${ }^{95}$ (we must judge whether it would be reasonable to hold a person to account for the costs of this taste, taking into account factors such as whether it was deliberately cultivated for snobbish 
reasons): ${ }^{96}$

I distinguish among expensive tastes according to whether or not their bearers can reasonably be held responsible for the fact that their tastes are expensive. There are those that they could not have helped forming and/or could not now unform without violating their own judgment, and then there are those for whose cost, by contrast, they can be held responsible, because they could have forestalled their development, and/or because they could now quite readily unlearn them, without violating their own judgment. ${ }^{97}$

Thus, whether we should correct inequalities in welfare depends on notions of choice and luck. However, the two reasons Cohen gives for compensating expensive tastes relate to two different sources of bad luck. If compensation is justified, the bad luck can result from the unchosen nature of the preference itself, or alternatively, from the fact that a valued preference is expensive to satisfy. In a recent response to Cohen's critique, Dworkin usefully described these types of luck as bad preference luck, and bad price luck. ${ }^{98}$ Interestingly, whilst both grounds for compensation were discussed in Cohen’s original 1989 critique, the bad price luck argument was given a less prominent role in his original "flagship statement." The above quotation is the revised form of this statement that appeared in his more recent, 2004 discussion of the issue. ${ }^{99}$

Dworkin has responded to this criticism, continuing to maintain his position that individuals should not receive compensation for expensive tastes. ${ }^{100}$ He begins by arguing that Cohen's position actually “collapses back into... simple equality of welfare" because individuals never fully choose their preferences. ${ }^{101}$ We do not fully control what we come to value in life. For instance, recall Dworkin's character Louis (Bourbon) who deliberately cultivates certain expensive tastes. Dworkin says that “[h]e cultivated refined tastes because, given his royal Bourbon heritage, he thought such tastes 
appropriate to him: he had, we might say, a taste for refined tastes.” ${ }^{02}$ However, this is no reason to compensate Louis because individuals should, and normally do take responsibility for the tastes and preferences that they value:

Ordinary people, in their ordinary lives, take consequential responsibility for their own personalities. We know that when we make the decisions, grand and small, that will shape our lives, we must often struggle against or accommodate or submerge or otherwise come to terms with our inclinations, dispositions, habits, and raw desires, and that we must do this in the service of our judgments and convictions of various kinds, including moral convictions about what is fair to others and ethical judgments about what kind of life would be appropriate or successful for us. We do not think that we have chosen these various judgments and convictions from a menu of equally eligible alternatives, the way we might choose a shirt from a drawer or dishes from a menu. True, it is up to us what to read, or listen to, or whether to study or ponder, and for how long and in what circumstances. But it is not up to us what, having done what we have done in that way, we conclude. We nevertheless do not count the fact that we have reached some particular moral or ethical conclusion as a matter of good or bad luck. That would be to treat ourselves as dissociated from our personalities rather than identified with them -- to treat ourselves as victims bombarded by random mental radiation. We think of ourselves differently -- as moral and ethical agents who have struggled our way to the convictions we now find inescapable. It would strike us as bizarre for someone to say that he should be pitied, or compensated by his fellow citizens, because he had the bad luck to have decided that he should help his friends in need, or that Mozart is more intriguing than hip-hop, or that a life well lived includes foreign travel. ${ }^{103}$

Thus, because our tastes are never fully chosen, Cohen’s approach collapses into equality of welfare, which offers compensation for all expensive tastes, regardless of how they were formed. This is misguided because people should 
not (and do not) demand extra state assistance, if the goals they value are particularly difficult to meet.

According to Dworkin, Cohen's alternative account seems to be based on the assumption that human beings are buzzes and tick addicts, who try to pursue "buzzes of pleasure or ticks of desire satisfaction,"104 without any deeper personal consideration or endorsement of them. In fact, Dworkin believes that we tend to regard preferences quite differently:

Since our preferences and ambitions are infused with judgments of value, and since, at least for most of us, these judgments include both ethical convictions about the shape of an overall successful life and moral judgments about the reasonableness, fairness, and justice of any particular assignment of resources, we could not separate ambition and judgment in the way that any scheme of justice defined in a welfare vocabulary requires. ${ }^{105}$

In other words, Cohen presents humans as beings who are disconnected from their preferences. This picture of humanity is at odds with our normal ethical understanding.

Dworkin also criticises Cohen's bad price luck argument for compensation. Once again, it would signal the collapse of equality of opportunity for welfare into equality of welfare, because "everyone, no matter how cheap his tastes and ambitions are to satisfy, can complain that it is his bad luck that other people's tastes, or the fortunes of supply and demand, are not such that his own tastes would be cheaper still.”106 Thus, whether or not a taste was chosen becomes irrelevant -- the cost of a taste is a matter of bad luck, regardless of how it was formed, so all persons should be able to enjoy the same level of taste satisfaction. This renders equality of opportunity for welfare and equality of welfare indistinct. This line of argument is also flawed because the needs and opinions of others are "parameters of justice." 107 They are not 
"matters of the kind of luck that can relieve us of consequential responsibility for our acts or circumstances.”108

Before we examine the strength of Dworkin's response, we should recall that he does not completely rule out offering compensation for tastes. He believes that some tastes should actually be classified as handicaps, which hamper a person's ability to pursue the life she values (see chapter 1 ). Whether a particular taste should be regarded as a handicap depends on whether it is endorsed by the person who holds it. In other words, is it valued despite its cost (such as a taste for classical music), or would an individual be happy to live without the preference (such as a drug addiction)? For example, Cohen's photographer, Paul would not be prepared to take an imaginary pill that would somehow remove his expensive taste for photography because photography is crucial to his conception of the good life. ${ }^{109}$ Thus, he should not be compensated for it because it cannot sensibly be described as a handicap.

However, Dworkin's counter-argument is flawed. Firstly, even if his account of preference formation is correct, and we never fully choose our tastes and preferences, this does not mean that "equality of opportunity for welfare collapses into equality of welfare." ${ }^{110}$ There is still a difference at the theoretical level. ${ }^{111}$ A proponent of equal opportunity for welfare still endorses equal opportunity for welfare, it is just that this approach recommends complete equality of welfare when applied to the real world. Furthermore, although preferences are not simply chosen, "we can devote more or less control to the development of our preferences, and be differentially responsible for their cost as a result.”112 Cohen supports “graded and shaded judgments about choice”,113 which means that equality of opportunity for welfare does not necessarily recommend the same thing as equality of welfare, even though individuals 
make decisions about which preferences to develop against a "choice-affecting background.” 114 So Cohen’s approach does not collapse into straight equality of welfare.

Secondly, there is no inconsistency in receiving state assistance to help satisfy an expensive judgemental taste. The compensation is not provided for the preference itself, but for the expense of satisfying it, so receiving compensation does not involve repudiating something of value. ${ }^{115}$ If it did, then we would be forced to accept the analogous claim that "bereaved air travelers repudiate their desire to show solidarity with their loved ones when they request and accept the low ticket price that some airlines charge for last-minute bookings to attend funerals." 116 Thus, Dworkin is wrong to link compensation for expensive judgemental tastes to some kind of dissociation from one's personality.

Ultimately, Cohen is correct to argue that egalitarians have obligations to assist (to the extent possible) those with expensive tastes. The focus of egalitarian justice should be on the extent to which individuals are able to live fulfilling lives, which means ensuring that they have an equal capacity to satisfy their valued preferences (provided that these preferences are not inegalitarian or offensive). To live a fulfilling life, some people will require more resources than the average, and some will require less, but there is no reason why resources should be the key measure here. It is what we can get from with these resources that matters, and to assume otherwise is a form of commodity fetishism. ${ }^{117}$ The market is arbitrary from the point of view of egalitarian justice, so it should not be used to evaluate the level of advantage we enjoy. It is "at best a mere brute luck machine" 118 and is inconsistent with the underlying motivation of luck egalitarianism. For a luck egalitarian, bad price luck should 
not constrain individuals from having an equal opportunity to pursue fulfilling lives, and thus expensive judgemental tastes are compensable. This conclusion holds, even if the individuals concerned are partly responsible for the fact that they have expensive judgemental tastes. ${ }^{119}$ A crucial part of egalitarian advantage is being able to satisfy your valued preferences, even if they were, in part, deliberately cultivated. ${ }^{120}$ This highlights the radical nature of luck egalitarianism.

Brute tastes, on the other hand, are a different matter. By definition, they are not closely connected to our conception of a valuable life. Thus, if we cultivate an expensive brute taste, we must bear responsibility for it. An example might be smoking. A rational agent who has obtained her majority may start smoking, find she enjoys it, and decide to continue doing it. If she continues smoking because she enjoys it, but does not strongly identify with the taste because it is not central to her conception of a valuable life, then it is a brute taste. If she is fully aware of the risks of addiction and the financial and health costs involved when she starts smoking, but continues to smoke anyway, she must bear responsibility for the disadvantage associated with these costs. Alternatively, if she quits, she must bear responsibility for the disutility she suffers as a result. It is reasonable to ask people in such situations to bear the costs associated with deliberately cultivated brute tastes because having to abandon such tastes, as opposed to expensive judgemental tastes, does not force individuals "to accept an alienation from what is deep in them." ${ }^{121}$

It is also worth noting that Dworkin himself draws on welfarist criteria to determine when tastes are compensable. For Dworkin, whether something is categorised as a resource depends on whether one identifies with it, or whether it is seen as an obstacle to pursuing what one values in life. Yet giving 
endorsement such a crucial role introduces an important subjective element into a purportedly resourcist approach.

Moreover, Dworkin's approach to handicaps in one part of his essay, “Equality and Capability,” suggests that he has (unconsciously) changed his view on the issue of compensation for brute expensive tastes, a shift which Cohen describes as "a remarkable and consequential U-turn."122 In chapter 7 of Sovereign Virtue, Dworkin discusses the example of an individual who hates the taste of tap water, which he finds "unbearably sour.” Instead, he purchases bottled water, which is more costly. Dworkin claims that: "[i]t is true that he has a choice whether or not to do that. But he did not choose to have the property -- a special sensory reaction -- that made the choice not to do so distasteful. That physiological condition is his bad luck, and he should therefore be compensated for his misfortune: he should be given extra resource [sic] so that he will not be worse off buying bottled water than others are who make do with tap water."123 This seems inconsistent with his original approach, outlined in "Equality of Resources," where a taste is only regarded as a (potentially compensable) handicap if we disidentify with it. But in the example above, the man involved is unlikely to either identify or disidentify with his hatred of tap water. ${ }^{124}$ It is not his dislike of tap water per se that he regrets, but rather, the cost that this distaste imposes on him, as he is forced to buy expensive bottled water. Thus, Dworkin now seems to hold that regretting the cost of a taste is enough to justify providing compensation, provided that the individual involved does not actually identify with this taste. If this interpretation is correct, Dworkin would now support compensation for all expensive brute tastes because individuals who hold such tastes will not, by definition, identify with them (otherwise they would be judgemental tastes), whilst they will regret the 
expense these tastes impose on them. Thus, as Cohen puts it: "Dworkin's market treatment of goods that provide brute satisfaction falls to the (in my view morally superior) principle: to each according to what they need for their satisfaction. In the huge domain of brute taste, market prices cease to embody justice.”125

In response to the charge of inconsistency, Dworkin refers back to his original view that the key test is whether a person would happily lose the taste that he has and "[p]resumably almost everyone for whom tap water tastes sour or who gags on chicken eggs would prefer to lose those vulnerabilities." ${ }^{126}$ Yet there is still a problem here. Perhaps the individuals who find tap water unpleasant would choose to be without this preference if they are forced to meet its expense. But if bottled water were no more expensive than tap water, and as readily available, this conclusion is unlikely to hold. There is no intrinsic value to drinking tap water, so the only reason to regret reliance on bottled water is the cost/inconvenience involved. Whether a person regrets her brute tastes will depend on the costs they impose on her, not on the content of the preference itself.

Leaving aside this “U-turn,” Dworkin's original approach may lead to compensation for expensive tastes, anyway. Because endorsement of a taste is the key to determining whether it is compensable, snobs could receive compensation for their cheap expensive tastes. For example, a person may simply love large amounts of simple, cheap food cooked at home, but hate eating out at fine, expensive restaurants because the portions of meat, pasta and vegetables tend to be too small, and come smothered in rich seasoning and sauces, which she dislikes. ${ }^{127}$ However, this person is also a snob, and desperately wishes she found more enjoyment in eating out, because it goes 
with a certain upper middle-class lifestyle and sophistication, which she desperately wishes to have. If she could, she would take an expensive pill that would alter her physiology such that she would find simple food too plain, but fine dining very enjoyable. Most egalitarians will oppose providing compensation to this person, whose dissociation from her tastes stems from snobbery, rather than a sense that she is missing out on the finer pleasures in life. But under Dworkin's original criterion, this dislike of fine dining would be classified as a handicap. Theoretically, this taste should then become part of the hypothetical insurance auction and if enough persons believed it to be a serious concern, it would attract compensation. ${ }^{128}$ If there are enough snobs out there, Dworkin's scheme would justify providing compensation to individuals who consider themselves to have an expensive "addiction" to cheap tastes. Thus, Dworkin's scheme could potentially provide compensation for inegalitarian expensive tastes. $^{129}$

Although Cohen is right that some expensive tastes are compensable, his position, too, may have inegalitarian implications. As I discussed earlier, Cohen emphasises that he and Dworkin are using the term "expensive taste" in a technical sense. They are not talking about wealthy people who live extravagant lifestyles, but people who need more than others to reach a given level of welfare. However, the problem of adaptive preferences means that this distinction will not always hold. Those who grow accustomed to a life of higher-than-average satisfaction may suffer significant disutility if they are forced (for whatever reason) to live a life of only average satisfaction. For instance, take two individuals -- Joan and Maxine -- who both find great enjoyment in studying political theory at graduate level. They both come to believe that a valuable and successful life is one spent pursuing this interest, 
and as a result, they develop a strong judgemental preference for a life devoted to teaching and researching political theory. However, after their final year of study, Joan is lucky enough to secure a postdoctoral research position and subsequent posts as a temporary lecturer, whilst Maxine is unable to do so, and is forced to pursue some other job that involves no research in this area. Joan then spends the next ten years performing work that she finds particularly fulfilling (because she is able to spend her time engaged in an activity she greatly values), and enjoyable (because it is fulfilling and associated with a high level of autonomy, and flexibility in her working hours). In contrast, Maxine works in an occupation that she finds unfulfilling and unpleasant, with inflexible hours and little autonomy. In essence, Joan enjoys higher-thanaverage job satisfaction, whilst her friend enjoys a below-average level of satisfaction. But after 10 years as a researcher, Joan has been unable to secure a permanent position and with a tight job market is unable to find more work in her preferred area. The only job she can find is working in the same area as Maxine. Maxine has not come to love her job -- in fact the level of (dis)satisfaction she experiences has not changed much since she started. Joan gets a similar level of (dis)satisfaction from her new job as Maxine, but the shock of having to work in such a dissatisfying occupation, compared to what she is used to, means that Joan is much unhappier than Maxine. Joan and Maxine get similar levels of satisfaction from the job that they do, but Joan's welfare is lower than Maxine's because she is used to having more satisfaction from the work she does. In sum, Joan may need more satisfaction than Maxine to achieve a given level of welfare and in this instance, the distinction between the common and technical understandings of the term "expensive taste" collapses. 
If we identify the different types of welfare at work here, then we can better understand what is going on. In the Joan and Maxine example, two kinds of welfare are involved, namely, welfare as relative success and conscious-state welfare. Whether a job is satisfying will depend on the extent to which it consistent with an individual's preference for a particular kind of work (welfare as relative success), and it will also depend on the level of enjoyment (in the sense of a desirable conscious state) this individual gets from performing this work. ${ }^{130}$ In section 2, I endorsed success theories of welfare (pending resolution of the expensive tastes objection). If we rely solely on this notion of welfare, then the Joan-Maxine example poses no particular problem for welfare egalitarianism. They both have a similar (low) degree of success, judged in terms of their own deep preferences, so no redistribution will follow from Maxine to Joan. The problem arises when we bring conscious-state welfare into play. It is in this sense of welfare that Joan is worse off than Maxine. At first, this seems a poor reason to provide extra resources to Joan because both are equally disappointed with the work they are doing and find it equally frustrating. Joan only suffers extra disutility because she is used to a higher level of job satisfaction. Nonetheless, there are three points to make in defence of providing compensation to Joan. Firstly, if Joan's conscious-state welfare becomes so low that she is unable to properly function, then I think the idea of providing compensation seems more intuitively acceptable. The compensation could be used to help her obtain medication or counselling which might be of assistance. Secondly, we would anticipate that over time Joan will grow accustomed to performing more boring work, just as Maxine has. If she does not, then there must be some luck-based difference between Joan and Maxine that is compensable. Thirdly, part of the problem is that Joan has spent ten 
years performing fulfilling and enjoyable work, which Maxine would have loved to do. It seems unfair to reward Joan for the effects of ten years of good fortune. However, from a luck-egalitarian perspective, Maxine should have received compensation during the previous ten years for the fact she suffered from a lower level of job-satisfaction than Joan. The disadvantage Maxine suffered should already have been compensated for. ${ }^{131}$ In sum, Joan is potentially entitled to compensation, particularly if she suffers from a very low level of conscious-state welfare, but this is less counter-intuitive than it first seems. This example also highlights why it is important for welfarist egalitarians to clarify the kind of welfare they are interested in. ${ }^{132}$

An obvious problem with adopting a partially welfarist conception of advantage is that it will be impossible to accurately determine the precise level of welfare that individuals enjoy. However, this is no reason to reject the focus on welfare. As I have emphasised throughout the thesis, the fact that a theory is difficult or impossible to implement in practice does not count against it at the theoretical level, and as I emphasised at the start of section 2, we are interested in the best theoretical understanding of egalitarian advantage, abstracting from practical considerations. Moreover, we can make general judgements about the likely impact of particular policy measures on the distribution of welfare. Cohen distinguishes two ways of providing subsidies to those with expensive tastes: "general subsidies reduce the cost of a given good to all comers, and therefore not only to those whose taste for that good is in the relevant way expensive; special subsidies are to those particular consumers of a given good whose taste for it is expensive.”133 Compensation for expensive tastes can only occur through the provision of general subsidies because it is impossible for the state to collect the accurate information about the welfare level of individuals 
and the aetiology of tastes, which is needed to provide targeted, special subsidies. However, general subsidies apply to all comers, so the subsidy goes to anyone who engages in the subsidised activity, whether or not they have a genuine, compensable expensive taste. Thus, "we produce some injustice whether we leave the market alone or interfere with it in a generally subsidizing way. If we wish to serve justice as well as we reasonably can, then we have to try to guess when taste differences make general subsidy more just than market upshots, and in some cases, such as that of libraries, my guess is that justice is indeed better served by our actual practice of subsidy; it is less insensitive to individual need than the market is." 134

Cohen highlights a number of examples where justice is likely to be served by the provision of general subsidies. For example, libraries subsidise expensive tastes by providing access to a range of books, some more expensive than others, to suit the reading tastes of their members. ${ }^{135}$ They do not charge extra for taking out expensive books, which means that members with expensive reading tastes benefit from a general subsidy. Other examples include community leisure centres, which enable citizens who have expensive tastes in leisure to pursue the activities they prefer, ${ }^{136}$ and a variety of multicultural policies, which support minority cultures. ${ }^{137}$ In these instances, it is likely that a high proportion of those who benefit from the subsidies will have genuinely compensable expensive tastes, so the subsidy is well-targeted, from the point-of-view of egalitarian justice. ${ }^{138}$ Thus, although it will be impossible to determine the precise level of welfare that individuals enjoy in the real world, this does not mean that a welfarist conception of advantage is theoretically flawed, or practically useless.

Before we conclude, it is worth considering one final example that 
poses a challenge to my position on the expensive tastes issue. ${ }^{139}$ Consider a man who has an expensive taste for a jet-set lifestyle because he grew up in a wealthy family and became accustomed to taking numerous overseas holidays each year. If his family has lost its enormous wealth by the time he reaches his majority, and he is left with only an average income and wealth, he is now unable to pursue his jet-set lifestyle, and suffers below-average welfare as a result. Surely egalitarianism does not owe this man compensation?

In response to this example, I firstly concede that there may be situations where luck egalitarians will support providing compensation to individuals with an expensive taste for overseas travel. I admit that this is counter-intuitive, but if we wish to correct the influence of bad luck on people's ability to live fulfilling lives then we must accept this conclusion. However, in reality, I think there are two reasons why luck egalitarians are likely to be sceptical about providing compensation in the jet-set case above. Firstly, in the real world, many people struggle to obtain the necessities of life. The welfare level of the jet-set addict is likely to be much higher than those who lack basic food, clothing, and shelter, so subsidising his expensive taste in travel is unlikely to be a high priority for luck egalitarians now, or at any time in the near future. Secondly, luck egalitarians would be reluctant to provide compensation to the addict because his expensive taste results from the fact he was the beneficiary of past injustice (his family's wealth meant that he got the opportunity to travel overseas regularly, an opportunity which most never have). As I demonstrated in chapter 3, luck egalitarians should be very wary about perpetuating background inequalities, and this provides grounds for refusing to provide compensation in this instance. Thus, whilst there will be cases where luck egalitarianism does support providing compensation to those 
with an expensive taste for travel, there are strong grounds for denying compensation in this particular example.

In this section, I have demonstrated that egalitarians have an obligation to provide extra resources to those with expensive tastes. This means that Dworkin's expensive tastes objection fails, and combined with my arguments in section 2, we can conclude that welfare as success and welfare as enjoyment are both important components of an egalitarian conception of advantage. Nonetheless, both the welfarist and resourcist approaches have been subjected to strong criticism by Amartya Sen, which I will analyse in the next section.

\section{CAPABILITY EQUALITY}

Sen demonstrates that neither welfare, nor primary goods, nor a combination of the two provides an adequate conception of advantage for egalitarians to use. To illustrate this, he gives the example of a crippled person who "is no worse off than others in utility terms despite his physical handicap because of certain other utility features. This could be because he has a jolly disposition. Or because he has a low aspiration level and his heart leaps up whenever he sees a rainbow in the sky. Or because he is religious and feels that he will be rewarded in after-life, or cheerfully accepts what he takes to be just penalty for misdeeds in a past incarnation." ${ }^{140}$ Because he does not suffer any welfare disadvantage, a welfarist approach to equality will not assist him in meeting any special needs that arise from his disability. ${ }^{141}$ Yet as we discussed above, a focus on primary goods will not help him either because it is insensitive to the diverse needs of different individuals. ${ }^{142}$ Thus, we cannot solve the problem by focusing on welfare and primary goods. ${ }^{143}$

Sen's solution emerges from the realisation that both approaches are 
missing something crucial. Egalitarians should not be concerned with goods per se, but rather, with what people get from these goods. ${ }^{144}$ Although a welfarist approach is consistent with this line of thinking, it focuses on the mental reaction we have to these goods, missing the importance of what really matters -- the capabilities we are endowed with. As Sen says, "[i]t is arguable that what is missing in all this framework is some notion of 'basic capabilities': a person being able to do certain basic things.” ${ }^{145}$ In essence, capabilities are the freedom to achieve well-being, whilst well-being itself is a matter of functionings:

Functionings represent parts of the state of a person -- in particular the various things that he or she manages to do or be in leading a life. The capability of a person reflects the alternative combinations of functionings the person can achieve, and from which he or she can choose one collection. The approach is based on a view of living as a combination of various 'doings and beings', with quality of life to be assessed in terms of the capability to achieve valuable functionings. ${ }^{146}$

This capabilities approach is an alternative to conceptualising advantage in terms of resources or welfare.

Capability equality seems compatible with luck egalitarianism because it gives choice and responsibility an important role to play in egalitarian justice -- individuals must exercise their capabilities in order to achieve a particular level of functioning. The key difference is that Sen guarantees all persons access to basic capabilities throughout their lives, whereas luck egalitarianism would (potentially) allow the victims of bad option luck to lose these capabilities.

Sen's focus on capabilities to achieve functionings is an appealing way of understanding advantage. However, as Dworkin points out, capability equality may simply collapse into a more familiar resourcist or welfarist 
approach. When measuring a person's bundles of resources, Dworkin includes personal resources such as health and physical capacity, which suggests that his approach actually is sensitive to human diversity. So the fact people have different metabolic rates, to use Sen's example, is relevant to equality of resources. ${ }^{147}$ This is different to the practical issue of whether a person will be compensated for having an inefficient metabolism. In equality of resources, this will depend on the outcome of the hypothetical insurance market, but Dworkin believes that those severely disadvantaged by an inefficient metabolic rate are likely to receive assistance. ${ }^{148}$ In this aspect, the capabilities approach does not add anything to Dworkin's theory of equality of resources.

Dworkin argues that the only way the two approaches could differ on a theoretical level is if Sen actually supports equality of welfare. This interpretation is possible because Sen includes happiness, self-respect and community participation in his list of functionings. ${ }^{149}$ Yet our ability to achieve these functionings varies greatly, reflecting many factors including the distribution of opinions throughout the community. To insist we have an equal capacity in these areas is dangerous and strange. ${ }^{150}$ Dworkin argues that a lack of resources is usually the key obstacle to achieving these functionings, and in this respect, equality of resources will help individuals achieve happiness, selfrespect and community participation without making these functionings the object of the theory. ${ }^{151}$

Cohen also links capability equality to his theory of equality of access to advantage. ${ }^{152}$ He highlights that his notion of “access” is quite similar to Sen’s "capability," and he understands "advantage” as a heterogeneous notion that draws on welfarist and resourcist considerations, as does Sen's notion of functionings. Nonetheless, Cohen highlights an ambiguity in Sen's approach, 
relating to the notion of "midfare," which is an important component of egalitarian advantage. $^{153}$

\section{COHEN AND HETEROGENEOUS ADVANTAGE}

Cohen uses the term "midfare" to describe that part of individual well-being that lies between primary goods and utility. It describes what individuals get from goods, other than utility:

It is indeed false that the whole relevant effect on a person of his bundle of primary goods is on, or in virtue of, his mental reaction to what they do for him. There is also what welfarists ignore: what they do for him, what he gets out of them, apart from his mental reaction to or personal evaluation of that service. I shall call that non-utility effect of goods midfare, because it is in a certain sense midway between goods and utility. Midfare is constituted of states of the person produced by goods, states in virtue of which utility levels take the values they do. It is 'posterior' to 'having goods' and 'prior' to 'having utility'. ${ }^{154}$

Cohen argues that the term “capability” fails to capture (or, at least obscures) an important component of midfare, even though Sen himself identifies this component in his work.

Goods endow individuals with three different types of midfare. Firstly, there are the capabilities that goods endow us with; secondly, the valuable activities and desirable states that arise from exercising these capabilities; and thirdly, the "further desirable states directly [caused by these goods], without any exercise of capability on the part of their beneficiary: an example would be the goods which destroy the insects that cause malaria.”" 155 Not having malaria is part of midfare (it is a desirable state) without the individual involved having to do anything to bring it about. The point is that " $[\mathrm{w}]$ hat goods do to people is identical neither with what people are able to do with them nor with what they 
actually do with them (and it is also not identical with all or part of the combination of these two things)."156 The most important thing that individuals get from food is nourishment. But it is usually the state of being nourished, rather than having the capability to nourish oneself that matters. So a baby who is fed enjoys midfare, even though she exercises no capability herself (unless sucking and chewing counts). Similarly, an individual enjoys midfare even when she gets nutriment through a hospital drip. ${ }^{157}$ Thus, whilst egalitarians should be concerned with what people are able to achieve, and with a notion of an individual's state of being that sits between resources and utility, these are separate concerns. Moreover, the second concern -- well-being between resources and utility -- cannot sensibly be described as “capability.” 158

This conceptual confusion reflects the way Sen "overestimates the place of freedom and activity in well-being.”159 Even when he defines functionings as doings and beings, which seems to extend it into the third component of midfare, he claims that "the central feature of well-being is the ability to achieve valuable functionings.” ${ }^{160}$ In other words, he places achievement squarely back into the picture and, as Cohen has already established, key aspects of a person's well-being can be improved without her needing to exercise any capability.

Cohen takes this further arguing that the most important aspect of human well-being for egalitarians, is satisfying basic midfare requirements. This could be determined objectively, based on the midfare that is required for “a normal human existence... whose absence spells non-satisfaction of need.”161 Similar reasoning also explains why, pace Arneson, the capability approach need not collapse into equality of opportunity for welfare. ${ }^{162}$ Even if 
higher-level capabilities can only be ranked in terms of their utility value, at the basic level, we may be able to determine the ranking objectively because it is more obvious what basic things are needed for "a normal human existence." Nonetheless, Cohen supports the idea of access to advantage, rather than capability because “[i]n that proposal, 'advantage' is, like Sen’s 'functioning' in its wider construal, a heterogeneous collection of desirable states of the person reducible neither to his resources bundle nor to his welfare level. And, while 'access' includes what the term normally covers, I extend its meaning under a proviso that anything which a person actually has counts as something to which he has access, no matter how he came to have it, and, hence, even if his coming to have it involved no exploitation of access in the ordinary sense (nor, therefore, any exercise of capability).”163

Cohen's approach becomes even more complex when we realise just how expansive his notion of advantage is. When comparing how individuals fare, egalitarians must pay attention to resource holdings, as well as basic midfare. To demonstrate the relevance of a resourcist component, Cohen gives the example of Tiny Tim who needs a wheelchair to secure a basic level of mobility, but who also has a happy disposition, which leaves him "with abundant opportunity for happiness: he need not do much to get a lot of it.”164 Cohen points out that it would be counter-intuitive for egalitarians to deny Tim his wheelchair purely because his welfare level is high. ${ }^{165}$ Egalitarians support providing assistance to the disabled for reasons that are independent of any welfarist considerations.

Nonetheless, Cohen believes that welfare is relevant to an egalitarian conception of advantage. He demonstrates this by extending the Tiny Tim example further. As well as paralysis, Tiny Tim suffers from severe pain every 
time he moves his arms. He is able to move his arms, and in fact he is particularly good at doing so, but the pain he experiences afterwards means that this action is very costly for him. ${ }^{166}$ Cohen believes that most egalitarians would support providing this man with expensive medicine to suppress his pain. However, the disadvantage here is in the level of welfare he enjoys. We are compensating him for the pain he suffers, not because of any resource incapacity. ${ }^{167}$ Thus, welfare sits alongside resources and basic midfare in Cohen's complex, heterogeneous conception of advantage.

Although Cohen's argument for a heterogeneous conception of advantage is a convincing one, this heterogeneity may be considered a drawback. ${ }^{168}$ This problem is exacerbated by the fact Cohen does not explain in detail how we should balance resources, welfare and midfare in a workable conception of advantage. This is not necessarily a decisive objection to Cohen's approach, but it does raise the possibility that its appeal is chimerical. It is only because it is undefined and imprecise that it can be all things to all people (a criticism that Dworkin makes of both Cohen, and welfarist approaches generally). ${ }^{169}$ Although Cohen has not responded to this objection in detail, he has mounted a short, unpublished defence of this heterogeneity. ${ }^{170}$

To reiterate why we need a heterogeneous measure, Cohen proposes an example that relates more directly to the kind of challenges egalitarian policymakers face. ${ }^{171}$ It involves two families who are both poorly housed, and who, in an objective sense, equally need better accommodation. Despite the fact both families are subjected to sub-standard accommodation, “the Happy family’s members are serene while the Sad family’s are in great distress.”172 In this case, egalitarian justice would recommend prioritising the Sad family on the housing 
waiting list. In fact, even were the Sads to enjoy better accommodation, they may still have "some priority" over the Happy family. ${ }^{173}$ However, Cohen believes that there are limits in the latter case. It would seem unjust to make the Happy family endure a ten year wait for better housing because they are happier than the Sads. A six month wait, on the other hand, would not seem so bad. If this response is correct, then both resources and welfare have a role to play in egalitarian justice. ${ }^{174}$ When egalitarians ask “Equality of What?” the answer is not a homogeneous quantity of something. ${ }^{175}$

This response to the example also suggests a way to render the heterogeneous conception of advantage more precise. As Cohen puts it:

Perhaps the right course is to develop a metric with complex lexicalities: in the housing example, we look at the resource position first (how bad is a person's current accommodation?), then her welfare matters, but only if it is below a certain level, yet how much it matters depends on how bad other people's resource position is, and so on. ${ }^{176}$

The approach Cohen proposes would impose much greater order on a heterogeneous conception of advantage, apparently without sacrificing the broader appeal of the ideal.

At this point, it might be helpful to briefly recap my own position on the issues we have discussed in this chapter. I agree with Cohen that egalitarians should use a heterogeneous notion of advantage. Resources, welfare and basic midfare are all relevant to interpersonal comparisons of well-being. Dworkin was wrong to dismiss welfarism on the grounds of the expensive tastes criticism. Both conscious-state welfare and welfare as relative success are defensible and important factors for egalitarians to take into account when assessing well-being. I also think that Cohen's lexical approach provides a 
promising basis for developing a more precise notion of advantage. Nonetheless, Cohen's proposal is brief, and in need of further refinement. In the remainder of this section, I will outline my own version of this lexical approach. In the final section of the chapter, I will examine whether this conception of advantage is sensitive to the kind of oppression discussed in chapter 2 .

I agree with Cohen's claim that the most important aspect of egalitarian advantage is the extent to which individuals enjoy a basic level of midfare. This basic level must be objectively defined to include the kind of physiological requirements that are needed to live an autonomous life. However, once this basic level (or midfare threshold) has been reached, midfare no longer matters. For instance, if all humans are able to obtain a sufficient level of nutrition to live a full, healthy life, then egalitarian interest in this matter is exhausted. It does not matter whether some are able to enjoy extra nutrition (unless it actually does improve their quality of life somehow). ${ }^{177}$ Prioritising basic midfare does not mean that we have switched from an egalitarian approach, to a prioritarian or threshold approach. We are still interested in the relative standing of individuals below this threshold (though naturally most egalitarians would, for non-egalitarian reasons, hope that they reach this threshold, the same way a welfare egalitarian would want all individuals to enjoy a higher level of welfare). Thus, in a two-person world where egalitarian justice is our only consideration, we should redistribute resources from a person whose midfare level is above the threshold, to help raise the midfare level of someone whose midfare level is below the threshold. But once everybody reaches this threshold, we become more interested in other aspects of their condition. If two individuals are above the threshold, but have different levels of midfare, neither 
is considered to be disadvantaged, on these grounds alone. Basic midfare is the most important component of advantage but once we have reached the threshold, midfare is no longer relevant to interpersonal comparisons, and we turn to focus on the other components of advantage.

The next consideration is achieving a minimum level of conscious-state welfare (“enjoyment” and “dissatisfaction” in Dworkin's terms). In other words, once the basic midfare requirements have been met, we are interested in the level of "enjoyment” and "dissatisfaction," which individuals enjoy. Once again, we will need to make an objective judgement about where the threshold should be set. An obvious example is that individuals should be able to live their lives without suffering from severe pain, or crippling depression. Achieving a basic level of conscious-state welfare is more important to an individual's level of well-being than her share of social resources, or relative success, so it takes priority over these other aspects of advantage.

The next most important component of advantage is having access to a basic range of resources that are necessary to achieve a minimum degree of functioning in society. This requirement is consistent with our intuitive response to the Tiny Tim example. Those who require a wheelchair to achieve a sufficient level of mobility should have access to one, even if they enjoy a high level of welfare. However, the basic resources requirement does come after a minimum conscious-state welfare requirement. This means that Tiny Tim's need for a wheelchair is deemed less important than the needs of someone who suffers from crippling pain, or some other form of severely low conscious-state welfare. However, in reality, most people are likely to fall below the minimum level of conscious-state welfare if their mobility is restricted, so they would be guaranteed access to wheelchairs on these grounds anyway. Nonetheless, the 
resourcist component explains why egalitarians consider Tiny Tim and the Happy family disadvantaged despite their high level of welfare.

Up to this point, my account has contained components of advantage covering the basic requirements of life. The remaining categories are concerned with the level of "non-basic" advantage we enjoy, beginning with welfare as relative success, with only inegalitarian and offensive preferences excluded from consideration. This measure is included because egalitarians should care about the extent to which people are able to live fulfilling lives. This means that an important component of egalitarian advantage is the extent to which individuals are able to satisfy their valued preferences. Taking this into account means that luck egalitarians may be obliged to provide compensation to those who have expensive tastes

The final component of egalitarian advantage is non-basic consciousstate welfare. When individuals are equal in all the components of advantage that I have just outlined, then the extent to which they experience enjoyment, as opposed to dissatisfaction is relevant. For instance, if two individuals are equal in every way except that one experiences great enjoyment most of her life, when the other is only just on the minimum threshold of conscious-state welfare, then she does seem to be at a disadvantage. Other things being equal, we should redistribute resources between these two individuals so as to equalise their level of enjoyment. This is the final plank in a complicated, but logical and ordered account of egalitarian advantage.

A possible objection might arise from the problem of cheap adaptive preferences. ${ }^{178}$ Preferences are influenced by our social circumstances, so individuals who become accustomed to conditions of poverty may develop stunted ambitions, demanding little from life in terms of material comfort and 
preference satisfaction. If we accept, for the sake of argument, that this does occur, then any egalitarian theory with a welfarist conception of advantage may have inegalitarian implications. The victims of an unequal distribution of income and wealth will become accustomed to their poverty, and will be satisfied with very little, whilst epicures who are used to the trappings of wealth will only reach an equivalent level of welfare if they are able to live a far more expensive lifestyle. In subsidising expensive tastes, egalitarians simply perpetuate the existing, unequal distribution of resources.

However, an egalitarian theory that is based on the notion of advantage I have outlined here is less susceptible to the adaptive preferences problem than purely welfarist accounts. My approach gives priority to meeting the basic midfare, conscious-state and resource needs of individuals, before taking into account broader notions of welfare. Consequently, the basic needs of those with cheap adaptive preferences will be satisfied before we start giving extra to those with a taste for an expensive lifestyle. This does not entirely alleviate our concern, but it does at least partially address it. Furthermore, we can only hope that once people enjoy access to the necessities of life, they will become accustomed to a higher standard of living, and start to demand more. Finally, as I explained in section 3, expensive tastes may be non-compensable if they have arisen as a result of past injustices.

The account of egalitarian advantage I have developed here is a complex but structured one. Combined with the theory of luck egalitarianism I outlined in chapter 3, which involves difficult judgements about individual responsibility and choice, we are left with a very unwieldy theory. It would be easier if egalitarians could avoid this complexity but, in itself, this provides no reason to reject either luck egalitarianism or the conception of egalitarian 
advantage I have outlined here (at least, not at the fact-insensitive level of principle that we are concerned with). Moreover, the practical policy applications of this theory may be more straightforward than they initially appear to be, as I shall explain in chapter 7. Nonetheless, a final theoretical challenge to my account of egalitarian advantage must be considered. Does it lead to a theory of luck egalitarianism that is sensitive enough to the disadvantages associated with social oppression?

\section{SOCIAL OPPRESSION}

In chapter 2 I argued, pace Anderson, that luck egalitarianism will condemn instances of oppression, provided that we adopt a conception of advantage that is sensitive to non-material inequalities. I argued that we should regard social oppression as bad brute luck because it is objectively disadvantageous. Even if this oppression arises because of a preference we deliberately cultivate, it is bad brute luck. For instance, if we decide to convert to an oppressed religion, any oppression we suffer as a result is considered to be an unjust, objective disadvantage from a luck-egalitarian perspective. It is bad brute luck to be oppressed because of preferences and commitments we deeply identify with, regardless of whether they were deliberately cultivated. In effect, these preferences and commitments are a form of judgemental taste. Is the account of advantage that I have offered here consistent with this position?

My approach to these expensive tastes in chapter 2 is similar to Cohen's approach, which I endorsed in section 4 of this chapter. Cohen also supports compensation for expensive tastes that are crucial to our identity because they are crucial to our identity. However, our accounts partly differ on why the oppression that arises from these beliefs is unjust. In chapter 2, I argued that 
oppression counts as bad brute luck because it is objectively disadvantageous. Egalitarians should support an objective view of the good life that includes the idea of being able to pursue our legitimate beliefs and preferences free from persecution. In contrast, there is nothing in my account of advantage in this chapter, nor, as far as I can see, in Cohen's account, that rules out such oppression, independent of its impact on our subjective welfare. In practice, this is unlikely to be a problem because the oppressed will suffer severe disutility from the oppression of beliefs and ways of living that they deeply identify with. However, as Anderson argues, oppression would offend egalitarian justice, even if it had no impact on our subjective welfare. For egalitarians, oppression is fundamentally bad for human beings. It is intrinsically disadvantageous, whatever the individual concerned thinks about it.

I must refine my account of advantage to incorporate this idea. Phrased in positive terms, it is a claim that freedom from oppression is objectively advantageous. Although it is difficult to determine where this notion of advantage should be located in the approach I outlined in the last section, I think it should come after the basic level of resources, and before welfare as success. For egalitarians, freedom from oppression is a basic requirement of living a good life. By incorporating it as an objective component of advantage, we ensure that it will be taken into account. This allows us to condemn the kind of social oppression highlighted by Young and Anderson and discussed in chapter 2 .

One problem with treating oppression in this way is that it raises the spectre of false consciousness. I am assuming that a person may be disadvantaged by something that she herself does not regard as disadvantageous. However, it is not false consciousness simply to claim that 
individuals can be disadvantaged in ways that they do not recognise. For instance, returning to Cohen's midfare example, having malaria is a disadvantage, regardless of the view of the malaria victim. We need not make assumptions about "real will" or "genuine selves" to reach this conclusion. Moreover, it must be remembered that the account of advantage I propose in this chapter is part of a broader theory of luck egalitarianism, which is based on the notion of individual choice. If an autonomous individual were genuinely to choose oppression, then luck egalitarianism provides no grounds for condemning or preventing this state of affairs. The individual concerned has genuinely chosen to expose herself to something that egalitarians regard as disadvantageous. ${ }^{179}$ There may be other reasons to prevent such oppression, but they have nothing to do with luck egalitarianism. Thus, the version of the theory that I support cannot be condemned on the grounds of false consciousness.

\section{CONCLUSION}

In this chapter, I have identified an account of advantage to help egalitarians conduct interpersonal comparisons. After reviewing welfare and resources, I concluded that Cohen is right to suggest that a heterogeneous conception of advantage is needed. Focusing on resources seems fetishistic and ignores welfarist considerations, particularly pain, that are relevant to egalitarian judgements. And despite the power of Dworkin's critique, he does not successfully show that we should exclude subjective welfare from our account of egalitarian advantage. However, the Tiny Tim example demonstrates that it would also be unsatisfactory to restrict our focus to welfare, ignoring the importance of resources. Sen and Cohen also offer convincing arguments that 
something other than welfare and resources is relevant to advantage, which led me to incorporate the notion of midfare in my account. To make this heterogeneous conception of egalitarian advantage more precise, I explained how the different components of advantage relate to each other, modifying Cohen's use of complex lexicalities. I have also added an objective component of advantage, associated with freedom from social oppression, which satisfies the theoretical challenge raised in chapter 2 .

Before we conclude, I want to emphasise that this account of egalitarian advantage is likely to require further refinement. I have attempted to defend the use of a heterogeneous approach, and to outline a basic framework for rendering this approach more precise, but it is possible that further modifications and clarifications will be needed. In particular, it may be necessary to alter the ordering of the various components of advantage. For example, access to basic resources may be deemed more important than achieving a basic level of conscious-state welfare. If so, then there would be grounds for altering the ordering of these two components. There may also be grounds for expanding the scope of the objective component of egalitarian advantage. Nonetheless, I hope that my analysis in this chapter can provide a basic framework for future work on this topic.

Having outlined a conception of egalitarian advantage to incorporate into the theory of luck egalitarianism I outlined in chapter 3, we can now take a broader focus. In the next chapter, I will analyse the challenge posed by alternative theories of distributive justice and egalitarianism, and in the final chapter I will examine the practical applications of the theory. 


\section{NOTES}

${ }^{1}$ J. Rawls, A Theory of Justice, Oxford, Oxford University Press, 1972, p. 92.

${ }^{2}$ Rawls, A Theory of Justice, p. 92. See also p. 62.

${ }^{3}$ Rawls, A Theory of Justice, p. 92. Rawls explains his principles of justice with reference to representative individuals: "when principles mention persons, or require that everyone gain from an inequality, the reference is to representative persons, holding the various social positions, or offices, or whatever, established by the basic structure.” See A Theory of Justice, p. 64.

${ }^{4}$ Rawls, A Theory of Justice, pp. 92, 303 and see also p. 62. Also note the modified list of primary goods offered by Rawls in "Social Unity and Primary Goods," in S. Freeman (ed.), Collected Papers, Cambridge, Mass., Harvard University Press, 1999, pp. 359-87, at pp. 362-3; Political Liberalism, New York, Columbia University Press, 1996, p. 181; and Justice as Fairness: A Restatement, ed. E. Kelly, Cambridge, Mass., Harvard University Press, 2001, pp. 58-9. The key change in these later works is the addition of two categories of primary goods which replace (or more accurately, expand on) the "powers and opportunities" category. Thus, Rawls adds to his list of primary social goods the "freedom of movement and free choice of occupation against a background of diverse opportunities;" and "powers and prerogatives of offices and positions of responsibility in the political and economic institutions of the basic structure”. Although these quotations are from Political Liberalism, very similar statements are also found in "Social Unity and Primary Goods" and Justice as Fairness: A Restatement. Rawls also raises the possibility of expanding his account of primary goods "to include other goods, for example, leisure time, and even certain mental states such as freedom from physical pain.” See Political Liberalism, pp. 181-2 \& also note "Reply to Alexander and Musgrave," in Collected Papers, pp. 232-53, at pp. 252-3.

${ }^{5}$ Rawls, A Theory of Justice, p. 62.

${ }^{6}$ This is the theme of Political Liberalism (e.g. pp. 173-6). See also "Social Unity and Primary Goods,” pp. 359, 365-8.

${ }^{7}$ Rawls, “Social Unity and Primary Goods,” p. 365.

${ }^{8}$ Rawls, “Social Unity and Primary Goods,” p. 365. I have chosen to quote this passage from “Social Unity and Primary Goods” because it is a fairly concise summary of Rawls's conception 
of the person. For a more extensive discussion, see Political Liberalism, pp. 18-20.

${ }^{9}$ Rawls, “Social Unity and Primary Goods,” p. 366.

${ }^{10}$ All quotations in this paragraph are from Rawls, "Social Unity and Primary Goods,” p. 366.

${ }^{11}$ Rawls, “Social Unity and Primary Goods,” pp. 366-7.

${ }^{12}$ Rawls, “Social Unity and Primary Goods,” p. 367; Political Liberalism, p. 187.

${ }^{13}$ Rawls, “Social Unity and Primary Goods,” p. 367.

${ }^{14}$ Rawls, “Social Unity and Primary Goods,” p. 368.

${ }^{15}$ Rawls, “Social Unity and Primary Goods,” p. 367.

${ }^{16}$ Rawls, “Social Unity and Primary Goods,” p. 364.

${ }^{17}$ Rawls, A Theory of Justice, p. 95. See also “Social Unity and Primary Goods,” pp. 370-1, 373-4; Political Liberalism, pp. 187-9; Justice as Fairness: A Restatement, p. 60.

${ }^{18}$ Rawls, “Social Unity and Primary Goods,” pp. 373-4; Political Liberalism, especially pp. 188-9, including n. 20; Justice as Fairness: A Restatement, p. 60.

${ }^{19}$ E.g. A.K. Sen, “Equality of What?” in S. Darwall, (ed.), Equal Freedom: Selected Tanner Lectures on Human Values, Ann Arbor, University of Michigan Press, 1995, pp. 307-30, at pp. 325-6; and K.J. Arrow, “Some Ordinalist-Utilitarian Notes on Rawls’s Theory of Justice,” Journal of Philosophy, V. 70, no. 9, 1973.

${ }^{20}$ Sen, “Equality of What?” pp. 325-6.

${ }^{21}$ Sen, “Equality of What?” p. 326, his emphasis.

${ }^{22}$ Sen, “Equality of What?” p. 326.

${ }^{23}$ Rawls, Political Liberalism, p. 183. See also “Social Unity and Primary Goods,” p. 368; Justice as Fairness: A Restatement, pp. 60, 169-70.

${ }^{24}$ Rawls, Political Liberalism, p. 184.

${ }^{25}$ Rawls, Political Liberalism, p. 184. See also “Social Unity and Primary Goods,” p. 368; Justice as Fairness: A Restatement, p. 173.

${ }^{26}$ Rawls, Justice as Fairness: A Restatement, p. 169.

${ }^{27}$ Rawls, Justice as Fairness: A Restatement, pp. 169-170.

${ }^{28}$ See also “Social Unity and Primary Goods,” pp. 368-9; Political Liberalism, pp. 185-6.

${ }^{29}$ Cohen also uses the pain example to show why egalitarian advantage must contain a welfarist component. See, for example, "On the Currency of Egalitarian Justice,” Ethics, V. 99, no. 4, 
1989 pp. 906-944, at pp. 918-919. I discuss Cohen’s views on this issue in more detail below.

${ }^{30}$ Rawls actually presents the offensive tastes objection as a criticism of utilitarianism rather than welfarism, but the criticism also extends to cover welfarism more generally. See Sen, “Equality of What,” p. 321; \& Cohen, “On the Currency of Egalitarian Justice,” p. 912. I draw the "offensive tastes" terminology from Cohen.

${ }^{31}$ Rawls, A Theory of Justice, pp. 30-1.

${ }^{32}$ Rawls, “Social Unity and Primary Goods,” p. 369.

${ }^{33}$ Rawls, Political Liberalism, p. 185 \& p. 185 n. 15.

34 Although, as Arneson and Cohen point out, egalitarians who focus on equalising opportunities for welfare will not necessarily view this disadvantage as unjust. Rather, this judgement depends on whether the person concerned is responsible for the taste in question. See Chapter 1 for more discussion of this issue.

${ }^{35}$ Rawls, “Social Unity and Primary Goods,” p. 369. See also Political Liberalism, pp. 33-4, 185-87.

${ }^{36}$ Rawls, “Social Unity and Primary Goods,” p. 371. Note also Political Liberalism, pp. 189-90.

${ }^{37}$ Political Liberalism, pp. 181-82. However, immediately after making this suggestion, Rawls suggests that "the political and the practicable" provide limits on the kind of things we can take into account when making interpersonal comparisons.

${ }^{38}$ Dworkin, Sovereign Virtue, Cambridge, Mass., Harvard University Press, 2000, p. 12.

${ }^{39}$ See Dworkin, Sovereign Virtue, pp. 113, 299-301, 491 n. 15.

${ }^{40}$ Cohen, “On the Currency of Egalitarian Justice,” p. 918. This is the Tiny Tim example, which I discuss in more detail below.

${ }^{41}$ Cohen, “On the Currency of Egalitarian Justice,” p. 919. See also “Expensive Taste Rides Again,” pp. 9-10.

${ }^{42}$ Cohen, “On the Currency of Egalitarian Justice,” p. 920.

${ }^{43}$ See Sen, “Equality of What?” p. 315.

${ }^{44}$ Dworkin Sovereign Virtue, p. 14.

${ }^{45}$ Dworkin, Sovereign Virtue, pp. 16-19. It should be noted that Dworkin is interested, specifically, in the three different forms of equality of welfare that emerge from these different ways of interpreting "welfare.” 
${ }^{46}$ See also Dworkin, Sovereign Virtue, p. 16.

${ }^{47}$ Dworkin Sovereign Virtue, p. 17.

${ }^{48}$ For related criticisms to this one, see also Rawls, A Theory of Justice, pp. 30-1; and see and cf. Sen, “Equality of What?” pp. 320-1.

${ }^{49}$ Dworkin, Sovereign Virtue, p. 22.

${ }^{50}$ Dworkin, Sovereign Virtue, p. 25.

${ }^{51}$ See also Sovereign Virtue, p. 25. Dworkin also says that unrestricted equality of success will collapse into equality of nonpolitical preferences if everybody shares the same political preference for equality of unrestricted success. See Sovereign Virtue, pp. 24-5. I have also left aside a number of other technical and practical problems, as Dworkin himself does. See Sovereign Virtue, pp. 21-2.

${ }^{52}$ Cohen makes a similar response to the "offensive tastes criticism." See "On the Currency of Egalitarian Justice,” pp. 912-13.

${ }^{53}$ Macleod makes a similar point in his critique of Dworkin’s theory of equality of resources. If individuals have warped preferences then this will affect their behaviour in the initial auction process and the insurance market, and may produce apparently inegalitarian outcomes. This means that it is important for supporters of Dworkin's approach to focus on the conditions in which people’s preferences are formed. See C.M. Macleod, Liberalism, Justice, and Markets: A Critique of Liberal Equality, Oxford, Oxford University Press, 1998, especially chapter 2, pp. 19-45.

${ }^{54}$ Dworkin, Sovereign Virtue, p. 17.

${ }^{55}$ Dworkin Sovereign Virtue, pp. 25-6.

${ }^{56}$ Dworkin, Sovereign Virtue, pp. 27, 38-42.

${ }^{57}$ Dworkin, Sovereign Virtue, p. 17.

${ }^{58}$ Dworkin, Sovereign Virtue, p. 28.

${ }^{59}$ Dworkin, Sovereign Virtue, pp. 28-9.

${ }^{60}$ Dworkin, Sovereign Virtue, p. 30.

${ }^{61}$ Dworkin, Sovereign Virtue, p. 30.

${ }^{62}$ Dworkin, Sovereign Virtue, p. 30.

${ }^{63}$ Dworkin, Sovereign Virtue, p. 29. I have added "relative" to this quotation because the 
sentence immediately following this one reads: "At least they do in one sense of success and failure.” Dworkin then outlines the relative-overall success distinction pp. 29-30.

${ }^{64}$ One source of this problem is the fact that some individuals might care more about their political or impersonal preferences than their personal preferences, but the approach under consideration here only takes the latter into account. However, Dworkin does not believe that this is a decisive objection because supporters of this approach could still claim that it "makes people equal in what they all value equally and fundamentally so far as their own personal situations or circumstances are concerned.” See Dworkin, Sovereign Virtue, p. 31.

${ }^{65}$ Dworkin, Sovereign Virtue, p. 31.

${ }^{66}$ Dworkin, Sovereign Virtue, pp. 31-32.

${ }^{67}$ G.A. Cohen, “Expensive Taste Rides Again,” in J. Burley (ed.), Dworkin and his Critics, Malden, Mass., Blackwell Publishing, 2004, p. 16.

${ }^{68}$ Of course, the fact relative success is not fundamentally important to all does undermine one of the reasons we might be initially attracted to equality of success, but, as Dworkin points out, it does not constitute a decisive objection to the theory.

${ }^{69}$ See Arneson, "Liberalism, Distributive Subjectivism, and Equal Opportunity for Welfare," Philosophy and Public Affairs, V. 19, no. 2, 1990, pp. 158-194, at pp. 180-1. However, I should note that Arneson goes on to reject equality of relative success. See pp. 181-2 n. 29.

${ }^{70}$ Dworkin, Sovereign Virtue, p. 36.

${ }^{71}$ Dworkin explores alternatives ways of measuring overall success which could help overcome this problem, pp. 36-8. He suggests that we could ask an individual to compare the value of her current life to the value of her life under ideal/worst conditions, or to what she considers to be a completely valueless life. However, the problem we faced above would resurface-- inequalities in the overall success of individuals would reflect differences in their beliefs, not the overall quality of their lives. See Sovereign Virtue, pp. 36-38. Dworkin also levels the "reasonable regret” criticism against equality of overall success. See Dworkin, Sovereign Virtue, pp. 38-9.

${ }^{72}$ Note also Arneson, "Liberalism, Distributive Subjectivism, and Equal Opportunity for Welfare,” p. 181.

${ }^{73}$ Dworkin, Sovereign Virtue, pp. 17-18.

${ }^{74}$ Dworkin, Sovereign Virtue, p. 18. 
${ }^{75}$ Dworkin, Sovereign Virtue, p. 18.

${ }^{76}$ Dworkin, Sovereign Virtue, p. 42.

${ }^{77}$ Dworkin, Sovereign Virtue, pp. 42-3.

${ }^{78}$ Dworkin, Sovereign Virtue, pp. 43-4.

${ }^{79}$ Dworkin, Sovereign Virtue, p. 44.

${ }^{80}$ Dworkin, Sovereign Virtue, p. 44.

${ }^{81}$ Dworkin, Sovereign Virtue, pp. 44-45.

${ }^{82}$ Dworkin, Sovereign Virtue, p. 45.

${ }^{83}$ This support was conditional upon being able to provide a satisfactory response to the expensive tastes objection in the next section.

${ }^{84}$ Dworkin, Sovereign Virtue, p. 46, my emphasis.

${ }^{85}$ Dworkin, Sovereign Virtue, p. 46.

${ }^{86}$ Dworkin, Sovereign Virtue, p. 46.

${ }^{87}$ Dworkin, Sovereign Virtue, p. 47.

${ }^{88}$ I have not discussed Dworkin's brief argument against the idea that equality of welfare could be rescued by combining the various welfarist approaches he examines. See section VII, in Sovereign Virtue, pp. 47-8. I do not believe that the points he raises here would alter my conclusion that his critique of equality of welfare is unsuccessful.

${ }^{89}$ Dworkin, "Ronald Dworkin Replies,” in J. Burley (ed.), Dworkin and His Critics: with Replies by Dworkin, Malden, Blackwell Publishing, 2004, pp. 339-395, at p. 389 n. 5.

${ }^{90}$ He shows that equality of welfare inevitably results in compensating individuals for their expensive tastes. Any attempt to modify the theory to avoid this conclusion ultimately leads to the abandonment of equality of welfare and the adoption of equality of resources. See Sovereign Virtue, pp. 48-59.

${ }^{91}$ G.A. Cohen, “Expensive Taste Rides Again,” in Dworkin and His Critics, pp. 5-6. Embedded quotations are from Dworkin, Sovereign Virtue, p. 48.

${ }^{92}$ Cohen, “Expensive Taste Rides Again,” p. 6.

${ }^{93}$ Cohen, “Expensive Taste Rides Again,” p. 7.

${ }^{94}$ Unless stated otherwise, "compensable tastes" in the rest of this chapter refers to tastes that are compensable on the grounds of egalitarian justice. 
${ }^{95}$ Cohen, “Expensive Taste Rides Again,” p. 7.

96 "So it is no reason to deny support that the claimants in question identify with their preferences. But I do not say the polar opposite of what Dworkin does: I do not say that wherever there is an expensive identification, there is a case for support. And... I was certainly wrong, in 'Currency,' to distinguish the cases merely according to presence and absence of will, although I think they do count.” Cohen does not give a detailed explanation of the grounds for withholding support for an expensive judgemental preference, but one example is when individuals deliberately cultivate preferences that are expensive for "Louis-like snobbish reasons that justify less sympathy." See "Expensive Taste Rides Again,” pp. 12, 14, 20, quotations at p. 12.

${ }^{97}$ Cohen, “Expensive Taste Rides Again,” p. 8.

${ }^{98}$ Dworkin, “Ronald Dworkin Replies,” p. 344.

${ }^{99}$ See Cohen, “Expensive Taste Rides Again,” pp. 7-8 \& cf. Cohen, “On the Currency,” p. 923.

${ }^{100}$ Dworkin, “Equality and Capability” in Sovereign Virtue, pp. 285-303; “Ronald Dworkin Replies,” pp. 339-50.

${ }^{101}$ Dworkin, Sovereign Virtue, p. 289.

${ }^{102}$ Dworkin, “Equality and Capability” in Sovereign Virtue, p. 289.

${ }^{103}$ Dworkin, Sovereign Virtue, p. 290.

${ }^{104}$ Dworkin, Sovereign Virtue, p. 289 \& pp. 291-96.

${ }^{105}$ Dworkin, Sovereign Virtue, p. 295.

${ }^{106}$ Dworkin, Sovereign Virtue, p. 298.

${ }^{107}$ Dworkin, Sovereign Virtue, pp. 298-9.

${ }^{108}$ Dworkin, Sovereign Virtue, p. 298, his emphasis.

${ }^{109}$ Dworkin, Sovereign Virtue, p. 291. I discussed this example in chapter 1 of the thesis.

${ }^{110}$ Cohen, “Expensive Taste Rides Again,” p. 19.

${ }^{111}$ See Cohen’s objection 1 in “Expensive Taste Rides Again,” p. 19.

${ }^{112}$ Cohen, “Expensive Taste Rides Again,” p. 20. See also Cohen’s objection 2 on p. 19, and pp. 20-22.

${ }^{113}$ Cohen, “Expensive Taste Rides Again,” p. 22.

${ }^{114}$ See objection 2 on p. 19 and section X, pp. 20-22 for more detailed discussion of the idea 
"that some preferences reflect more will than others do, in a way that bears on justice." It should also be noted that Cohen actually supports equality of access to advantage, not opportunity for welfare. The fact he includes non-welfarist elements in his notion of advantage is a further reason why his approach does not collapse into equality of welfare. See objection 3 , p. 19.

${ }^{115}$ Cohen, “Expensive Taste Rides Again,” pp. 11-12.

${ }^{116}$ Cohen, “Expensive Taste Rides Again,” p. 12.

${ }^{117}$ Sen, “Equality of What?” p. 326. I discuss Sen’s argument in more detail in the next section.

${ }^{118}$ Cohen, “Expensive Taste Rides Again,” p. 17.

${ }^{119}$ Obviously, there will be non-egalitarian limitations on our ability to compensate individuals for their expensive tastes and to challenge market outcomes. One obvious such limitation is individual privacy. See Cohen, “Expensive Taste Rides Again,” pp. 17-18. I discuss this issue in more detail below.

${ }^{120}$ Once again, this assumes that the preference is not inegalitarian or offensive.

${ }^{121}$ Cohen, “Expensive Taste Rides Again,” p. 7.

${ }^{122}$ Cohen, “Expensive Taste Rides Again,” p. 9.

${ }^{123}$ Dworkin, Sovereign Virtue, p. 288. Cohen also gives a slightly longer version of this quote in “Expensive Taste Rides Again,” p. 9.

${ }^{124}$ Cohen, “Expensive Taste Rides Again,” p. 9.

${ }^{125}$ Cohen, “Expensive Taste Rides Again,” p. 9.

${ }^{126}$ Dworkin, “Ronald Dworkin Replies,” p. 350.

${ }^{127}$ Although he is illustrating a different point from mine, Dworkin gives a related example of snobbery, commenting that "Louis would have suffered if he found, to his dismay, that he continued to enjoy TV dinners.” See \& cf. Sovereign Virtue, p. 289.

${ }^{128}$ Admittedly, this is highly unlikely to occur in reality, but it does remain a theoretical possibility and thus a theoretical weakness in Dworkin's approach.

${ }^{129}$ In contrast, Cohen's scheme will be less sympathetic towards snobbery. See p. 158 and n. 96 above.

130 Thus, although I follow Dworkin in explaining conscious state welfare in terms of enjoyment and dissatisfaction, "job satisfaction" uses the term "satisfaction" in a broader sense 
to include welfare as relative success, as well as conscious-state welfare.

${ }^{131}$ If no compensation was provided to Maxine in the past, then she was the victim of injustice. This would also mean that Joan's current disutility reflects the fact she was the beneficiary of past injustice, and this may provide sufficient grounds for refusing to provide Joan with compensation. I return to this issue in my discussion of the jet-set addict, below.

${ }^{132}$ Dworkin criticises Cohen for not being clear about this. See "Ronald Dworkin Replies,” pp. $341-42$.

${ }^{133}$ Cohen, “Expensive Taste Rides Again,” p. 17.

${ }^{134}$ Cohen, “Expensive Taste Rides Again,” pp. 17-18.

${ }^{135}$ See Cohen, “Expensive Taste Rides Again,” pp. 17-18.

${ }^{136}$ See Cohen, “On the Currency of Egalitarian Justice,” p. 923.

${ }^{137}$ G.A. Cohen, "Expensive Tastes and Multiculturalism,” in R. Bhargava, A.K. Bagchi, R. Sudarshan, (eds.), Multiculturalism, Liberalism and Democracy, New Delhi, Oxford University Press, 1999, pp. 80-100.

138 In chapter 7, I will demonstrate another practical consequence of taking welfarist considerations into account, focusing on the link between job satisfaction, labour market decommodification, and the welfare state.

${ }^{139}$ I thank David van Mill for this example.

${ }^{140}$ Sen, “Equality of What?” p. 327.

${ }^{141}$ Sen, “Equality of What?” pp. 327-8.

${ }^{142}$ Sen, “Equality of What?” pp. 325-6.

${ }^{143}$ Dworkin's understanding of resources is broader than Rawls's notion of primary goods, and will be sensitive to the kind of disadvantage involved in this example. I discuss the relationship between Dworkin’s theory and the capability approach below.

${ }^{144}$ Sen, “Equality of What?” pp. 326, 328.

${ }^{145}$ Sen, “Equality of What?” p. 328.

${ }^{146}$ Sen, "Capability and Well-Being," in M. Nussbaum \& A. Sen (eds.), The Equality of Life, Oxford, Clarendon Press, 1993, p. 31, his emphasis.

${ }^{147}$ Dworkin, Sovereign Virtue, pp. 300-1.

${ }^{148}$ Dworkin, Sovereign Virtue, p. 301. 
${ }^{149}$ Dworkin, Sovereign Virtue, p. 301.

${ }^{150}$ Dworkin, Sovereign Virtue, p. 302.

${ }^{151}$ Dworkin, Sovereign Virtue, p. 302. For Sen's response to Dworkin, see A. Sen, Resources, Values and Development, Cambridge, Mass., Harvard University Press, 1984, pp. 321-23. Sen states that Dworkin "comes close to taking explicit note of capabilities in defining the resources themselves, and it could be argued that this way of seeing resources would lead to a congruence of the requirements of equality of capabilities and that of equality of resources.” But ultimately, Dworkin does not treat handicaps as resources, and instead relies on the counterfactual insurance mechanism to determine the level of compensation that should be provided for them. Moreover, handicaps are not the only cause of differences in individuals' ability to convert resources into capabilities. Lastly, there does not seem to be any reason to adopt "an idea of equality of resources that is thoroughly parasitical on the idea of equality of capabilities.” The quotations are from pp. 321, and 322.

${ }^{152}$ Cohen, “On the Currency of Egalitarian Justice,” pp. 941-44.

${ }^{153}$ Another major criticism of Sen's approach is that the capabilities approach is indeterminate without reference to an objective conception of the good life. See, especially M.C. Nussbaum, Women and Human Development: The Capabilities Approach, Cambridge, Cambridge University Press, 2000. Arneson argues that such ranking can only occur with reference to welfarist criteria. Arneson, “Equality and Equal Opportunity for Welfare,” pp. 91-92. I will not explore this criticism here because I ultimately support Cohen's related conception of advantage, not the capabilities approach. Nonetheless, there is also a danger of indeterminacy with this heterogeneous account. I attempt to address this issue in section 6.

${ }^{154}$ G.A. Cohen, “Equality of What? On Welfare, Goods, and Capabilities,” in M. Nussbaum \& A. Sen, (eds.), The Quality of Life, Clarendon Press, Oxford, 1993, pp. 9-29, at p. 18. Cohen 1993, p. 18, his emphasis. Embedded quotes are from Sen.

${ }^{155}$ Cohen, “Equality of What,” p. 18.

${ }^{156}$ Cohen, “Equality of What?” p. 19. Italics removed.

${ }^{157}$ Cohen, “Equality of What?” p. 20.

${ }^{158}$ Cohen, “Equality of What?” pp. 20-1. For Sen’s response to Cohen, see “Capability and Well-Being,” in M. Nussbaum \& A. Sen, (eds.), The Quality of Life, Clarendon Press, Oxford, 
1993, pp. 30-53.

${ }^{159}$ Cohen, “Equality of What?” p. 25.

${ }^{160}$ Sen, cited in Cohen, “Equality of What?” p. 25.

${ }^{161}$ Cohen, “Equality of What?” p. 27.

${ }^{162}$ See Cohen, “Equality of What?” pp. 26-27.

${ }^{163}$ Cohen, “Equality of What?” p. 28.

${ }^{164}$ Cohen, “On the Currency of Egalitarian Justice,” pp. 917-18, quotation at p. 18. Italics removed.

${ }^{165}$ Cohen, “On the Currency of Egalitarian Justice,” pp. 917-18. However, Cohen also notes that Tiny Tim would not receive his wheelchair if there were other people with a welfare level so low that assisting them would take priority.

${ }^{166}$ Cohen, “On the Currency of Egalitarian Justice,” pp. 918-19.

${ }^{167}$ Cohen, “On the Currency of Egalitarian Justice,” p. 919.

${ }^{168}$ Note Cohen, “On the Currency of Egalitarian Justice,” p. 921.

${ }^{169}$ Dworkin, Sovereign Virtue, p. 285.

${ }^{170}$ G.A. Cohen, “Afterword to Chapters XI and XII,” [mimeo]. Hereafter, I shall refer to this document as "Afterword."

${ }^{171}$ Cohen, “Afterword,” p. 33.

${ }^{172}$ Cohen, “Afterword,” p. 33.

${ }^{173}$ Cohen, “Afterword,” p. 33.

${ }^{174}$ Cohen, “Afterword,” p. 33.

${ }^{175}$ Cohen, “Afterword,” p. 34.

${ }^{176}$ Cohen, “Afterword,” pp. 33-4.

${ }^{177}$ Egalitarians may still be interested in the quality of the food to which individuals have access, for reasons independent of its nutritional value. For instance, large numbers of people may have a preference for fine dining, which makes food quality relevant to the relative success component of egalitarian advantage.

${ }^{178}$ For discussion of this problem, see, for example, Callinicos, Equality, p. 54; and Sen, Inequality Reexamined, p. 55.

${ }^{179}$ See chapter 3 for an account of the conditions that must be in place for a choice to be 
considered genuine. Of course, like many egalitarians, I am inclined to believe that individuals will rarely, if ever, genuinely choose to enter oppressive social relationships. 


\section{CHAPTER 6}

\section{RIVAL THEORIES}

In this chapter, I will compare luck egalitarianism to three leading alternative theories of distributive justice and/or egalitarianism. Although two of these theories, the Priority View and the threshold account, are not theories of egalitarian justice, their supporters argue that they manage to capture the appealing features of egalitarianism, whilst avoiding its defects. However, I will argue that neither theory can replace luck egalitarianism. Comparative fairness matters even above a threshold of "sufficiency," whilst the appeal of the Priority View depends on the Levelling Down Objection which, as I shall discuss, is not a decisive argument against egalitarianism. The final section explores social equality (also referred to as democratic equality), which is an alternative approach to egalitarianism that focuses on the nature of social relationships among citizens. Although I have already discussed this theory in the thesis, I want to conclude with a more thorough analysis. I refute a number of the criticisms social egalitarians have made against luck egalitarianism, and I argue that the distributive implications of social equality are either ambiguous or ungenerous, or collapse into luck egalitarianism.

\section{THE LEVELLING DOWN OBJECTION}

Whilst luck egalitarians have sought to develop a complex brand of egalitarianism that is sensitive to notions of individual choice and responsibility, a number of philosophers, most notably Derek Parfit and Larry Temkin, have sought to improve our understanding of the differences between prominent accounts of equality. These differences have often gone unnoticed, despite their importance. In this section, I will outline two different approaches 
to equality identified by Parfit (the Telic View of Equality and the Deontic View) and explain the advantages and disadvantages of each approach. I will focus on the Levelling Down Objection, which affects Telic accounts of equality, and the Priority View, which is presented as a third alternative. My central aim in this section is to briefly introduce these concepts, leaving the bulk of the analysis for sections 2 and 3.

The first approach identified by Parfit is the "Teleological” (or "Telic”) Egalitarian View, which holds that inequality is bad. Thus, a Telic Egalitarian believes that equality has intrinsic value, ${ }^{1}$ and "is in itself good.” ${ }^{2}$ Equality may also have instrumental value because inequality produces conflict, envy, and powerlessness, but supporting equality because it achieves these other values does not make you a genuine (Telic) egalitarian. Under this view, egalitarianism seems naturally to have a wide scope, extending to "everyone who ever lives." 3 Thus, it is bad for two groups to be unequal, even if they are unrelated to each other.

An alternative approach is the "Deontological" (or "Deontic") Egalitarian View. According to this view, “[w]e may believe we should aim for equality, not to make the outcome better, but for some other moral reason. We may believe, for example, that people have rights to equal shares.” ${ }^{4}$ Often this moral reason is connected to the idea of comparative justice. Inequality is objectionable when it is unjust, in the sense that some people have been treated differently from others. The injustice, and thus the inequality, is bad because it involves wrong-doing. ${ }^{5}$ For Deontic Egalitarians, “[w]hen we claim that inequality is unjust, our objection is not really to the inequality itself. What is unjust, and therefore bad, is not strictly the state of affairs, but the way in which it was produced.” ${ }^{6}$ On the other hand, if a particular inequality is unavoidable, 
then no wrong-doing exists, and the inequality is not unjust. Thus, for a Deontic Egalitarian, there is nothing in itself bad about the fact some are born with more natural talent than others. However, for many Telic Egalitarians, inequalities like this are intrinsically bad, even if they are unavoidable. ${ }^{7}$ The scope of the Deontic View is also likely to be narrower. ${ }^{8}$ It may only apply to the individuals within one community, not to outsiders. It may also apply only to inequalities that we are responsible for bringing about.

But for our purposes, the most important difference between the two approaches is that the Telic version is subject to a strong criticism that Parfit terms the "Levelling Down Objection." "9 This objection arises if "those who are better off suffer some misfortune, so that they become as badly off as everyone else. Since these events would remove the inequality, they must be in one way welcome, on the Telic View, even though they would be worse for some people, and better for no one." ${ }^{10}$ This has implications that many find troubling. For example, according to the Telic View, it would be in one way good if we were to remove the inequality between the blind and the sighted by blinding the sighted. Of course, a Telic Egalitarian is unlikely to actually support such a policy because she will believe in some other, non-egalitarian principle which would rule it out. However, we might still object "that, if we achieve equality by levelling down, there is nothing good about what we have done."11 Unless it somehow allows us to improve the condition of the sighted, there is nothing good about blinding people. Any approach which holds otherwise is seriously flawed. This provides a strong argument against Telic Egalitarianism. ${ }^{12}$

In the face of this criticism, we may wish to salvage egalitarianism by adopting the Deontic View. Deontic Egalitarians can avoid the Levelling Down Objection because they do not believe that inequality is intrinsically bad. ${ }^{13}$ 
Rather, inequality is only objectionable when it is unjust. If no one benefits when we eliminate an inequality, then we could mount a plausible argument that we have no obligation of justice to do so, and thus Deontic Egalitarians may have no reason to endorse levelling down. However, if we adopt the Deontic View, then we may be forced to accept inequalities that many egalitarians are inclined to condemn. ${ }^{14}$ For instance, in Parfit's Divided World example, the Deontic View does not support the more equal outcome over the more unequal outcome. ${ }^{15}$ In this example, the world is evenly divided into two groups, but neither group knows of the other's existence, so neither is directly responsible for the welfare of the other. Assume that, in such a world, two outcomes are possible:

1) Half at $100 \quad$ Half at 200

2) Everyone at 145

Although most egalitarians will be inclined to favour 2) over 1), the Deontic View provides no reason to support this judgement. The inequality is not the result of wrong-doing because the groups are separate, and thus, no injustice is involved. If this conclusion is troubling, we may be tempted to return to the Telic View which opposes all inequality, but this forces us to confront the Levelling Down Objection once again.

Parfit identifies a third option that avoids this dilemma. The Priority View, or prioritarianism, is consistent with the intuitive egalitarian response to the Divided World example yet avoids the Levelling Down Objection. According to the Priority View, “[b]enefiting people matters more the worse off these people are.”16 When deciding between scenarios which deliver benefits to 
different groups, we should give greater moral weight to benefits that go to the worse off, over equally valuable benefits that go to the better off. Of course, if the benefits in question are not equally valuable, things may become more complex. If, for instance, the benefits that would flow to the better off in one scenario are far more valuable than the benefits which would flow to the worse off in the alternative, then a Prioritarian may decide to choose the former, which delivers benefits to the better off. But the point is, benefits to the worse off do have extra moral weight in distributive ethics.

The Priority View is not "egalitarian" in the strict sense of the word. ${ }^{17}$ The focus is not on relativities, but people's absolute levels. We give priority to the worse off because of their low absolute level, not because they are worse off than others, as such. The Priority View holds "that benefits matter more the worse off the people are who receive them,"18 so the lower a person's absolute level of well-being, the greater weighting benefits to her should have. This means that we will give priority to people who are (relatively) worse off than others, but this is not directly because of their relative position. The particular weighting a benefit has depends on the absolute level of the person receiving it, not her relative position. Thus, "benefits to the worse off matter more, but that is only because these people are at a lower absolute level. It is irrelevant that these people are worse off than others. Benefits to them would matter just as much even if there were no others who were better off." 19 The weighting given to a benefit is tied to the condition of the person receiving it, so it remains the same regardless of her relative position. The reason we end up prioritising benefits to the worse off is because we know that their condition will be (relatively) lower and thus that it will attract a (relatively) greater weighting. However, many have missed the distinction between the Priority View 
and the Egalitarian View. $^{20}$ In fact, some well-known accounts of egalitarianism, such as Thomas Nagel's, are more accurately described as prioritarian. This might be because "[t]he Priority View often coincides with the belief in equality." ${ }^{21}$ Returning to the Divided World example, a Telic version of the Priority View can explain why we should choose 2). The reason is that the worse off group in this scenario have 145, whilst in 1) they only have $100 .^{22}$ Thus, the idea that we should give priority to the worse off explains why many react as they do to the Divided World. This gives the approach an advantage over the Deontic Egalitarian View, which is unable to explain why we should favour 2). It also has an advantage over the Telic Egalitarian View because it escapes the Levelling Down Objection. ${ }^{23}$ If our concern is to give priority to the worse off, then we have no reason to support levelling down. That is, we have no reason to reduce the welfare of the better off to the level of the worse off, if this is of no benefit to the worse off. Thus, the Priority View seems a compelling approach to distributive ethics, which captures the key appeal of egalitarianism, whilst avoiding its disadvantages.

\section{A THRESHOLD ACCOUNT}

Before we test whether luck egalitarianism can avoid the Levelling Down Objection and resist the appeal of the Priority View, I want to examine another approach, a threshold or sufficiency account of justice, which challenges both prioritarianism and egalitarianism. My analysis will focus on Roger Crisp’s recent argument for this approach.

Although Crisp endorses a form of the Levelling Down Objection, ${ }^{24}$ he ultimately rejects the Priority View, highlighting problems with its different interpretations. He begins by highlighting the flaws in the Absolute Priority 
View, which holds that:

when benefiting others, the worst-off individual (or individuals) is (or are) to be given absolute priority over the better off. ${ }^{25}$

He argues that this is counter-intuitive because it is "innumerate." That is, "like Rawls's 'difference principle,' [it will] allow the smallest benefit to the smallest number of worst off to trump any benefit, however large, to any but the worst off, even the next worst off. And this, it may be thought, is almost as absurd as leveling down." 26 This leads us to support the Weighted Priority View which holds that:

benefiting people matters more the worse off those people are, the more of those people there are, and the greater the benefits in question. ${ }^{27}$

The problem with this approach is that there may be circumstances where it will support very small improvements in the condition of the better off over significant improvements in the condition of the worse off. This situation will occur if the number of beneficiaries in the better off category greatly outweighs the number of beneficiaries in the worse off category (the aggregation of benefits mean that the small benefit to a great many counts for more than a larger benefit to the few). ${ }^{28}$ In response to this, we are drawn towards the Number-Weighted Priority View, which holds that:

benefiting people matters more the worse off those people are, the more of those people there are, and the larger the benefits in question. But the number of beneficiaries matters less the better off they are. ${ }^{29}$

But this approach is also flawed, as Crisp illustrates with the "Beverly Hills case”. In this case, there are two groups of individuals, both of whom are welloff (Crisp calls them "Rich" and "Super-rich"). He argues that there is no reason to give priority to either group when deciding questions of distributive justice: 
[E]ven if the benefits to each of the Rich and the Super-rich are identical and their numbers are the same, there still seems to me nothing to be said for giving priority to the "worse off." At this level, only utilities matter, so there would be nothing to choose between the two distributions. ${ }^{30}$

This leads us away from the Priority View, towards a threshold account of justice.

Crisp argues that the threshold account can avoid the Levelling Down Objection and the problems with the Priority View. But to be a compelling approach to distributive justice it must also be able to explain why our intuitive judgements seem to support egalitarianism and the Priority View in certain situations. In order to determine this, and to develop his account of the threshold approach, Crisp draws on the idea of an impartial spectator. To be consistent with our distributive intuitions, the threshold account must be able to explain our support for the distribution labelled Equality in the following example: ${ }^{31}$

\section{Group $1 \quad$ Group 2}

Equality $\quad 50 \quad 50$

Inequality $\quad 10 \quad 90$

In this example, we believe that the impartial spectator should show concern for the members of Group 1 because they are worse off than the members of Group 2 (assuming that this is not another Beverly Hills case), and thus support the "Equality" distribution. But if egalitarianism and prioritarianism are ruled out, what concern should motivate the impartial spectator? Why should the spectator show concern for the worse off in this example, but not in the Beverly 
Hills case? The answer, Crisp suggests, is that the spectator should be motivated by the virtue of compassion. ${ }^{32}$

The idea of an impartial spectator, motivated by the virtue of compassion (in a technical sense) leads us to a threshold account of justice. ${ }^{33} \mathrm{~A}$ threshold account is only concerned with giving priority to the worse off (or some variation of giving priority to the worse off) if the worse off fall below a certain threshold. Thus, Crisp concludes that questions of distributive justice should be decided according to the Compassion Principle which holds that:

absolute priority is to be given to benefits to those below the threshold at which compassion enters. Below the threshold, benefiting people matters more the worse off those people are, the more of those people there are, and the greater the size of the benefit in question. Above the threshold, or in cases concerning only trivial benefits below the threshold, no priority is to be given. ${ }^{34}$

This, he believes is a far more compelling approach to distributive justice than egalitarianism or the Priority View.

But a crucial issue remains unresolved. We must determine the level at which the threshold should be set. Crisp endorses the Sufficiency Principle which holds that:

compassion for any being B is appropriate up to the point at which B has a level of welfare such that B can live a life which is sufficiently good. ${ }^{35}$

However, he emphasises that sufficiency cannot simply be equated with needfulfilment. He believes that the impartial spectator will continue to feel compassion towards the worse off, even when the needs of the worse off are satisfied, ${ }^{36}$ so the threshold would be set above the point at which human needs are satisfied. Crisp's “own intuition is that, say, eighty years of high-quality life on this planet is enough, and plausibly more than enough, for any being.”37 Thus, there is an important role for the idea of priority to the worse off in 
distributive justice, but this concern disappears once everyone is deemed to have “enough.” From this point onwards, distributive justice provides no reason for us to worry about the condition of the worse off.

However, it is arguable that we could take this point further. Once everybody has "enough" it may well be that questions of distributive justice become irrelevant. After all, distributive justice is concerned with conditions of scarcity, and once everybody has "enough" these conditions are no longer in place. This seems to be implied by the very definition of "enough": if we all have enough resources, how can resources be in scarce supply? For this reason it is unclear that a threshold account actually adds anything significant to the Priority View. Once we reach the threshold, questions of distributive justice no longer arise, so it is obvious that the Priority View, like any other approach, will cease to be relevant. ${ }^{38}$

A defender of Crisp's approach might argue that this sets the threshold too high. In reality, we are able to "live a life which is sufficiently good" even in a world of scarcity. That is, we can have "enough" even in conditions of scarcity, without entering a world of abundance where questions of distributive justice are irrelevant. For instance, a "sufficiently good life” might require access to safe, secure, and reasonably paid employment. But many people will want more than this. Instead of safe, secure, reasonably paid work, they will want to spend their days pursuing more fulfilling forms of productive activity with greater scope for developing their natural capacities and expressing themselves. If the latter is impossible because of the constraints imposed by (the lack of) natural resources and technological development, then conditions of scarcity persist, even though each person has enough for a "sufficiently good life.” Thus, the Sufficiency Principle can be satisfied before we enter conditions 
of abundance where questions of distributive justice become irrelevant. The threshold approach is not a redundant conception of distributive justice.

However, whilst this response rescues the threshold approach from the charge of redundancy, it demonstrates why it is unsatisfactory as a conception of distributive justice. The individuals in the example could plausibly dispute the claim that they have "enough." 39 Although the Sufficiency Principle appears to hold and everybody is or appears to be above the threshold, they could argue that they do not have "enough" until they are able to devote their lives to more fulfilling forms of productive activity. If their conception of a valuable life is impossible under current conditions, the Sufficiency Principle is not satisfied. This problem becomes more serious when we recognise that individual desires are elastic. As our standard of living improves, we will demand more from life, and the threshold will move up so that we never feel we have "enough.” We may be able to overcome this objection by denying the relevance of individual preferences, and working with an objectively defined notion of "a sufficiently good life." We could argue that priority to the worse off does not matter if everyone is able to live a life that is sufficiently good (according to this objective measure), even though most people deny that they have “enough.” But this approach will lead to unjust results because some individuals will have far better lives than others, even when the objectively defined Sufficiency Principle holds. Many people will want better lives than they are guaranteed at the objectively defined threshold, but only some will be able to pursue these lives (perhaps, in this example, because their enormous wealth frees them from the necessity of labour market participation). As long as this is the case, relative fairness, or at least priority to the worse off, seems to remain a concern. In short, until we reach a point in human development where 
abundance obtains, we must pay attention to differences in the kind of lives that individuals are able to live. Unless we are living in a world of abundance and people at the threshold are completely satisfied with the lives they are able to live, the Principle of Sufficiency will not be a satisfactory approach to distributive justice. If the threshold is set any lower (which it must be to avoid the charge of redundancy), we will once again be drawn back to principles of relative fairness, or to the Priority View.

Defenders of Crisp's approach could re-assert the virtue of compassion here. They could say: we are not interested in relative fairness or the Priority View in this situation. People above the threshold may have a varying ability to live valuable lives, but this is irrelevant. Ultimately, distributive justice is about the virtue of compassion, and an impartial spectator is unlikely to feel compassion for people who must work in secure, safe and reasonably paid jobs whilst another group pursues more fulfilling activities. But I think this is far from self-evident. I think we could intelligibly imagine an impartial spectator who feels compassion for individuals in this position, particularly if we were living in a society evenly split between this "working class," and another "leisure" class that is able to perform more fulfilling activities. This highlights an important point about compassion. Whether we feel compassion towards an individual or group will depend partly on our personal conception of the good life. But it will also depend on the kind of lives that are available to other members of the community. That is, if half of society is able to spend its days engaged in productive activity it finds valuable, while the other half is forced to perform far less fulfilling work, then I think we will feel compassion for the second group. The point is that judgements of compassion depend, in part, on judgements of relative fairness. Moreover, a similar line of argument is open to 
proponents of the Priority View. They could argue that in this example, we feel compassion for members of the working class because although they are above the threshold, they are worse off than the other half of society. Thus, the judgements of a compassionate impartial spectator may also lead to the Priority View. I shall argue against the Priority View in the next section, but it is interesting to note that the virtue of compassion pulls us back towards the two approaches to distributive justice that Crisp wishes to criticise.

It is also interesting to note that whatever side of the threshold, our feelings of compassion are also influenced by the degree of responsibility a person bears for the situation in which she finds herself. That is, if a person is worse off than others because of bad luck, then we will feel more compassion towards her than we do towards someone who is equally badly off but (largely) responsible for her parlous condition. Of course, this is not to deny that we may feel great compassion for both individuals. I simply suggest that we feel extra concern for those who end up very badly off through no fault of their own. ${ }^{40}$ In this way, incorporating the notion of compassion into distributive justice leads us towards a form of the Priority View that takes into account considerations of individual responsibility, perhaps along the lines of Arneson's theory of responsibility-catering prioritarianism. Thus, if we agree with Crisp that an impartial spectator motivated by compassion is a good basis for determining principles of distributive justice, we may be led towards an approach that is sensitive to individual responsibility.

However, the most important reason for opposing a threshold approach is that comparative fairness matters, independent of any reference to compassion. To illustrate this, it is helpful to examine Temkin's counterexample to Crisp's argument. ${ }^{41}$ Two sisters, Andrea and Becky are "incredibly 
well-off” without being super-rich. They "are extremely intelligent and attractive, have deep friendships, a stable home, high self-esteem, rewarding projects, fantastic careers, and a long healthy future.”42 But Andrea (by good fortune) is slightly better off than Becky in each of these aspects of life. Moreover, she finds $\$ 20$ on the ground whenever she goes for her weekly walk. She has not specifically set out to find money on her walk, and it does not affect her life much, but she gets a thrill of excitement and happiness when she finds it. In contrast, Becky never finds money while walking, even though she walks in similar areas to her sister, and goes more frequently. Temkin agrees with Crisp that most people would not feel compassion for Becky. However, he does believe that we have some grounds for give priority to Becky over Andrea (a claim that Crisp would reject). ${ }^{43}$ Despite the fact that both sisters are well off, Andrea consistently enjoys advantages that Becky does not, purely as a result of luck. If we have the chance to deliver some advantage to either of the sisters then most people would feel inclined to give it to Becky. After all, "[i]t is pure luck that Andrea is better off in a multitude of ways that matter. Hence, Becky is not merely worse off than Andrea; she is worse off through no fault, or choice, of her own. Egalitarians believe that this crucial fact about the relation between Becky and Andrea provides them with reason to give Becky priority over Andrea: not the reason provided by compassion, but the reason of equality, or comparative fairness.” ${ }^{44}$ For Temkin, “[t]he essence of the egalitarian's view is that comparative unfairness is bad and that if we could do something about life's unfairness, we have some reason to do so. Such reasons may be outweighed by other reasons, but they are not, as anti-egalitarians suppose, entirely without force." 45 Thus, a threshold account cannot replace egalitarianism. 


\section{RESPONDING TO LEVELLING DOWN}

Having dealt with the threshold account, we can return to the challenge that the Priority View poses to Telic Egalitarianism. In section 1, I discussed the claim that we should abandon Telic Egalitarianism in the face of the Levelling Down Objection, and give priority to the worse off instead. This is particularly relevant because I defended luck egalitarianism as a form of Telic Egalitarianism in chapter 4. Luck egalitarians believe that it is inherently unfair or unjust for luck to have a differential impact on the level of advantage persons enjoy, which exposes the theory to the Levelling Down Objection. In this section, I will defend Telic (and thus luck) egalitarianism against this objection, drawing particularly on work by Parfit and Temkin who argue that equality, through the notion of comparative fairness, plays a distinct role in distributive justice.

Before I begin this analysis it is worth noting that some luck egalitarians have been tempted to adopt a modified form of the Priority View in light of the Levelling Down Objection. Perhaps the most notable example here is Richard Arneson. Previously a supporter of a luck-egalitarian theory he calls equal opportunity for advantage (see chapter 1), he now supports "responsibilitycatering prioritarianism." ${ }^{46}$ This view holds "that justice requires us to maximize a function of human well-being that gives priority to improving the well-being of those who are badly off and of those who, if badly off, are not substantially responsible for their condition in virtue of their prior conduct." ${ }^{\text {} 47}$ However, whilst the attraction of the Priority View is evident, I do not believe that luck egalitarians need abandon/modify their approach in this way.

Telic egalitarians can defend their position against the Levelling Down Objection in a number of ways, but I shall focus on the most persuasive 
counter-arguments. ${ }^{48}$ To begin this task, it is important to understand "the Slogan” which motivates the Levelling Down Objection. As Temkin explains it, "the Slogan" holds that "[o]ne situation cannot be worse (or better) than another if there is no one for whom it is worse (or better)." ${ }^{49}$ Thus, levelling down is problematic because it does not actually improve anyone's condition. The Slogan can be understood in a number of ways, but Temkin focuses on the most challenging interpretation, according to which, “[o]ne situation cannot be worse (or better) than another in any respect if there is no one for whom it is worse (or better) in any respect." 50 This is the most testing version of the Slogan because it extends to pluralist theories of egalitarianism. ${ }^{51}$ According to a pluralist egalitarian theory, equality has moral value, but it can be outweighed by other, non-egalitarian values. Thus, a pluralist Telic Egalitarian could oppose levelling down all things considered because non-egalitarian values such as efficiency outweigh the egalitarian benefits of levelling down. However, the testing version of the Slogan also condemns such all-thingsconsidered judgements. ${ }^{52}$ On this testing version, there is nothing good at all about levelling down, and there is something fundamentally wrong with a theory that holds otherwise. Thus, Telic Egalitarians cannot defend their approach by appealing to non-egalitarian values.

However, this testing version of the Slogan does not stand up to closer analysis, despite its initial appeal. To illustrate this, Temkin presents a modified version of Crisp's Beverly Hills case, adding to the example the millions of children who die each year from preventable causes. ${ }^{53}$ Modified in this way, Temkin believes that there is a sense in which it would be better to avoid giving further benefits to the Rich and the Super-rich (in Crisp’s example, the benefits in questions are bottles of wine), even if this has no effect on the children's 
level of welfare. That is, "even if the resources spent on the Rich and Super-rich couldn't be diverted to aid the needy, there would be something bad about using those resources to further indulge the Rich or the Super-rich."54 Of course, nonegalitarian reasons might outweigh this concern, and convince a Telic egalitarian to support the allocation of the wine to the wealthy, all things considered. But there would still be something bad about this outcome, because it increases inequality, and offends the value of comparative fairness. ${ }^{55}$ If we endorse this view, then we have rejected the testing version of the Slogan. Equality matters, even when it does not improve anybody's position.

The Slogan ${ }^{56}$ also ignores claims about proportional justice, which many find plausible. ${ }^{57}$ Take, for example, a situation that involves "sinners," who have acted wrongly, and "saints," who have always acted morally. In the first outcome, saints enjoy a higher level of welfare than sinners. However, in the second outcome, the condition of the sinners improves, whilst the saints stay at the same level. Now the sinners actually enjoy a higher level of welfare than the saints. Is there any sense in which this second outcome is worse than the first outcome? If we support the Slogan, the answer must be "no.” After all, the position of the saints is the same, whilst that of the sinners improves. How could this worsen the situation? Although we may ultimately support moving from outcome 1 to outcome 2, all things considered, many people are likely to think that there is at least something wrong with the fact that sinners do better than saints. This suggests that the Slogan will not be as compelling as it first appears to be.

Parfit gives a related example to challenge the Slogan (or what he calls the "Person-affecting Claim”). ${ }^{58}$ We may well want to support the claim "that it would have been better if Hitler, unknown to others, had suffered for what he 
did." 59 If so, the Slogan must be wrong because it denies that there is anything good about Hitler suffering in this way. Hitler's suffering does not make anybody better off because nobody is aware of his suffering, but it does make one person, Hitler, worse off. Of course, there might be other reasons (that is, reasons unconnected to the Slogan) for us to reject the "retributive view" that Hitler's suffering is good. For instance, we might doubt that individuals have the free will necessary to justify such retribution. ${ }^{60}$ But this would not refute our argument against the Slogan. We could oppose retribution because of our beliefs about free will and responsibility, but still maintain that retribution would be justified if free will were possible. If this is our position, then we should reject the Slogan. ${ }^{61}$

Moreover, “[t]he Slogan is most naturally interpreted as making a claim about what is relevant to a situation's being good." ${ }^{62}$ But no plausible form of the Slogan emerges when it is combined with any standard theory of the good. ${ }^{63}$ To fully understand this problem, identified by Temkin, it is necessary to distinguish the two components of a full theory of the good. One component is a theory about the self-interest of individuals, "which tells us what is good or bad for someone," and the other is a theory about outcomes, which allows us to identify good or bad outcomes. ${ }^{64}$ The Slogan "implies that one's theory of outcomes must be a direct function of (perhaps, in a sense, subservient on) one's theory of self-interest.”65 However, Temkin demonstrates that none of the major theories of the good offer support for the Slogan, at least as it is commonly used to motivate anti-egalitarian arguments. ${ }^{66}$

This is evident if we examine "Mental State Theory" (MST) which holds that "only conscious states have intrinsic value or disvalue, and everything else has value or disvalue only to the extent that it promotes positive 
or negative conscious states.”67 This theory seems to have some appeal as a theory regarding self-interest because whether something is good or bad for you does seem closely related to its impact on your conscious state. ${ }^{68}$ But it is less appealing as a theory about outcomes because it may ignore values such as freedom, autonomy, virtue, and duty when assessing outcomes. ${ }^{69}$ If the goodness of an outcome simply depends on the quality of individuals' conscious states, these values do not have a secure footing for there is no guarantee that they will have a positive impact on conscious states. Even when they do improve our mental state, it could be that the increase in utility which results from protecting these values is outweighed by the increase in utility that would result from pursuing some other alternative. For example, under MST, a world with less freedom but higher quality mental states would be deemed better than a world with more freedom but lower conscious states. Because this line of thinking is unacceptable to many of us, we may decide to reject MST as a theory regarding outcomes, but to support it as a theory regarding self-interest. But for supporters of the Slogan, this is no solution. ${ }^{70}$ According to the Slogan, the goodness of an outcome depends only on what is good for people. But under MST, what is good for people is whatever promotes the quality of their mental states. Thus, if we combine the Slogan with MST as a theory regarding self-interest, we end up with MST as a theory regarding outcomes, and once again, values such as freedom, virtue, autonomy and duty have no independent weight in assessing the goodness of an outcome. Like Temkin, I find this troubling because the goodness of an outcome is about something more than the quality of mental states. If we believe this to be correct, and we subscribe to MST as a theory of the good regarding self-interest, we are denying the very thing the Slogan wishes to assert because we believe that outcomes can be 
better or worse without being better or worse for anyone. If we wish to defend the Slogan, we will need to seek another theory of the good.

However, there are also problems with an alternative approach, The Subjective Desire Fulfilment Theory (SDFT). As the name suggests, this theory defines goodness and badness in terms of desire fulfilment. More specifically, "[a]s a theory about self-interest, SDFT holds that something will be good or bad for someone insofar, and only insofar, as it promotes or contravenes the fulfillment of her desires; where, roughly, the value of fulfilling an agent's desires is ultimately derivable from her desires themselves." ${ }^{71}$ However, this seems implausible. If someone slanders a deceased person then SDFT would classify this as bad for the person who is slandered because it violates a preference she had when she was living. Of course, we might think that there is something bad about a situation or outcome where this slander occurs, but it seems difficult to maintain that it is actually bad for the deceased person, as she is now dead and unaware of the fact this slander has occurred. ${ }^{72}$ Moreover, there are problems with using SDFT as a theory about outcomes. This means that "roughly, one outcome will be better than another if there is a greater fulfillment of people's desires in the one outcome than the other (where this, of course, must take account of both the number and strength of fulfilled [good] and unfulfilled [bad] desires)." ${ }^{73}$ This is unattractive because it means that fulfilling the desires of sadists, bigots, and distant historical movements counts as improving the goodness of an outcome. ${ }^{74}$ It also precludes the existence of any objective moral values. ${ }^{75}$ Whether freedom, justice, or autonomy count towards the goodness of an outcome depends on whether these values are desired by individuals, which seems unsatisfactory. In sum, there are significant problems with SDFT as a theory of the good, independent of its links to the 
Slogan.

Moreover, were SDFT somehow able to avoid these difficulties, it would not provide a strong basis for the Slogan. To see this, we need to distinguish between Restricted SDFT, which only takes into account an agent's self-regarding desires, and Unrestricted SDFT, which takes into account all her desires, including her other-regarding desires and desires about the world generally. ${ }^{76}$ Unrestricted SDFT is not plausible as a theory of self-interest because the satisfaction of a person's other-regarding desires counts as good for her, even when she has forgotten about the desire concerned. For instance, if you meet a person who is suffering from a fatal disease, you may strongly want him to be cured. But if you have later forgotten about him and he is cured, then it hardly makes sense to say that this is good for you. ${ }^{77}$ Unrestricted SDFT as a theory about outcomes, on the other hand, is more plausible. But it is mutually exclusive with support for the Slogan. On this view, other-regarding preferences count towards the goodness of an outcome, despite the fact they are not good for a particular person. ${ }^{78}$ For instance, a person's desire that graves be well tended counts towards the goodness of an outcome, even though it is not really good for her. This contradicts the central claim of the Slogan.

Restricted SDFT (which excludes other-regarding preferences from consideration) is also problematic for a supporter of the Slogan. Firstly, it is not plausible as a theory about outcomes because it would support fulfilling a weak self-regarding desire over a strong other-regarding desire. For example, faced with a choice between satisfying someone's strong wish that gravesites be well maintained, and her weaker preference for suntan oil, Restricted SDFT says that we should aim to achieve the latter over the former because the preference for suntan oil is self-regarding, and the preference for maintaining gravesites is 
other-regarding. ${ }^{79}$ Thus, if Restricted SDFT is to be a plausible theory of the good for a supporter of the Slogan, it can only be a theory about self-interest. But this leads us back to the same problem. The Slogan defines the goodness of an outcome only in terms of what is good for a person. So faced with the example above, it will once again recommend satisfying the preference for suntan oil. If we adopt a Restricted form of SDFT as a theory of the good regarding self-interest, the Slogan will exclude from consideration factors that we believe relevant to the goodness of an outcome (for instance, in this case, the strong other-regarding desire for the maintenance of gravesites is ignored). ${ }^{80}$ Thus, an attractive version of the Slogan does not emerge from adopting SDFT, in any of its forms, as a theory of the good regarding outcomes or self-interest. $^{81}$

The Objective List Theory (OLT) does not provide a secure basis for anti-egalitarian arguments based on the Slogan, either. ${ }^{82}$ When applied to "selfinterest, OLT would hold that some things are good or bad for people independent of the quality of their conscious states or the fulfillment of their desires. Similarly, as a theory about outcomes, OLT would hold that some things are intrinsically good or bad -- that is, make an outcome good or bad -independent of the quality of people's conscious states or the fulfillment of people's desires.” ${ }^{83}$ This approach allows us to decide which things are good, coming up with an objective list which could include notions such as pleasure and desire fulfilment, as well as independent moral values, such as freedom, autonomy, or rights. ${ }^{84}$ This objective list could apply to either self-interest or outcomes, but either way, combining the Slogan with OLT does not provide a strong basis for attacking equality. If OLT is a theory of the good regarding self-interest, and certain moral values are deemed to be (objectively) good for a 
person, then egalitarians could argue that equality is one of these values. ${ }^{85}$ That is, if we believe that freedom and rights are good for people, independent of their impact on the quality of our conscious state or desire fulfilment, then egalitarians could follow suit, arguing that equality is also good for people. If they could successfully argue this, then the Slogan could not be used to motivate anti-egalitarian arguments because levelling down to achieve equality would in at least in one respect make the situation better for the individuals involved (by making the distribution more equal). Nonetheless, Temkin remains doubtful about the claim that moral values can be good for people independent of their impact on the quality of our conscious state, or desire fulfilment. ${ }^{86} \mathrm{~A}$ more plausible approach is to protect moral values such as freedom and autonomy by including them on the objective list for outcomes. But if we do this we have effectively abandoned the Slogan because we hold that certain moral values improve the goodness of a situation, even though they have not improved it for anyone. ${ }^{87}$ Temkin emphasises that he has not given a positive argument for the inclusion of justice and equality on the objective list for outcomes. ${ }^{88}$ But his discussion highlights that the Slogan cannot motivate anti-egalitarian arguments unless those seeking to advance these arguments are able to show why equality should not be included on the objective list. Temkin concludes that none of these theories of the good leads to a convincing form of the Slogan, which robs the Levelling Down Objection of its force.

In chapter 4 , I offered a positive argument for the claim that equality has objective moral value. All persons have a fundamental claim to equal moral worth, which means that their lives have equal value. This means that it is intrinsically bad if one person ends up with a better life than another as a result of luck. On the other hand, if persons genuinely choose, to the same extent, the 
level of advantage they enjoy, then the inequalities which result are fair. If the individuals in question exercise control over the outcomes that emerge, then the inequality is not morally arbitrary. This account explains why luck egalitarianism has objective moral value when judging the goodness of outcomes, and thus it shows why the Levelling Down Objection is not decisive against luck egalitarianism.

However, it is important to remember that I support the notion of valuepluralism, as do Temkin and other Telic Egalitarians. Thus, whilst equality has moral weight, it can be overridden by other values. All things considered, a Telic Egalitarian might decide to give the wine to the wealthy in the Beverly Hills example, perhaps for reasons of beneficence, or to avoid waste, but there is at least one respect - fairness -- in which this would be bad. ${ }^{89}$ Thus, Telic Egalitarians believe that there is something good about levelling down (it improves things from the perspective of comparative fairness or equality), but they can reject levelling down if they believe it offends other values. This means that luck egalitarianism, understood as a pluralist form of Telic Equality, avoids the Levelling Down Objection, and because questions of comparative fairness and justice matter, it cannot be replaced by the Priority View.

\section{SOCIAL EQUALITY}

The final alternative approach I will examine in this chapter is social or democratic equality, which focuses on the nature of social relationships, rather than distributive justice. ${ }^{90}$ Social equality is about ensuring that citizens in a particular society can relate to each other as equals, avoiding hierarchical relationships of dominance and subservience. Michael Walzer has called this living in a "society of misters." 91 People in such a society refer to each other as 
"mister", rather than "sir" or "lord”, etc. For social egalitarians, the focus of egalitarianism is on socially imposed disadvantage rather than the "supposed cosmic injustice” in the distribution of luck. ${ }^{92}$ There are a variety of theories of social equality in the literature, ${ }^{93}$ but few have been developed in great depth. Rather than focusing on a specific theory, I will examine five key arguments that proponents of social equality have made against luck egalitarianism. In defending luck egalitarianism against these criticisms, I draw together material from earlier in the thesis, as well as developing new arguments. In particular, I contend that the distributive implications of social equality are either ambiguous, ungenerous, or collapse into luck egalitarianism.

The first and central criticism that social egalitarians make is that luck egalitarianism fails to capture the real point of equality. ${ }^{94}$ It is trapped in the distributive paradigm and focuses on the distribution of luck, rather than the importance of social relationships and the injustice associated with oppression and hierarchy. However, as I argued in chapter 4, luck-egalitarian principles of justice have an important role to play in any genuine "society of equals." Moreover, as I argued in chapter 2, a theory of luck egalitarianism will condemn instances of involuntary social oppression, provided that it operates with a sufficiently sensitive conception of advantage (like the account I offered in chapter 5).

An obvious response here is available to proponents of social equality. An oppressive relationship is unjust even if it has been genuinely chosen. But when would such an inequality be genuinely chosen, as opposed to forced on somebody as a result of their circumstances? I am hard pressed to imagine a real situation where someone genuinely chooses to be in a subservient relationship. But if individuals do make such a choice, I do not think that we 
have strong grounds for ignoring the fact that they have genuinely chosen this state of affairs. To do so leaves us open to the charge of false consciousness. In effect, the proponent of social equality is saying to them: I refuse to respect your genuine choice because you do not know what is in your best interest, so I regard you as victims of injustice.

It is ironic if social equality ends up drawing on a theory of false consciousness because the second underlying impulse of the theory is that egalitarians should avoid making disrespectful judgements about individuals. ${ }^{95}$ This is one of the major reasons proponents of social equality are opposed to luck egalitarianism. Instead of focusing on the internal life of individuals, we should focus on external relations between citizens. Egalitarians should avoid making judgements about the natural endowments of individuals, and the level of subjective welfare they enjoy because this is disrespectful and misguided. Instead of relationships of equality, luck-egalitarian redistribution is motivated by envy of the fortunate and condescending pity towards the unfortunate.

However, as I argued in chapter 2, luck egalitarianism is not motivated by a desire to disparage the disadvantaged. Rather, the driving idea behind the theory is that it is unfair and unjust for individuals to be worse off than others, as a result of luck. Moreover, we must pay careful attention to our motivating concerns, and the level of abstraction at which we are operating. When attempting to implement the theory in practice, non-egalitarian considerations such as individual privacy must be taken into account. But difficulties implementing luck egalitarianism do not count against the theory at the level of principle. $^{96}$

The third feature of social equality is the idea that luck-derived inequalities are not, in themselves, unfair. ${ }^{97}$ In particular, it is fair for the 
talented to end up with greater income and wealth than the untalented purely because of their more lucrative natural abilities. One reason for this is that our internal endowments are crucial to our identity as persons. It does not make sense to talk of a person who is independent of the preferences, talents, and disabilities that she possesses. Once we take away these aspects of her personality, we are left with a bare self, who lacks the qualities required for responsible agency. A classic statement of this position is David Miller's argument that individuals should be entitled to the rewards that come from exercising their talents:

[I]f we decide that we want to keep the concept [of desert] in a form that captures most of the desert judgments people actually make, then we cannot hope to find a basis for desert that is untouched by contingency. What we need instead is the idea of an agent and a performance, where the performance is intended and controlled by the agent, but makes use of qualities and characteristics that are integral to him or her -- natural tastes and abilities among them. We want to factor out luck proper -- features of the environment like the fraying rope that makes the agent's performance turn out differently from what she might reasonably have expected -- but if we try to eliminate contingency of every kind we find that our judgments are directed at a radically thinned-down idea of the human agent. Instead of assessing the deserts of flesh-and-blood actors who make a visible impact on the world, we find ourselves at best judging the qualities of Kantian noumenal wills. ${ }^{98}$

There is a sense that we cannot have any meaningful notion of agency and responsibility when we seek to correct the differential impact of luck on individuals' lives. The luck-egalitarian concept of responsibility is so stripped back that it is basically meaningless. The choices we make and the preferences we have can all be explained by some unchosen feature of our background. How can there ever be such thing as genuine choice when our background and genetic make-up plays such a big role in determining who we are? 
A closely related objection is that luck egalitarianism, as I outlined it in chapter 3, relies on a theory of false consciousness. If choices must be "genuine," and not a reflection of our background then we are in the business of judging whether or not individuals know their real preferences. This form of luck egalitarianism assumes that individuals do not know their "real will.” In contrast, social equality avoids having to judge the genuineness of choices because it focuses on relations between persons, not on the metaphysics of preference formation and the cosmic distribution of luck.

However, the theory of luck egalitarianism I outlined in chapter 3 avoids these objections. Let me begin by addressing the charge of false consciousness. If it were true, then I agree this would be a significant drawback of the theory, but it is not a charge of which luck egalitarianism stands convicted. ${ }^{99}$ For a start, the theory I have outlined does not depend on notions of "genuine preferences" or "real will." Rather, it focuses on the importance of genuine choice, and my understanding of genuine choice does not lend support to a theory of false consciousness. As I explained in chapter 3, the genuineness of a choice depends on the extent to which a person is aware of the options available to her and the likely consequences of each option. If, for instance, a high school graduate decides that college is not for her because she finds the idea of working as a highly skilled tradeswoman more appealing, then there is nothing unjust or false about this choice. If, on the other hand, she does not attend college because her parents' views mean that she never seriously considers it an option, then it is unjust if she later comes to realise that she is better suited to a professional occupation, for which she is not qualified. The decision she makes to not attend college would not be regarded as genuine, but this is not because she failed to realise her "real will” but because she never really considered 
alternative options (as a result of her circumstances). Her decision was based on her parents' views, rather than her own assessment of the options she faced, and this is why it is not genuine. ${ }^{100}$ Of course, in practice, it will often be impossible to determine the difference between choices that reflect external constraints and choices that reflect one's preferences. But once again, I emphasise that this is no reason to reject luck egalitarianism at the theoretical level. The point is, whether or not a choice is genuine does not depend on whether a person knows her "real will."

A critic might object to this response, arguing that luck egalitarianism does rely on a theory of false consciousness because it abrogates persons of responsibility for the disutility associated with their preferences if they deeply identify with these preferences. But whilst it is true that other things being equal, persons are not held responsible for having a lower level of welfare because of their judgemental/unchosen preferences, this position does not rely on any theory of false consciousness. Rather, it results from the conception of advantage I support, which takes into account the level of (dis)utility individuals experience as a result of preference satisfaction (or a lack of preference satisfaction). Egalitarian justice is about the extent to which individuals are able to live flourishing lives and an important part of a flourishing life is being able to satisfy one's valued preferences. I am not disparaging the worth of these preferences, or claiming that they are false. Rather, compensation should be given precisely because they are valuable to the person who holds them. ${ }^{101}$

A similar line of thinking also explains how the theory escapes the bare persons objection, although things are admittedly more complicated here. Luck egalitarianism does not strip away so many constitutive features of our lives 
that responsible agency becomes impossible. Our background may well influence our preferences and thus our choices, but this does not necessarily mean that we lack control over the choices we make. A rational agent who freely decides on a particular course of action from a reasonable set of options, with full knowledge of the consequences involved is responsible for this action. But, as I argued in chapter 3, the real question for luck egalitarians is the extent to which individuals are genuinely responsible for the level of advantage they enjoy, and this is a more complicated question. In particular, the answer will depend on the kind of options that a person faces. For example, Kath might decide to save for her future by investing in the stock market. Assuming she is a rational agent, and that she freely makes this choice, she is responsible for this decision. Her friend Kim, on the other hand, inherits a valuable block of land from her parents, and decides to develop it. She is also responsible for her decision to develop the land. But although both Kath and Kim are responsible for their actions, this does not mean that they are automatically responsible for the outcomes of these actions, or for the relative position in which they end up. Imagine, for instance, that Kim ends up with significantly greater wealth than Kath because she can sell her developed land for hundreds of thousands of dollars. She has benefited from inheriting the land, and thus, although she is responsible for her decision to develop this land, luck has still played a big role in determining her level of advantage. Both Kath and Kim faced a reasonable set of options, but Kim had more lucrative alternatives available to her than Kath did. Consequently, luck egalitarianism views the inequality between them as a matter of luck that is unjust and should be corrected. This demonstrates that luck egalitarianism can equalise the impact of luck on people's lives without denying the possibility of responsible agency. 
The fourth characteristic of social equality is the tendency to downplay the importance of distributive justice. For most theorists of social equality, distributive justice only matters to the extent that it influences the nature of social relationships. As Miller puts it:

Social equality is not a principle of distributive justice. It does not tell us anything directly about how social institutions should assign benefits and burdens to individuals. It describes the overall character of a society, and it directs our attention to the way in which the members understand their relationship to one another. It does have implications for distributive justice, but only because the way in which we distribute goods and resources almost inevitably effects [sic.] the way in which we regard one another. Certain kinds of material inequality may destroy social inequality -- but that is something that has to be established empirically, not demonstrated as a matter of conceptual necessity. ${ }^{102}$

Distributive inequalities are only a concern if they prevent individuals from being able to stand in relations of equality. Luck egalitarianism gets things the wrong way around because it focuses on distribution rather than social relationships.

However, the social egalitarian position on this issue is unconvincing. There is a risk that the distributive implications of social equality will be indeterminate. For a start, it is difficult to determine at what point inequalities in the distribution of income and wealth undermine egalitarian social relations. Consider a society where some individuals have highly marketable talents, which enable them to perform fulfilling work and to live lives of enormous material consumption, whilst others are stuck with less fulfilling jobs and lives which involve much less material consumption. Individuals in this situation can hardly be considered to be in relationships of equality with each other, but what kind of redistribution would bring about equality? More importantly, why is 
equality of status violated in the first place? A plausible answer to this second question is that prior to redistribution occurring some individuals enjoy much more fulfilling lives than others do. But if this is the correct answer, then it brings us back to a focus on relative fairness and justice. How do we ensure that individuals live in a relationship of equality? Arguably, we must equalise the level of advantage to which they have access, bringing us back towards the luck-egalitarian position. We could argue that nobody is genuinely treated with respect if luck is allowed to have a large impact on the quality of lives which we enjoy. If we truly respect each other as equals then we will correct the differential impact of luck on our lives. Thus, social equality may be indeterminate, or actually imply support for luck egalitarianism.

Alternatively, we could avoid this by arguing that one's material standard of living does not matter beyond a certain point. What matters is that we have access to the range of goods and services needed to live a life of reasonable quality. But, as I argued above, this "threshold account" or "sufficiency view" is an unsatisfactory approach to distributive justice. The problem is that material wealth does matter to most people. Those who are able to live lives of great luxury are seen as enjoying a significant advantage. If this is the case, then what basis do we have for discounting the importance of material inequalities? The answer must be that individuals are wrong to place so much emphasis on their material standard of living. Presumably the fact that so many people actually do care simply means they have a mistaken view of what it is to live a good life. It is false to care about material things beyond a certain point because it is social relations that matter.

However, this response conflicts with the fifth central feature of social equality. One of the main criticisms social egalitarians make of luck 
egalitarianism is that it is inconsistent with the kind of attitudes to distributive justice and egalitarianism that exist in the real world. ${ }^{103}$ An underlying theme here is that real people and real political movements accept the fact that the talented will end up with an above-average income and wealth. What people are more concerned with is their social standing compared to others. Citizens want to be able to view each other as equals and thus, the prime target of egalitarian social movements is to attack social oppression which robs people of this equal standing.

This is not a convincing argument for adopting social equality rather than luck egalitarianism. As I argued above, the reality is that people do care about how well-off they are. For example, politicians regularly appeal to individuals' financial self-interest at election time, and the upper middle-class (and other classes) frequently welcome tax breaks, which increase their income. Similarly, in relation to egalitarian political movements, trade unions still pursue issues relating to pay and entitlements. Most people believe that increases in material wealth improve their lives, even if they are reasonably affluent. If social egalitarians believe that popular beliefs are relevant to theoretical debate over distributive justice, then they must explain this divergence.

At any rate, I dispute the social egalitarian claim that popular attitudes should play an important role in theoretical debate over distributive justice. Whilst we can be guided by our considered responses to examples, and our intuitive understanding of what particular terms mean, this is different from making the attitudes of the community decisive in debates over political theory. The arguments I have given in this thesis lead towards a theory of luck egalitarianism that has radical redistributive implications, extending far beyond 
the requirements of more popular theories of distributive justice, but if the arguments are strong ones, then this radicalism does not provide any reason to reject the theory.

In sum, social equality cannot replace luck egalitarianism. Luck egalitarianism is not trapped in the distributive paradigm, disrespectful, or susceptible to the bare persons objection. Moreover, social equality has concerning implications when applied to the distributive sphere. It is either indeterminate with regard to distributive justice, reduces to luck egalitarianism, or is ungenerous.

\section{CONCLUSION}

In this chapter, I have compared luck egalitarianism with three leading alternative theories of social justice and/or egalitarianism. I analysed the threshold/sufficiency view, prioritarianism, and social equality, and I concluded that none of these approaches can replace luck egalitarianism. In developing this argument, I have also defended the theory against the Levelling Down Objection, the claim that relative fairness only matters below a certain threshold, and a variety of criticisms advanced by proponents of social equality. This completes the central theoretical defence of luck egalitarianism. In the final chapter, I will examine the practical applications of the theory. 


\section{NOTES}

${ }^{1}$ D. Parfit, “Equality or Priority?” in M. Clayton \& A. Williams (eds.), The Ideal of Equality, Houndmills, Palgrave Macmillan, 2002, pp. 81-125, at p. 86. Or more precisely, Parfit believes that the core of the Telic approach is that inequality has disvalue. However, he avoids this phrasing in the rest of his lecture.

${ }^{2}$ T. Nagel, quoted in Parfit, “Equality or Priority?” p. 86.

${ }^{3}$ Parfit, “Equality or Priority?” pp. 88, 94.

${ }^{4}$ Parfit, “Equality or Priority?” p. 84.

${ }^{5}$ Parfit, “Equality or Priority?” pp. 88-90.

${ }^{6}$ Parfit, “Equality or Priority?” p. 90.

${ }^{7}$ Parfit, “Equality or Priority?” p. 90.

${ }^{8}$ Parfit, “Equality or Priority?” pp. 94-97.

${ }^{9}$ Parfit, “Equality or Priority?” especially pp. 97-99. Parfit links this objection to work by Raz and Temkin. See Parfit, “Equality or Priority?” p. 123 n. 27; J. Raz, The Morality of Freedom, Oxford, Oxford University Press, 1986, ch. 9; L. Temkin, Inequality, New York, Oxford University Press, 1993, pp. 247-48.

${ }^{10}$ Parfit, “Equality or Priority?” p. 98.

${ }^{11}$ Parfit, “Equality or Priority?” p. 99. Telic Egalitarians may be able to avoid this particular example by responding that they are only interested in inequalities in the resources individuals hold. But this restriction may seem difficult to justify. Surely the inequality between the sighted and the blind is also bad? Moreover, we could simply adjust the example so it involves resources, in order to make the same point. See “Equality or Priority?” pp. 97-98.

${ }^{12}$ However, Parfit believes that Telic Egalitarians may be able to defend themselves against the Levelling Down Objection. I will examine this possibility below.

${ }^{13}$ Parfit, “Equality or Priority?” p. 99.

${ }^{14}$ Parfit, “Equality or Priority?” pp. 99-100.

${ }^{15}$ Parfit, “Equality or Priority?” pp. 99-100. Parfit's original presentation of the Divided World Example is on p. 87.

${ }^{16}$ Parfit, "Equality or Priority?” p. 101. Temkin discusses a similar approach to the Priority View which he calls "extended humanitarianism". An extended humanitarian "wants each 
person to fare as well as he possibly can, but he is especially concerned with the worse-off.” See Temkin, Inequality, especially pp. 245-48.

${ }^{17}$ See Parfit, “Equality or Priority?” pp. 103-5. However, as it "has a built-in bias towards equality, it could be called Egalitarian in a second, looser sense. We might say that, if we take this view, we are Non-Relational Egalitarians.” See p. 106, his emphasis.

${ }^{18}$ Parfit, “Equality or Priority?” p. 104.

19 Parfit, "Equality or Priority?” p. 104.

${ }^{20}$ Parfit, “Equality or Priority?” p. 107.

${ }^{21}$ Parfit, “Equality or Priority?” p. 116. See also pp. 106-107.

${ }^{22}$ Parfit, “Equality or Priority?” pp. 100, 116.

${ }^{23}$ Parfit, “Equality or Priority?” p. 105.

${ }^{24}$ See R. Crisp, “Equality, Priority, and Compassion,” Ethics, V. 113, no. 4, 2003, pp. 745-63, at pp. 745-50. However, Crisp does not believe that the force of the Levelling Down Objection derives from the Slogan. See pp. 747-48.

${ }^{25}$ Crisp, “Equality, Priority, and Compassion,” p. 752.

${ }^{26}$ Crisp, “Equality, Priority, and Compassion,” p. 752.

${ }^{27}$ Crisp, “Equality, Priority, and Compassion,” p. 752.

${ }^{28}$ Crisp, “Equality, Priority, and Compassion,” p. 754.

${ }^{29}$ Crisp, “Equality, Priority, and Compassion,” p. 754.

${ }^{30}$ Crisp, “Equality, Priority, and Compassion,” p. 755. I should note that in his original presentation of this case, the benefits to Rich and Super-rich are not identical, and nor are the two groups equal in number. In the original example, the number-weighting means that a far greater aggregate benefit to the Super-rich is outweighed by a much lower aggregate benefit to the Rich, which seems counter-intuitive. But this detail need not concern us here as Crisp goes on to make the stronger claim quoted above. That is, he goes on to argue that there would be no reason to favour the Rich, even if the aggregate benefits to each group were equal, rather than greater for the Super-Rich.

${ }^{31}$ Crisp, "Equality, Priority, and Compassion,” p. 746. The numbers in this example refer to the welfare of each group member under a particular distribution. For example, each member of Group 1 has a welfare level of 10 if we adopt the distribution labelled "Inequality”. Groups 1 
and 2 are also equal in size.

${ }^{32}$ Crisp, “Equality, Priority, and Compassion,” pp. 756-57.

${ }^{33}$ Crisp, “Equality, Priority, and Compassion,” p. 757.

${ }^{34}$ Crisp, “Equality, Priority, and Compassion,” p. 758.

${ }^{35}$ Crisp, “Equality, Priority, and Compassion,” p. 762.

${ }^{36}$ Crisp, "Equality, Priority, and Compassion,” p. 759. Crisp uses the term "needs” here in a narrow sense, so that our needs are distinct from other components of our welfare, such as desire satisfaction. He also acknowledges that more work is needed on how notions of desert affect the approach he has outlined. See p. 759 n. 31.

${ }^{37}$ Crisp, “Equality, Priority, and Compassion,” p. 762.

${ }^{38}$ Of course, this might be pushing the argument too far. We might argue that distributive justice does still matter, even in a world of abundance. I am not sure this could be the case, though, because in a world of abundance, no further redistribution of resources could actually make anybody any better off. Temkin suggests that we might react to the Beverly Hills case in the way Crisp suggests precisely because we (mistakenly) equate it with this situation of abundance. That is, we might feel that neither the Rich nor the Super-rich can actually enjoy a higher level of welfare than they currently have, which explains why we feel it does not matter who we give the wine to -- neither of them is really any better off than the other. However, as Temkin points out, this misunderstands the example because Crisp himself says that the values assigned to the groups are the level of advantage that they enjoy. That is, Rich and Super-rich are actually unequally well-off. See L.S. Temkin, "Egalitarianism Defended,” V. 113, no. 4, 2003, pp. 764-82, at pp. 769-70.

${ }^{39}$ For related comments, although not specifically directed against Crisp’s argument, see also R.J. Arneson, "Perfectionism and Politics," Ethics, V. 111, 2000, pp. 37-63, at p. 56; and Rakowski, Equal Justice, New York, Oxford University Press, 1991, p. 66.

40 Temkin makes a related point in his response to Crisp. He agrees that we will feel compassion for a miserable person, and that we will feel a strong pull to aid him, regardless of questions of responsibility. However, he thinks that we will feel a stronger pull to help if he is not responsible for his predicament. According to Temkin, "[t]his suggests that fairness and compassion are distinct concerns and that each may play a role in our giving priority to some 
who are worse off than others.” See L.S. Temkin, "Egalitarianism Defended,” V. 113, no. 4, 2003, pp. 764-82, at pp. 772-3, quotation at p. 773. I agree with Temkin that considerations of fairness have a moral value that is independent of compassion, as will become obvious in the next paragraph. Nonetheless, I have also suggested that our feelings of compassion are greater towards a person who bears no responsibility for his badly off state. Temkin briefly discusses this response on p. 773.

${ }^{41}$ See Temkin, “Egalitarianism Defended,” pp. 773-76.

${ }^{42}$ Temkin, “Egalitarianism Defended,” p. 773.

${ }^{43}$ Temkin, “Egalitarianism Defended,” pp. 774-75.

${ }^{44}$ Temkin, “Egalitarianism Defended,” p. 775.

${ }^{45}$ Temkin, “Egalitarianism Defended,” p. 775.

${ }^{46}$ See R.J. Arneson, “Equality of Opportunity for Welfare Defended and Recanted,” Journal of Political Philosophy, V. 7, no. 4, 1999, pp. 488-97; “Luck Egalitarianism and Prioritarianism,” Ethics, V. 110, no. 2, 2000, pp. 339-49.

${ }^{47}$ Arneson, “Luck Egalitarianism and Prioritarianism,” p. 340.

${ }^{48}$ Perhaps most notably, I exclude from this discussion Parfit's Non-Identity problem. See his Reasons and Persons, Part IV, especially pp. 351-79. It is also discussed in Temkin, Inequality, pp. 255-56; and Crisp, “Equality, Priority, and Compassion,” p. 747.

${ }^{49}$ Temkin, Inequality, p. 248, original emphasis.

${ }^{50}$ Temkin Inequality, p. 256, original emphasis.

${ }^{51}$ By "pluralist theories of egalitarianism," I mean theories which support the existence of other, non-egalitarian values, which must be taken into account when making all-thingsconsidered judgements. In Cohen’s terms, such theories advance "weak equalisandum claims.” See “On the Currency of Egalitarian Justice,” Ethics, V. 99, no. 4, 1989 pp. 906-944, at p. 908.

${ }^{52}$ See Temkin, Inequality, pp. 257-58.

${ }^{53}$ Temkin, “Egalitarianism Defended,” pp. 771.

${ }^{54}$ Temkin, Inequality, p. 771.

${ }^{55}$ Temkin, Inequality, pp. 771-72.

${ }^{56}$ When I mention "the Slogan" in the remainder of this section, I am referring to the testing version of the Slogan identified by Temkin (see p. 209 above). 
57 Temkin, Inequality, pp. 260-61; Temkin, “Equality, Priority, and the Levelling Down Objection," in The Ideal of Equality, pp. 126-61 at pp. 138-40; \& see also Temkin, “Egalitarianism Defended,” pp. 779-80.

58 Parfit, “Equality or Priority?” pp. 114-15. According to the Person-Affecting Claim, “if an outcome is worse for no one, it cannot be in any way worse.”

${ }^{59}$ Parfit, “Equality or Priority?” p. 115.

${ }^{60}$ Parfit, “Equality or Priority?” p. 115. In making this point I am not endorsing this view of free will and responsibility, or claiming that we should reject the retributive view.

${ }^{61}$ Parfit, “Equality or Priority?” p. 115.

62 Temkin, Inequality, p. 258.

63 Temkin, “Equality, Priority, and the Levelling Down Objection,” p. 154.

64 Temkin, Inequality, p. 258.

${ }^{65}$ See Temkin, “Equality, Priority, and the Levelling Down Objection,” p. 142.

66 Temkin, Inequality, p. 277.

${ }^{67}$ See Temkin, Inequality, pp. 258-59, italics removed.

68 Temkin, Inequality, p. 260; Temkin, “Equality, Priority, and the Levelling Down Objection,” p. 142.

69 Temkin, Inequality, pp. 260-62; Temkin, "Equality, Priority, and the Levelling Down Objection,” p. 141; \& also note Temkin, “Egalitarianism Defended,” pp. 777-80.

70 Temkin, Inequality, p. 263.

${ }^{71}$ Temkin, Inequality, p. 264.

72 Temkin, Inequality, pp. 266-67.

73 Temkin, Inequality, p. 265.

${ }^{74}$ Temkin, Inequality, pp. 267-68.

75 Temkin, Inequality, pp. 268-69.

${ }^{76}$ Temkin, Inequality, pp. 269-70.

77 Temkin, Inequality, p. 270. The example is originally from Parfit, Reasons and Persons, p. 494.

78 Temkin, Inequality, p. 270; \& Temkin, “Equality, Priority, and the Levelling Down Objection,” p. 144. 
${ }^{79}$ Temkin, Inequality, p. 270.

${ }^{80}$ Temkin, Inequality, pp. $270-71$ \& p. 271 n. 41 . Note that Temkin assumes here "that the people in the graves had no desires one way or the other about the tending of their graves.”

${ }^{81}$ Leaving aside these problems, Temkin gives another reason why SDFT is unlikely to be a satisfactory theory of the good for anti-egalitarian arguments based on the Slogan. If our theory of the good takes into account the satisfaction of desires that are associated with people's deepest commitments, as any plausible version of SDFT must, then it will also have to take into account the desires of egalitarians. Egalitarians are worse off in at least one respect in situations where there is greater inequality, so it will be difficult to use the Slogan to motivate antiegalitarian arguments. See Temkin, Inequality, pp. 271-72; \& Temkin, “Equality, Priority, and the Levelling Down Objection,” pp. 144-45.

${ }^{82}$ See Temkin, Inequality, pp. 272-77; \& Temkin, “Equality, Priority, and the Levelling Down Objection," pp. 145-46.

${ }^{83}$ Temkin, Inequality, p. 272.

${ }^{84}$ Temkin, Inequality, pp. 272-73.

${ }^{85}$ Temkin, Inequality, pp. 274-75; \& see also Temkin, “Equality, Priority, and the Levelling Down Objection,” p. 140.

${ }^{86}$ Temkin, Inequality, pp. 273, 274.

${ }^{87}$ Temkin, Inequality, pp. 275-76.

${ }^{88}$ Temkin, Inequality, p. 277.

${ }^{89}$ See Temkin, "Egalitarianism Defended,” pp. 771-72. However, in this case, the unfairness involved is so great that Temkin is inclined to make the stronger claim that all-thingsconsidered nobody should get the wine.

${ }^{90}$ In this section, I will assume use the term "social equality" to refer to theories of both social equality and democratic equality.

${ }^{91}$ W. Kymlicka, Contemporary Political Philosophy: An Introduction, Oxford, Clarendon Press, 2002, p. 196.

${ }^{92}$ E.S. Anderson, “What is the Point of Equality?” Ethics, V. 109, no. 2, 1999, pp. 287-337, at p. 288.

${ }^{93}$ E.g. D. Miller, “What Kind of Equality Should the Left Pursue?” in J. Franklin (ed.), 
Equality, London, Institute for Public Policy Research, 1997, pp. 83-99; and Principles of Social Justice, Cambridge, Mass. \& London, Harvard University Press, 1999; Anderson, "What is the Point of Equality?”; S. Scheffler, “What is Egalitarianism?” V. 31, no. 1, 2003, pp. 5-39.

${ }^{94}$ Anderson, "What is the Point of Equality?"

${ }^{95}$ Anderson, “What is the Point of Equality?” pp. 304-7.

${ }^{96}$ Cohen, "Facts and Principles," Philosophy and Public Affairs, V. 31, no. 3, 2003, pp. 207245, pp. 244-45.

${ }^{97}$ Kymlicka, Contemporary Political Philosophy, p. 197.

${ }^{98}$ Miller, Principles of Social Justice, pp. 148-49.

${ }^{99}$ At least, the revised form of luck egalitarianism that I outlined in chapter 3 is not susceptible to this objection.

${ }^{100}$ Some may suggest that this example is too unrealistic to carry the weight it bears. Every high school graduate will consider her own preferences when making a decision on further education and consequently, every such choice will be genuine. In instances where this accurately describes the situation, I would agree with the critic's judgement. Nonetheless, I deny that my example is implausible. The idea of actually studying at college may never be realistically considered by the graduate precisely because she is never expected (and so never expects) to do so. That is, it is simply not an option she seriously entertains. In addition, her parents' views may leave her with a misleading picture of college life and the choices involved. If she does not fully appreciate the consequences of the decision she makes and we have no reasonable grounds for believing that she should have known better then the choice is not genuine.

${ }^{101}$ Note also G.A. Cohen, “Expensive Taste Rides Again,” in J. Burley (ed.), Dworkin and His Critics: with Replies by Dworkin, Malden, Blackwell Publishing, 2004, pp. 3-29, at pp. 10-13. ${ }^{102}$ Miller, “What Kind of Equality Should the Left Pursue?” p. 94. However, the work of some other social egalitarians seems more ambiguous on this issue. Anderson seems to support a similar approach to Miller, where questions of distribution matter to the extent that they affect the character of social relationships (e.g. pp. 313-14). However, she also says that democratic equality leads to principles of justice (e.g. p. 314). Presumably, this means that for Anderson, democratic equality is a theory of egalitarian justice, but one that focuses on the nature of social 
relationships, as a matter of justice.

${ }^{103}$ See, for example, Anderson, "What is the Point of Equality,” p. 288; Scheffler, "What is Egalitarianism?” pp. 14-15, 21-24, 32-33. 


\section{CHAPTER 7}

\section{LUCK EGALITARIANS AND THE WELFARE STATE}

In this thesis, I have shown that luck egalitarianism is a powerful and compelling interpretation of the egalitarian ideal because it focuses squarely on ensuring that the good and bad effects of morally arbitrary forces are shared equally throughout the community. However, as we have seen, critics have increasingly questioned and criticised the emphasis on individual responsibility in contemporary egalitarian thought. ${ }^{1}$ One of their major objections relates to the practical applications of this approach. Critics point out that in practice, determining whether individuals are responsible for the level of advantage they enjoy will depend on the existence of an intrusive state apparatus that makes highly demeaning and moralistic judgements about citizens' natural abilities, social background and choices. For instance, if we are interested in the relative income individuals enjoy, we must focus on factors relevant to their success in the labour market, which means assessing characteristics such as natural talent (or lack thereof), family background, choice of occupation, and effort in the workplace. We must also assess whether they have made prudent judgements in their "personal” life. For instance, we might be interested in whether they have chosen a partner who is likely to earn a high income, ${ }^{2}$ and whether they have decided to have children at an appropriate time, given their financial situation. Many are repelled by the idea that the state should collect such information, or even make such judgements.

These criticisms are directed against an unqualified implementation of luck egalitarianism that could only occur in an "ideal” world. However, there is a danger that the emphasis on individual responsibility in egalitarian thinking will also have serious implications for real-life policy debate. In particular, 
there is a risk that luck egalitarianism adds moral weight to the increasingly paternalistic, intrusive and demeaning approach to social protection in the Anglo-American world. ${ }^{3}$ Since the 1980s, governments have tightened the eligibility criteria for receiving welfare benefits, forcing recipients to do more to "prove" that they truly need and deserve social support. Much of this is done in the name of responsibility and choice, so there is a danger that luck egalitarianism will be interpreted as lending support to these developments:

If policy makers were to read Dworkin and others, what message might they come away with? That egalitarians, like conservatives, now favor highly conditional welfare benefits. But in the real world this does not give us egalitarianism. Rather, it gives us Thatcherism, in which the poor are singled out for insulting levels of scrutiny. Egalitarians might protest that this is to take their proposals out of context, and they do not advocate such things in the real, unjust world, only in the ideal, just, world to be. But they do hope to influence policy makers, and give little clue about how to change the real world in their favored direction. ${ }^{4}$

Many will find the idea that egalitarianism implies support for Thatcherism (or even conditional welfare payments more generally) strongly counter-intuitive.

Luck egalitarians can respond to this criticism in a number of ways. For instance, Cohen has argued that we must avoid confusing our motivating concerns. ${ }^{5}$ His famous outline of a luck-egalitarian theory defends a "weak equalisandum claim," which "says that... [people] should be as equal as possible in some dimension but subject to whatever limitations need to be imposed in deference to other values.” ${ }^{6}$ If liberty is one of these non-egalitarian “other values” to which egalitarians should defer, it might provide a reason to avoid implementing luck egalitarianism through intrusive forms of social policy. In a more recent and explicit response to luck egalitarianism's critics, Cohen has also emphasised that we must distinguish between principles of 
regulation and ultimate, fact-insensitive principles when making moral judgements. ${ }^{7}$ The fact that luck egalitarianism can only be implemented with a repellent degree of state interference is no reason to reject it at the level of factinsensitive principle. It simply means that we lack the policy instruments to apply satisfactorily the theory we support. But whilst this is a strong response, it does not entirely alleviate the problem. Many of those opposed to Thatcherite social policies believe them to be wrong precisely because they are antiegalitarian not because they offend some other non-egalitarian value. ${ }^{8}$

Wolff has attempted to explain why intrusive and demeaning forms of social policy offend egalitarianism by distinguishing between two different values which play a role in what he calls the "egalitarian ethos." One of these values is fairness, which theorists such as Dworkin, Cohen, Arneson and others understand "in opportunity terms." ${ }^{9}$ That is, they believe that fairness is about equalising opportunities rather than equalising outcomes per se. ${ }^{10}$ But Wolff identifies another, competing egalitarian value of "respect." The main reason conditional welfare policy troubles egalitarians is because it violates the principle of respect for all. For example, it shows a distrust of welfare recipients and assumes that they are trying to cheat the system, which is a very disrespectful assumption to make. ${ }^{11}$ But of greatest concern to egalitarians is the fact that it forces recipients to reveal information about themselves that they might find shameful. For example, it is demeaning to have to prove that one is unable to find a job at a time of low unemployment. As Wolff puts it, "think how it must feel -- how demeaning it must be -- to have to admit to oneself and then convince others that one has not been able to secure a job, despite one's best efforts, at a time when others appear to obtain employment with ease. This removes any last shred of dignity from those already in a very unfortunate 
position.” ${ }^{12}$ Thus, whilst the value of fairness implies a system of conditional welfare payments, the value of respect explains why egalitarians have good reason to oppose such a system.

Although Wolff's argument is powerful, it does not entirely solve the problem facing luck egalitarianism. The value of respect certainly provides a strong reason for egalitarians to support universal forms of social provision. However, many egalitarians are opposed to conditional welfare payments, at least in a world like our own, because they believe them to be unfair from an egalitarian point of view. Indeed, there is a sense in which relying on the notion of respect to justify universalism reflects the pro-market flavour of much contemporary political thought. Increasingly, the main function of social policy, even for those on the centre-left, is to encourage participation in the market, not to challenge the market or significantly alter market outcomes. Wolff supports universal welfare provision on the grounds of respect, not because the egalitarian notion of fairness represents a fundamental challenge to the market and market outcomes, which can only be met through the universal welfare state or some more radical proposal. ${ }^{13}$

In fairness to Wolff, he does seem to recognise that the social policy implications of luck egalitarianism will diverge from those of Thatcherism in the real, inegalitarian world that we live in today. The problem, rather, is that luck egalitarians have not properly explained the policy applications of their theory. As he puts it, they have not focused enough on "issues of transition" from the real world to the ideal world. ${ }^{14}$ In this chapter, I aim to fill this gap in the literature, ${ }^{15}$ focusing specifically on which model of the welfare state is most consistent with luck egalitarianism. ${ }^{16}$ By restricting my focus to the welfare state, I do not wish to deny that luck egalitarianism represents a radical 
challenge to capitalism that goes beyond the models discussed here. Rather, I restrict the set of policy options under consideration because I am interested in the implications of luck egalitarianism for the more limited policy debates and policy approaches that are a feature of advanced capitalist nations today. To borrow Wolff's term, I focus on these welfare state models because I am interested in "issues of transition.” While egalitarians dispute the implications of luck egalitarianism in the ideal world, the idea of unconditional social support is increasingly being challenged in the real world. It is important for luck egalitarians to explain whether their theory endorses or condemns this policy direction because these changes have a big impact on the lives of many citizens. As important as it is to have a sense of the ideal policy end-goals of a normative theory, we cannot forget the importance of explaining its policy recommendations for the long journey there.

My argument is that luck egalitarianism is a radical theory that endorses the social democratic model of the welfare state over the liberal alternative, and thus provides strong grounds for opposing the current direction of social policy in the Anglo-American world. In section 1, I outline the models contested in contemporary debate over the welfare state. In section 2, I develop the first strand of my argument, arguing that luck egalitarianism has radical redistributive implications when applied to advanced capitalist societies, and that the social democratic welfare state is likely to secure a distribution of income that is more in keeping with this radicalism than the liberal welfare state. In section 3, I establish a deeper link between universal welfare provision and a welfarist interpretation of luck egalitarianism. Returning to the idea that certain expensive tastes are compensable, I show that a welfarist form of luck egalitarianism represents a strong challenge to the market, and that this is linked 
to the kind of decommodification that occurs in the social democratic welfare state. Universal social provision gives individuals more control over the kind of lives that they are able to live, and in doing so, brings us closer to a society where individuals enjoy equality of access to welfare. Thus, for a luck egalitarian, the current direction of Anglo-American social policy is wrong because it violates the egalitarian notion of fairness. In sections 2 and 3 I highlight the significance of my argument for the role of normative political theory in public policy debate.

\section{COMPETING APPROACHES TO THE WELFARE STATE}

In an influential study, Gosta Esping-Andersen argues that three different models of the welfare state emerged in advanced economies over the twentieth century: the liberal model, the corporatist model, and the social democratic model. ${ }^{17}$ To support this claim, Esping-Andersen makes extensive use of statistical data to compare welfare states in the OECD. He shows that certain countries have welfare states with similar characteristics and concludes that three broad approaches exist. Esping-Andersen is not saying that all countries have a welfare state that perfectly matches one of these three models, acknowledging, "that there is no single pure case." ${ }^{18}$ However, his research suggests that welfare states do tend to approximate one of these three approaches.

Luck egalitarianism seems to lend support to the kind of conditional and intrusive forms of social provision that, according to Esping-Andersen, tend to be associated with the liberal welfare state. In the liberal welfare state:

means-tested assistance, modest universal transfers, or modest social-insurance plans predominate. Benefits cater mainly to a clientele of low-income, usually working- 
class, state dependents. In this model, the progress of social reform has been severely circumscribed by traditional, liberal work-ethic norms: it is one where the limits of welfare equal the marginal propensity to opt for welfare instead of work. Entitlement rules are therefore strict and often associated with stigma; benefits are typically modest. In turn, the state encourages the market, either passively -- by guaranteeing only a minimum -- or actively -- by subsidizing private welfare schemes. ${ }^{19}$

Countries such as the US, Canada, Britain, and Australia have welfare states that fit this model.

Underlying the liberal approach is a desire to support the market and market outcomes. ${ }^{20}$ Ideally, those who can afford it should protect themselves against future risk by taking out social insurance. However, the state will need to provide a residual welfare safety net for those who fall outside the scheme of social insurance. The benefits provided tend to be limited, designed to meet the basic needs of the deserving poor without otherwise subverting market outcomes. Benefits are generally conditional upon citizens meeting certain criteria, which are designed to test whether they are genuinely needy and deserving of support. Usually, welfare recipients must satisfy a means test, which is designed to exclude those who could meet their basic needs by relying on income or assets from other sources, and a work test, which is designed to exclude those who are able to meet these needs through paid employment. To prove that they satisfy these criteria, recipients are subjected to intrusive interference by the state. For instance, the unemployed may be required to prove that they have attended the required number of job interviews and they will generally be expected to take whatever job is offered. They may be forced to participate in labour market programs, or to perform community service. They may have to meet with officials who have the power to strip them of their benefits if they have not met these requirements. Similar criteria are often 
attached to other welfare benefits, too, particularly single parent payments. Critics of these policies argue that they are intrusive and demeaning to welfare recipients. Luck egalitarianism may be seen to support such policies by linking distributive justice to notions of individual responsibility.

In contrast, the egalitarian approach to social protection in capitalist societies tends to be associated with the social democratic welfare state. Under this model, generous welfare services and benefits are provided universally. Rather than targeting benefits at the needy, forcing others to achieve social protection through the market, all citizens, including the more affluent middle classes are entitled to receive assistance. As Esping-Andersen puts it:

Rather than tolerate a dualism between state and market, between working class and middle class, the social democrats pursued a welfare state that would promote an equality of the highest standards, not an equality of minimal needs as was pursued elsewhere. This implied, first, that services and benefits be upgraded to levels commensurate with even the most discriminating tastes of the new middle classes; and, second, that equality be furnished by guaranteeing workers full participation in the quality of rights enjoyed by the better-off. ${ }^{21}$

This contrasts markedly with the limited, targeted welfare payments and services that characterise the liberal welfare state. The social democratic model, with its emphasis on universalism, is commonly associated with Scandinavia.

The social democratic welfare state represents a significant challenge to market outcomes. In a free market economy, most goods and services are commodities, which are bought and sold at prices determined by the market. But a social democratic welfare state is associated with a high degree of decommodification, providing a range of benefits and services universally, particularly in areas such as health, education, housing, and income security. ${ }^{22}$ In the social democratic model, citizens are able to satisfy their needs in these 
areas through the state, not the market. Instead of buying the health services you need at a market-determined price, they are provided by the state universally (that is, to all citizens, on the basis of need). In this way, these benefits and services are no longer commodities. The fact that they are provided to all citizens unconditionally also, to an extent, decommodifies labour. ${ }^{23}$ In a liberal welfare state, the unemployed are obliged to look for paid employment, and to accept any job on offer. But if citizens are able to meet their needs through universal services provided by the state, they have more control over their labour power. If the state provides unconditional access to the basic necessities of life, workers have more choice over whether they work, the type of work they do, and the conditions under which they perform this work. Because it provides a more generous level of social support, decommodifies workers' labour, and avoids the intrusive and demeaning policies associated with the liberal model, the social democratic welfare state seems to be more consistent with egalitarian values.

These models are intended as ideal-types, so no country completely embodies one model. However, in recent years, many Anglo-American nations seem to be heading even further down the liberal path, which emphasises the importance of providing welfare to the "truly needy." Increasingly, they seek to avoid distorting market outcomes by closely targeting welfare benefits and services, and closely monitoring the lives of welfare recipients in an attempt to prevent people from receiving welfare unless they are deemed truly to need it. Underlying this is the idea that we must avoid decommodification -- people should seek social protection through the market unless it is impossible for them to do so. As I explained above, luck egalitarianism can be criticised for lending support to this approach. After all, determining whether a person's 
condition is the result of choice or luck seems to involve the very kind of intrusive judgements associated with the liberal welfare state. In the remainder of the paper, I will challenge this characterisation of luck egalitarianism.

\section{EQUALITY OF OUTCOME AND UNIVERSAL PROVISION}

Practically implementing luck egalitarianism would require that the state make precise judgements about individuals on a case-by-case basis, working with detailed information about their genetic make-up, family background and educational history. This would imply a huge welfare state that intrudes into almost all areas of human life, keeping extensive records about the opportunities we have had, and the choices we have made. But such an extreme proposal does not feature in the policy debate that interests us here. Rather, the focus is on determining which of Esping-Andersen's models is most consistent with luck egalitarianism. Having already ruled out the corporatist approach, ${ }^{24}$ we are left with a choice between the liberal welfare state and the social democratic approach. In order to make this choice, we must decide which model comes closest to achieving a luck-egalitarian pattern of distribution.

Although it is impossible to determine precisely the overall pattern of distribution that would emerge if luck egalitarianism were applied to an advanced capitalist nation today, we can arrive at a reasonable approximation, as I have argued elsewhere in the thesis (see chapter 3). At first glance, the market distribution of income (that is, the distribution that results purely from market transactions, prior to any redistribution by the state through the taxtransfer system) appears consistent with luck egalitarianism because it simply reflects the choices individuals have made. However, the market also reflects the differential impact of luck on people's lives. For instance, it tends to reward 
the talented and punish the untalented, and other things equal, this is inconsistent with luck egalitarianism. Other forms of background luck will also be of key concern to luck egalitarians. If, for instance, differences in our family background, education and access to opportunities affect the choices we make and the outcomes that emerge, then luck egalitarians should consider the results a matter of luck. ${ }^{25}$ Because significant luck-derived inequalities of this type are a feature of advanced capitalist nations today, the market distribution of income is not inherently just from a luck-egalitarian perspective.

We can push this point further, and reasonably claim that much of the inequality that exists in society today reflects the influence of luck. This seems obvious when we think about the extent of differences in natural ability, family environment, educational opportunity and inherited wealth that exist. Against this background, it is difficult to argue that a similar range of opportunities are open to all individuals, which means that few inequalities can be attributed to choice. Although there is insufficient room here to justify fully this claim, it is supported by recent research which highlights the limited nature of intergenerational economic mobility in America. ${ }^{26}$ In particular, Mazumder estimates that the level of intergenerational elasticity in earnings in the US is 0.62, which indicates that there is actually less mobility than was previously thought. ${ }^{27}$ Moreover, his research suggests that 50 percent of men with fathers in the bottom earnings decile earn below the $30^{\text {th }}$ decile. In contrast, over half of those with fathers in the top decile earn above the $80^{\text {th }}$ percentile. ${ }^{28}$ At either end of the earnings spectrum, a man has a high chance of ending up with a similar income to his father. Of course, this does not prove conclusively that earnings in the US entirely reflect the impact of luck, but it does suggest that background inequalities have a significant impact on the earning capacity of 
Americans. Given evidence of such a strong link between the economic success of fathers and sons, and given the state's need to make policy decisions based on general judgements about the overall patterns of inequality in society, it is difficult to avoid the conclusion that most of the inequalities which exist in the US should be considered the compensable results of luck, not genuine choice. ${ }^{29}$ Thus, the best way for governments to implement luck egalitarianism in the real world is to aim for equality of outcome, ${ }^{30}$ or something close to it. ${ }^{31}$

A critic of this argument could object that some real world income inequalities are just, even from a luck-egalitarian perspective. Take, for example, a talented but lazy person from a privileged background who ends up with less than others because he refuses to take the opportunities available to him, despite realising the full consequences of doing so, and in spite of his parents' attempts to instil in him a strong work ethic. I admit that such a person will be treated overly-favourably, from a luck-egalitarian perspective, if we aim for equality of outcome. But I am confident that very few such people exist. There are, of course, some cases where the children of the well-to-do seem to squander an excellent start in life, but even here luck may be at work. For instance, growing up in the lap of luxury might result in a failure to appreciate the consequences of laziness.

A related example might involve individuals from low-income families who end up in high-earning occupations. Surely, this shows that most people can enjoy material success if they are prepared to make the right choices and to endure hard work and sacrifice? If this is the case then most inequalities are likely to be non-compensable because they reflect choice, which means that luck egalitarians should not aim for equality of income, even as a second-best measure. My response is that most wealthy, high-income-earning individuals 
are likely to be the beneficiaries of very good luck, regardless of their economic background. Even in this particular example, where the individuals involved start with much less than others (in terms of material wealth), they are likely to have very marketable talents. It is not simply hard work that makes them well off, but also the fact that they have the kind of talents that enable this hard work to result in material success. At any rate, I need not deny here that some inequalities in income and wealth are just. My point is that most are not, and that as long as we are forced to make general judgements, the best approximation of a luck-egalitarian pattern of distribution is equality of outcome.

If this conclusion is correct, then the social democratic welfare state is more consistent with luck egalitarianism than the liberal alternative because it leads to a more equal distribution of income. ${ }^{32}$ Although there is only room here for a brief discussion of this point, the evidence does seem to suggest that the social democratic welfare state is the most successful at reducing income inequality. $^{33}$ For instance, a recent study, drawing on data from the Luxembourg Income Study, found that countries with a social democratic welfare state had, on average, lower levels of post-tax and transfer household income inequality than other OECD nations. ${ }^{34}$ Rothstein also cites evidence that post-tax and transfer income inequality is lower and income redistribution greater in countries where the welfare state most closely resembles the universal model. ${ }^{35}$ This suggests that luck egalitarianism is achieved better through the social democratic welfare state than the liberal alternative.

It could be argued that this gets things the wrong way around. There does seem to be strong evidence to support the claim that inequalities generally reflect the differential impact of luck on people's lives, but this is no reason to 
discount the role of genuine individual choice in every case. In fact, the best approach is not to adopt a form of social provision that brings us closer to equality of outcome, but rather, to adopt one that makes assessments of responsibility on a case-by-case basis. This leads us towards the liberal form of the welfare state, which actually attempts to make such assessments.

This criticism is flawed. Luck egalitarianism is built on a much more sophisticated understanding of individual responsibility and choice than the liberal welfare state. For luck egalitarians, knowing that someone has not been turning up for job interviews is not enough to justify holding her responsible for her material condition. Rather, we must also take into account the impact of other factors such as the individual's natural ability, family background, educational opportunities, and the satisfaction that she would get from the work that is available. We cannot simply adopt existing instruments of social policy, such as case management and job interview requirements, to obtain this kind of information. It would require further steps such as the genetic testing of potential welfare recipients, detailed records of their parents' economic status, a full record of the various decisions they have made in terms of their education and employment, and some subjective account of how enjoyable they find the prospect of working in the jobs available. ${ }^{36}$ Adopting the liberal approach to social policy will not help us collect this information, or make these judgements. In fact, the liberal approach may struggle to judge accurately questions of responsibility, even if we work with a more simplistic notion of responsibility. As Goodin points out, setting tight eligibility criteria risks denying support to those who really deserve it. ${ }^{37}$ Having tighter criteria creates less room for error, which means that mistakes and miscalculations by recipients and administrators may result in people being stripped of their 
benefits when they have not deliberately set out to cheat the system. So rather than relying on inaccurate judgements by the state, the best approach for luck egalitarians is to focus on the overall pattern of disadvantage in society. Ultimately, this pattern suggests that most inequalities reflect, to a significant extent, the influence of luck. Consequently, luck egalitarianism implies something close to equality of outcome, and because the social democratic welfare state leads to lower income inequality than the liberal model, luck egalitarianism endorses this approach. ${ }^{38}$

This conclusion counters a possible misconception about luck egalitarianism and has significance for the relationship between political theory and public policy. ${ }^{39}$ When we seek to link a normative theory or principle to real world policy debate then we should look at the kind of options that really feature in this policy debate. There is nothing wrong with pushing a theory to its logical conclusion by imagining the extreme policies and mechanisms that would be required to implement it in a hypothetical world where the state could do almost anything. But this approach cannot determine the implications for the real world where the state cannot do just anything. For instance, if we look at the kind of state intrusion that would occur if we adopted a pure form of luck egalitarianism, then it might seem that the theory endorses the conditional and intrusive approach to social protection that increasingly dominates in the Anglo-American world. But we cannot simply move between ideal and real policy conditions in this way. If we are talking about the implications of luck egalitarianism for real policy debates then we must focus directly on the kind of options that actually feature in these policy debates. We cannot simply take the theory's policy recommendations in an ideal setting and assume that it will automatically support some weaker version of these recommendations in the 
real world. Although the liberal welfare state appears superficially consistent with luck egalitarianism, this is misleading because the liberal model relies on overly simplistic conceptions of individual choice and responsibility. When faced with a choice between the welfare state models that actually exist, luck egalitarianism supports the social democratic approach.

In the next section, I will argue that there is also a more fundamental link between luck egalitarianism and universal social provision. In establishing this link, I will return to the issue of expensive tastes, which I discussed earlier in the thesis.

\section{EXPENSIVE TASTES AND DECOMMODIFICATION}

As we discussed in chapter 5, the controversy over expensive tastes is part of a broader dispute between egalitarians over the appropriate conception of advantage to use for the purposes of interpersonal comparison. Whilst some egalitarians focus on the share of resources that individuals hold, others are interested in the level of subjective welfare or objective well-being they enjoy. The expensive tastes objection applies to welfarist forms of egalitarianism. Individuals with expensive tastes need more resources than others to reach a given level of welfare, and under various forms of welfare egalitarianism this disadvantage is compensable.

In chapter 5, I supported Cohen's position in this debate, arguing that luck egalitarians should adopt a heterogeneous conception of advantage that includes a subjective welfarist component alongside resources, midfare, and objective well-being. Consequently, luck egalitarians may be obliged to support providing compensation to those with expensive tastes. These tastes are compensable if the person who holds them is the victim of bad preference luck, 
where the expensive taste is involuntarily acquired, or bad price luck, where a valued preference is expensive to satisfy. The bad price luck argument, in particular, highlights a crucial difference between Cohen and Dworkin. For Cohen, the fact that a person endorses an expensive taste as valuable may be enough to justify compensation for it. After all, it is not her fault that something she values is so expensive. For Dworkin, in contrast, she should not receive compensation for this taste precisely because she endorses it as valuable. ${ }^{40}$

In essence, this difference over bad price luck relates back to the idea of decommodification, which is a key difference between the liberal and social democratic models of the welfare state (see section 1 above), and is a key difference between Dworkin's liberal egalitarian approach to the expensive tastes issue and Cohen's analytical Marxist approach. Decommodification has an important place in socialist thought ${ }^{41}$ and refers to the idea that under capitalism, human life and human relations are commodified along with our productive life. Roughly put, this means that everything becomes a commodity that is bought and sold on the market, no matter the deeper value it has for us. Whilst liberals may support a limited degree of decommodification in certain areas of life, they are generally opposed to it because of their strong belief in the market. $^{42}$

Dworkin believes that markets should play a key role in egalitarianism and in many ways, his theory of equality of resources represents the commodification of egalitarian justice. Recall that Dworkin uses hypothetical markets to determine the appropriate distribution of social resources, and the level of compensation which individuals should receive for handicaps. The level of advantage a person enjoys is understood in terms of the resources she holds, and the value of these resources is determined by a hypothetical auction. 
By giving market mechanisms such a crucial role, Dworkin weds egalitarian justice to the notion of commodification. ${ }^{43}$

But as I argued in chapter 5, we need not accept this characterisation. Ultimately, the focus of egalitarian justice should be on the extent to which individuals are able to live fulfilling lives, and an important component of a fulfilling life is being able to satisfy valued preferences. Because some people’s preferences are more expensive to satisfy than others' are, we will end up compensating individuals for having expensive tastes. But, to reiterate the point, if we are truly concerned with the ability of individuals to live fulfilling lives, then we have no alternative but to accept this conclusion. There is no reason why resources, valued by market mechanisms should be the key focus of egalitarian justice. Markets are "brute luck machines" 44 because they simply reflect people's preferences, combined with limitations on production, and what we are able to do with our lives should not be constrained by morally arbitrary bad price luck. This leads luck egalitarians back to the traditional socialist notion of decommodification, highlighting once again the radical nature of the theory.

Amongst our most important preferences are those regarding how we spend our time, particularly relating to the balance we wish to strike between labour market participation and leisure. For instance, one person might believe that the pursuit of leisure activities is crucial to the good life, whilst another places greater emphasis on the pursuit of a successful career and a life of high material consumption. ${ }^{45}$ If two individuals are equal in every way except for their preferences regarding the work-leisure balance, then we should ensure that they are equally able to satisfy these preferences. A second major issue relates to differences in the kind of jobs we wish to pursue. Some want high-pressured 
jobs in the corporate sector, others want less pressured, more physical work, whilst others place a high value on pursuing an activity they believe intrinsically important, such as research. Other things being equal, this means we should ensure that individuals are equally able to satisfy their preference for a particular kind of labour market involvement. In effect, individuals should have equal access to "job satisfaction.”

If this argument is correct, then there is a deep connection between luck egalitarianism and universal social provision. Recall that the social democratic welfare state is associated with a high degree of decommodification because it provides a range of benefits and services universally. The benefits and services provided in this way are usually those most people consider vital to their lives. In areas such as health and education, social democratic governments tend to provide benefits and services collectively, on the basis of need, rather than at market prices. The state effectively guarantees access ${ }^{46}$ to the things that most people need to live a reasonable life, which facilitates labour market decommodification. By guaranteeing reasonable access to what most people would consider the basic necessities of life, individuals have much greater capacity to determine whether they enter the labour market, and the terms on which they do so. At least in theory, people are guaranteed access to a reasonable standard of living without having to perform paid employment. This ensures that, other things being equal, everybody has a greater ability to choose the kind of balance between work and leisure that suits them. If a person would rather surf than work in a corporate law firm or factory, then she can do so without facing starvation. Of course, she will still suffer a loss in her material standard of living, and earn much less than those who choose to spend their days working long hours, but her basic needs are satisfied and she is living a 
life that she finds truly fulfilling. Some may think this is unfair, but they are not really in a position to complain because the choice this person made was also open to them. ${ }^{47}$ By giving individuals more control over how they spend their lives, we move closer to a truly egalitarian world where all individuals have equal access to a life they find fulfilling. ${ }^{48}$

A number of criticisms are immediately apparent. Firstly, the model I endorse here seems likely to have disastrous economic consequences. After all, why bother working if your basic needs are guaranteed by the state? Although this objection seems troubling, it is not decisive against my argument that luck egalitarianism endorses the social democratic welfare state over the liberal model. In deciding between these two approaches, my central concern is with luck egalitarianism, not economic growth and efficiency. However, this response may not allay our concerns. In the last section, I said that we should focus on the policy options that really feature in policy debates, if we want to use normative theory to inform these debates. If the social democratic model is economically unfeasible, then, a critic might argue, it is not a realistic policy option. How could any policy-maker seriously consider a social policy model that would have such dire economic consequences?

Whilst fully assessing the economic impact of the social democratic model is beyond the scope of this thesis, it is important to remember that many people will want a higher material standard of living than they can get from relying on the social benefits and services provided by the social democratic welfare state. They will want to earn a higher-than-average income, which means that they will have an incentive to work in highly paid occupations, ${ }^{49}$ lessening the economic costs of the model. Moreover, it is important to remember that the social democratic welfare state (or at least something closely 
resembling the ideal-type) does exist in countries such as Sweden and Norway, which enjoy a high standard of living. ${ }^{50}$ Thus, there is no reason to think that the social democratic model will cause economic disaster. It remains a genuine alternative in real world policy debate.

The second criticism is that the social democratic welfare state is an imperfect implementation of luck egalitarianism. Some individuals will get to work in well-paid jobs that they greatly enjoy, which means that they are likely to enjoy much greater-than-average levels of welfare (they get a high level of utility from their job, and a high level of resources because it is well-paid). In practice, individuals may also have problems accessing the goods and services to which they are entitled, whilst low-income earners may be paid little more than those who choose not to work, living off welfare payments. This means that the social democratic model is not, in practice, as consistent with luck egalitarianism as it first appears. However, in general, the social democratic approach will perform far better than the liberal alternative on each of these fronts. Under the liberal approach, there is no choice whether to work. All citizens who can participate in the labour market are effectively forced to do so, regardless of their attitudes to work and leisure, and without much choice over the work that they do. Thus, high income-earners will continue to enjoy high utility and incomes whilst the low-paid will be even worse off because they will have less choice over the work that they do. This stands in contrast to the kind of choices individuals have under a social democratic welfare state where labour and human life are decommodified to a greater extent. In sum, luck egalitarianism supports universal, not highly conditional forms of social provision.

This conclusion also has significance for the way we use political theory 
to inform public policy. As I argued in section 2, when we seek to draw out the relevance of normative principles or theories for policy debate, we must focus directly on the actual policy options involved. However, this does not mean that we should retreat from abstract theory altogether. Critics have objected to the bizarre hypothetical examples that some political theorists use to test the intuitive appeal of their ideas, arguing that they are too removed from real world political disputes and policy debates. ${ }^{51}$ But my argument in section 3 highlights precisely why such highly abstract theorising is important. Even the bizarre debate over compensation for expensive tastes, with its eccentric cast of hypothetical characters, has crucial significance for the real world. Our response to this issue is linked to whether we are obliged, from the point of view of egalitarian justice, to provide all citizens with the necessities of life

unconditionally. ${ }^{52}$ Abstract theoretical argument allows us to see precisely why the liberal approach to social policy is wrong. If we truly believe in egalitarian justice and the importance of individual choice, then we should support universal forms of social provision.

\section{CONCLUSION}

In this chapter, I have argued that luck egalitarianism is a radical theory that lends support to the social democratic welfare state over the liberal alternative. Given the inability of the welfare state models to collect the detailed information needed to make accurate assessments of individual responsibility, luck-egalitarian policy-makers are forced to make approximate judgements about a just distribution of income. Because luck egalitarianism has radical redistributive implications, the safest bet is to aim for a pattern of distribution that approximates equality of outcome, and the evidence suggests that income 
inequality is lower in countries with a social democratic welfare state. Secondly, a radical form of luck egalitarianism focuses on equalising the extent to which individuals are able to live fulfilling lives, even though this might involve compensating individuals who have expensive tastes. Because preferences relating to work, leisure, and job satisfaction have crucial significance for the quality of individuals’ lives, luck egalitarians should ensure that individuals have an equal ability to satisfy their preferences in these areas (or as close to equal as it is possible to get). This creates a strong link between luck egalitarianism and labour market decommodification, and this decommodification is most likely to be achieved through the social democratic welfare state. Thus, contrary to the views of its critics, luck egalitarianism explains precisely why recent trends in Anglo-American welfare policy are of such concern to egalitarians. The policy implications of normative theory are often more complex than they first appear to be. 


\section{NOTES}

${ }^{1}$ E.g. J. Wolff, “Fairness, Respect, and the Egalitarian Ethos,” Philosophy and Public Affairs, V. 27, no. 2, 1998, 97-122; E.S. Anderson, “What is the Point of Equality?” Ethics, V. 109, no. 2, 1999, pp. 287-337; S. Scheffler, “What is Egalitarianism?” Philosophy and Public Affairs V. 31, no. 1, 2003, pp. 5-39; A. Phillips, "Defending Equality of Outcome," The Journal of Political Philosophy V. 12, no. 1, 2004, pp. 1-19.

2 Note A.T. Coram, “Social Class and Luck: Some Lessons from Gambler’s Ruin and Branching Processes,” Political Studies V. 45, no. 1, 1997, pp. 66-77, at p. 66.

${ }^{3}$ See also W. Kymlicka, Contemporary Political Philosophy: An Introduction, second edition, New York, Oxford University Press, 2002, pp. 93-4.

${ }^{4}$ Wolff, “Fairness, Respect, and the Egalitarian Ethos,” p. 112.

${ }^{5}$ I should note that Cohen's argument is a more general response to the criticisms discussed in the previous paragraph rather than a specific attempt to justify the universal welfare state. To the best of my knowledge, Cohen has not discussed in great detail the policy implications of luck egalitarianism (or equality of access to advantage, which is his version of it). He has suggested that capitalism and the market are ultimately inconsistent with egalitarianism, although market socialism would be an improvement on current arrangements. See G.A. Cohen, “Why Not Socialism?” in E. Broadbent, Democratic Equality: What Went Wrong? Toronto, University of Toronto Press, 2001, pp. 58-78, at p. 73. He also labels his response to Anderson's critique as "promissory." See G.A. Cohen, "Facts and Principles," Philosophy and Public Affairs V. 31, no. 3, 2003, pp. 207-245, at p. 244 n. 48.

${ }^{6}$ Cohen, “On the Currency of Egalitarian Justice,” p. 908.

${ }^{7}$ Cohen, “Facts and Principles,” pp. 244-5.

${ }^{8}$ See Wolff, “Fairness, Respect, and the Egalitarian Ethos,” pp. 102-3. Perhaps this is also what Cohen means when he says, "it might be claimed that the difficulties of implementation that Anderson raises have a special character which makes them a true test of justice, so that it is not merely 'difficulties of implementation just as such' that she is pressing." See Cohen, "Facts and Principles,” p. 244 n. 48.

${ }^{9}$ Wolff, “Fairness, Respect, and the Egalitarian Ethos,” pp. 100-1, 103. However, Wolff points out (pp. 101, 103) that there are significant differences between these theorists, and that 
Dworkin, in particular, is likely to reject the "opportunity” terminology.

${ }^{10}$ Although he does not use the term, Wolff's opportunity conception of fairness is essentially luck egalitarianism.

${ }^{11}$ However, as Wolff recognises, this problem will not necessarily afflict the kind of conditional welfare schemes that could be established in a more egalitarian society. Wolff, “Fairness, Respect, and the Egalitarian Ethos,” pp. 111-12.

${ }^{12}$ Wolff, “Fairness, Respect, and the Egalitarian Ethos,” pp. 113-15, quotation at p. 114. There is also a third way in which conditional schemes of welfare provision, at least as implemented in the real world, tend to offend the value of respect. In practice, "[w]elfare claimants are often treated with great rudeness and in some cases are routinely humiliated.” But as Wolff points out, this "is usually a failing of individuals, not institutions, and there is no reason to think that this is a deep feature of any welfare system.” See pp. 110-11.

${ }^{13}$ This is not, of course, to deny the importance of Wolff's argument for public policy debate, or to deny that it gives us a strong reason to reject conditional welfare payments.

${ }^{14}$ Wolff, "Fairness, Respect, and the Egalitarian Ethos,” p. 113 \& see also the passage quoted above.

${ }^{15}$ One author who does discuss this issue is Kymlicka, in Contemporary Political Philosophy, pp. 79-96. For related discussion, see also R.J. Arneson, “Egalitarian Justice Versus the Right to Privacy?” Social Philosophy and Policy, V. 17, no. 2, 2000, pp. 91-119.

${ }^{16}$ If I were to conclude that the liberal welfare state, with its emphasis on conditional welfare payments, is the best way of implementing luck egalitarianism in the real world, this would not necessarily indicate that the theory is flawed. Rather, it might simply mean that I am wrong and that the egalitarian notion of fairness provides no reason to oppose this approach to social policy.

${ }^{17}$ G. Esping-Andersen, The Three Worlds of Welfare Capitalism, Cambridge, Polity Press, 1990. I will focus on the liberal and social democratic models in this paper because the corporatist model seems of little relevance to the debate over luck egalitarianism. The corporatist approach is the conservative model of the welfare state, "which is a sort of middle category" between the social democratic and liberal approaches (see Bo Rothstein, Just Institutions Matter: The Moral and Political Logic of the Universal Welfare State, Cambridge, 
Cambridge University Press, 1998, p. 145 n. 3). It offers reasonably high levels of benefits and services, but tends to provide them in ways that reinforce existing social hierarchies. Because of this anti-egalitarian motivation, I have excluded it from the discussion below. There would be reason to re-consider this if the corporatist model, in practice, outperformed the social democratic model in terms of income equalisation. But recent research suggests that this is not the case (although the corporatist model does have some redistributive impact). See D. Bradley, E. Huber, S. Moller, F. Nielsen, J.D. Stephens, "Distribution and Redistribution in Postindustrial Democracies,” World Politics V. 55, 2003, 193-228.

${ }^{18}$ Esping-Andersen, The Three Worlds of Welfare Capitalism, pp. 28-9.

${ }^{19}$ Esping-Andersen, The Three Worlds of Welfare Capitalism, pp. 26-7.

${ }^{20}$ Esping-Andersen, The Three Worlds of Welfare Capitalism, pp. 42-4.

${ }^{21}$ Esping-Andersen, The Three Worlds of Welfare Capitalism, p. 27.

${ }^{22}$ R. E. Goodin, B. Headey, R. Muffels, H. Dirven, The Real Worlds of Welfare Capitalism, Cambridge, Cambridge University Press, 1999, p. 49.

${ }^{23}$ Esping-Andersen, The Three Worlds of Welfare Capitalism, pp. 44-7.

${ }^{24}$ See n. 17.

${ }^{25}$ I explored this point in more depth in chapter 3.

${ }^{26}$ S. Bowles, H. Gintis, M.O. Groves (eds.), Unequal Chances: Family Background and Economic Success, Princeton, Princeton University Press, 2005.

${ }^{27}$ B. Mazumder, “The Apple Falls Even Closer to the Tree Than We Thought: New and Revised Estimates of the Intergenerational Inheritance of Earnings,” in Unequal Chances: Family Background and Economic Success, pp. 80-99. To put this in perspective, a figure of 1 would indicate a very rigid society where there is little class mobility. In contrast, 0 would indicate that there is a very high level of mobility, where there is generally no connection between father-son earnings. See pp. 83-4.

${ }^{28}$ Mazumder, “The Apple Falls Even Closer to the Tree Than We Thought,” p. 92.

${ }^{29}$ See also Phillips, “Defending Equality of Outcome.” Phillips argues that outcome inequality is usually a sign of unequal opportunity. Whilst I have not made the case for such a strong claim here, I think there is much to be said in its favour. However, this does not indicate that we should support, at a theoretical level, the principle of equality of outcome instead of equality of 
opportunity or luck egalitarianism. Rather, it means that the practical implication of equality of opportunity or luck egalitarianism (which we support at the theoretical level) is equality of outcome.

${ }^{30}$ Of course, equality of outcome does not simply mean straight equality of income. We will also have to take into account obvious differences in people's ability to convert resources into welfare. This provides a strong reason for establishing a universal healthcare system, and for providing extra financial support to large households.

${ }^{31}$ See also C.M. Macleod, Liberalism, Justice, and Markets: A Critique of Liberal Equality, Oxford, Clarendon Press, 1998, pp. 117-8, 153.

${ }^{32}$ And when people have special needs, such as the need for expensive healthcare, the generous range of universal services provided by the social democratic welfare state is more likely to help alleviate this disadvantage than the more limited range of state services provided under the liberal model.

${ }^{33}$ W. Korpi, \& J. Palme, “The Paradox of Redistribution and Strategies of Equality: Welfare State Institutions, Inequality, and Poverty in the Western Countries,” American Sociological Review, V. 63, no. 5, 1998, pp. 661-87; A. Fenna, Australian Public Policy, second edition, Frenchs Forest NSW, Pearson Education, 2004, p. 336.

${ }^{34}$ Bradley, et al., "Distribution and Redistribution in Postindustrial Democracies," especially Table 2, p. 210.

${ }^{35}$ Rothstein, Just Institutions Matter, pp. 146-50. Based on post-tax and transfer income inequality, Rothstein lists ten countries in the following order, from least unequal to most unequal: Sweden, Norway, Germany, the UK, Australia, Canada, the Netherlands, France, the US and Switzerland. Sweden and Norway are generally regarded as having a universal social policy, unlike seven of the other eight nations. The Netherlands also follows the universal model, but only to an extent See p. 18 n. 60, and Table 6.3 on p. 150.

${ }^{36}$ Job satisfaction is relevant if we adopt a welfarist understanding of advantage for the purposes of interpersonal comparison (see chapter 5). I return to this theme in the next section.

${ }^{37}$ R.E. Goodin, “False Principles of Welfare Reform,” Australian Journal of Social Issues V. 36, no. 3, 2001.

${ }^{38}$ Shlomi Segall provides another reason for luck egalitarians to support universal provision in 
his powerful critique of civic egalitarian attempts to justify conditional welfare payments. He points out that high income earners receive a disproportionate material reward for the work they do. Thus, if we are to keep rewards proportional to effort, as luck egalitarianism might seem to demand, then those who do not work (or, at least, those who perform relatively few hours of work) will also be entitled to a basic level of income. See S. Segall, "Unconditional Welfare Benefits and the Principle of Reciprocity,” Politics, Philosophy \& Economics V. 4, no. 3, 2005, pp. 331-54, at pp. 341-4.

${ }^{39}$ For related arguments, see also R.E. Goodin, Political Theory and Public Policy, Chicago, The University of Chicago Press, 1982; B. Rothstein, Just Institutions Matter, pp. 6-18; Macleod, Liberalism, Justice, and Markets, pp. 223-4.

${ }^{40}$ Cohen, “Expensive Taste Rides Again,” p. 7.

${ }^{41}$ See, for example, Esping-Andersen, The Three Worlds of Welfare Capitalism, pp. 44-7.

${ }^{42}$ However, most egalitarian liberals want markets to operate with certain background conditions in place, such as equality of opportunity. See, for example, Dworkin, Sovereign Virtue, Cambridge, Mass., Harvard University Press, 2000, p. 76. Absent these conditions, they support redistribution aimed at ameliorating the inequalities that emerge in a market economy.

${ }^{43}$ For an excellent critique of Dworkin's use of markets, see Macleod, Liberalism, Justice, and Markets.

${ }^{44}$ Cohen, “Expensive Taste Rides Again,” p. 17.

${ }^{45}$ There are similarities here to Van Parijs’s “Crazy” and "Lazy” example. See P. Van Parijs, Real Freedom for All: What (if anything) can justify capitalism? Oxford, Clarendon Press, 1995, especially pp. 92-6.

${ }^{46}$ Although, in reality, background inequalities in class, ethnicity and gender may affect people's capacity and willingness to take up these benefits and use these services. There may also be geographical inequalities in the location and quality of services such as schools and hospitals.

${ }^{47}$ My argument in this paragraph has been influenced by Van Parijs's argument for an unconditional basic income in Real Freedom for All.

${ }^{48}$ I am not claiming that it is feasible for the state to provide every person with whatever they think they need to live a fulfilling life, although this might be our objective in an ideal world. 
Rather, the universal welfare state guarantees access to a generous but limited range of benefits and services, and aims to ensure that everybody has the necessities of life. This gives individuals more control over the kind of life that they are able to live because it means they have access to these necessities, whether or not they work. Individuals have more ability to choose a balance between work and leisure that suits them, and this takes us closer towards a world where individuals have equal access to lives of equal fulfilment.

${ }^{49}$ If my claim here is correct, the economic viability of the model may depend, perversely, on widespread commodity fetishism. It is largely the demand for greater income and wealth that will motivate people to work. I thank David van Mill for this point.

${ }^{50}$ Admittedly, these countries have not adopted a pure form of the social democratic model that completely decommodifies labour (see, for example, Esping-Andersen, The Three Worlds of Welfare Capitalism, pp. 37, 49). This could lead to criticism that the social democratic welfare state is only economically feasible in a watered-down form that is little different from the liberal approach. However, I disagree with this claim. The Scandinavian and Nordic approach to social policy is still characterized by a higher degree of universality, a higher degree of decommodification, and a more equal distribution of income, than occurs in Anglo-American nations which adopt the liberal approach. This means that the social democratic model, even in this watered-down form, is a genuine alternative to the liberal model.

${ }^{51}$ E.g. Goodin, Political Theory and Public Policy, especially pp. 8-12; Anderson, "What is the Point of Equality?”

${ }^{52}$ Cohen gives a related justification of why he has "spent so much time and energy on what might seem to be such an unimportant issue.” See Cohen, "Expensive Taste Rides Again,” p. 16. 


\section{CONCLUSION}

In this thesis, I have investigated whether luck egalitarianism is a compelling interpretation of egalitarian justice. I have challenged existing interpretations and criticisms of luck egalitarianism, and emphasised the radical consequences of the theory. I scrutinised the distinction between option luck and brute luck, and proposed a revised theory of luck egalitarianism that focuses on the extent to which persons have genuinely chosen the level of advantage they enjoy. I concluded that this revised theory of luck egalitarianism does represent a compelling interpretation of egalitarian justice.

In chapter 1, I outlined the development of luck egalitarianism, explaining how it can be seen as a response to Rawls's theory of justice as fairness. I focused particularly on Dworkin's equality of resources, and the way theorists such as Arneson, Cohen, Roemer, and Rakowski have drawn on and re-interpreted his underlying emphasis on notions of choice, responsibility, and luck. I emphasised that there are important differences between these theorists, and that it is unclear exactly what luck egalitarianism is.

In chapter 2, I defended a general form of luck egalitarianism against Anderson's influential critique. I argued that, pace Anderson, luck egalitarianism is not motivated by a sense of pity, or trapped in the distributive paradigm. I demonstrated that the approach is sensitive to the injustice associated with Young's five faces of social oppression, provided that a sensitive enough conception of advantage is used. I also defended luck egalitarianism - at least as an abstract interpretation of the ideal of egalitarian justice - against Anderson’s “intrusion” objection, and against her claim that it treats the victims of bad option luck too harshly. I emphasised that luck 
egalitarianism has radical redistributive implications when applied to the real world, where inequality is rife. I concluded that luck egalitarianism can overcome Anderson's major criticisms and that it is consistent with our intuitive understanding of egalitarian justice.

In chapter 3, I focused on the internal consistency of luck egalitarianism, highlighting two major flaws with the distinction between compensable option luck and non-compensable brute luck. The first problem is that some option luck inequalities are unjust because they reflect the influence of luck not choice. The second problem is that the distinction is insensitive to the way background inequalities shape individual choice. In response to these objections, I proposed a revised theory of luck egalitarianism that focuses on the extent to which individuals have genuinely chosen the level of advantage they enjoy. I concluded the chapter by highlighting, once again, the radical implications of the theory.

In chapter 4, I sought to provide a stronger justification of luck egalitarianism, linking it to a broader notion of equality as a moral and social ideal, and moving beyond the focus on our intuitive understanding of egalitarian justice. I began by outlining and supporting Hurley's argument that responsibility and luck cannot provide a basis for luck egalitarianism. I then drew on Scheffler's recent critique of luck egalitarianism, highlighting why the Rawlsian project does not provide a secure grounding for luck egalitarianism, and analysing the problems with Dworkin's “statocentric” justification. However, I also emphasised that principles of egalitarian justice will have an important role to play in a genuine "society of equals," guiding the behaviour of individuals as well as social institutions. I concluded the chapter by explaining 
how luck egalitarianism emerges from the idea that all persons have equal moral worth and equally valuable lives, thus establishing firmer moral foundations for the theory.

I further refined the theory in chapter 5, arguing that luck egalitarians should adopt a heterogeneous conception of advantage. I developed a more precise account than existing approaches in the literature, developing Cohen's proposal, which involves using a lexical ordering of the various components of advantage. I devoted particular attention to the expensive tastes objection and supported the view that we may be obliged to provide compensation to individuals who have expensive tastes. I also argued that egalitarian advantage should include an objective component relating to the importance of egalitarian social relations. This ensures that luck egalitarianism is sensitive to the kind of social oppression that Anderson and Young are concerned with, providing another link between luck egalitarianism and social equality.

In chapter 6, I argued that luck egalitarianism cannot be replaced by three leading alternative approaches to egalitarianism and/or social justice. We should reject the sufficiency approach because as long as conditions of scarcity obtain, inequalities above the relevant threshold of "sufficiency" are unfair. In these conditions, individuals at the threshold do not have "sufficient." Secondly, I defended luck egalitarianism as a form of Telic Egalitarianism. Drawing on work by Temkin and Parfit, I argued that the notion of relative fairness is relevant to our moral judgements, and that whilst the Levelling Down Objection is a powerful challenge to luck egalitarianism, it cannot defeat a pluralist form of the theory. Thus, we cannot replace luck egalitarianism with the Priority View. I concluded by refuting a number of criticisms of luck 
egalitarianism advanced by proponents of social equality, and I highlighted that the distributive implications of social equality are either ambiguous, ungenerous, or collapse into luck egalitarianism.

In chapter 7, having completed my theoretical defence of luck egalitarianism, I turned to the practical applications of the theory, examining its implications for contemporary debates over the welfare state. Although its emphasis on notions of individual choice and responsibility suggests that luck egalitarianism will lend support to the liberal model of the welfare state over the universal, social democratic alternative, I made the counter-intuitive argument that luck egalitarianism is more likely to be achieved through the social democratic approach. The first reason for this is that luck egalitarianism has radical redistributive implications, which are more consistent with the patterns of income distribution achieved by the universal welfare state. This counter-intuitive conclusion highlights the importance of assessing the policy alternatives that are actually at stake when we are using political theory to inform policy debate. Secondly, I argued that because welfare is an important component of egalitarian advantage, we should give individuals as much choice as possible over the kind of work that they do, which links luck egalitarianism to the labour market decommodification that is associated with the universal welfare state. This highlights the practical relevance of the expensive tastes debate, and shows why the use of seemingly bizarre hypothetical examples is a useful tool for political theorists. I emphasised the counter-intuitive nature of luck egalitarianism's policy applications, which are radical given the current direction of welfare policy reform in the Anglo-American world.

This highlights the important contribution luck egalitarianism can make 
to political debate more generally. In recent years, politicians and policymakers on the left and right of the political spectrum have been increasingly interested in emphasising the importance of individual choice and responsibility. However, in this thesis, I have shown the radical consequences of a theory that is built around these notions. The revised form of luck egalitarianism I proposed provides a way of linking left-liberal political theory to the popular notion of individual responsibility, but it also has radical redistributive implications that run counter to the recent direction of liberal and social democratic policy “modernisation.” Thus, whilst luck egalitarianism is a compelling interpretation of egalitarian justice, it will have little appeal for those who are searching for a normative justification of this modernisation project. 